\title{
The User Experience Redesign of a Product Instruction Manual Using the Poka Yoke Principle
}

\author{
Ephraim A. Pittore
}

Follow this and additional works at: https://researchrepository.wvu.edu/etd

\section{Recommended Citation}

Pittore, Ephraim A., "The User Experience Redesign of a Product Instruction Manual Using the Poka Yoke Principle" (2018). Graduate Theses, Dissertations, and Problem Reports. 6425.

https://researchrepository.wvu.edu/etd/6425

This Thesis is protected by copyright and/or related rights. It has been brought to you by the The Research Repository @ WVU with permission from the rights-holder(s). You are free to use this Thesis in any way that is permitted by the copyright and related rights legislation that applies to your use. For other uses you must obtain permission from the rights-holder(s) directly, unless additional rights are indicated by a Creative Commons license in the record and/ or on the work itself. This Thesis has been accepted for inclusion in WVU Graduate Theses, Dissertations, and Problem Reports collection by an authorized administrator of The Research Repository @ WVU. For more information, please contact researchrepository@mail.wvu.edu. 
The User Experience Redesign of a Product Instruction Manual Using the Poka Yoke Principle

\author{
Ephraim A. Pittore
}

Thesis submitted to the

Davis College of Agriculture, Natural Resources and Design

at West Virginia University

in partial fulfillment of the requirements for the degree of

Master of Science

in

Design and Merchandising

Chris Haddox, Ph.D., Chair

Craig Nelson, MID.

Thorsten Wuest, Ph.D.

School of Design and Community Development

Morgantown, West Virginia

2018

Keywords: Instruction Manuals, Poka Yoke, Product Design, User Experience

Copyright 2018 Ephraim A. Pittore 


\begin{abstract}
The User Experience Redesign of a Product Instruction Manual Using the Poka Yoke Principle
\end{abstract}

\title{
Ephraim A. Pittore
}

The purpose of this research is to address the issues associated with user experience in consumer products, particularly in the introduction phase of consumer product acceptance. Instructional manuals serve the role of educating new users on how to assemble or operate a new product, aiming to bridge the gap between the intended use idealized by the designer and the actual use that a consumer would intuitively perform. Historically however, instruction manuals have been known to be confusing and not usful.

The design of a toy spider instruction manual was analyzed using sequential explanatory method to determine the effectiveness of the instruction manual using a descriptive survey (User Experience Questionnaire) and grounded theory was used to develop themes that would describe issues in the instruction manual. The study utilized the design aspects of user experience, usability and desirability to determine the successes and short comings of the manual. To address design issues, the industrial manufacturing principle, poka yoke was used. Poka yoke, or mistake proofing, is a strategy used by engineers to inspect products during the assembly process to check for errors instead of conducting quality control at the end of assembly.

The results presented 12 themes that were used to revise the instruction manual. For this experiment, it was found that the implementation of the poka yoke principle increased the scales of attractiveness and desirability, and decreased the usability of the instruction manual as defined by the descriptive survey. 


\section{DEDICATION}

God, being rich in mercy, because of the great love with which He loved me, even when I was dead in my trespasses, made me alive together with Christ - by grace I have been saved through faith. And this is not my own doing; it is the gift of God, not a result of works, so that I may not boast in myself. For I am His workmanship, created in Christ Jesus for good works, which God prepared beforehand, that I should walk in them.

It is the will of God that we all would become the fullness of who He made us to be. There is a specific plan and purpose for my life and yours that is beyond what we could think or imagine. With it comes the mission to tell the world that Jesus died, was buried, and rose from the dead to save the world from being separated from our heavenly Father.

Let no one be deceived, the same God that sent His Son to be the payment for our sins is not an angry old man waiting to smite the world. He is a God who is passionate for his creation, longing for us to accept his love, and desires to bring full restoration to our spirit, mind, and body.

The only boast I hold is that my life is in the hands of my heavenly Father and every good thing that comes from me is through the power of the Father and is for the life of the world. 


\section{ACKNOWLEDGMENTS}

This thesis marks my highest academic achievement and end of my studies as I look to begin a career that will hopefully make a difference in the world. Up to this point, I have trained and studied under great and passionate minds and have been spurred on by family and friends.

To Chris Haddox, my advisor: thank you for leading me through this process and helping me strive towards accomplishing this great task. I appreciate your ability to understand how I work and help guide me around pitfalls and into success.

To Craig Nelson, my design mentor: your insight and creative spirit continually inspire me. I hold you in the highest regard as you have challenged my artistic skills and have unlocked my love for design.

To Thorsten Wuest, my engineering mentor: thank you for seeing my potential and bringing me on board with your research group. I have great respect for how you conduct a team and work with students to achieve their best.

To Lyndsey Pittore, my wife: laughter is your song and delight is your profession. Thank you for helping me to achieve my best and live a joyful life. I love you.

To Ettore and Maritza Pittore, my parents: thank you for believing in me and investing in what I have completed. My hope is that in everything I do, you would be honored.

To Emmanuel Pittore and Mariana Miller, my brother and sister: Manny, as a younger brother I can't help but be fascinated by everything to you do. Your interests have always been unique and have greatly influenced what I like, how I think, and where I am today.

Mariana, I am still looking for someone who is as determined and hardworking. I feel as though the fire inside of me that pushes me forward is half the size of the one burning inside of you.

To Wayne: there is a compass in my heart that is always pointing home. If I will return is a question that I cannot answer, but the memories, the people, and the hills will always be a part of me.

To the Pooplex and all who shared in its vision: it might be impossible that so many amazing people would come together again, but I am deeply privileged to have seen and been a part of a group of Christians set on seeing heaven on earth. I have never been more convinced of God's love for the world as having witnessed it inside of you. 


\section{TABLE OF CONTENTS}

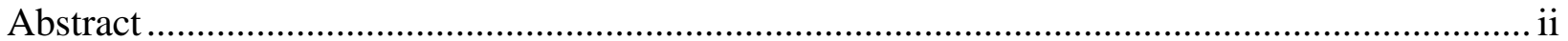

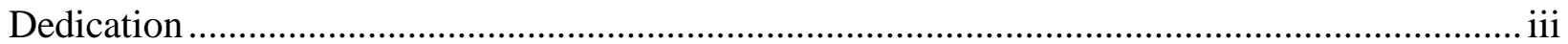

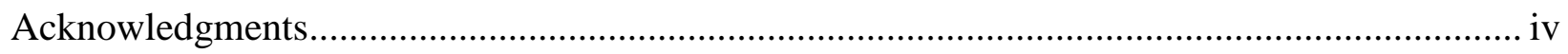

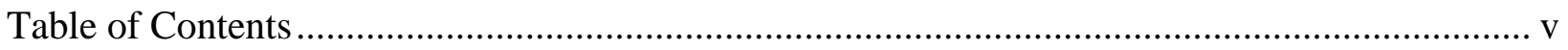

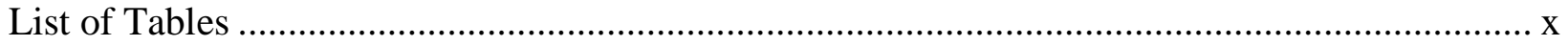

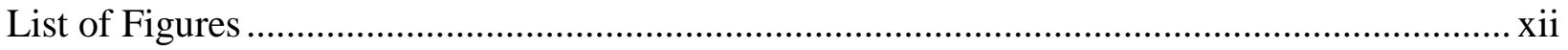

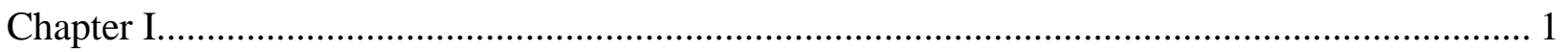

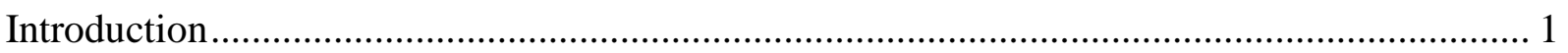

The Out-of-Box User Experience ............................................................................ 1

The Infamy Of Instruction Manuals: Intentions and Short Comings ............................... 1

User Experience and Product Acceptance ......................................................................... 2

Successes In Process Optimization: Manufacturing ..................................................... 2

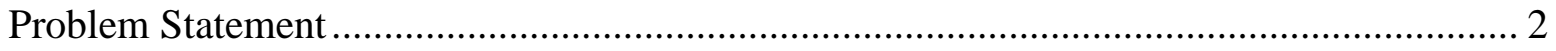

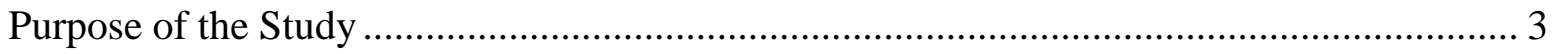

Theoretical Framework ....................................................................................... 3

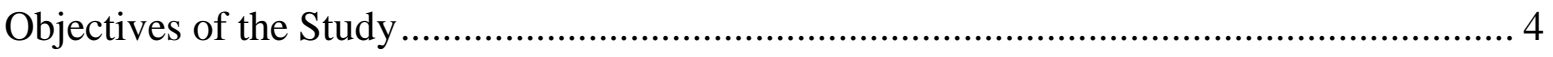

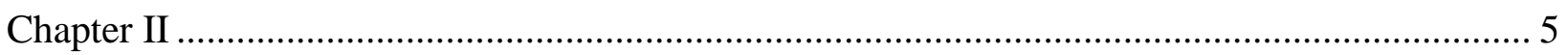

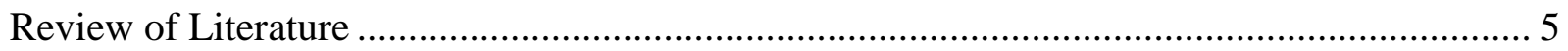


Instruction Manuals: An Overview

Designer: Education and Guided Learning.................................................................... 5

Customer: Human Behaviors, Reader Perceptions ......................................................... 8

Manual: Technical Communications and Visual Design.............................................. 9

Poka Yoke: Principle Application ........................................................................... 12

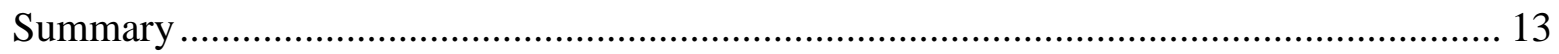

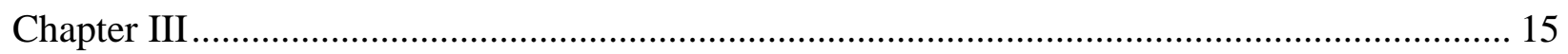

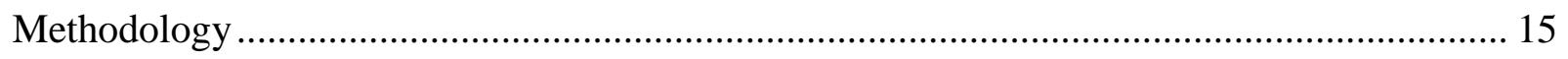

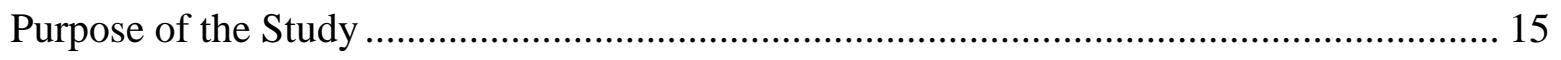

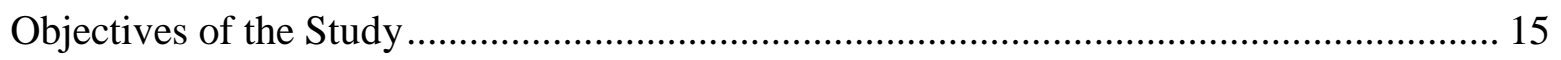

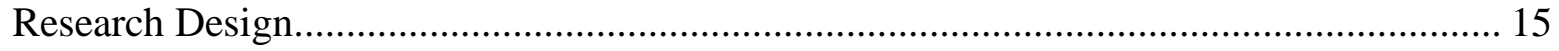

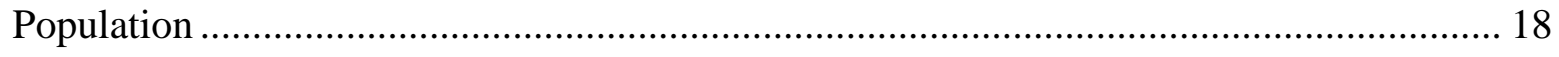

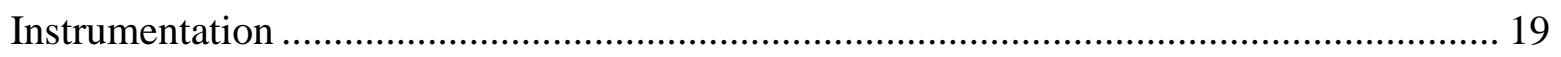

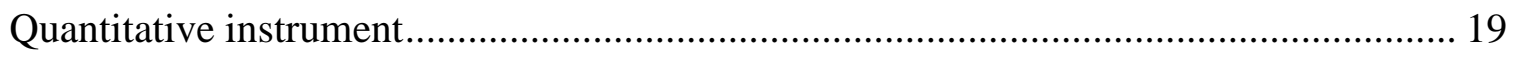

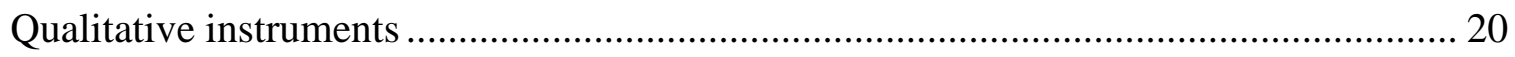

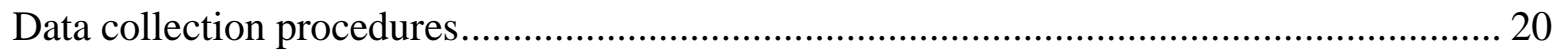

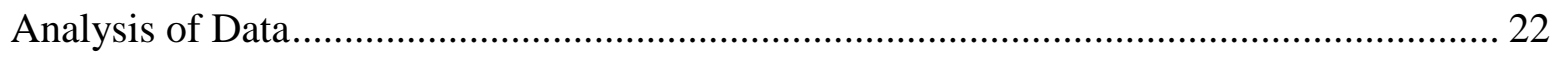

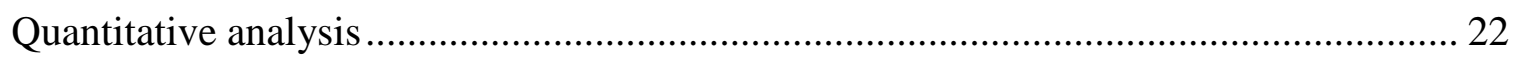

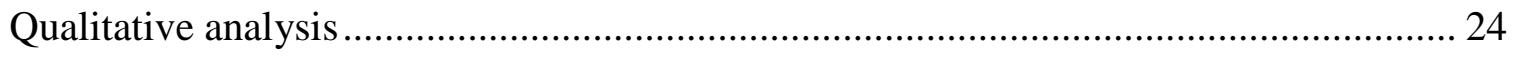

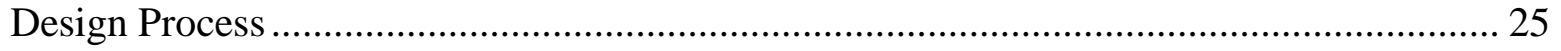




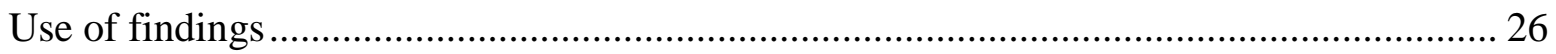

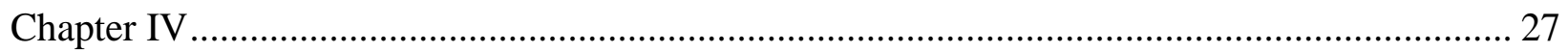

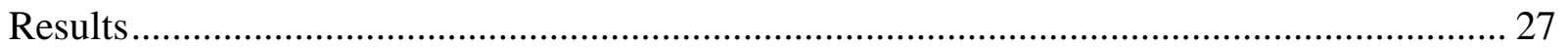

Phase 1: Evaluate Initial Product .............................................................................. 27

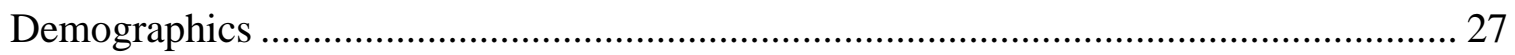

Descriptive analysis of overall manual and step rankings ....................................... 30

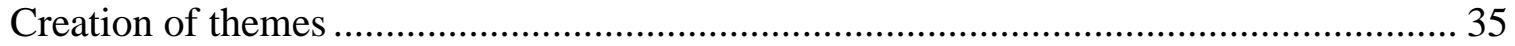

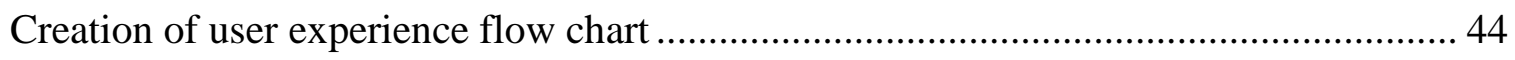

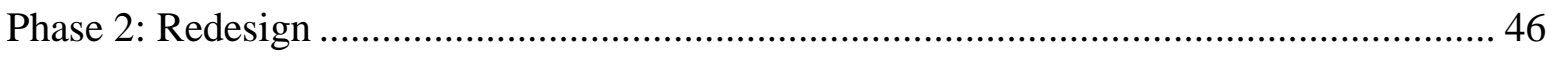

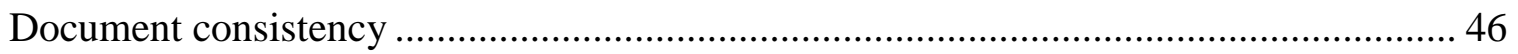

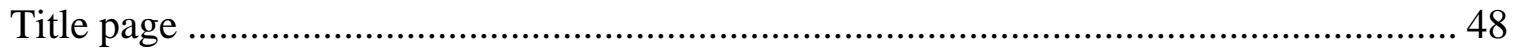

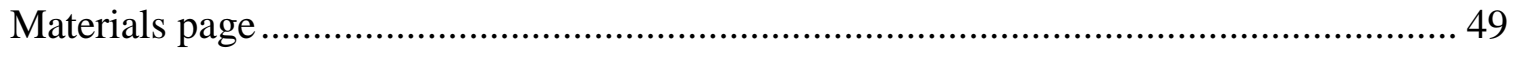

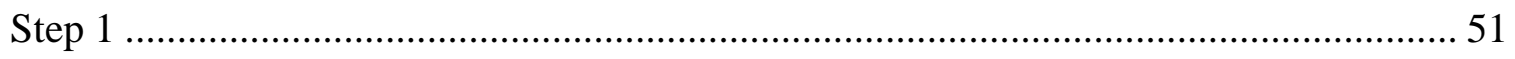

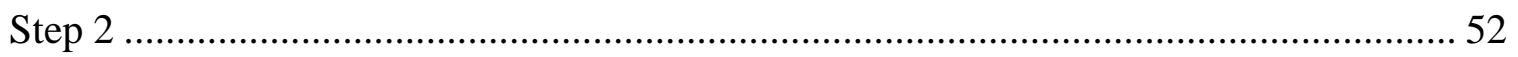

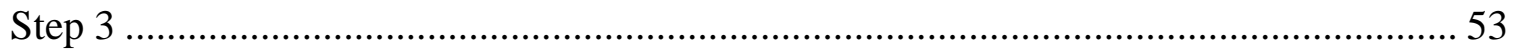

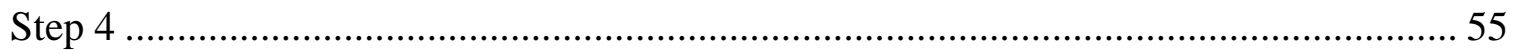

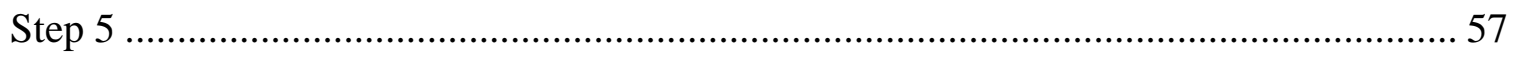

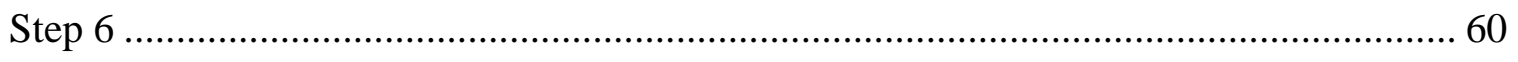

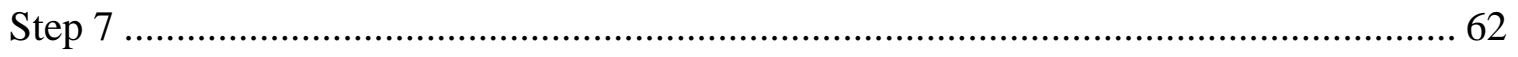

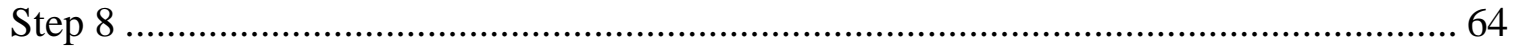


Step 9

Step 10

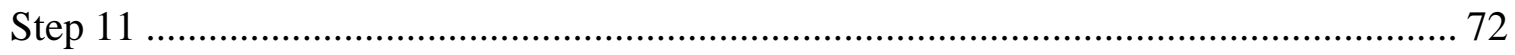

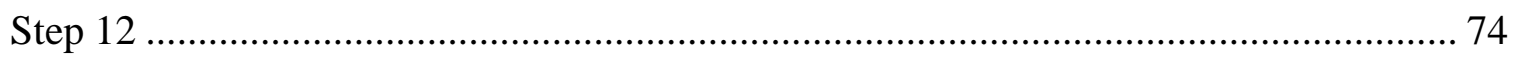

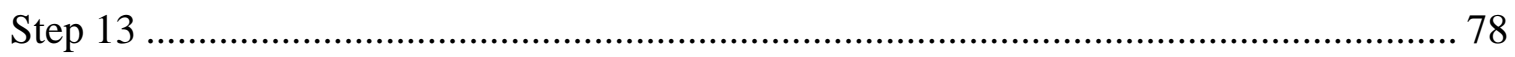

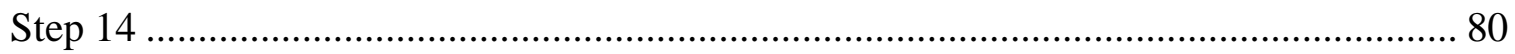

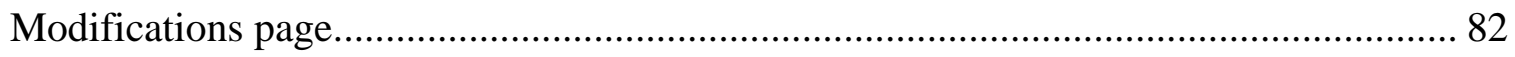

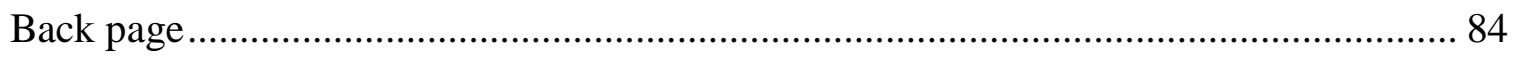

Phase 3: Evaluate Redesign and Compare with Initial Product............................................. 86

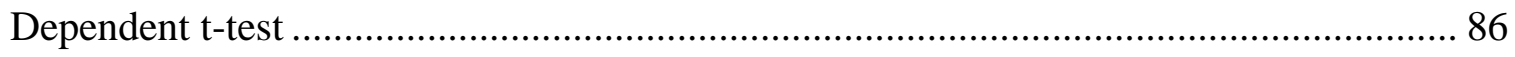

Step comparison evaluations...................................................................................... 90

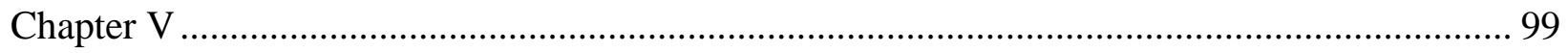

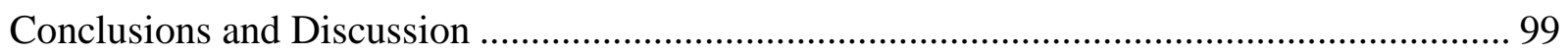

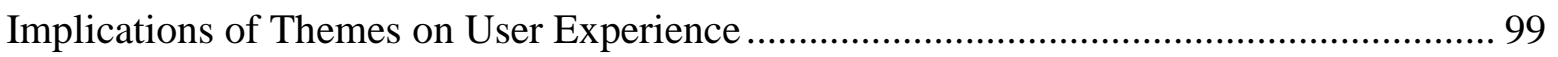

Successful Poka Yoke Implementations ............................................................................ 100

Study Limitations, Inconsistencies, and Personal Biases ................................................. 100

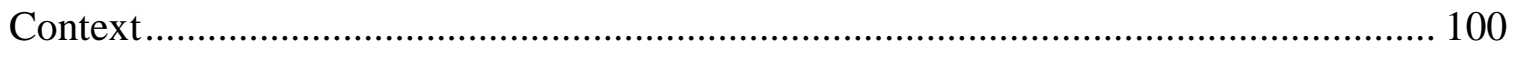

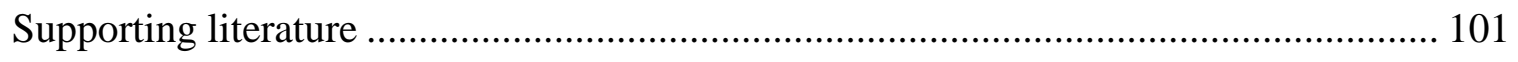

Experiment design ................................................................................................ 101

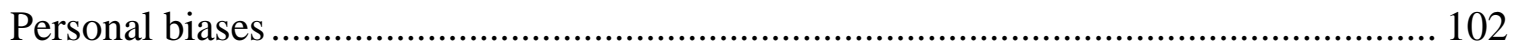




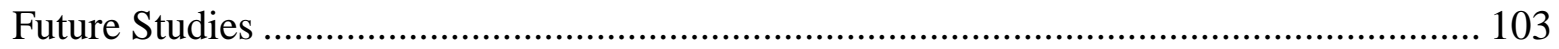

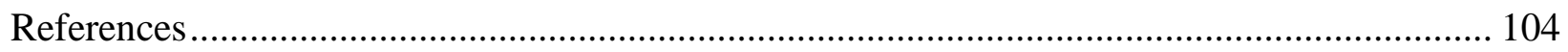

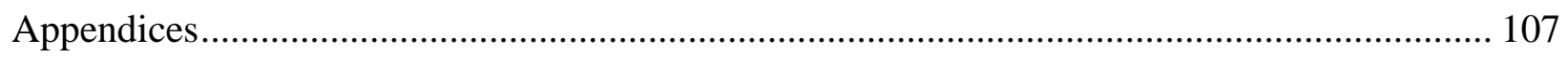

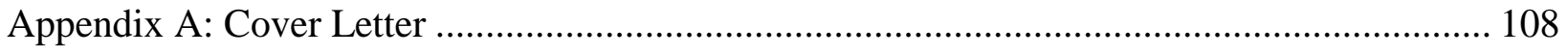

Appendix B: UEQ Descriptive Survey ……...................................................................... 109

Appendix C: Interview and observation sheet ..................................................................... 114

Appendix D: Overall Scales Data Analysis For Original Manual............................................... 115

Appendix E: Individual Step Data Analysis For Original Manual ............................................. 118

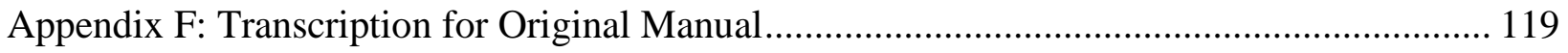

Appendix G: Themes Analysis Original Manual....................................................................... 139

Appendix H: Themes Analysis Original Manual.................................................................... 164

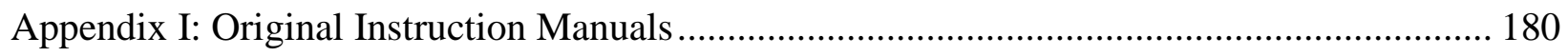

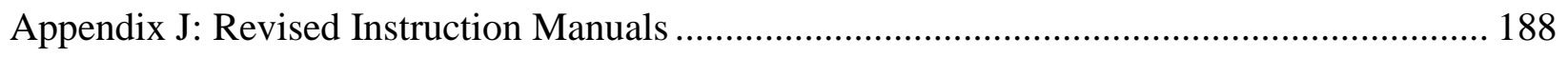

Appendix K: Revised Instruction Manual Quantitative and Qualitative Data ............................. 196

Appendix L: Themes Analysis Original Manual ........................................................................ 256 


\section{LIST OF TABLES}

Table 1 Demographic Characteristics of Participants from Group 1 and Group 2.................... 29

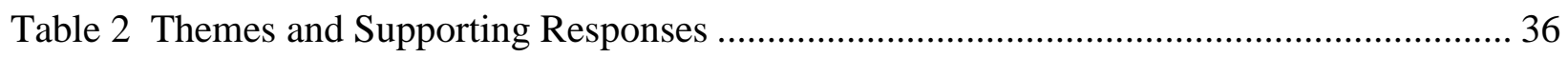

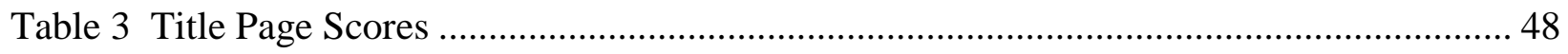

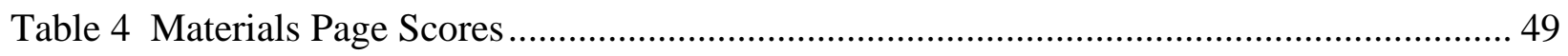

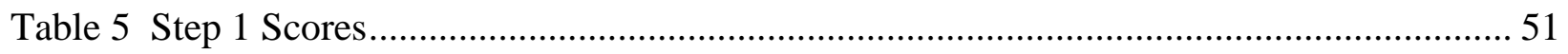

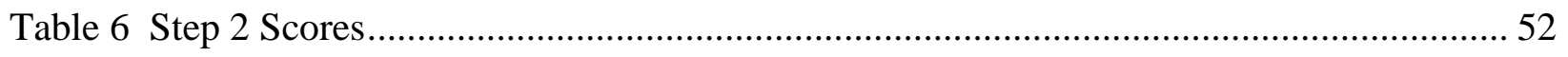

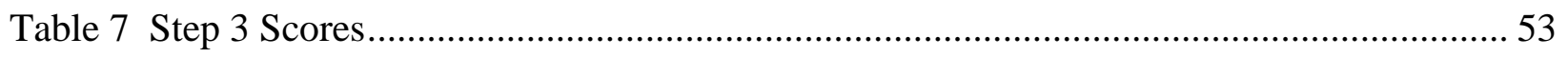

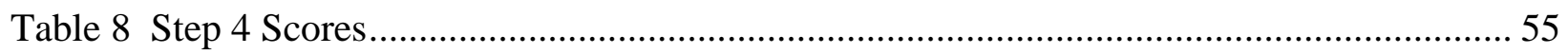

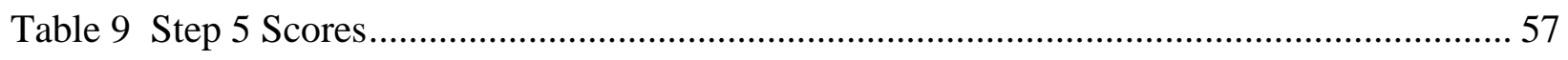

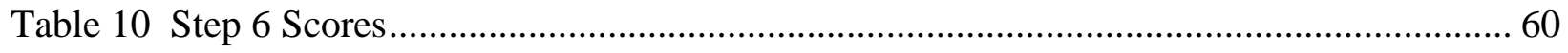

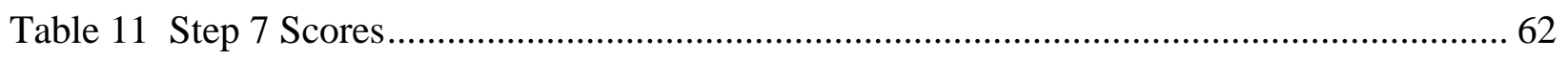

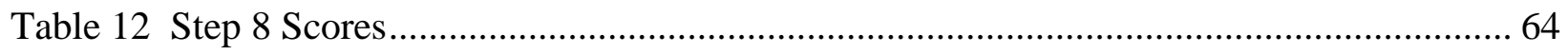

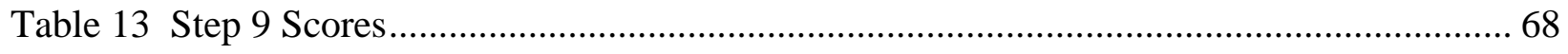

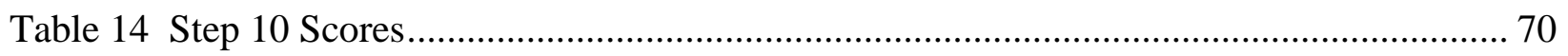

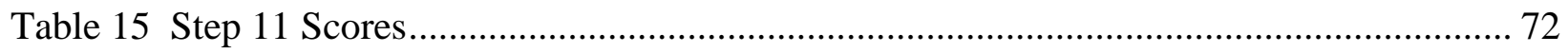

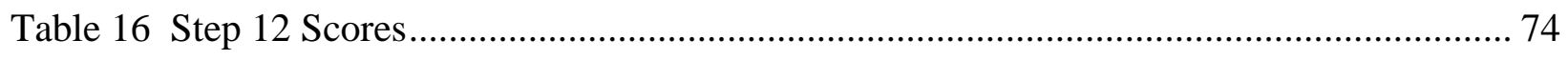

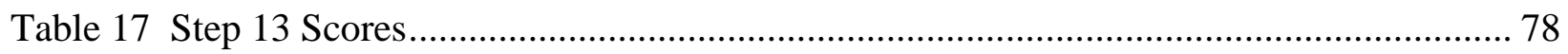

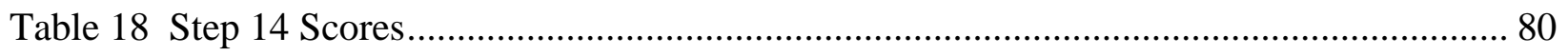

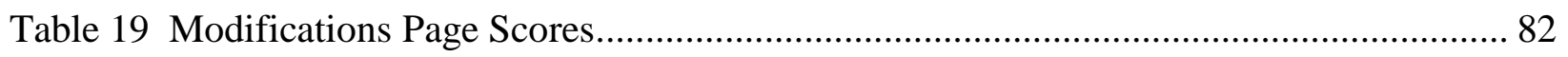

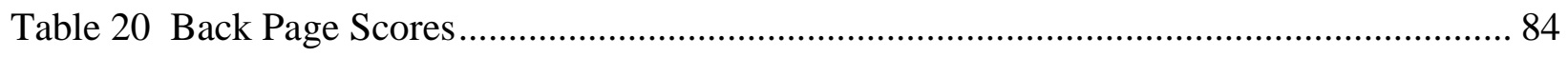

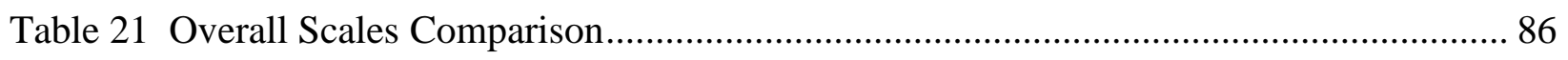

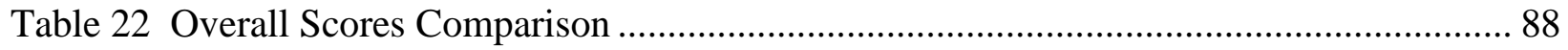


Table 23 Title and Materials Overall Score Differences ....

Table 24 No Change Overall Score Differences................................................................ 92

Table 25 Score Increase Overall Differences ................................................................. 95

Table 26 Score Decrease Overall Differences ...................................................................... 97 


\section{LIST OF FIGURES}

Figure 1. Mixed methods applied to iterative design cycle. .............................................. 17

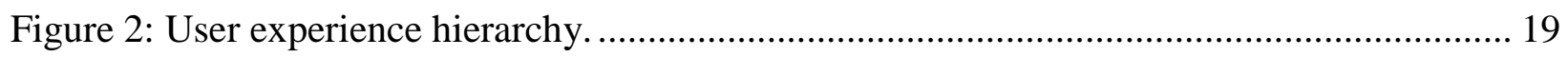

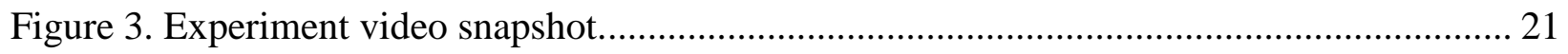

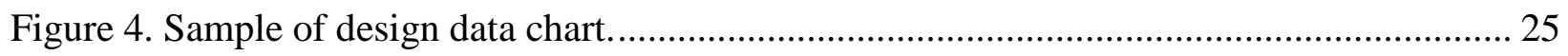

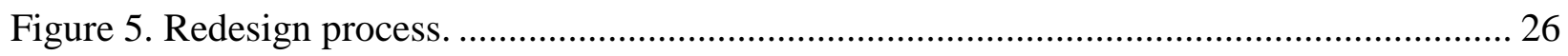

Figure 6. Overall Scores (Original Manual) .................................................................. 31

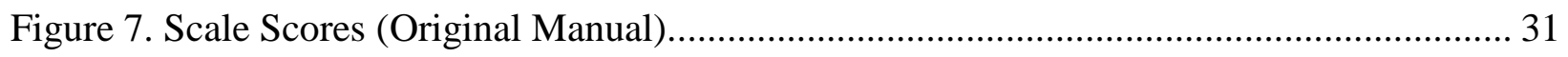

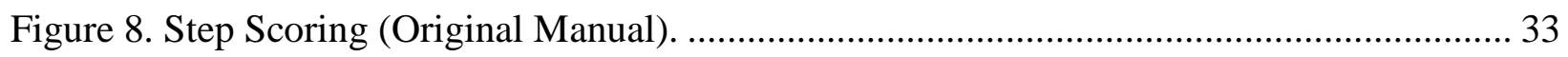

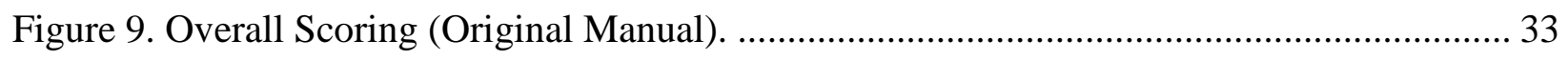

Figure 10. Usability Scoring (Original Manual) .............................................................. 34

Figure 11. Desirability Scoring (Original Manual).......................................................... 34

Figure 12. User experience framework with themes ...................................................... 45

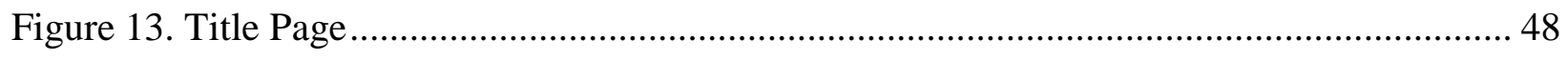

Figure 14. Materials Page: Original (Left), Revised (Right) ............................................. 50

Figure 15. Step 1: Original (Top), Revised (Bottom) ….................................................. 51

Figure 16. Step 2: Original (Left), Revised (Right) …........................................................ 52

Figure 17. Step 3: Original (Top), Revised (Bottom) ...................................................... 54

Figure 18. Step 4: Original (Top), Revised (Bottom) ....................................................... 56

Figure 19. Step 5: Original (Left), Revised (Right) …....................................................... 57

Figure 20. Motor Unit Assembly: Original (Left), Revised (Right) ....................................... 59

Figure 21. Step 6: Original (Top), Revised (Bottom) ..................................................... 61

Figure 22. Step 7: Original (Top), Revised (Bottom) ...................................................... 63 


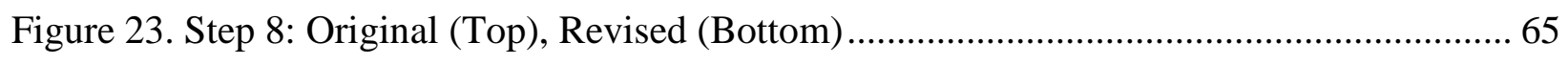

Figure 24. Gear and Leg Assemblies: Original (Left), Revised (Right),....................................... 67

Figure 25. Step 9: Original (Left), Revised (Right)........................................................................ 69

Figure 26. Step 10: Original (Left), Revised (Right)................................................................... 71

Figure 27. Step 11: Original (Left), Revised (Right)..................................................................... 73

Figure 28. Step 12: Original (Left), Revised (Right)_.................................................................... 75

Figure 29. Leg Assembly: Original (Left), Revised (Right)......................................................... 77

Figure 30. Step 13: Original (Top), Revised (Bottom) …………................................................ 79

Figure 31. Step 14: Original (Top), Revised (Bottom) ………………………………............... 81

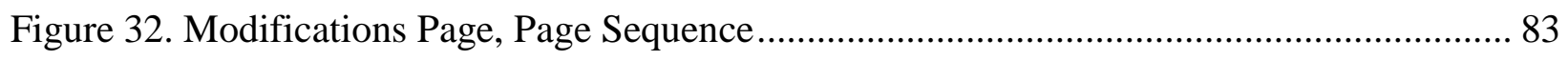

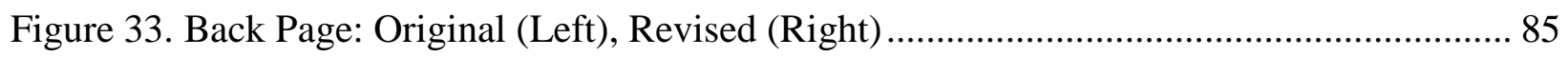

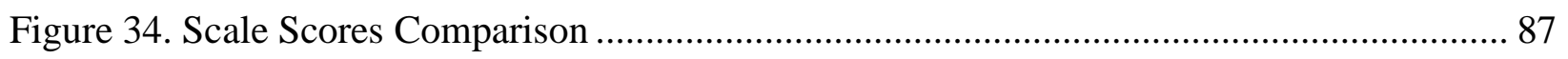

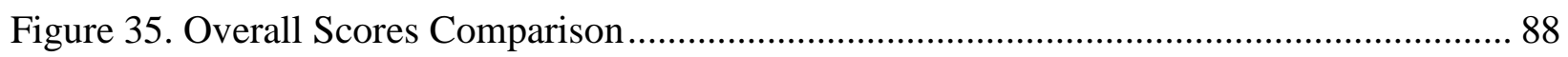

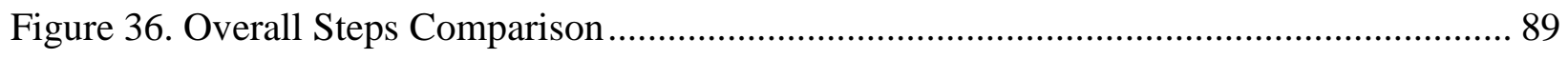

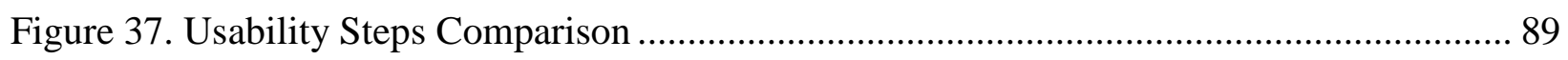

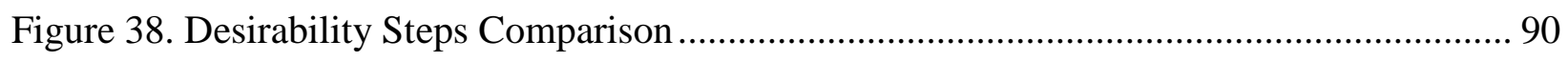

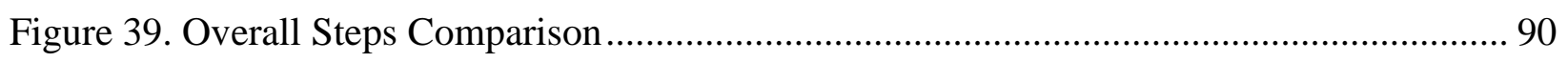




\section{CHAPTER I}

\section{Introduction}

\section{The Out-of-Box User Experience}

GfK Research published an article on the implications of the introductory experience of consumers when purchasing a product. According to Flori Manning (2015), it is at the point of purchase that a user's level of satisfaction begins. Prior to purchase, a customer has expectations of the product they purchase.

Defined as the "out-of-box experience" (OOBE), this introduction phase of a product is incredibly important for a user's experience with a product and satisfaction as a whole: OOBE includes the unpackaging of the product, and setup and initial use guided by instructional materials (Manning, 2015).

\section{The Infamy Of Instruction Manuals: Intentions and Short Comings}

Instruction manuals are known for being unhelpful. Reasons vary from offering steps filled with technical jargon, essay long explanations, and vague imagery aiding the reader (Valeriano, 1994). Instructional manuals serve the role of educating new users on how to assemble or operate a new product, aiming to bridge the gap between the intended use idealized by the designer and the actual use that a consumer would intuitively perform. Valeriano (1994) interviewed information designers from various manual design firms to evaluate cases of instructional manuals. Issues of cutting corners, short deadlines, no proof reading, and over technical information were reported. 


\section{User Experience and Product Acceptance}

A common issue for the acceptance of computer programs among new users is his or her initial impressions. If in the trial period of program use the user makes too many mistakes, the user will abandon it all together. It has been found that individuals using word processing software for the first time spent a significant amount of time evaluating errors as opposed to progressing in learning the program (Booth, 1991).

\section{Successes In Process Optimization: Manufacturing}

Fisher (1999) discusses the fundamentals of poka yoke. Poka yoke is the Japanese word for mistake-proofing, a manufacturing technique developed by Shigeo Shingo. The technique is used to prevent defective products from coming off the assembly line by identifying and removing opportunities to make mistakes during the assembly process. The technique commonly enacts its function through providing immediate or "source inspection” (Fisher, 1999) during assembly. This may be through instructing assemblers to set out the required materials for a step to ensure that no pieces are overlooked. Another basic function is to develop steps or parts that, if installed incorrectly, will not allow assembly to continue. These inspection prompting processes and devices allow for accurate and first-time through assembly.

\section{Problem Statement}

The introductory phase of a consumer using a product creates a first impression for their future use and purchase of products from a company. The design of instructional materials must be intentionally developed to provide an adequate user experience to retain business. Designers must consider instructional manuals to the degree at which products are created. 


\section{Purpose of the Study}

The purpose of this research is to explore the issues associated with user experience in consumer products, particularly in the introduction phase of consumer product acceptance. Instructional manuals serve the role of educating new users on how to assemble or operate a new product, aiming to bridge the gap between the intended use idealized by the designer and the actual use that a consumer would intuitively perform. The results of this study aim to gauge the successfulness of an instruction manual through the implementation of the lean manufacturing principles: specifically, poka yoke. The implications of the study may provide a method for designers to create effected instruction manuals to improve user experience.

\section{Theoretical Framework}

User experience defines the full interaction of a person with a product or service. This interaction is initiated by the value perceived at the fundamental level of utility, or needing problem solved, and ascending to value associated with the company providing the product or service, also known as the brand experience (Interaction Design Foundation, 2018). A customer will be fully satisfied with a purchase if their interaction exceeds the four levels of user experience. The Nielsen Norman Group (Interaction Design Foundation, 2018) defines these levels as utility, usability, desirability, brand experience. A successful product/service will provide a solution to a problem (Utility), be easy for the customer to use (Usability), an enjoyment or perceived value that overcomes competition (Desirability), and the value ascribed to the product/service by the company of which it is associated (Brand Experience).

Within these guidelines, usability and desirability are the levels in which a designer has control to influence the user's experience (Interaction Design Foundation, 2018). Usability, in this context, provides the functional ability of the user to apply the product/service's utility to 
meet his or her needs while desirability convinces the user that the product is the best among all alternatives (Interaction Design Foundation, 2018). In terms of instruction manuals, the reader should be able to easily understand and apply the presented information, be engaged through the completion of the manual, and prefer future manuals to follow similar presentation.

In the context of this research, a current industry instruction manual was tested for adequate usability and desirability elements of user experience. This study addressed the "setup" instructional phase of OOBE through the analysis of an assembly manual. As poka yoke stands as a key principle in manufacturing, it will be used as the design theory for instruction manual improvements. The study tested the usefulness of macro-audience manufacturing principles to the individual level of instruction manuals for consumer products to provide a new strategy for current designers.

The poka yoke principle will guide design changes between control and test groups to measure differences in usability and desirability of a current industry instruction manual.

\section{Objectives of the Study}

The objectives of the study will be guided by the following research questions:

1. What are the major success or short comings of an assembly based instruction manuals in a current industry product?

2. What effect does the manufacturing principle poka yoke have on the user experience of instruction manuals?

3. What design elements or informational points can be offered to practicing designers to positively impact instruction manual design? 


\section{CHAPTER II \\ Review of Literature}

\section{Instruction Manuals: An Overview}

Academic literature will be reviewed in regards to theories, principles, and experiments that have application to better presenting information the purpose of task completion.

A review of academic literature on consumer product instruction manuals provided no exact body of knowledge on principles or practices to develop effective instruction manuals for general readers: that is, a reader who might have little to no foreknowledge on the manual's topic. Effective communication relies on the sender (designer), receiver (customer), and the channel (manual) (Shannon \& Weaver, 1998).

As such, the following topics follow this model: educational strategy of the designer, human behavior and experience of the customer, and the explicit technical information and implicit visual presentation of the instruction manual itself.

Strong efforts were made in the fields of computer science to develop instructional material during the rise of computers to education non-technical persons in word processing, email, and PowerPoint under which a number of studies use for context.

\section{Designer: Education and Guided Learning}

An experiment was conducted to determine the effectiveness of using narrative based instructions as compared to step-by-step instructions for learning to use a university email system (MacLeod \& Morrison, 1998). Narrative type instructions took form of paragraphs describing the process, while the step-by step instruction utilize modular section including both a screen shot image with several corresponding bulleted phrases. It was found that there were no significant differences in categories such as completion time, requesting help, number of times 
needed to look at instructions, shows frustration, and overall errors. The author suggests that these lack of difference may be due to the simplicity of the tasks that participants were asked to complete. There was however, a significant difference in errors by wrong command sequence in the most complex section of the experiment, suggesting the benefits of step-by-step instructions difficult or long tasks. They suggest that narrative type instructions lead to loss of concentration of readers.

Urata (2004) applies the outcomes of studies on teaching word processing to new users by creating a set of instruction manuals to teach users how to use Microsoft PowerPoint. The design of the manual was based on a survey of previous visual manual experiments. An experiment was conducted to determine participant learning and confidence level. The study was in the context of a classroom environment; the expectation was presented that that while learning computer skills was highly individually based, most computer learning would take place in the classroom setting. Participant journal entries suggested that having a visual instruction manual reduced learning anxiety and gave users a sense of confidence to use the software being taught.

Urata (2004) went on to say that having a visual manual aided learners in a classroom setting because it, "freed [the] pressure of remembering every step and function the instructor demonstrated...” (Urata, 2004). The visual manual allowed users to move at their own pace because the manual provided “immediate feedback" (Urata, 2004); when the user performed a command they had an image to compare their result on the computer screen to the desired result shown in the manual.

While training manuals offer ample information on how to perform a task, they often lack guidance in returning the user to information within the manual if they are derailed by a mistake (Lazonder \& Van Der Meij, 1995). The author uses the following process as a method of dealing 
with errors: Detection, Diagnosis, and Correction. Error correction information should tell the user when a mistake has been made, what and how the mistake was made, and steps to correct the error.

Two types of mistakes may be made by the user: semantic and syntactic. Semantic errors arise when the user initiates an action that will not end in the desired result. Syntactic errors occur when the user initiates the correct action by does not achieve the result due to poor performance.

When offering a user a correction, it is preferred to first provide the user with a generic solution such as an ‘undo’ option to offer a second attempt. Only after this method proves ineffective, should the user be provided a specific set of steps.

It is important to be prompt in providing error correction information to avoid back tracking multiple steps to fix mistakes. Frequent error information provides a "safety net” to allow users to move confidently through learning tutorials. Placement of error information may be predicted by foreseeing design elements that seem to present sublet mistake opportunities and error information may be placed at points where a mistake would cause a difficult correction process. Ultimately usability testing provides the best feedback on instructional design to provide the best error information in both content and time. The results of this study showed that the error information included in an instruction manual reduced the number of mistakes during the learning phase of the experiment but did not have noticeable improvements to a standard instruction manual in a skills test (Lazonder \& Van Der Meij, 1995).

Van der Meij and Carroll (1995) reviews and condenses research in the fields of technical communication, human-computer interaction, and instructional education to develop a set of guidelines for designing minimalist instruction manuals for software training and online 
support. The four principles that are presented are as follows: “Choose and action-oriented approach”, “Anchor the tool in the task domain”, "Support Error Recognition and Recovery”, “Support reading to do, study and locate” (Van der Meij \& Carroll, 1995).

\section{Customer: Human Behaviors, Reader Perceptions}

Lang, Martin, Sharples, and Crow (2013) discuss the lack of design for medical devices for the adolescents population. It is noted that while medical products are tested and deemed viable by the manufacturer's ability to attain the result that they are striving for, lack of testing the real world effectiveness makes medical devices ineffective or even negatively impacts different populations (Lang, Martin, Sharples, \& Crow, 2013). These short comings stem from “social, psychological, organizational, and clinical factors” (Lang, Martin, Sharples, \& Crow, 2013). It was found through a design interview with patients that the device being studies was not being used effectively because of several factors relating and not relating to the device. The device was a breathing resistance product the allowed users to perform breathing exercises. The device proved problematic in that there was no feedback provide to the user if they were using the device correctly or if they had used the device long enough. Other issues such as remembering to clean the device as well as taking it on the go created problems for users. It was concluded that a lack of understanding in the device-user relationship can result in a device not achieving its full effectiveness.

In terms of product design, Flori Manning (2015) describes that the “out-of- box experience" introduction of a product is incredibly important for a user's experience with a product as a whole: this includes the setup and use guided by instructional materials.

Lim and Hoffmann (2015) conducted an experiment to determine the effects of assembly jigs, instructions, and ergonomic workspace on people who were tasked with assembling 20 
hacksaws. It was found that after constructing the product about 10 times the support material played little role in performance improvement. Participants most frequently worked with the larger pieces of the assembly before working with the smaller parts and often refined a wide range of sequences to a single construction sequence (Lim \& Hoffmann, 2015).

According to Crossman (1959), when a person is tasked with building a complex object several times, a person will adapt to perform that task faster by changing his or her sequence of action. Unlike automated machines, people will likely try performing a task in multiple sequences if they lack specific instruction.

Karwowski, et al. (1999) addresses the effects of human mental perceptions on manually lifting tasks. While the purpose of their research was to suggest new methods of measuring psychophysical power, the concept is tied to the larger notion that task performance is influence by the ideas and perceptions of an individual causing them to perform differently under personal ideas of comfort and ease.

\section{Manual: Technical Communications and Visual Design}

Along the same lines, Bernhardt (1986) contrasts the development of written text in various fields (such as business, law, or science) to the traditional format of academic writing. The difference is said to be the expectation of academic essays where text is expected to be organized by introduction, body, and conclusion; and for the content of the text to be source of relaying information to the reader. This model differs from how other fields use spacing, various text size, modular layouts and images to not only convey information through the meaning of the text but also through the text as an image. The author continues to describe several visual laws (law of pragnanz and law of gestalt) that provide "visual features [that] take over the load of structuring and organizing the reader's processing, thus reducing the role of those semantic 
features which organize a form like the essay” (Bernhardt, 1986). These features provide the reader with an intrinsic guide to lead them through "smoothly" (Bernhardt, 1986) through logical trains of thought. There is an added value in using the graphical aspects of text to aid the reader advancing through a section of information or causing them to slow down to focus on a specific idea. The author states that there is a lack of research to define the function of text graphically as it should be viewed as an evolving art. It is suggested that research in this field be conducted base on what users of visual text do rather than creating a synthetic environment.

Supra-textual design is the textual, spatial, and graphic elements that creates a reader's experience when interacting with any form of documentation (Kostelnick, 1996). Textual elements include "textual cues" on the exterior and interior of the document to help the reader navigate the document and define borders of the content. Spatial elements include the size, orientation, material, arrangement, and succession of the document to impact how the reader interacts with the document. Graphic elements are non-textual elements such as shapes, colors, and background images that also aid the reader in understanding the structure of the documents and emphasizing information.

Supra-Textual design plays a role in creating "global” structures to bring unity within a document or connect a series of individual documents (Kostelnick, 1996). It also serves stylistics functions such as creating interest, setting the tone of the information being presented, and providing a context for how the reader should interact with the document.

Urata (2004) provides an example of how educators can quickly and easily develop their own software manuals based on the ‘step-by-step’ method. A printed document may be designed using PowerPoint to effectively guide readers through a series of commands by pairing a screenshot image with bulleted phrases describing what keystrokes to hit or buttons to select. 
Instruction manuals should be designed in modular units for reader conciseness and for ease of creation (Weiss, 1991).

Carroll, Smith-Kerker, Ford, and Mazur-Rimetz (1987) created an instructional curriculum in reaction to the growth of non-computer technical people needing to learn to use the computer for the purpose of word processing. An instructional packet called the 'Minimal Manual' was developed to improve learning speed, to better retain knowledge, and to engage the learner in a greater way. The characterizing elements of the Minimal Manual are "focus on real tasks and activities, slash the verbiage, support error recognition and recovery, and guided exploration” (Carroll, Smith-Kerker, Ford, \& Mazur-Rimetz, 1987). It was concluded that the minimal manual achieved greater efficiency in the areas that the manual was designed for as compared to the standard instruction manual that followed the common systematic approach.

Feiereisen, Wong, and Broderick (2008) discuss the role of advertisement in educating the public about new products that are significantly different from existing products. The authors describe these products at RNPs (Really New Products). New product innovations do not succeed in the market at a rate of $40 \%$ to $90 \%$ where marketing holds the main role of engaging and educating potential customers. Two practiced methods describe strategies that marketers use to engage viewer: analogies and mental simulations in either a written or pictorial medium. Analogies use viewers’ prior knowledge to describe the RNP through the example of an existing product. Visual stimulation is more direct in that viewers’ are prompted with imagery describing their use of the RNP (Feiereisen, Wong, \& Broderick, 2008). In a survey, where participants viewed three RNPs, it was found that a written description provided the best comprehensions. The authors discuss that one of the three product cases greatly differed from the others in that pictorial visual stimulation best aided viewer. They suggest that written analogies are more likely 
suited for utilitarian type products while pictorial visual stimulation may be more appropriate for hedonic, or enjoyment, type products.

Kovacevic, Brozovic, and Mozina (2016) analyze if the benefits of the graphical mediums with in instruction manuals such as the multimedia effect (Mayer \& Moreno, 1998), picture superiority effect, similarity, and bottom-up and top-down processing (Egeth \& Yantis, 1997) apply to improving visual search in instruction manuals. The multimedia effect states that communication is more effective when there is a unity of text and pictures as compared to only one. The picture superiority effect states that a viewer will remember $65 \%$ of material presented with an image after three days as compared to the viewer who will only remember $10 \%$ if presented information by text only. Bottom-up processing is the ability for the design of a document to guide a viewer's attention to aspects of the information being presented. Top-down processing is the viewer's analysis of a document based on what information they are seeking to find. It was found that pictograms do improve the visual search among viewers, but the gestalt law of similarity does not affect performance. It was determined that highlighting elements are functional means of directing a viewer's eyes to particular information as compared to the use of visual similarity.

\section{Poka Yoke: Principle Application}

Erlandson, Noblett, and Phelps (1998) identify the compatibility of utilizing manufacturing principles such as poka yoke in making assembly jobs more accessible to individuals who are cognitively-impaired. This is due to the fact that lean manufacturing principles, or Kaizen, naturally improve productivity in manufacturing tasks by "reduc[ing] physical and cognitive demands... mak[ing] jobs more accessible” (Erlandson, Noblett, \& Phelps, 1998). As these practices were developed to be cost effective, these improvements pair 
well with creating a good environment for works with disabilities. Historically, interventions for cognitive impairments are implemented on a case-by-case basis; however, Kaizen techniques provide simplifications and improvements that apply to the standard and impaired population.

A study was conducted to analyze and improve the assembly process of a fuel bracket among cognitively impaired students. A job was provided for students for pay, but was often ignored because of the difficulty of the task and payment was only received when the task was completed correctly. An assembly jig was provided to aid students, but it was found that the jig promoted mistakes rather than avoiding them. Two jig redesigns were created to improve the success rate of assembly. The jigs were found to vastly improve student performance and reduce the error rate from approximately 52\% to 1\%. Each redesigned used trial tests and user feedback to implement better elements to the jig design. It was stated that subtle design elements proved ineffective in guiding impaired student to properly use the jig, but when provided a jig that fully restricts poor physical placement the jig drastically decreased error.

\section{Summary}

The joining of expertise in fields such as technical communication, computer science, graphic design, and education define applicable studies and principles that aid readers in better understanding and accomplishing information and tasks provided by written instructional materials. The educational aspects of instructional materials have shown that action oriented content, simple progression, and opportunities to check correct progress support readers in navigated to instructional settings. Personal experience and perceptions cause individuals to perform tasks by their own definitions of success and ease. Visual communication is more diverse that the text and images. All aspects of a document aid the user in understanding information or completing a task; the use, amount, and orientation of text and images support 
comprehension from conducting tasks to navigating the document. Finally, the implementation of lean manufacturing principles, such as poka yoke, reduce the burdens of solving problems to improve the success potential of humans in work. 


\section{CHAPTER III}

\section{Methodology}

\section{Purpose of the Study}

Instruction manuals are used to help users assemble or operate a new product that he or she as purchased. In the past, however, instruction manuals have been known for being hard to understand and they make using a new product a frustrating experience. The purpose of this research is to address problems with instruction manuals and how customers learn how to use new products. The general aims of this research is to identify successes and short comings with assembly based instruction manuals that are used today, understand the nature of these findings and how to address them, and offer suggestions to designers who will make instruction manuals in the future.

\section{Objectives of the Study}

The objectives of the study were guided by the following research questions:

4. What are the major success or short comings of an assembly based instruction manuals in a current industry product?

5. What effect does the manufacturing principle poka yoke have on the user experience of instruction manuals?

6. What design elements or informational points can be offered to practicing designers to positively impact instruction manual design?

\section{Research Design}

The mixed method, sequential explanatory, will be utilized in this case study. Sequential explanatory method is the use of qualitative data to explain and interpret quantitative results (Ivankova, Creswell, \& Stick, 2006). Quantitative and qualitative data will be collected 
simultaneously and then will be analyzed in two phases: results of the quantitative analysis will guide the analysis of the qualitative data which will be the emphasized results.

The function of the quantitative component is to provide internal rankings for each test group to provide guidance on design decisions, and it will attempt to show if design changes improved the user experience between the original and revised manuals. The purpose of the qualitative component is to provide a description of how the manuals perform, and it aims to provide a more generalizable framework for instruction manuals in terms of user experience.

In this case, a descriptive study using a widely used User Experience Questionnaire (UEQ) (Laugwitz, Held, \& Schrepp, 2008) and short version (UEQ-S) (Schrepp, Hinderks, \& Thomaschewski, 2017) is going to collect data on the general success and short-comings of the instruction manual in the scope of the direct design components of user experience which is usability and desirability. Live and video recorded observations of the toy assembly exercise as well as individual interviews will be used to interpret the data from the questionnaire (Laugwitz, Held, \& Schrepp, 2008) through the analysis of themes using grounded theory (Martin \& Turner, 1986).

An experimental design will be implemented using the structure of the iterative design cycle, as defined by the Nielson Norman Group (Budiu, 2017), to test a control group and use results from the experiment to provide a modified experiment to gauge the impact of the poka yoke principle on a test group. The iterative design cycle uses an initial product evaluation followed by three repeating steps to collect, interpret, and apply user feedback to redesign a given product. As shown in the image below, the cycle accepts one or both quantitative or qualitative methods. 
Budiu (2017) states that the first and third steps are evaluation phases which "provide an overall assessment of a design" while the second step is "formative" meaning that information is used to make design decisions for improvement. The iterative methodology meshes well with sequential explanatory method as the initial experimental phase of the study will be to conduct a descriptive study to evaluate the quality of the instruction manual followed by grounded theory interviews to further understand the nature of the questionnaire results and guide design decisions. A second experimental group will test the design changes, and a second descriptive study will provide comparable quantitative data. A second set of interviews will be conducted to allow for future redesign. The union of the research methodology and design process is illustrated below (See Figure 1):

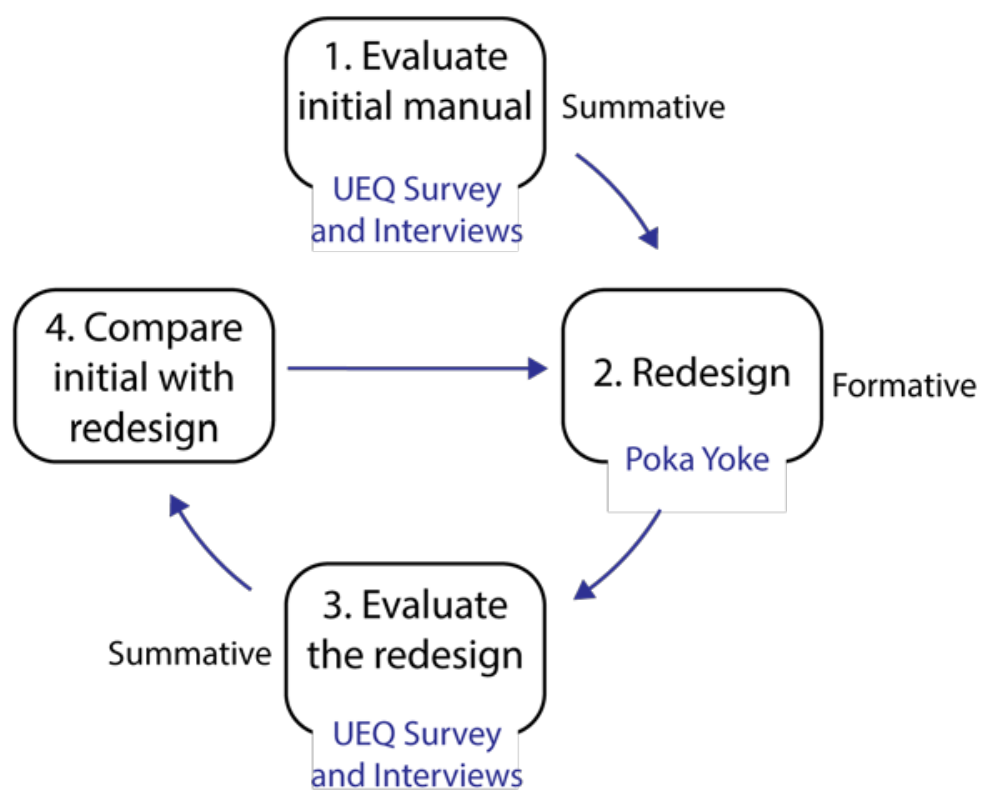

Figure 1. Mixed methods applied to iterative design cycle.

An aim of the design is to ground this study in a really industry setting. As a result, limitations in areas such as sample size and modifications to the test group instruction manual will be present to make results and experiment replication relevant and attainable to researchers 
and industry professionals alike. The nature of these limitations will be presented throughout the chapter as they arise.

\section{Population}

The target population of this study are adult individuals (age $18^{+}$) who would consider themselves to be generally untechnical or not mechanically inclined. A cover letter outlining the experiment was provided to them (See Appendix A). The identification of this population is to simulate a customer who purchases a product who would otherwise have no experience or previous knowledge of the product and would require some form of instructional material. Technical proficiency was chosen due to the nature of the exercise being presented to participants, which is the assembly of a mechanical toy: in this case, a mechanical spider.

Participants were recruited by the solicitation of the study under the premise that participants should not personally identify as mechanically inclined. The rational is that individuals who do not commonly utilize or practice a set of skills, such as mechanical assembly, would rely on the aid of an instruction manual as opposed to their own intuition. As the nature of the study is to understand the ability of the instruction manual, the nature of the task presented should not fall within the skill set of the user so that all provided information is considered by the reader, and thus providing more thorough results.

All results are limited to sample population of ten $(n=10)$ that participated. The nature of the exercise, the assembly of a toy robot spider, further limited the context that makes collected data applicable. Readers should take care to interpret all participants’ experiences, data, and results as having direct application only to the product use and similar demographics of this sample populations. Suggestions and observations from this study; however, maybe used as topics for research for other instructional contexts and participant demographics. 
For industry relevancy, the size of the sample population to five $(n=5)$. As stated by Jakob Nielsen (2012), 5 users in a usability study provides, “...close to user testing’s maximum benefit-cost ratio.” The sample size chosen should provide valuable data unhindered by cost.

\section{Instrumentation}

\section{Quantitative instrument}

The UEQ and UEQ-S combined are the primary quantitative instrument of the study by which the two questionnaires will gauge the effectiveness of a user's experience of an instruction manual in the areas of usability (perspicuity, efficiency, dependability), desirability (stimulation and novelty), and attractiveness as a whole; the short version questions will gauge the effectiveness of each step of the manual in the broader context of usability and desirability (See Figure 2).

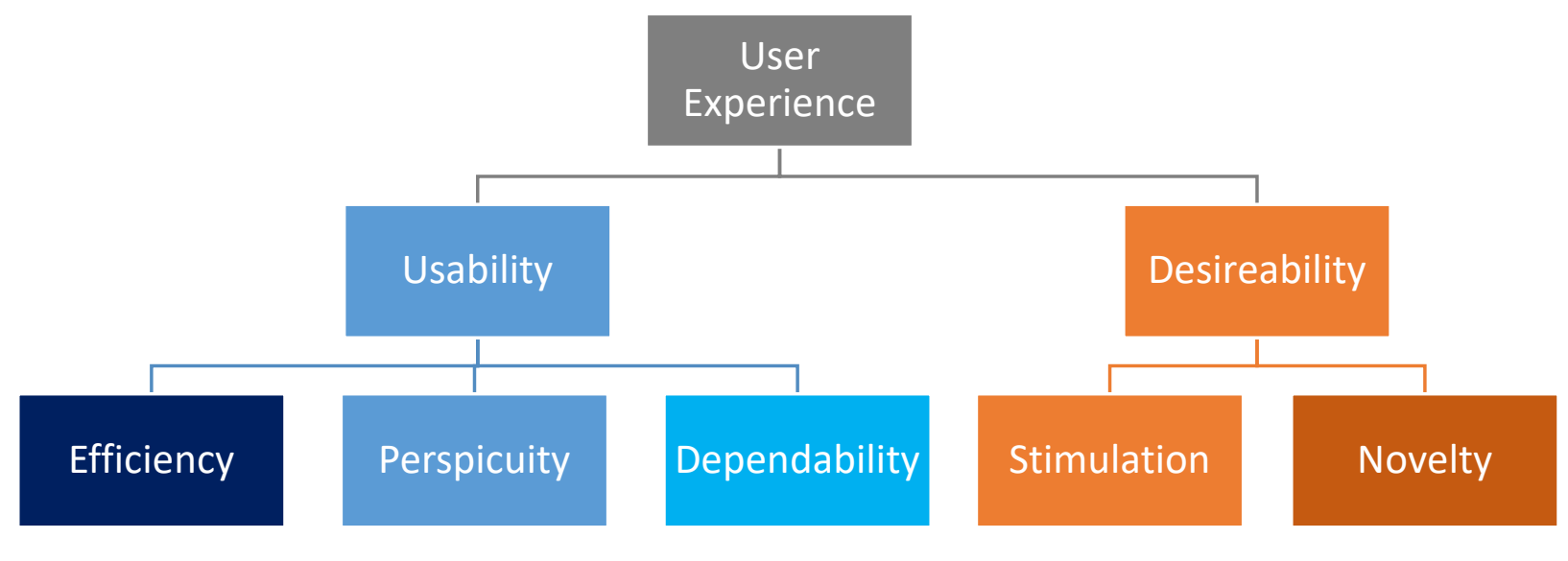

Figure 2. User experience hierarchy.

The instrument contains three sections: 26 likert scale questions on the overall effectiveness of the instruction manual, six likert scale questions on the effectiveness of each step of the manual (96 questions in all), and six multiple choice or written questions were asked concerning participants’ demographics (See Appendix B). 
Reliability and validity of the instrument were confirmed through the implementation of the instrument in two pilot tests. (Laugwitz, Held, \& Schrepp, 2008).

Some modifications, however, were made to adjust the UEQ and UEQ-S for this specific case. First, the seven-point likert scale used in the UEQ and UEQ-S providing a neutral response was omitted to require a positive or negative reaction from the questions asked. Indifferent responses would not aid in the decision to change or keep elements under scrutiny. Second, to reduce the time in filling out the UEQ the scales were unscrambled to show most positive responses on the right most side and negative responses of the left most side. Third, for the issue of time and for not direction translation to the subject of instruction manuals, the items of inventive-conventional and leading edge-usual were omitted from the UEQ.

\section{Qualitative instruments}

An interview was also provided to collect input from participants to describe their experiences. The interview contains two sections: seven open-ended questions on the participants perceived successes and short comings of the instruction manual, and a repeatable single question on observations of the researcher during the exercise. (See Appendix C.)

A video and audio recording of the assembly exercise and the interview will serve as a second qualitative instrument in which successes and short comings of the instruction manual may be reviewed through the physical actions of the participant.

\section{Data collection procedures}

Data collection procedures were conducted identically for a control group (original manual) and test group (revised manual) with exception of location for each group. The control and test groups conducted the exercise in comparable (low traffic, clean lab space, windows, day time, good lighting) work spaces. A single member of each group participated at any given time. 
The participant was set at a table with all research materials: instruction manual, toy, and tools. The participant was given an overview of the test session and about the purpose of the test. The participant was asked to perform an assembly task with a provided instruction manual. The participant was asked to think aloud during the assembly task. The researcher then began video and audio recording of the participant from the time they began the assembly task until completion (See Figure 3).

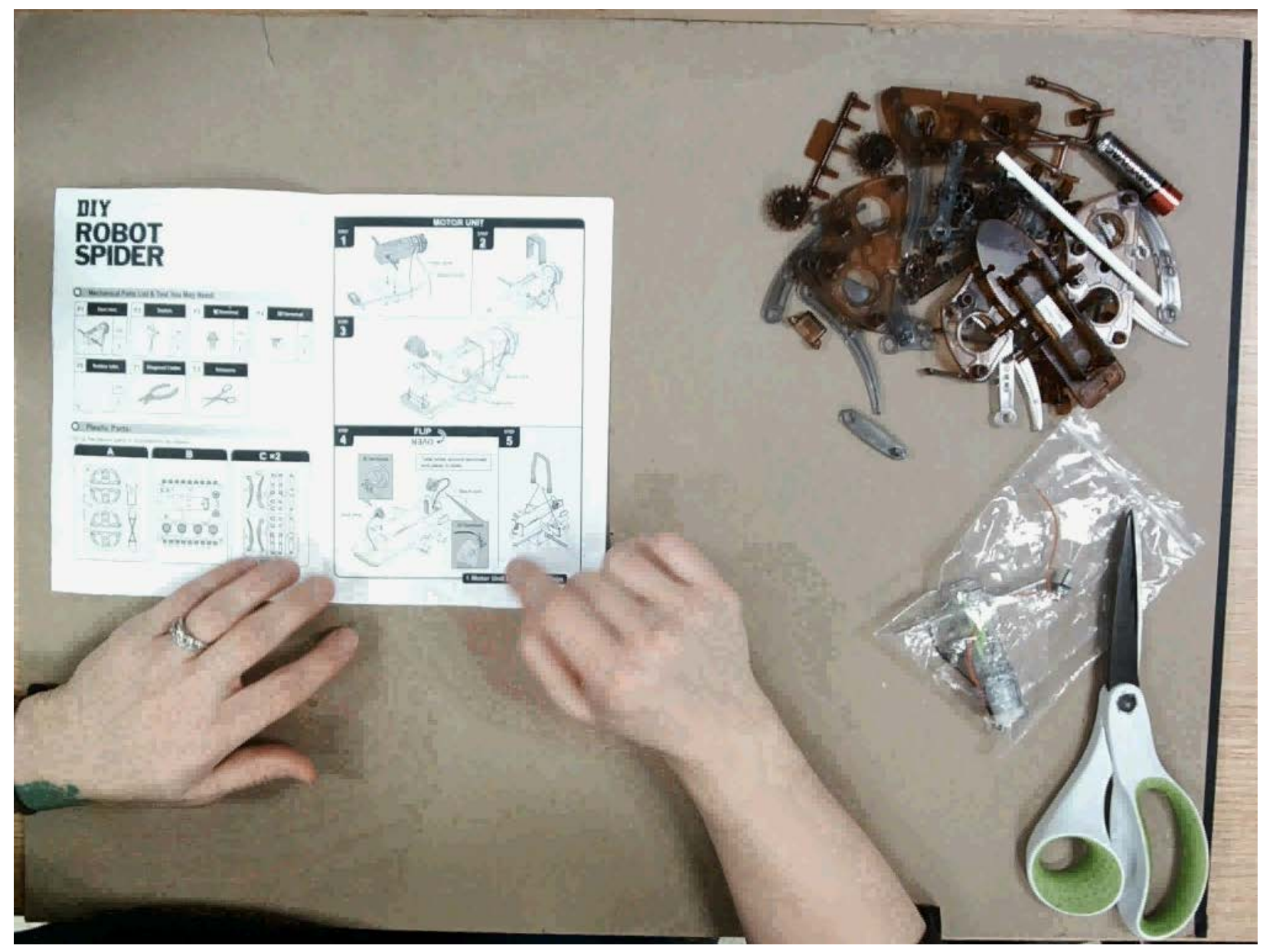

Figure 3. Experiment video snapshot.

Once the task was completed, the participant was given a questionnaire on the instruction manual and his or her experience. The participant could reference the instruction manual during that time. The researcher then conducted an audio recorded interview for the participant to 
discuss specific successes or short comings of the instruction manual. The researcher then asked questions related to the instruction manual based on observation during the test.

Upon completion of the control group testing, the collected data was analyzed and a revised instruction manual was prepared for the test group. The research experiment was approved by the IRB \#1801935840 with expedited status.

\section{Analysis of Data}

Data analysis was split into two sections. First, an overall analysis was conducted at a macro level to provide comparable results to determine if proposed changes between the original and revised instruction manuals were beneficial or not. This overview will help to define observations in the context of user experience framework. Second, a specific step analysis was conducted at a micro level to determine the nature of an issue and provide explicit design options.

\section{Quantitative analysis}

\section{Descriptive analysis}

Information from the questionnaire was collected and entered into Microsoft Excel for analysis. The utilization of the UEQ and UEQ-S provides the full analysis of data through a prebuilt Excel tool. The alpha level of significance was set $a$ priori at $\alpha \leq .05$ for all statistical tests. Descriptive analyses appropriate for the respective items and scales of measurement were performed on the data including measures of central tendency (mean) and variability (standard deviation). The results were represented as scored means, ranging from negative three to positive three (-3 to +3) (Laugwitz, Held, \& Schrepp, 2008), in both table and narrative form. 
The overall scored means of the original and revised instruction manual were presented as follows:

1. Overall attractiveness, usability, and desirability;

2. The components of these main categories: perspicuity, efficiency, dependability, stimulation, and novelty;

3. And the 26 questionnaire items that makes up the components.

The step specific scored means of the original and revised manual were presented as usability, desirability, and a combined overall score to organize each step from strongest to weakest for each category.

\section{Dependent t-test}

A dependent t-test statistical procedure was used to determine if there was a statistical difference between the scored means of the two instruction manuals. The test compared components of usability and desirability for the overall manuals, and the test compared each the usability/desirability of each step between the manuals

\section{Confidence intervals}

Confidence intervals $(\alpha \leq 0.05)$ were calculated to determine a general consistency of reported 'good' and 'bad' results for making design decisions, and they were used to determine if there were any statistically significant results beyond the sample population reported. It is expected that few or no instances of statistical significance may be reported as a result the small sample size. The UEQ does suggest minimum population sizes for each scale recorded. 


\section{Qualitative analysis}

Interview answers, observations, and assembly trial videos were collected and analyzed for themes that coincide with user experience. Interview answers, which contained participant feedback and explanations of recorded observations were transcribed for review.

\section{User experience themes}

In chronological order, similar comments from each interview were grouped into themes with working descriptions. These helped to define specific experiences of participants in both the reading of the instruction manual and physical assembly of the toy. Each interview was cross referenced as new themes were defined. Comments from the interviews that were vague, incomplete, or did not provide reasoning were omitted. When all interviews were analyzed, each theme was reviewed to ensure that there was no repetition, and a concise sentence was finalized for theme. Using the user experience framework, the themes (if applicable) were organized into the components of usability and desirability. The findings were presented in a flow chart and narrative form.

\section{Specific step feedback}

All participant feedback and observations were then organized by instruction manual steps (step 1, step 2...), pages (title page, materials page...), and an 'other’ category for transitional or non-step specific elements. Each entry was further defined by a positive, negative, or neutral marking.

- Positive entries: defined by a good review or a behavior offering new insight.

- Negative entries: defined by a poor review, participant having trouble completing a task or not completing it as described.

- Neutral entries: defined by a statement or action of fact. 
However, not all comments were compiled into this table. Entries omitted from the table were repetitive entries, non-step or element specific entries, or entries where a participant was contradictory. Similar to the themes analysis, all entries were group by participant. The purpose of these entries was to organize direct participant feedback to make informed design decisions.

\section{Design Process}

The redesign of the instruction manual utilized a chart combining the step specific quantitative and qualitative data in order to make revisions based on the user experience ranking and specific step feedback. The steps of the instruction manual were ranked from high to low score for overall performance, usability, and desirability. A chart was then created to organize each step’s examiner observations, participant feedback, then UEQ-S ranking results. The chart allowed the designer to view and compare the full evaluation for any given step (See Figure 4).

\begin{tabular}{|c|c|c|c|c|c|c|c|c|c|c|c|c|c|}
\hline \multirow{2}{*}{ Item } & \multicolumn{5}{|c|}{ Observation } & \multicolumn{5}{|c|}{ Remark } & \multirow{2}{*}{ Overall } & \multirow{2}{*}{ Usability } & \multirow{2}{*}{ Desirability } \\
\hline & $\# 1$ & \#2 & $\# 3$ & \#4 & \#5 & $\# 1$ & $\# 2$ & $\# 3$ & \#4 & $\# 5$ & & & \\
\hline Step 1 & & & & & & & & & & 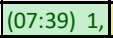 & 0.267 & 0.650 & -0.500 \\
\hline \multirow{2}{*}{ Step 2} & Pulled wir & & & & & $(03: 50)$ I th & & & $(05: 20) \mathrm{Th}$ & $(07: 39) \mathrm{An}$ & \multirow{2}{*}{1.267} & \multirow{2}{*}{2.650} & \multirow{2}{*}{-1.500} \\
\hline & & & & & & $(08: 59) 2$, & & & & & & & \\
\hline
\end{tabular}

Figure 4. Sample of design data chart.

The chart allows the designer to determine which steps require most attention, what issues or praises were associated with a step, and if the nature of a step's revision should be in terms of usability, desirability or both. The designer could then cross reference the instruction manuals themes to understand the underlaying issue of a particular response. A final column was provided for the designer to write a brief description of proposed design changes for each step. Finally, the designer could then create revisions to the instructions with the proposed changes list. 
For this case study, all revisions were defined by the poka yoke principle: prevent defects by identifying and removing opportunities to make mistakes during the assembly process. The technique commonly enacts its function when immediate inspection is prompted.

A model for the design process is illustrated below (See Figure 5):

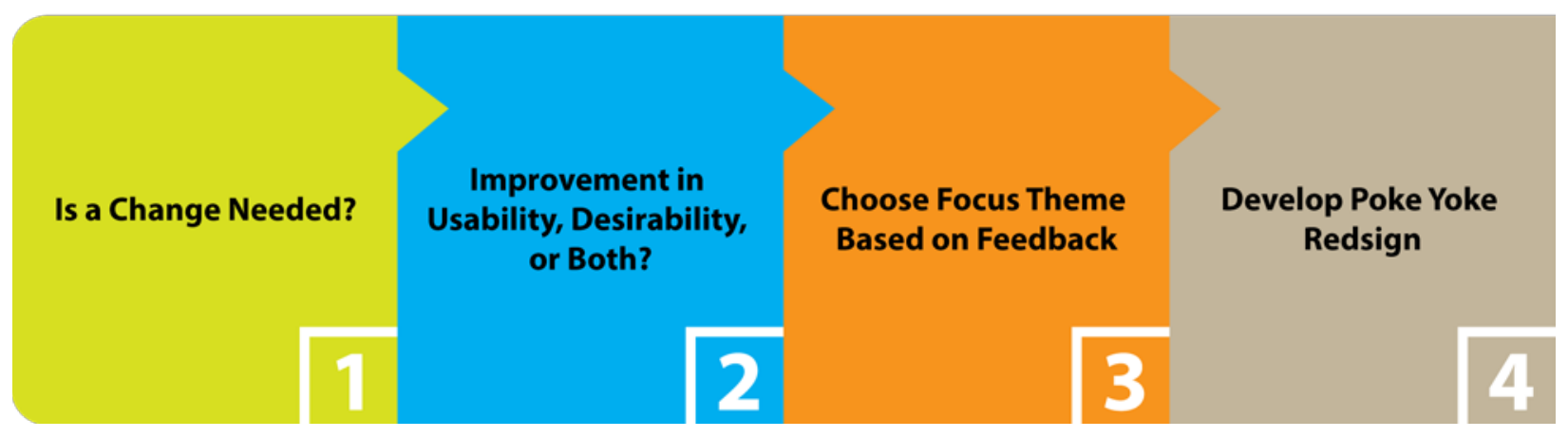

Figure 5. Redesign process.

\section{Use of findings}

The results of this study will provide a foundation for recommendations regarding the design and use of the manufacturing principle poka yoke in the creation of assembly based instructional materials. In addition, this experiment will be used as a framework in which designers may design experiments to other principles or theories that might improve the development of instructional materials. 


\section{CHAPTER IV}

\section{Results}

The results will unfold chronologically in the three phases following the iterative design cycle. The first phase (Step 1: Evaluate Initial Product) will review the demographics of all participants, score the manual overall and by individual instructional steps, and uncover the themes and their connection to user experience overall. The second phase (Step 2: Redesign) will review the design chart on how design changes were made and examples of how changes were actually reflected in the revised instruction manual. The final third phase (Step 3 and 4: Evaluate Redesign and Compare with Initial Product) will score the new instruction manual as done in Step 1, but will also compare the results overall with a dependent t-test and the individual steps side-by-side. The new participant feedback will also be reviewed to determine if there were any specific new or unfixed manual issues.

\section{Phase 1: Evaluate Initial Product}

\section{Demographics}

In addition to the UEQ, participants were asked to provide some general demographics. Participants were asked to indicate their gender, age, hometown, and race. From the control group (group 1), one participant (20\%) was male and four (80\%) were female. In the test group (group 2), one participant (20\%) was male and four (80\%) were female.

In group 1, one participant (20\%) was between age 18 and 21, one participant (20\%) was between age 22 and 25, and three participants (60\%) were between age 26 and 29. In group 2, one participant (20\%) was between age 18 and 21, one participant (20\%) was between age 26 and 29, two participants (40\%) were between age 30 and 39, one participant (20\%) was age 50 or above. 
In group 1, four participants (80\%) were from West Virginia and one (20\%) was from Virginia. In group 2, three (60\%) were from West Virginia, one (20\%) was from Pennsylvania, and one (20\%) was from India.

In group 1, all five (100\%) participants considered themselves white or Caucasian. In group 2, four (80\%) participants considered themselves white or Caucasian and one (20\%) was Indian (See Table 1). 
Table 1

Demographic Characteristics of Participants from Group 1 and Group 2.

\begin{tabular}{|c|c|c|c|c|c|c|}
\hline \multirow{2}{*}{ Variable } & \multicolumn{2}{|c|}{ Group 1} & \multicolumn{2}{|c|}{ Group 2} & \multicolumn{2}{|c|}{ Total } \\
\hline & $\mathrm{N}_{1}$ & $\%$ & $\mathrm{~N}_{2}$ & $\%$ & $\mathrm{~N}_{\mathrm{T}}$ & $\%$ \\
\hline \multicolumn{7}{|l|}{ Gender } \\
\hline Male & 1 & 20 & 1 & 20 & 2 & 20 \\
\hline Female & 4 & 80 & 4 & 80 & 8 & 80 \\
\hline \multicolumn{7}{|l|}{ Age } \\
\hline $18-21$ & 1 & 20 & 1 & 20 & 2 & 20 \\
\hline $22-25$ & 1 & 20 & 0 & 0 & 1 & 10 \\
\hline $26-29$ & 3 & 60 & 1 & 20 & 4 & 40 \\
\hline $30-39$ & 0 & 0 & 2 & 40 & 2 & 20 \\
\hline $40-49$ & 0 & 0 & 0 & 0 & 0 & 0 \\
\hline $50+$ & 0 & 0 & 1 & 20 & 1 & 10 \\
\hline \multicolumn{7}{|l|}{ State } \\
\hline West Virginia & 4 & 80 & 3 & 60 & 7 & 70 \\
\hline Virginia & 1 & 20 & 0 & 0 & 1 & 10 \\
\hline Pennsylvania & 0 & 0 & 1 & 20 & 1 & 10 \\
\hline India & 0 & 0 & 1 & 20 & 1 & 10 \\
\hline \multicolumn{7}{|l|}{ Race } \\
\hline White & 5 & 100 & 4 & 80 & 9 & 90 \\
\hline India & 0 & 0 & 1 & 20 & 1 & 10 \\
\hline
\end{tabular}




\section{Descriptive analysis of overall manual and step rankings}

\section{Overall ranking}

The UEQ contained 26 likert type questions that ranked the usability, desirability and overall attractiveness of the original instruction manual. Each item corresponded to an element of the three scores: usability (perspicuity, efficiency, dependability), desirability (stimulation and novelty), and attractiveness as a whole. The means of four questions per element were averaged to provide the sub-scores whose mean averages made up the three main scores.

On a scale of negative three to positive three $(-3$ to +3$)$, means from negative three to just 0.8 (-3 to -0.8$)$ were considered poor results, from just above negative 0.8 to just below zero (0.8 to 0 ) were considered slightly poor, exactly zero (0) was consider neutral, just above zero to just below ( 0 to 0.8 ) was considered slightly good, and 0.8 to three (0.8 to 3 ) was considered good results. It is typically uncommon to see a score of three $(-3$ or +3$)$ in either direction as it signifies an extremely good or poor result; instead, a score of two $(-2$ or +2$)$ was considered the upper and lower bounds for scoring (Laugwitz, Held, \& Schrepp, 2008).

The mean, variance, standard deviation, and confidence interval of every item was calculated and plotted to ensure consistency with the results. The full questionnaire item analysis maybe viewed in Appendix D. According to the results, the original manual received the following mean scores: Attractiveness, $M_{\text {att }}=-0.130$; Usability, $M_{\text {use }}=0.470$; Desirability, $M_{\text {des }}=$ 0.530 .

Figure 6 shows the scores relative to the regions of good and poor. 


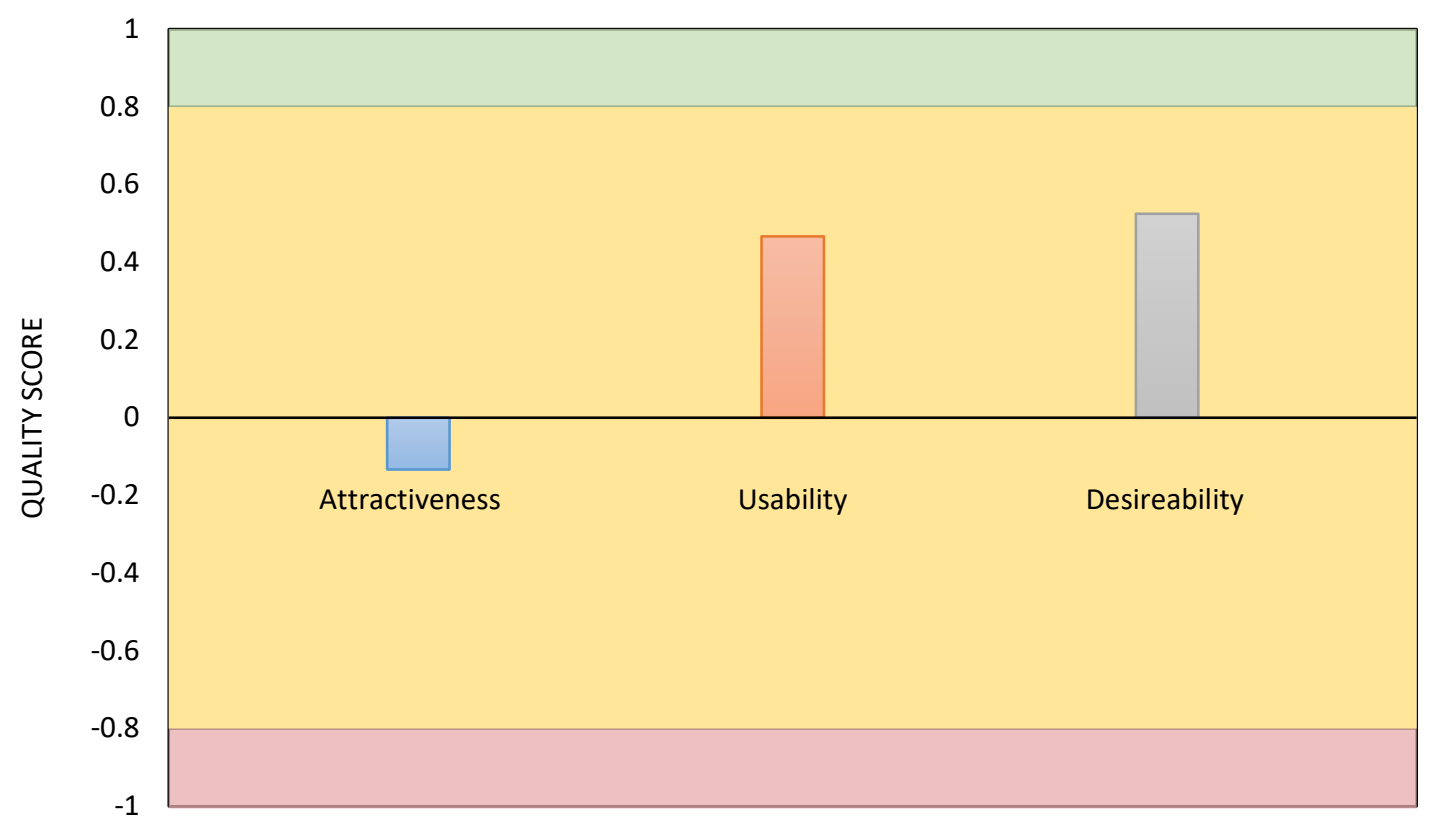

Figure 6. Overall Scores (Original Manual).

Figure 7 further defines the scores into the components that make up the overall scores.

The scores of the components are Perspicuity, $M_{\text {pers }}=-0.050$; Efficiency, $M_{\text {eff }}=0.600$;

Dependability, $M_{\text {dep }}=0.850$; Stimulation, $M_{\text {stim }}=0.400$; Novelty, $M_{\text {nov }}=0.650$.

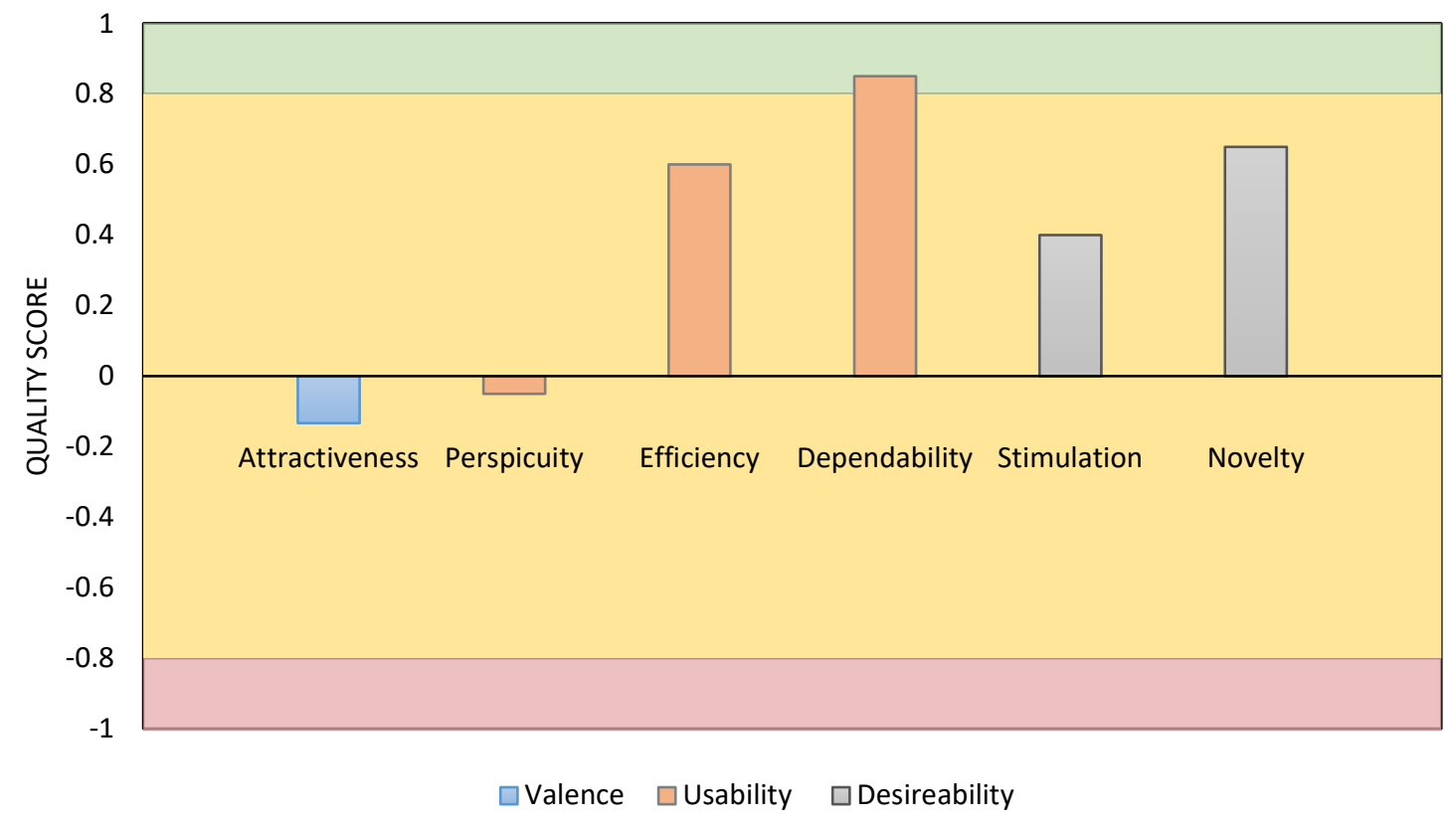

Figure 7. Scale Scores (Original Manual). 
The components of usability and desirability offer some detail as to what about these aspects are good or are lacking. The creators of the UEQ describe the categories as follows (Laugwitz, Held, \& Schrepp, 2008):

1. Pragmatic Quality (Usability): Goal directed aspects.

a. Perspicuity: Is the product easy to become familiar with and is it easy to learn?

b. Efficiency: Does the product provoke unnecessary effort?

c. Dependability: Does the user feel in control of the product?

2. Hedonic Quality (Desirability): Not goal directed aspects.

a. Stimulation: Is the product exciting and/or motivating?

b. Novelty: Does the product catch the interest of the user?

3. Attractiveness: A valence dimension to gauge general satisfaction.

\section{Step ranking}

In similar fashion, UEQ-S provided six likert type questions which only measured usability and desirability. Four questions were averaged to create a usability score while two questions made up desirability. The usability and desirability scores were then averaged to get an overall score. The mean, variance, standard deviation, and confidence interval of every item was calculated. The purpose is to provide a comparable set of scores for ranking within a manual to compare similar steps between the original and revised manual. The full item analysis for each step of the original manual (Group 1) may be viewed in Appendix E. The following charts show the overall scores and rankings from greatest to worst in each of the categories reported.

Figure 8 provides an 'snapshot' view of all information for each step of the instruction manual. 


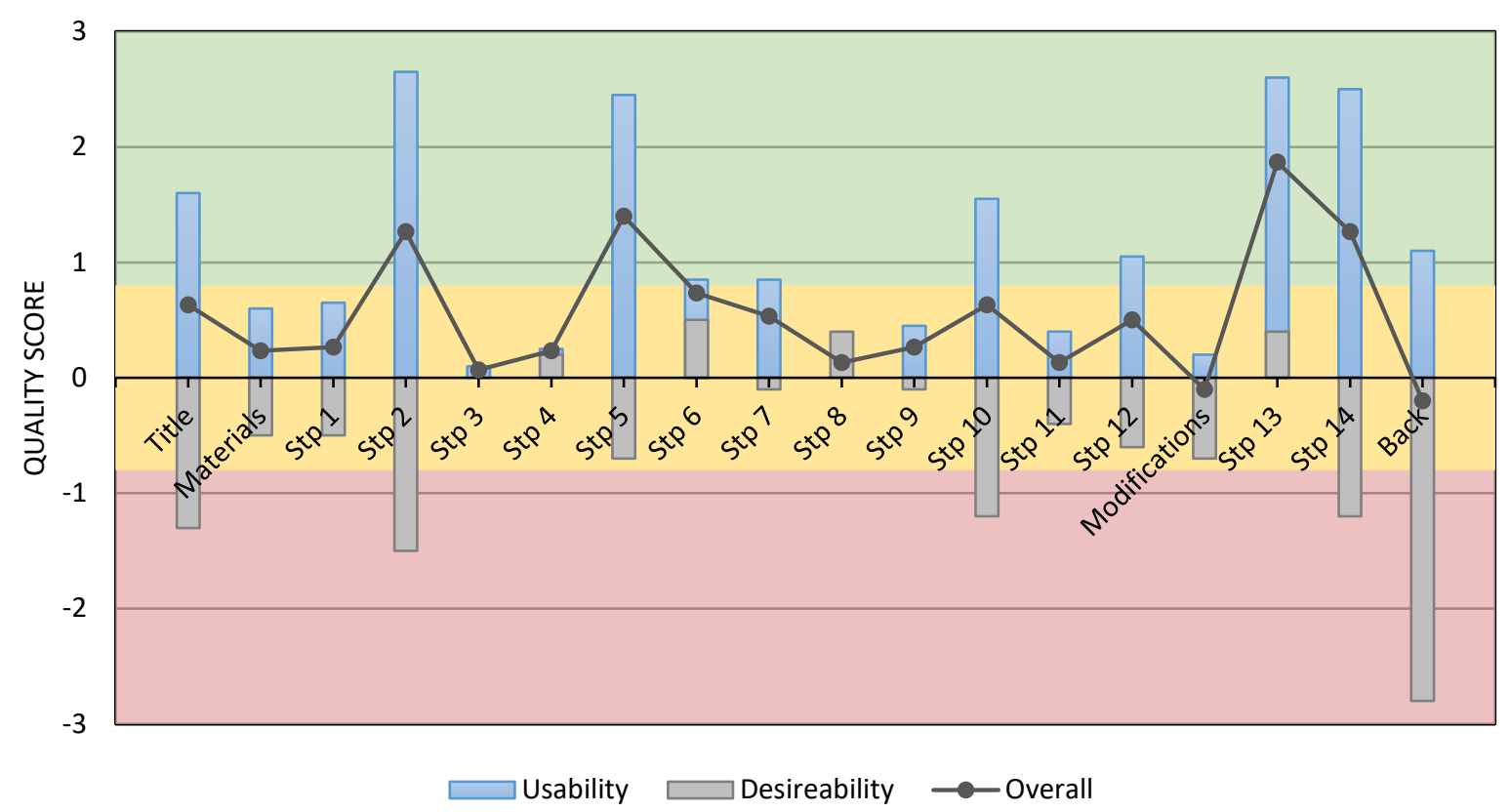

Figure 8. Step Scoring (Original Manual).

In Figure 9, the overall ranking organizes step from best to worst and shows whether the step ranked good, slightly good or slightly poor, or poor. The figure can then be used to prioritize which steps need design revisions.

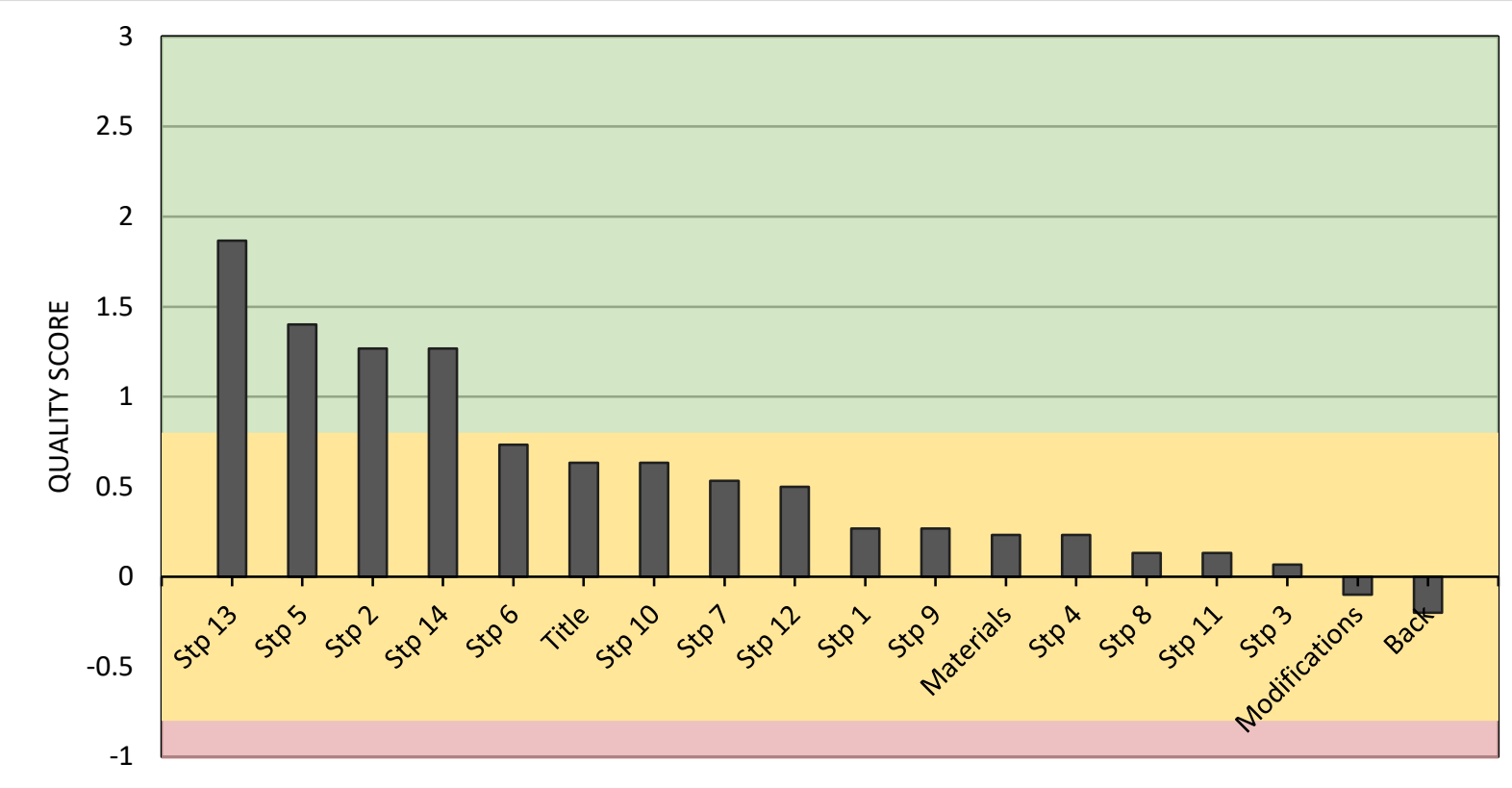

Figure 9. Overall Scoring (Original Manual). 
In Figure 10, Perceived goal directed effectiveness are ranked from best to worst.

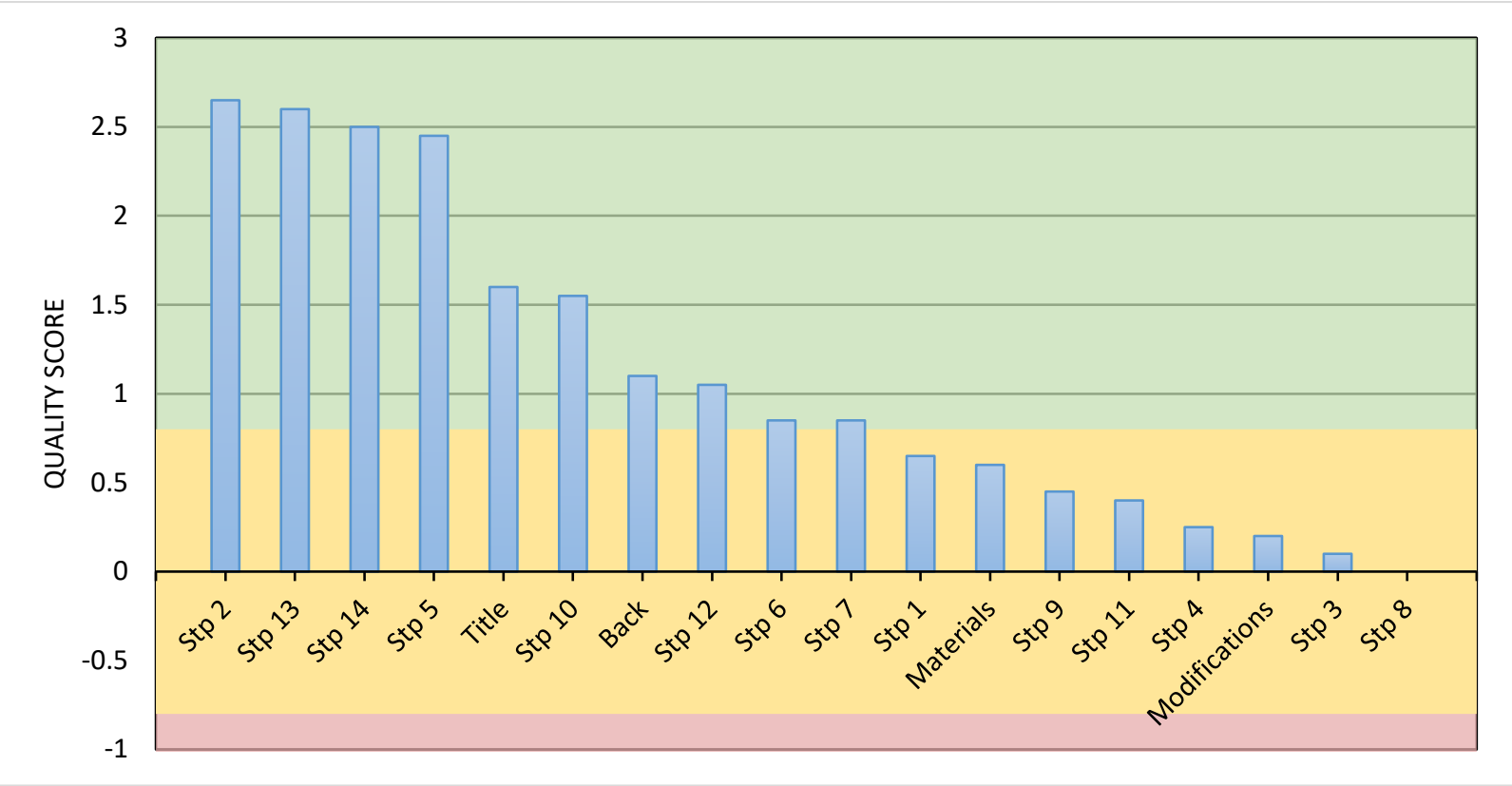

Figure 10. Usability Scoring (Original Manual).

Similarly, in Figure 11, the steps are ranked by desirability score. Perceived non-goal directed effectiveness are highlighted from best to worst.

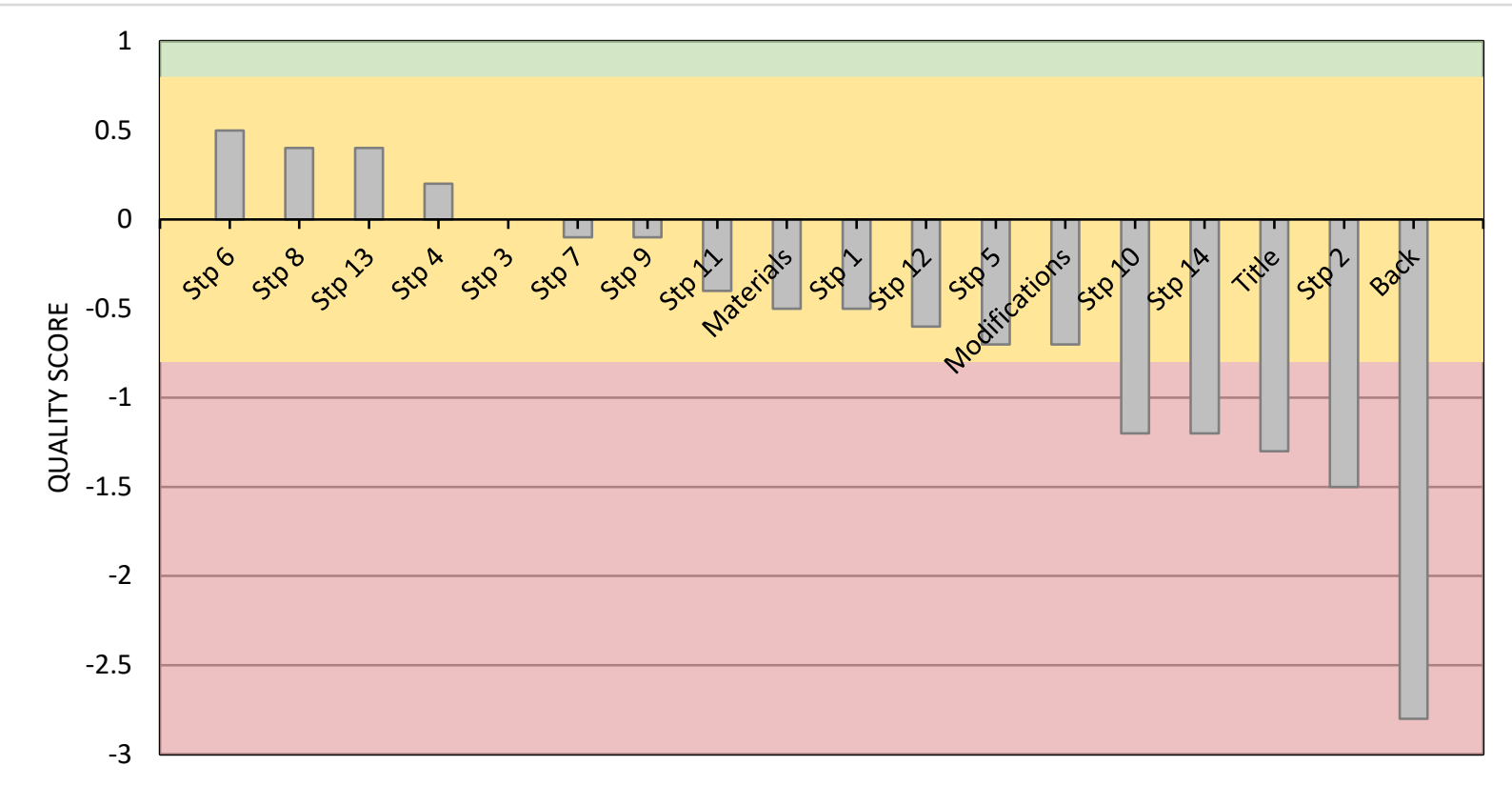

Figure 11. Desirability Scoring (Original Manual) 


\section{Creation of themes}

Interviews were prepared for analysis by transcribing and can be found in Appendix F. Themes were identified based on the repetitive occurrence of a majority of participants from the original manual group, meaning three or more participants mentioning an aspect that was reported. For the purpose of conversation, participants of the study will be referenced as 'reader' followed by a number 1 through 10 . The themes developed were focused at specific attitudes of participants or aspects of the manual. The themes were then applied to the components of user experience to provide a framework of understanding how the themes should be understood. The themes seen were step images, color coding, task completion, perceived uselessness, confidence, deeper knowledge of task, perceived correct implementation, element and image size, step and document organization, showing sides or differentiating parts, step progression, and word usage. A final overall impressions theme was used to capture comments that spoke to overall opinions about the instruction manual. Each theme is shown in the table below with a brief description and supporting comment (See Table 2). The full list of comments organized by participant and support for each theme may be found in Appendix G.

After creating the themes, they were analyzed for components of usability or desirability to see if the observed themes could play a role in improving the overall all user experience of the instruction manual. The impact of the themes in the hierarchy of user experience was then illustrated. 
Table 2

Themes and Supporting Responses

Theme Description Supporting Response

Step Images

Color Coding

Task Completion

Perceived Uselessness

Confidence

Deeper Knowledge

of Task
The message being conveyed

from an image in the manual

was or was not clear.

Color coding adequately or

inadequately provided helpful

information.

Sense of progress/completion or

lack thereof affects motivation

and interest.

Information provided cased

unnecessary effort or did not

provide additional information.

Information did or did not

affirm users' ability to complete

required tasks.

Understanding of task objective

or purpose did or did not

provide context or meet

expectations.
“... it doesn't even really look like

the part. I don't know, I just got confused and it didn't look like anything like on the actual toy."

"If they were different colors and it showed on this, that would have made my life easier."

“...getting to... put the two body parts... on to the center piece that holds the battery. There's that sense of 'yes! I'm finished.'”

"I didn't understand what this... I mean, I used it but then I started doing it without it."

"It was overall kind of empowering because I didn't think that highly of my ability to put together a... an electronic anything”

“...it's like 'oh, turn it upside down and put this thing on.' I didn't know what this was for or why I was doing it." 
Perceived Correct

Implementation

Element, Image Size

Document Organization
"I didn't see any other way to do it. So, I kept pushing but it felt like I was going to break it." information provided.

Size of information did or did not require additional review to understand its message.
“I really didn't understand it because it's so little and there are knobs everywhere and I can't tell what the knobs are."
Image did or did not provide complete 3D information. “...the steps are optional. Or you could put it at the end. So, you could switch these two pages."

“...they made sure to differentiate between which side of the piece was facing up or down."

Steps or step images did or not provide obvious next step.

The message being conveyed from text was or was not clear. “...it wasn't clear that you had to

"I didn't know what "note the direction" meant. ...but it wasn't showing me specifically how...” do the legs on the other side."

\section{Step images}

There were often times that participants referenced the clarity of manual images in both visually as Reader 4 said, “I don't really find whole pictures like this useful because there's so much going on that it doesn't makes sense.” Readers 1,3 , and 5 echoed the notion that if an image contained too much of an assembly or too much detail then readers could not find what 
task need to be accomplished. Directness was also a noted comment where Reader 5 said, “Those arrows [in step 8] did not compute in my mind so I can't '3D think' about it.” Both positive and negative remarks by Reader 3 and 4 also mentioned that simplicity in identifying parts and the directions offered by arrows.

These statements show a connection to perspicuity in that images that were not present clearly or easy to interpret hindered the user from completing the step.

\section{Color coding}

Readers identified a need for coloring to contrast information being presented in the manual images; however, there were disagreement on how color would bring improvement. Reader 1 said, "I guess you could have at least differentiated by the shading on what was grey what was brown. You can tell all these parts are different colors but they're all gray here [Reference Step 8 in manual].” This speaks to the idea that presenting the manual images similar to the characteristics of the pieces would help with part identification. On the other hand, Reader 4 suggested using color as a means of differentiating parts or assemblies:

...if each leg was a different color and they colored them all with the pieces that they needed to be [Reference Step 8 in manual and picture on box]. Yes, I think it would have understood it more if it showed me where the blue leg was supposed to go and the yellow was supposed to go especially when you flip the body piece [Reference Step 8 in manual].

Color coding also presents a tie to perspicuity where the reader's ability to identify a part or highlighted features in part relies on the color or shading used in depicting an image.

\section{Task completion}

It was a consistent statement among all readers that completing the project or reaching a milestone provided some level of engagement. Reader 2 said, "I would say the whole leg assembly part because it was more engaging, multiple steps, and seeing it really come to life 
[Reference Step 8-12 in manual].’” In a negative remark, Reader 5 said, “...pretty dissatisfied, especially because I didn't have it right by the end.”

Its these moment throughout the assembly process where the readers either moved forward with excitement or reluctantly returned to the manual with questions. This speaks to stimulation in that recognizable mile markers during the assembly process that provides reassurance. Novelty is also an expressed component in that completed tasks prompt users to reflect on what just happened.

\section{Perceived uselessness}

There were times during the assembly process where readers identified manual elements that did not provide new information or manual steps did not promote meaningful progress. Reader 3 stated, "The labels are kind of pointless though, because there's no labels in the actual toy [Reference spider toy]. So A1, B3, that's not on the toy.” Reader 2 also said, "I thought that was part of the machine, but then I was like but when I was like oh you're just using it took place it in these holes that are clearly yeah. It's not hard to figure out how they go in there.” In the first instance, the reader had to decide what information was useful and what was not. In the second, the reader was given a tool to make gear assembly easy, but the tool was presented as a part of the assembly causing confusion.

Deciphering necessary information from the manual causes the reader to interpret steps multiple times causing a lack in efficiency.

\section{Confidence}

Another consistent comment among readers were impressions about themselves before the assembly process. As Reader 1 said, "It's not one of my strong suits. Having to tinker with something small, or follow specific directions and look at tiny pieces. It kind of produces anxiety 
in me.” Similarly Reader 5 said, "I do think if there was a wire cutter involved I would have given up: especially on my own.” It was when readers were able to complete a task they did not believe they could that they felt empowered by the instruction manual. As Reader 3 said, “I don't know, I kind of like dealing with the wire stuff. It made me feel smarter.”

This comment shows stimulation because instructional step affirmed the reader's ability to complete the project thus encouraging them to move forward. The success of a seemingly hard step also promotes dependability because the reader is affirmed that the reader understands the manual and is in control.

\section{Deeper knowledge of Task}

Understanding the context of an instructional step affects multiple components of user experience. First, Reader 2 noted that they were sure about the proper placement of a piece because they did not know the purpose of the piece. Reader 2 stated:

...some of these pieces throughout once you would push on it some then it would kind of slide in but it wasn't an easy click [Reference Step 14 in manual] so I was just thinking, 'am I going to break it when I push it in or do I need to put it in a different way?' And I didn't know what the piece was so I was wondering if I break it?

Because there was resistance from the part during assembly, it called into question if the part was in fact supposed to be place as the reader was trying to do. This is an issue of dependability because although the reader had understood the step correctly, the reader could not back up their action with a reason, preventing the completion of the step.

Second, the Reader 4 exhibited interest when completing the one of the final assembly steps. They said, “Step 13 was pretty good because it showed you what you're doing in the whole step if that makes sense. It says you need to put these two legs onto the body with that picture.” Novelty is shown here because the understanding of the what the step is doing allows the reader 
to recognize the value being added to the project. Understanding purpose provides a deeper level of engagement of the reader the promotes interest.

The final example shows stimulation by their deeper knowledge of a given task. Reader 1 said,

I didn't understand step 6, putting them on to the assembly piece, and I knew they weren't moving so I thought how are these gears going to move and then when you put it into the body piece and snap on the other side then it's so satisfying because then you're like, 'yes! that's where the gears are going to move now.'

Because the reader knew that the gear should be turning, the process and completion of the gearbox assembly was an enjoyable moment for them.

\section{Perceived correct implementation}

There were times when the readers questioned correctly completed tasks as a result of some external factor. In two cases readers were deterred from completing a task because they felt that something was going to break. As Reader 4 described,

...when you're pushing it on, the plastic is pushing on the plastic right here so it feels like it's going to break it. I didn't see any other way to do it. So, I kept pushing but it felt like I was going to break it.

The feedback from the toy was contradicting the information provided by the manual and thus brought into question the correctness of the reader's actions. In the same way, Reader 5 brought into question the correctness of the assembly when they noticed extra parts. Reader 5 said, “And, there's extra pieces and now it's kind of frustrating.” Because the manual made no mention of extra parts, the reader was unable to confirm if the assembly was complete. These contradicting issues speak to dependability where readers are not able to confirm that the information provided by the manual is guiding them in the right direction. 


\section{Element, image size}

In several instances, image size confusion by information being missed because it was too small. Reader 5 said, “They also didn't differentiate between the short and a long [pegs]... It says that there should be a letter on it, but I didn't even notice that there was a little ' $\mathrm{B}$ ' on the piece.” Information being overlooked or not understandable is due to a lack of perspicuity.

\section{Document organization}

The logical progression of steps in the manual was mentioned by each of the readers. The main issue belonging to an extra page of modifications being misplaced in the manual. Reader 3 said,
Also, like with the same thing with the... [Reference Step extra step page in manual] I think the review part 'alternate modification steps' so like they put this before you're finished with the thing [Reference Step 13 in manual]. So I was confused because I was wondering if I was supposed to put these on first but then I realized it wasn't necessary so I finished it and then I went back and then put them on, yeah.

Misplaced information can be disrupting by bringing into question the reader's correct use of the instruction manual which raises question of dependability.

\section{Showing sides or part differences}

Another consistent topic was about being able to recognize when the instruction manual was showing two side of the same part or differentiating parts designated 'right' and 'left.' While readers disagreed on the ability of the manual to achieve this, the topic speaks to the perspicuity of the manual to clearly illustrate multiple images to create a single message. As Reader 2 stated, "I get really confused about my left and right so having the mirrored images were very useful." In disagreement, Reader 4 said, “It's still not clear to me that that's the other side of the leg.” 


\section{Step progression}

Similar to document organization, step progression defines the logical flow with in a step. In some cases, readers had trouble completing a step because there were more than one action that had to take place within that step. As Reader 2 describes,

I didn't realize that once you put it on it would swivel around because I was thinking it would hold him place. So the angle that I have to put this on for the others to fit on doesn't match the pegs on the other side, it doesn't fit. So once I realized I can put it on and it move the leg, then it made sense.

This disruption is the logical flow did not provide the reader with enough information to complete the step as was shown. In another case, steps did not adequately provide information on how many times a single step should be repeated. This left readers flipping back and forth through the manual repeating steps to ultimately move forward. As Reader 4 said, “...by looking at this picture I thought that there was only two sides to build.” These statements speak to dependability because information gaps in the instruction manual require readers to rely on their own intuition to guess on what actions should follow next.

\section{Word usage}

In serval cases, readers relied on words for context when an image was not immediately clear. While Reader 4 and 5 wanted to see more text in the manual, they also note issues with the text already provided. Reader 5 said,

It's just "note that direction.” [Reference Step 7 in manual] I should have looked at it closer. I didn't know what "note the direction" meant. I see that it tells me to note the direction of holes, but it wasn't showing me specifically how the holes were supposed to be directed. It would have helped if it said to note the male versus female holes.

While words may provide a quick note to focus on a particular aspect of an image, messages that are too vague negatively impact perspicuity. 


\section{Creation of user experience flow chart}

With each theme defined in terms of participant feedback and analyzed in terms of

usability and desirability components, A flow chart was created to understand the themes in terms of the framework of user experience (See Figure 12). 


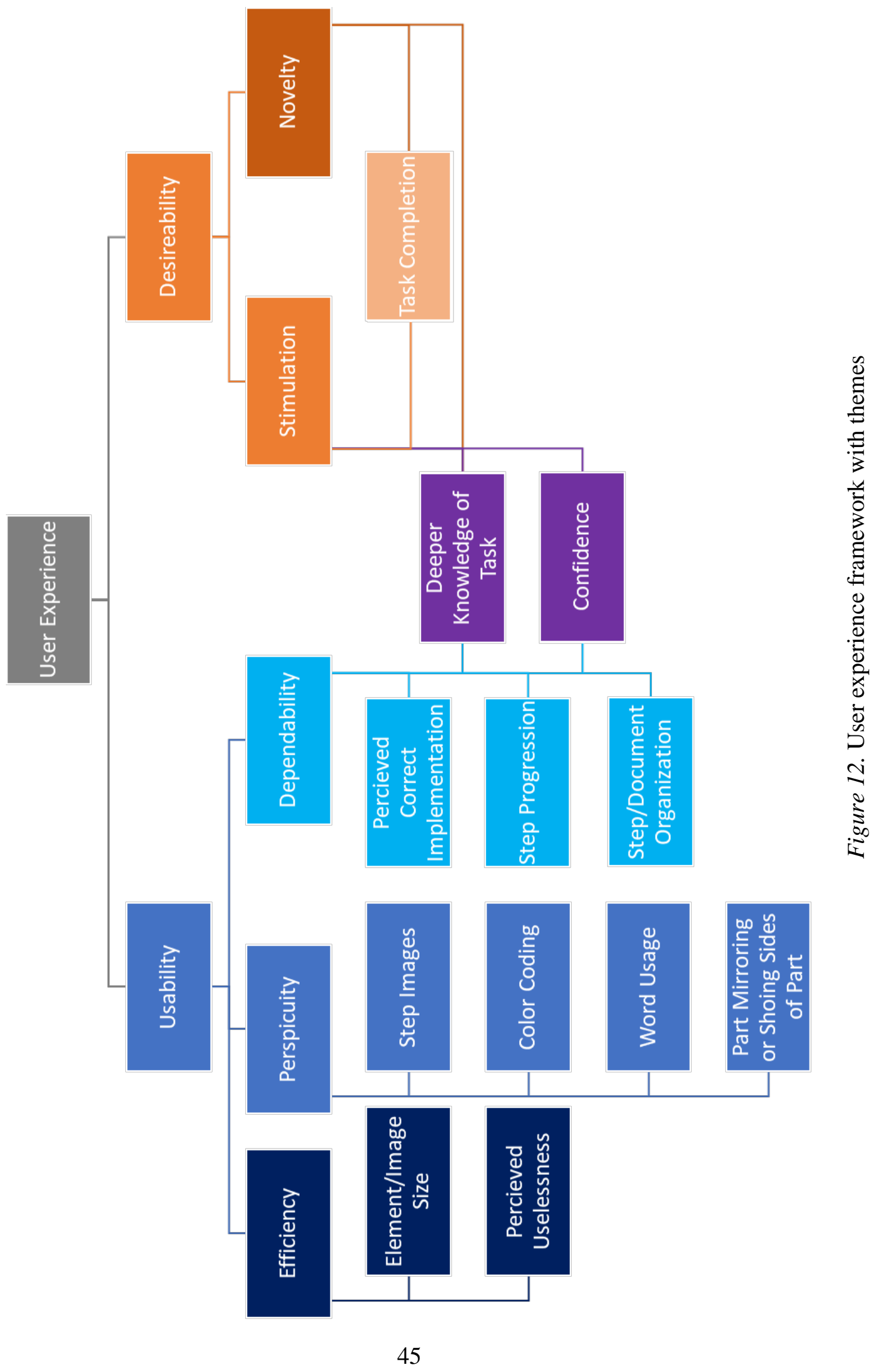




\section{Phase 2: Redesign}

With the themes analyzed, the comments could then be organized by steps and compared with the UEQ data. The process of making changes started with understanding the problem by determining which steps required the most attention, determining if step required attention to usability or desirability (or both), and finally the visual aspect that required revision based on the comments and corresponding themes. A brief statement was made to describe what change was made based on the poka yoke principle and then was made in Adobe Illustrator. The DIY TechKit Robot Spider editable PDF was provided by Five Below for the purposes of this study. The designer was provided creative freedom to apply the data as they felt was best (FiveBelow, 2017).

The progression of steps and pages for this section will be in the order in which they appeared in the original manual. The full list of comments and data for each step may be found in Appendix H. It should be noted that some data was lost in the pagination of the design chart. Specifically, comments by specific participants were reorganized to only show step specific designation. The full original and revised instruction manuals may also be found in Appendix I and Appendix J.

\section{Document consistency}

Supra textual design was utilized to standardize features in the manual to help readers understand how to read the instruction manual overall. In terms of poka yoke, conventions in document design help the user to predict how information should be interpreted and thus reducing confusion on what message is trying to communicate. The three elements were headers and footers, color coding, and omitted labels. In some cases, steps did not require modification or not enough feedback was provided to make a data based design revision. These three elements 
were applied to every step for overall document consistency to address all usability components. In several steps, these revisions were expressly mentioned as will be noted throughout the redesign.

Headers and footers were used to group major sections of the project as sub-assemblies. The groupings attempted to notify the beginning and end of major sections to show when a task was complete and to show when a task should be repeated.

Color coding was used to identify when a new part was introduced to the assembly and when the part was to be placed. Typically, a starting or base part was denoted with a white infill and the new part to be assembled was denoted with a grey infill. In some cases, gray infill was also used to highlight points of interest or as a contrast to help the user differentiate sides of similar parts.

Omitting part labels were used to remove information that were not immediately meaningful and to provide more image space. In several cases, it was mentioned that users either ignored part labels or used other means of confirming the identity of a part. In omitting part labels, images were enlarged when possible to promote readability. 


\section{Title page}

The title page ranked 6 of 18 with a slightly good overall score of 0.633 . Usability was good at 1.600 and desirability was poor at -1.300 (See Table 3).

Table 3

Title Page Scores

\begin{tabular}{|c|ccc|}
\hline \multirow{2}{*}{ Title Page } & Usability & Desirability & Overall \\
\cline { 2 - 4 } & 1.600 & -1.300 & 0.633 \\
\hline
\end{tabular}

No significant feedback was provided for the title page, so no changes were made. The title page for both instruction manuals is shown below (See Figure 13).

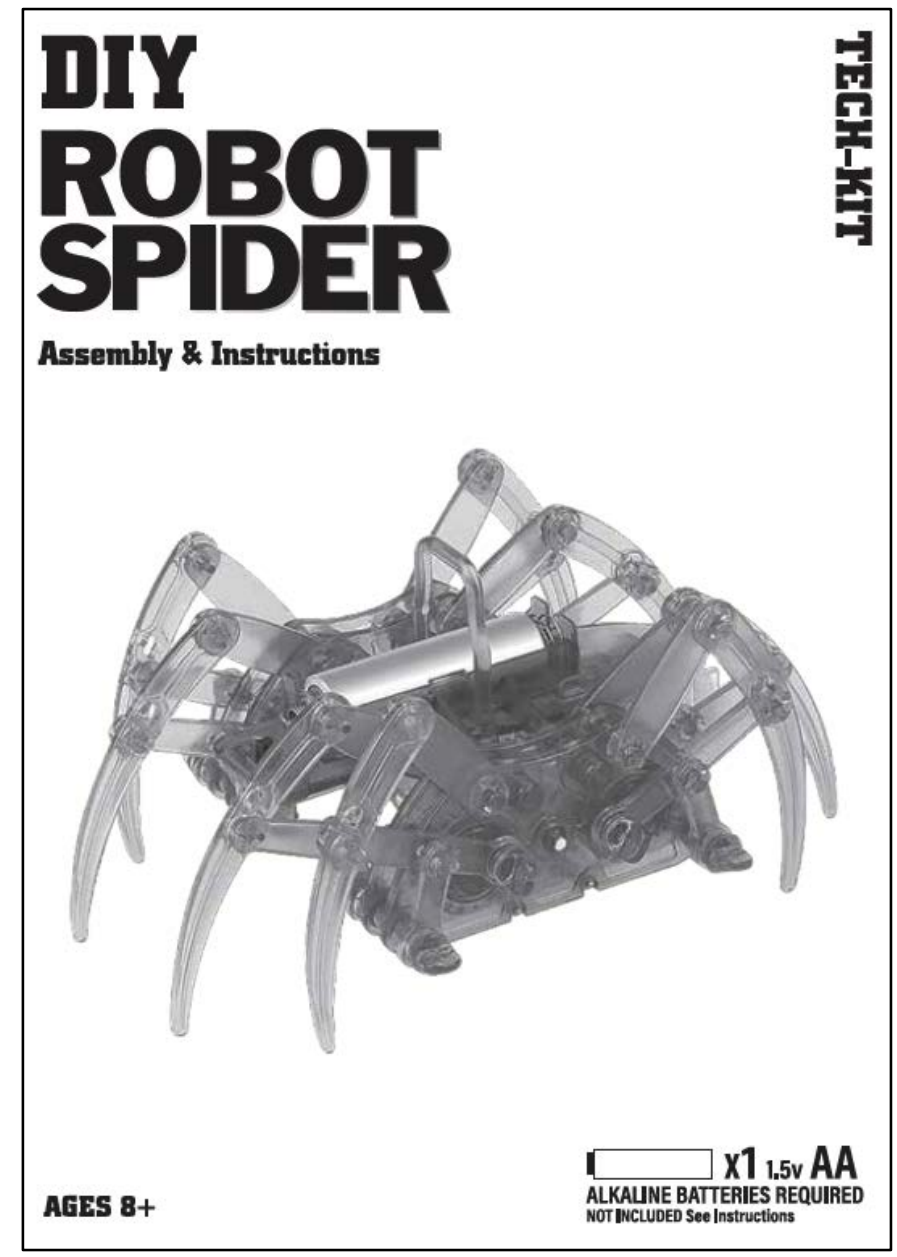

Figure 13. Title Page 


\section{Materials page}

The materials page ranked 12 of 18 with a slightly good overall score of 0.233 . Usability was slightly good at 0.600 and desirability was slightly poor at -0.500 (See Table 4).

Table 4

Materials Page Scores

\begin{tabular}{|c|ccc|}
\hline \multirow{2}{*}{ Materials Page } & Usability & Desirability & Overall \\
\cline { 2 - 4 } & 0.600 & -0.500 & 0.233 \\
\hline
\end{tabular}

It was typical for readers to view the materials page before beginning the assembly process. Only one reader referenced the plastic parts list to ensure that all pieces were accounted for. The same reader also referenced the materials list to ensure that two pegs were different. As no major feedback was provided, only a slight consistency issue was addressed in the mechanical parts and tools list. The tools in the list were denoted with a 'T1' and 'T2' in the headers just as the parts were denoted with 'P1' so on and so forth. Figure 14 shows the revised Materials Page (shown on right). 

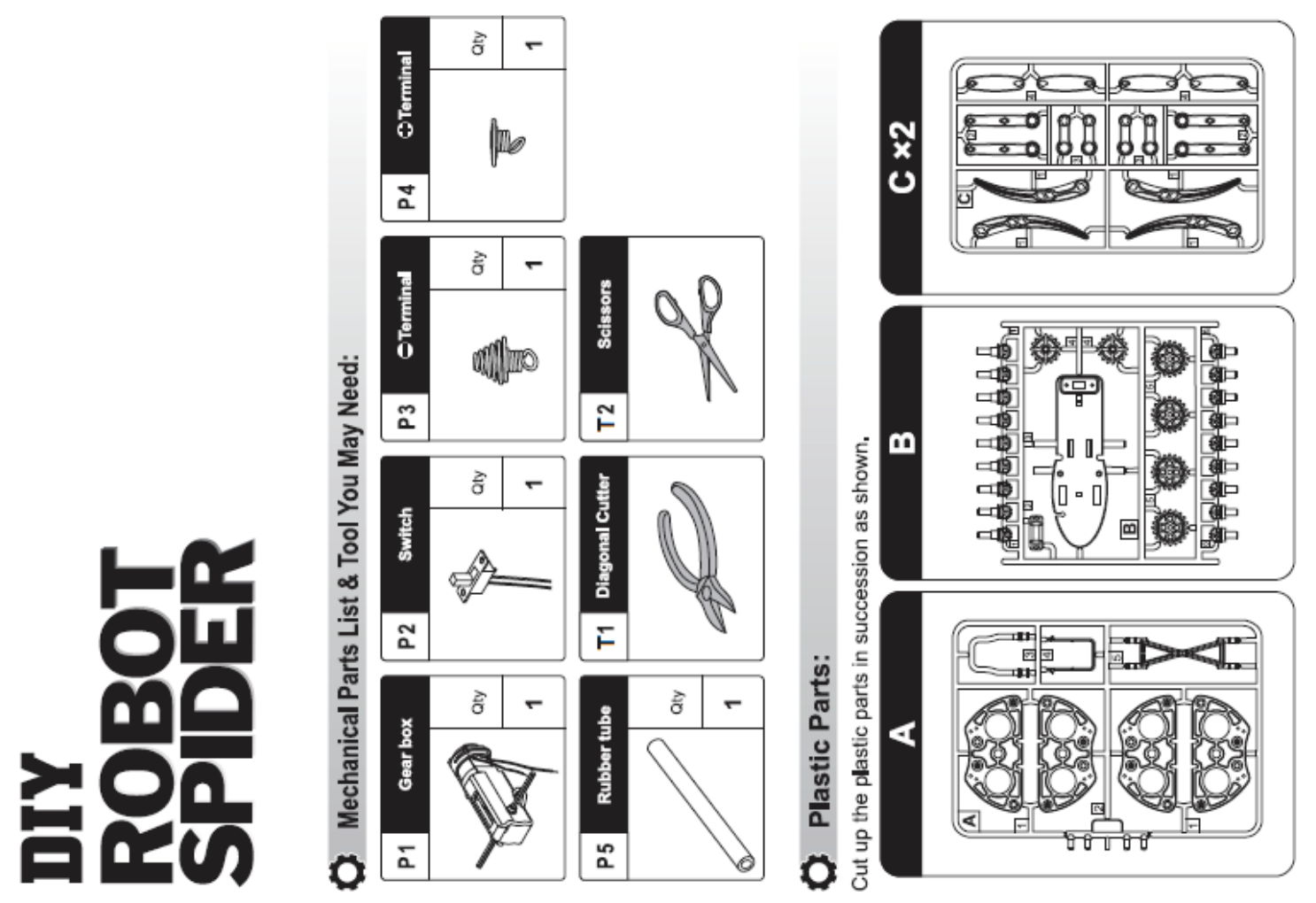

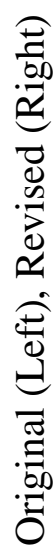

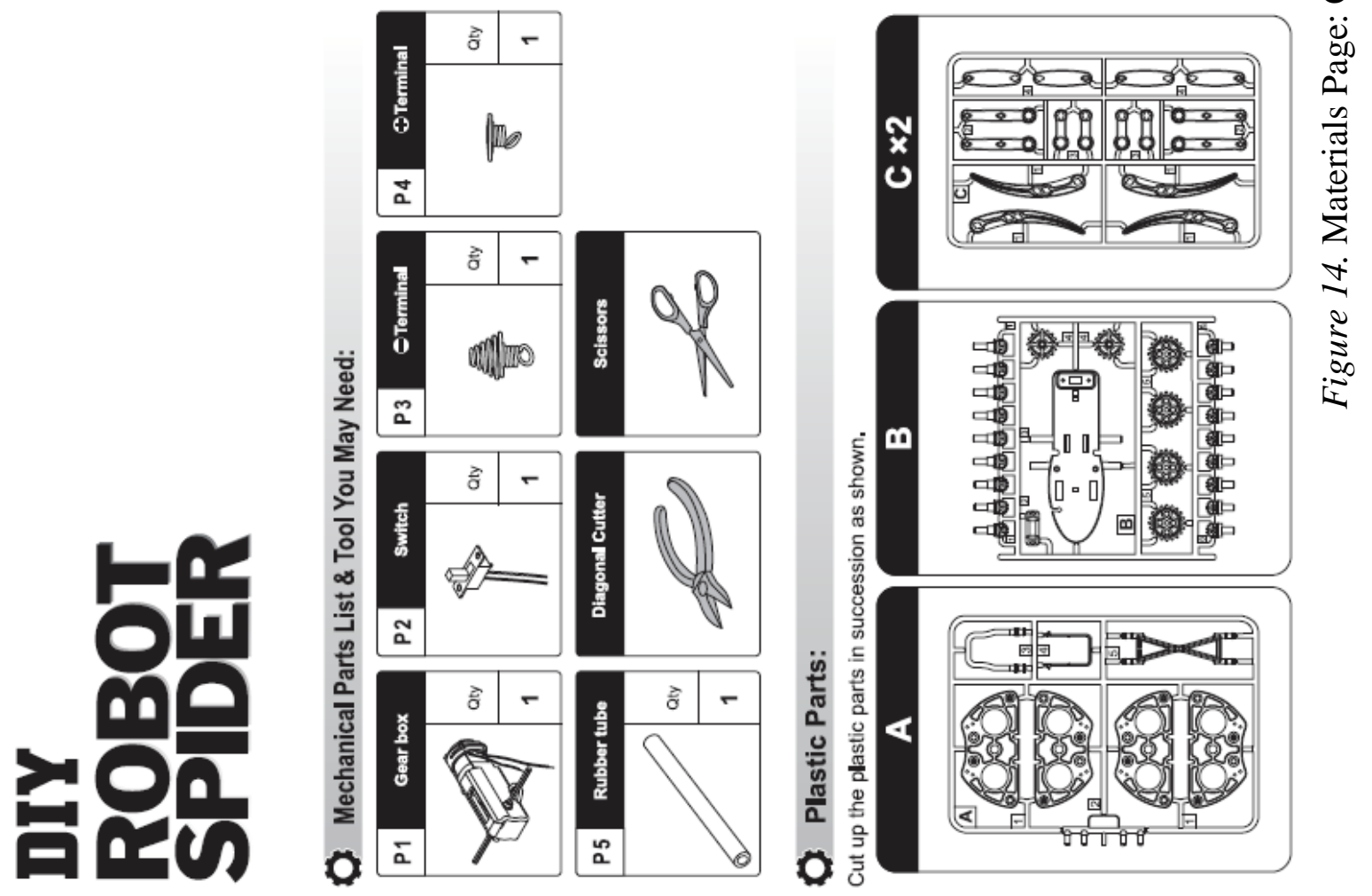




\section{Step 1}

Step 1 ranked 10 of 18 with a slightly good overall score of 0.267 . Usability was slightly good at 0.650 and desirability was slightly poor at -0.500 (See Table 5).

Table 5

Step 1 Scores

\begin{tabular}{|l|ccc|}
\hline \multirow{2}{*}{ Step 1 } & Usability & Desirability & Overall \\
\cline { 2 - 4 } & 0.650 & -0.500 & 0.267 \\
\hline
\end{tabular}

The only feedback regarding Step 1 was that the first step was simple in comparison to other steps in the manual. As such, document consistency was applied to the step (See Figure 15). The revised manual (shown on bottom) shows the changes described.
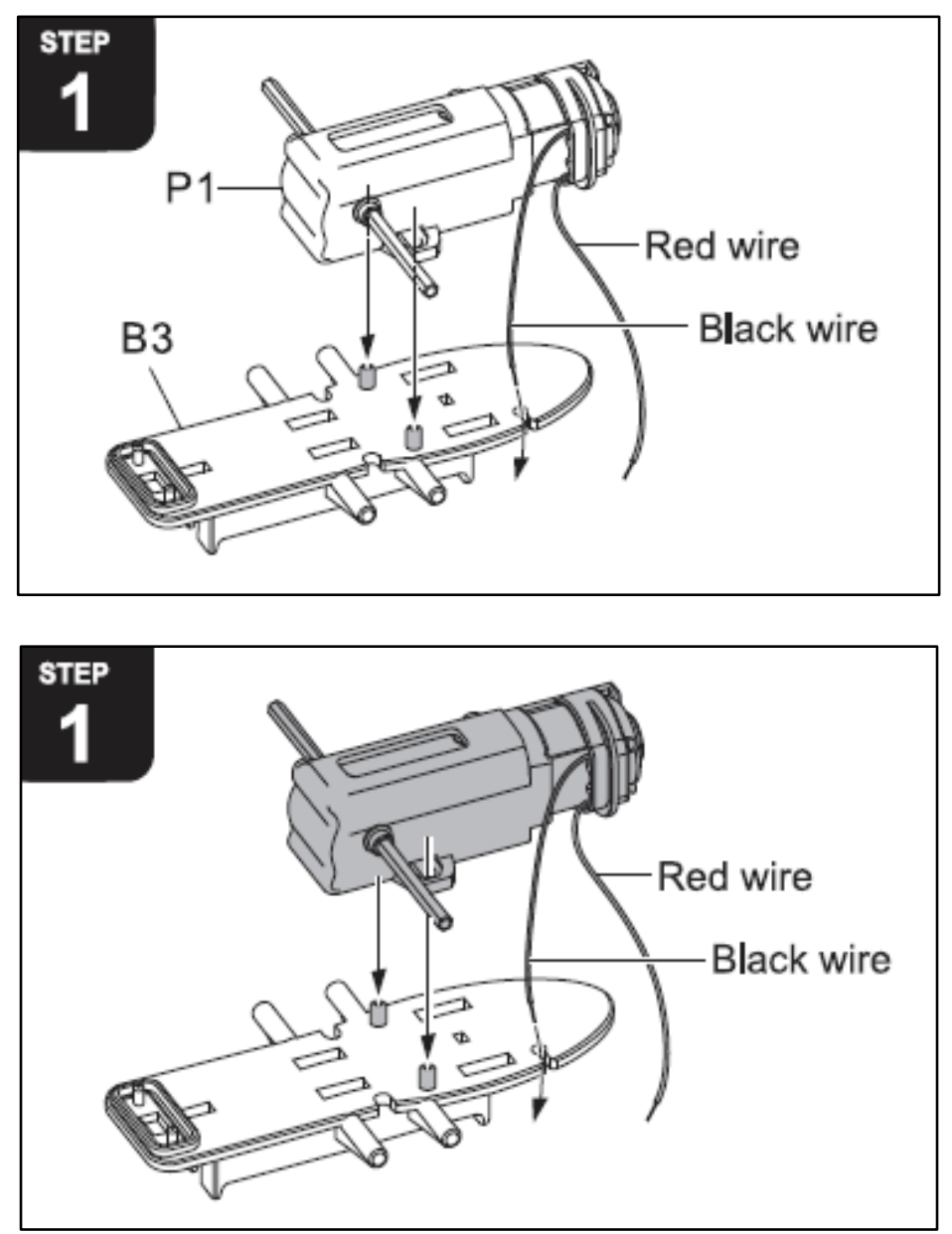

Figure 15. Step 1: Original (Top), Revised (Bottom) 


\section{Step 2}

Step 2 ranked 3 of 18 with a good overall score of 1.267 . Usability was good at 2.650 and desirability was poor at -1.500 (See Table 6).

Table 6

Step 2 Scores

\begin{tabular}{|c|ccc|}
\hline \multirow{2}{*}{ Step 2} & Usability & Desirability & Overall \\
\cline { 2 - 4 } & 2.650 & -1.500 & 1.267 \\
\hline
\end{tabular}

Step 2 showed a high usability due to the simplicity of placing "one piece on one piece” (Reader 4). The step’s low desirability may be due to the boringness of the same fact as described by Reader 1 shows a lack of stimulation. Document consistency was applied to the step (See Figure 16). The revised manual (shown on right) omitted labels, and slightly increased image size.
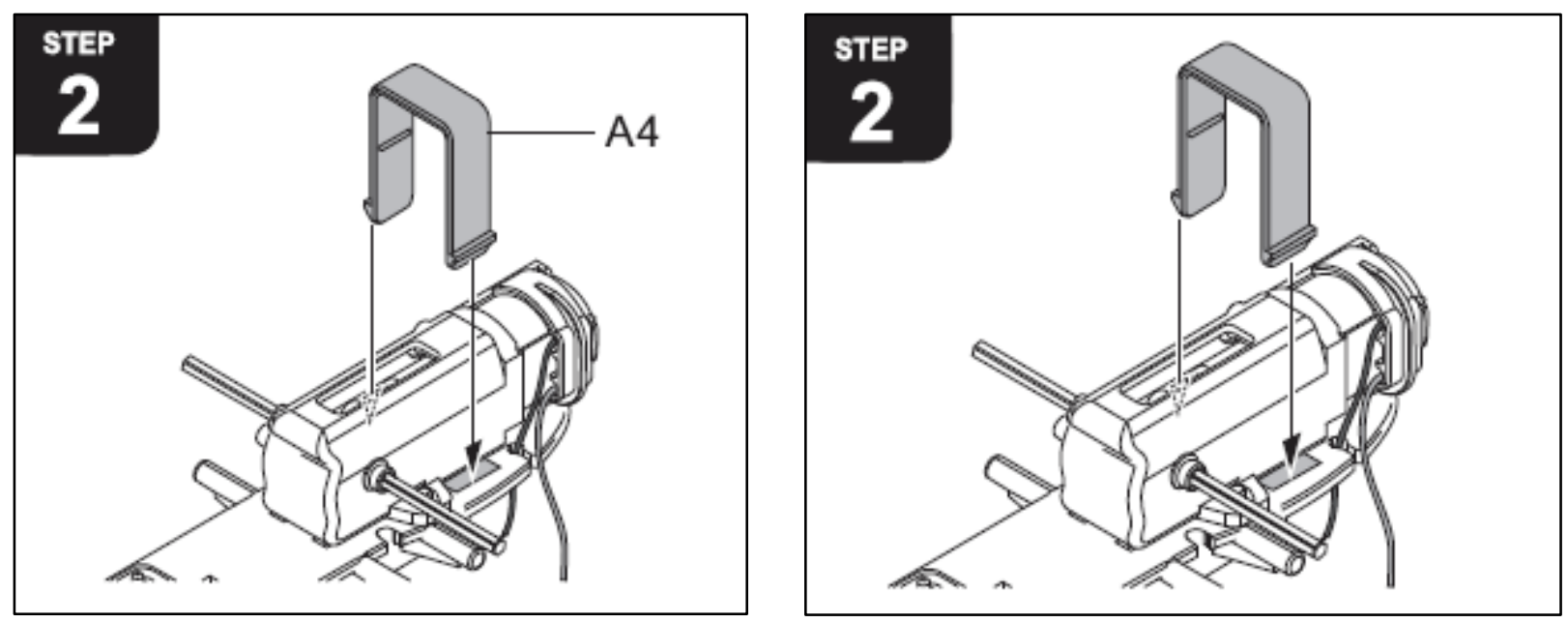

Figure 16. Step 2: Original (Left), Revised (Right) 


\section{Step 3}

Step 3 ranked 16 of 18 with a slightly good overall score of 0.067 . Usability was slightly good at 0.100 and desirability was neutral at 0.000 (See Table 7).

Table 7

Step 3 Scores

\begin{tabular}{|c|ccc|}
\hline \multirow{2}{*}{ Step 3 } & Usability & Desirability & Overall \\
\cline { 2 - 4 } & 0.100 & 0.000 & 0.067 \\
\hline
\end{tabular}

Readers on Step 3 exhibited problems identifying aspects of the image. Reader 5 noted that "A lot of things going on in image," which showed in various assembly issues among readers like orienting the assembly to match the image, placing the wires, and identifying pieces like the switch which shows an issue of perspicuity. For Readers 2 and 3, completing this step was a point of confidence for them. The revised manual (shown on bottom) grouped tasks by organizing wire labels together and part assembly together to show two major aspects that should be focused on in the image. A wiring chart and an extra arrow were omitted to promote image clarity. Document consistency was applied to the step (See Figure 17). 

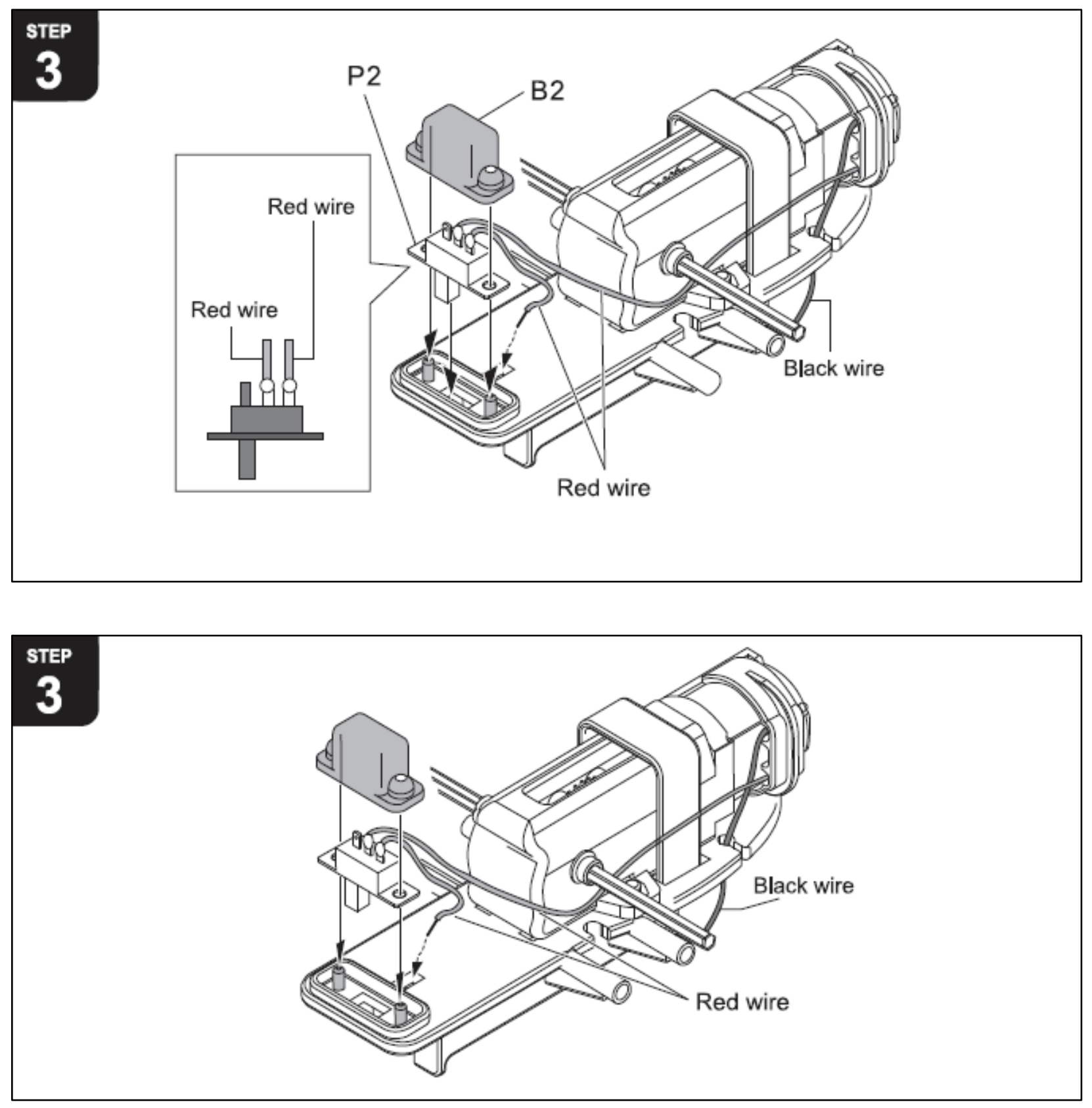

Figure 17. Step 3: Original (Top), Revised (Bottom) 


\section{Step 4}

Step 4 ranked 13 of 18 with a slightly good score overall of 0.233 . Usability was slightly good at 0.250 and desirability was slightly good at 0.200 (See Table 8 ).

Table 8

Step 4 Scores

\begin{tabular}{|c|ccc|}
\hline \multirow{2}{*}{ Step 4 } & Usability & Desirability & Overall \\
\cline { 2 - 4 } & 0.250 & 0.200 & 0.233 \\
\hline
\end{tabular}

In Step 4, it was consistent among readers a lack of clarity in showing where the battery terminals should be placed. In two cases, readers continued to step 5 to verify the placement of the terminals. Readers did note the usefulness of the enlarged images (callouts) for providing emphasized detail. Step 4 was made more concise by removing extra terminal views from the callouts and highlighting the call outs. The textbox of the image included the phrase, “Twist wires around terminals and place in slots," to reinforce the terminal placement. Extra detail of the motor unit was omitted to enlarge the image to provide greater necessary detail.

Some extra changes were made to Step 4 to provide consistency for future steps. For example, a header was added indicating to flip over the assembly. While readers did not have an issue with this, it was a good opportunity to introduce the element for future steps where flipping was not clear. In addition, Step 4 was condensed overall to fit Step 5 on the first assembly page. The revised manual (shown on bottom) shows all the changes mentioned (See Figure 18). 

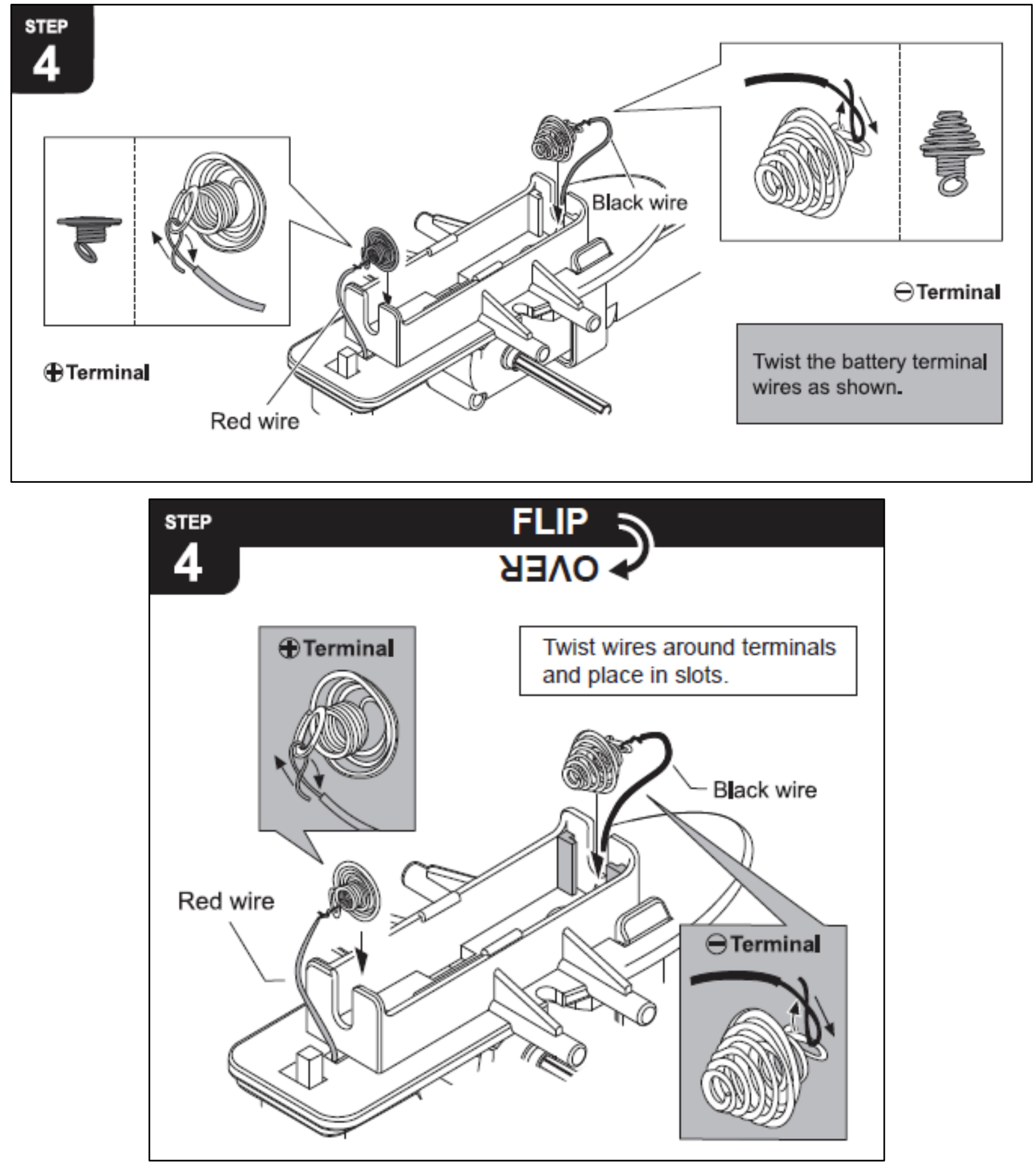

Figure 18. Step 4: Original (Top), Revised (Bottom) 


\section{Step 5}

Step 5 ranked 2 of 18 with a good score overall of 2.450. Usability was good at 1.400 and desirability was slightly bad at -0.700 (See Table 9).

Table 9

Step 5 Scores

\begin{tabular}{|c|ccc|}
\hline \multirow{2}{*}{ Step 5 } & Usability & Desirability & Overall \\
\cline { 2 - 4 } & 1.400 & -0.700 & 2.450 \\
\hline
\end{tabular}

Step 5 ranked high despite two instances were readers had closely inspect the image to understand how the arrows were directing the readers. It is possible that the low desirability is similar to Step 2 where the simplicity of the step did not promote interest or engagement. The line weight of the arrows were thickened to improve visibility and document consistency was applied. The revised manual (shown on right) shows all the changes mentioned (See Figure 19).
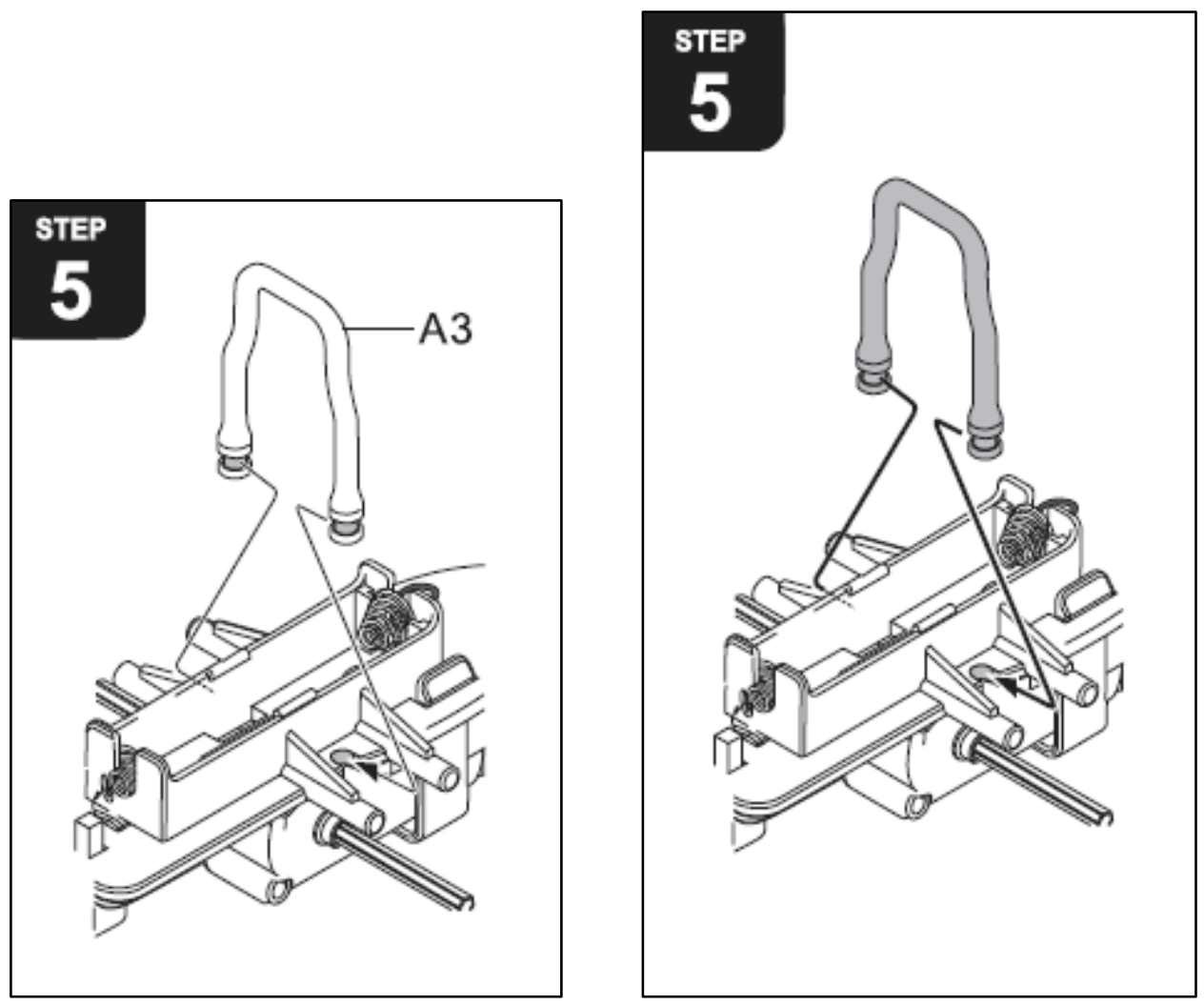

Figure 19. Step 5: Original (Left), Revised (Right) 
In addition, Step 5 was moved from the second assembly page to the first in order to associate the end of the page with the end of the sub assembly. This rearrangement provided the space to include a heading for the subassembly with the name 'MOTOR UNIT' to provide a deeper understanding of the task. A note added to the bottom of the page saying, " 1 Motor Unit Done? Turn Page” provided feedback to the user that a task was complete. In terms of poka yoke, grouping similar tasks helps users to not miss steps and notifying the user of task completion provides them with an opportunity to check their work before moving on. The revised manual (shown on right) shows page organization (See Figure 20). 


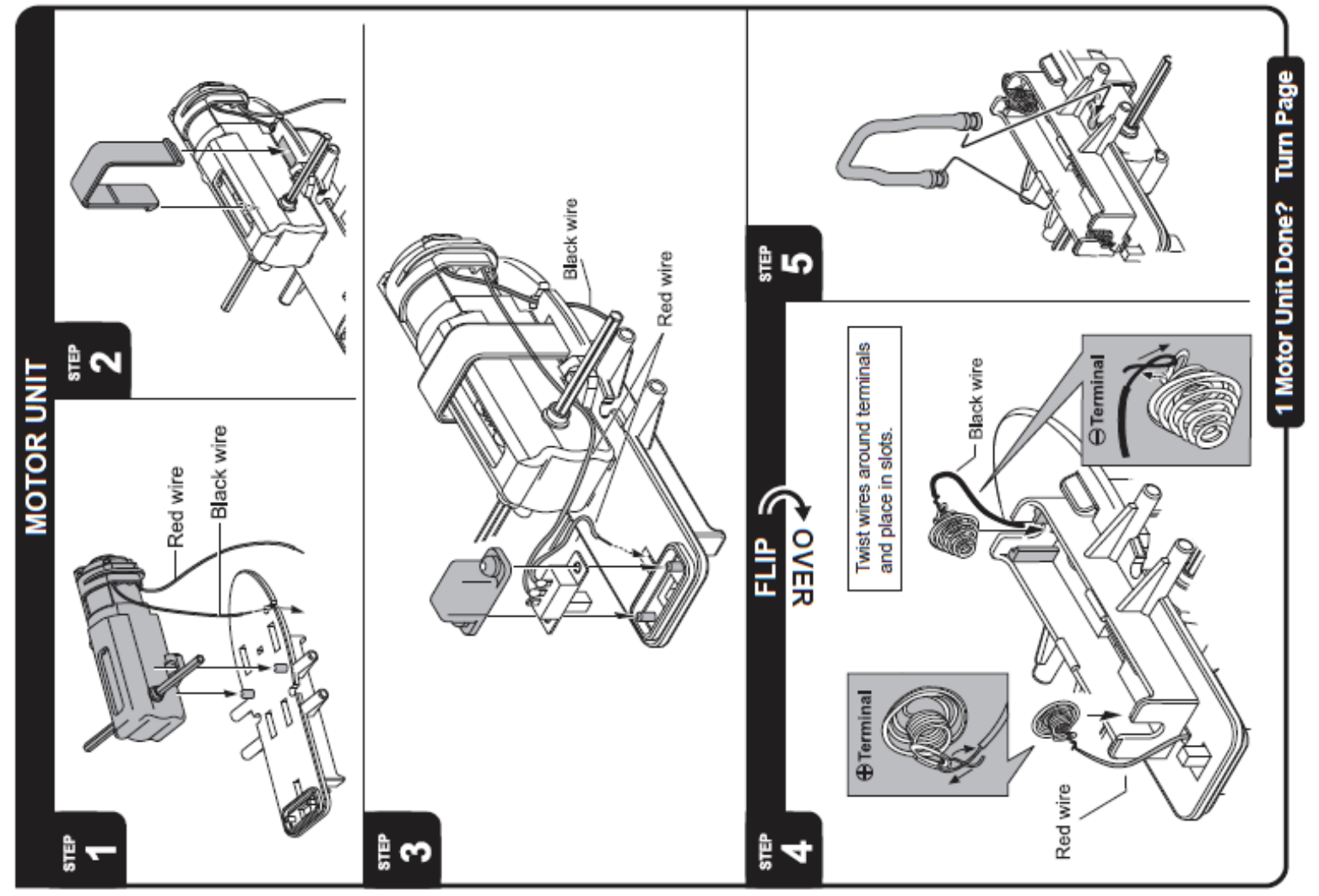

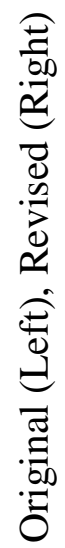

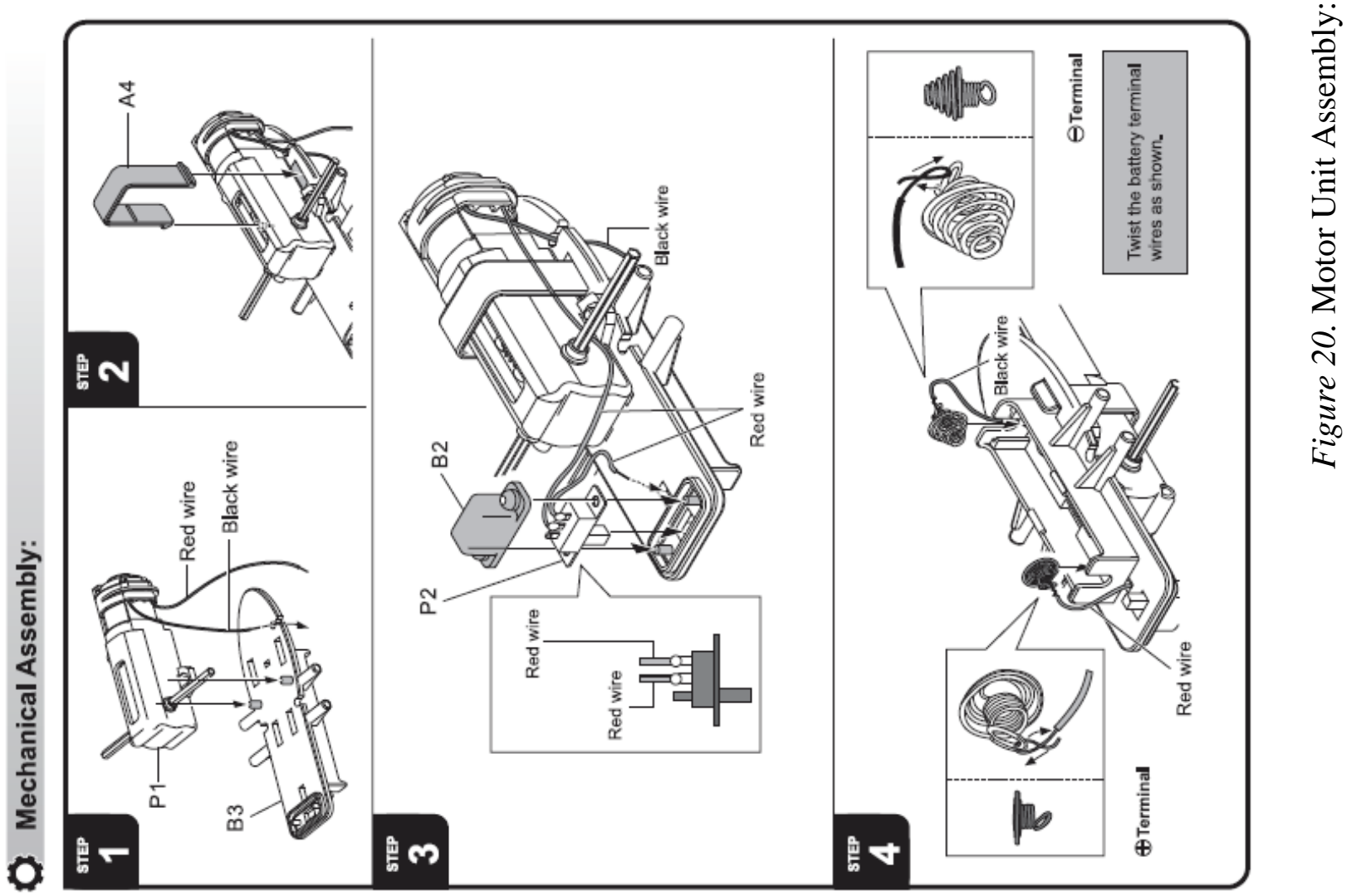




\section{Step 6}

Step 6 ranked 5 of 18 with a slightly good score overall of 0.733 . Usability was good at 0.850 and desirability was slightly good at 0.500 (See Table 10).

Table 10

Step 6 Scores

\begin{tabular}{|c|ccc|}
\hline \multirow{2}{*}{ Step 6 } & Usability & Desirability & Overall \\
\cline { 2 - 4 } & 0.733 & 0.500 & 0.733 \\
\hline
\end{tabular}

Step 6 showed a lack of clarity to readers because most readers did not recognize that the step was a tutorial in how to use a tool to organize a set of gears. As a result, readers expected the gears to turn and were let down when the tool restricted the expected movement bring into question dependability. Also, not knowing that the part was a tool caused readers to only use the tool once and then dismiss it. In one case, Reader 5 had to reassemble a gear box because they did not use the tool.

The textbox in the step included the use of the 'gear tool' to align the gears. The step was also organized sequentially along with document consistency. A header introducing Step 6 as part of the 'GEAR BOX (x2)' assembly shows that the step would have to be completed twice. The revised manual (shown on bottom) shows all the changes mentioned (See Figure 21). 

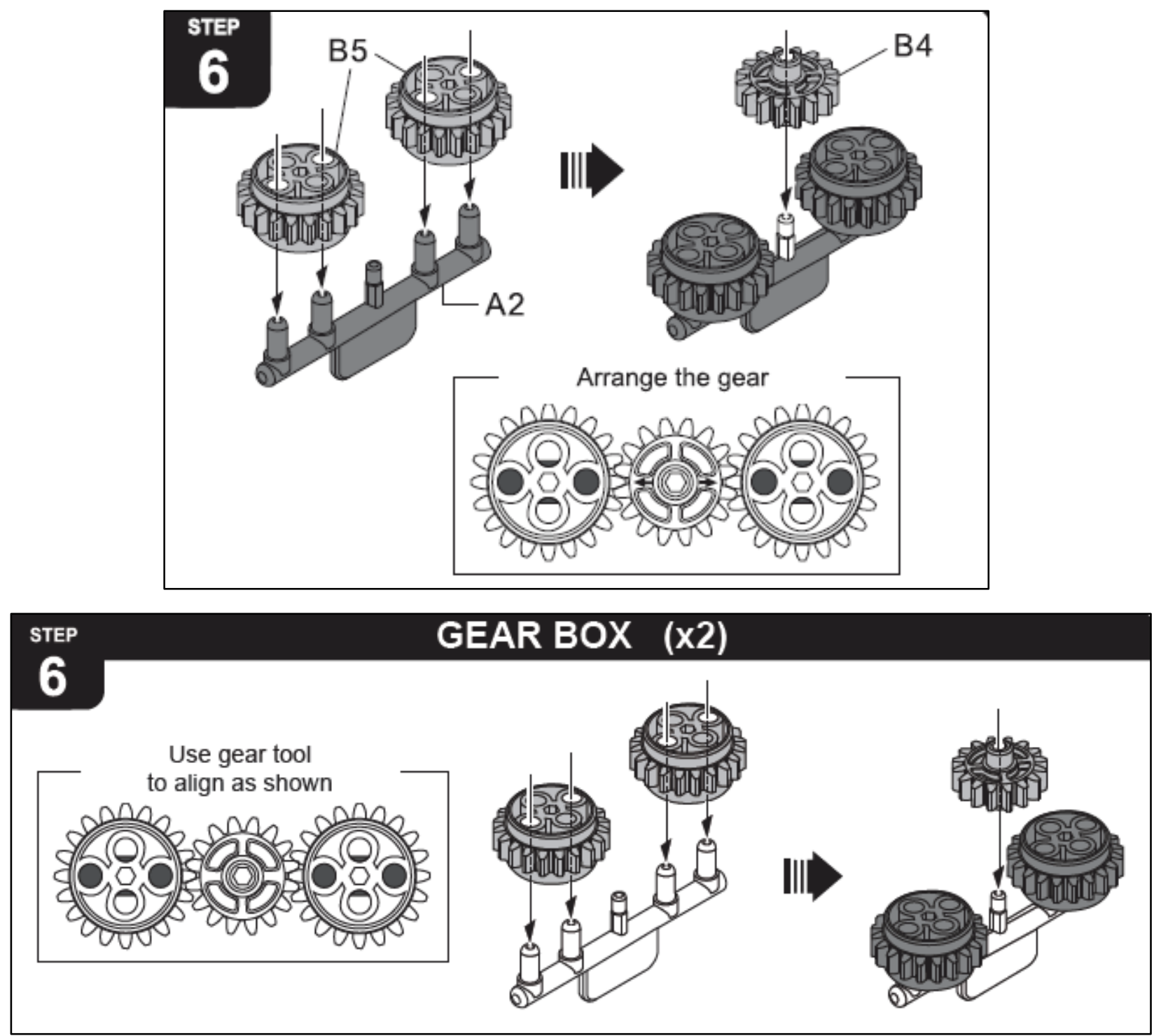

Figure 21. Step 6: Original (Top), Revised (Bottom) 


\section{Step 7}

Step 7 ranked 8 of 18 with a slightly good score overall of 0.533 . Usability was good at 0.850 and desirability was slightly bad at -0.100 (See Table 11).

Table 11

Step 7 Scores

\begin{tabular}{|c|ccc|}
\hline \multirow{2}{*}{ Step 7 } & Usability & Desirability & Overall \\
\cline { 2 - 4 } & 0.850 & -0.100 & 0.533 \\
\hline
\end{tabular}

While Step 7 scored well in usability, readers had trouble identifying key points within the images and following the progression of the step. First, four of the five readers were not able to correctly orient a male peg that required special attention. In at least two instances, readers were not able to connect word directions to the images. Second, readers often skipped the final image in the progression of Step 7. While the reason was not explicitly observed or stated, the elements of the step may have been too disorganized causing readers to lose its logical flow.

As a result, Step 7 was reorganized in a simple linear flow where a short note accompanied each image throughout the step. Also callouts were used to highlight the features necessary to correctly orient the halves of the gearbox. The revised manual (shown on below) shows all the changes mentioned (See Figure 22). 

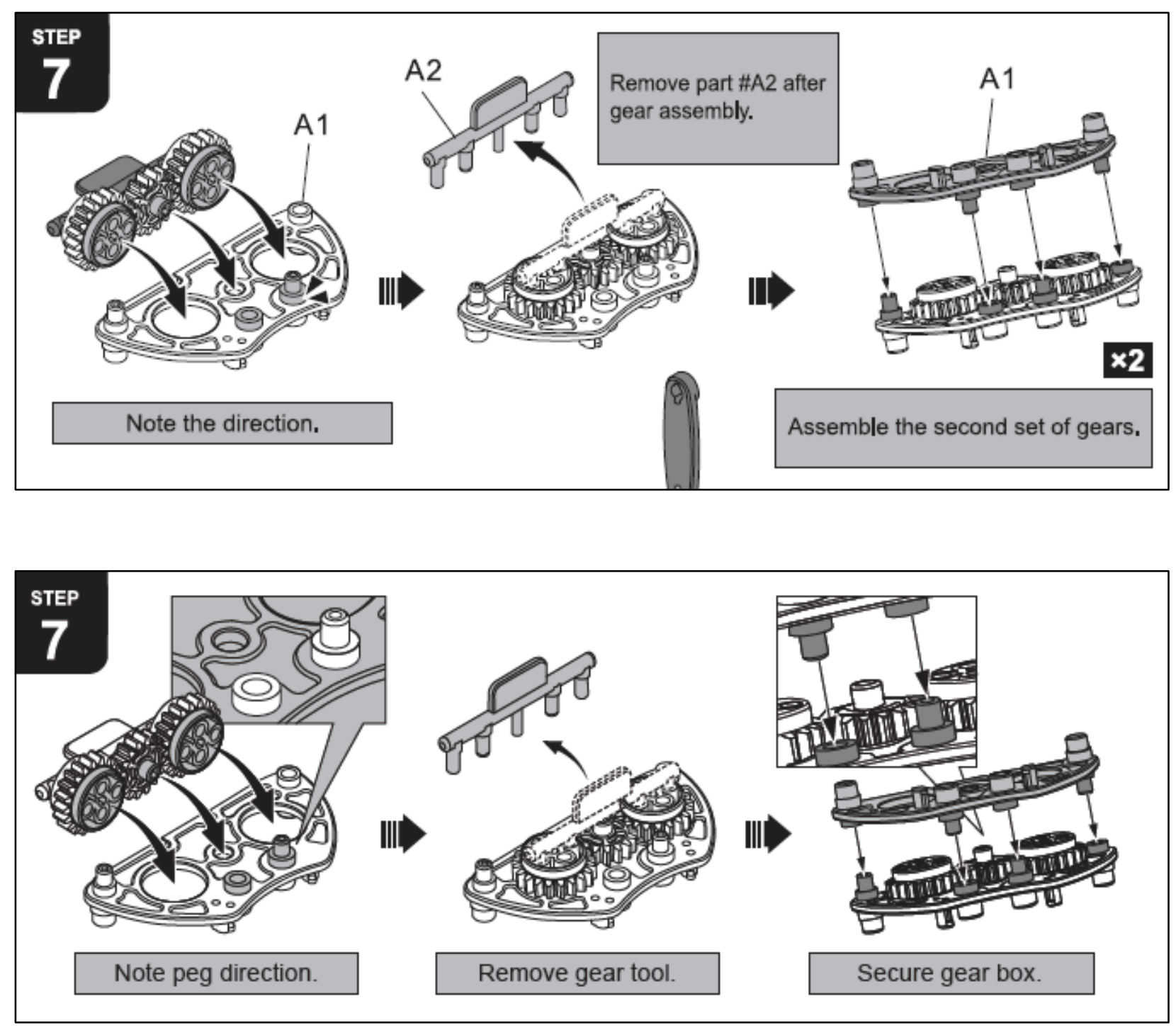

Figure 22. Step 7: Original (Top), Revised (Bottom) 


\section{Step 8}

Step 8 ranked 14 of 18 with a slightly good score overall of 0.133 . Usability was neutral at 0.000 and desirability was slightly good at 0.400 (See Table 12).

Table 12

Step 8 Scores

\begin{tabular}{|c|ccc|}
\hline \multirow{2}{*}{ Step 8 } & Usability & Desirability & Overall \\
\cline { 2 - 4 } & 0.000 & 0.400 & 0.133 \\
\hline
\end{tabular}

Step 8 presented issues with logical flow and color. The step includes an image of a complete leg unit assembly with a 'x2' indicator. In all cases, readers did not know what that image meant and did not know the number of legs that should be completed. All readers had to return to Step 8 to assemble the total number of legs required for the project. Readers also suggested alternative color code for the legs: color the parts to reflect the actual toy and color the parts to show where they go on the following steps.

Ultimately, Step 8 was simplified to show a right and left leg assembly with headers denoting the leg side and number of legs to complete. The backgrounds and titles of the two sides were contrasted with gray and white to help show that the assemblies were different. Document consistency was also applied to the step. The revised manual (shown on bottom) shows all the changes mentioned (See Figure 23). 

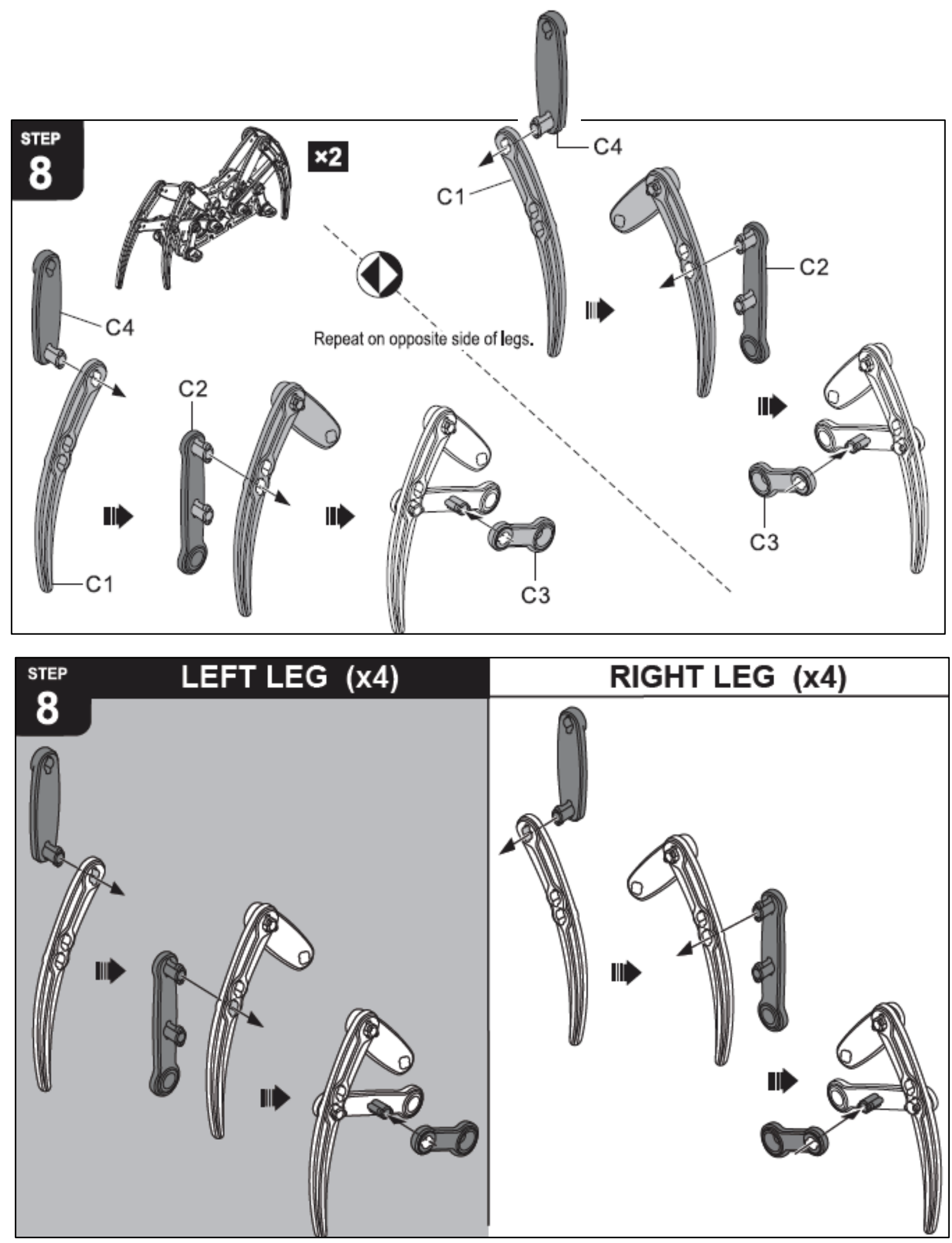

Figure 23. Step 8: Original (Top), Revised (Bottom) 
In addition, Steps 6 and 7, and Step 8 respectively were grouped into subassemblies similar to the motor unit. As mentioned in step 5, the grouping provides a deeper knowledge of the task, and opportunity to check for correctness, a sense of task completion, and a check to see if the correct number of assemblies were completed. The revised manual (shown on right) shows page organization (See Figure 24). 


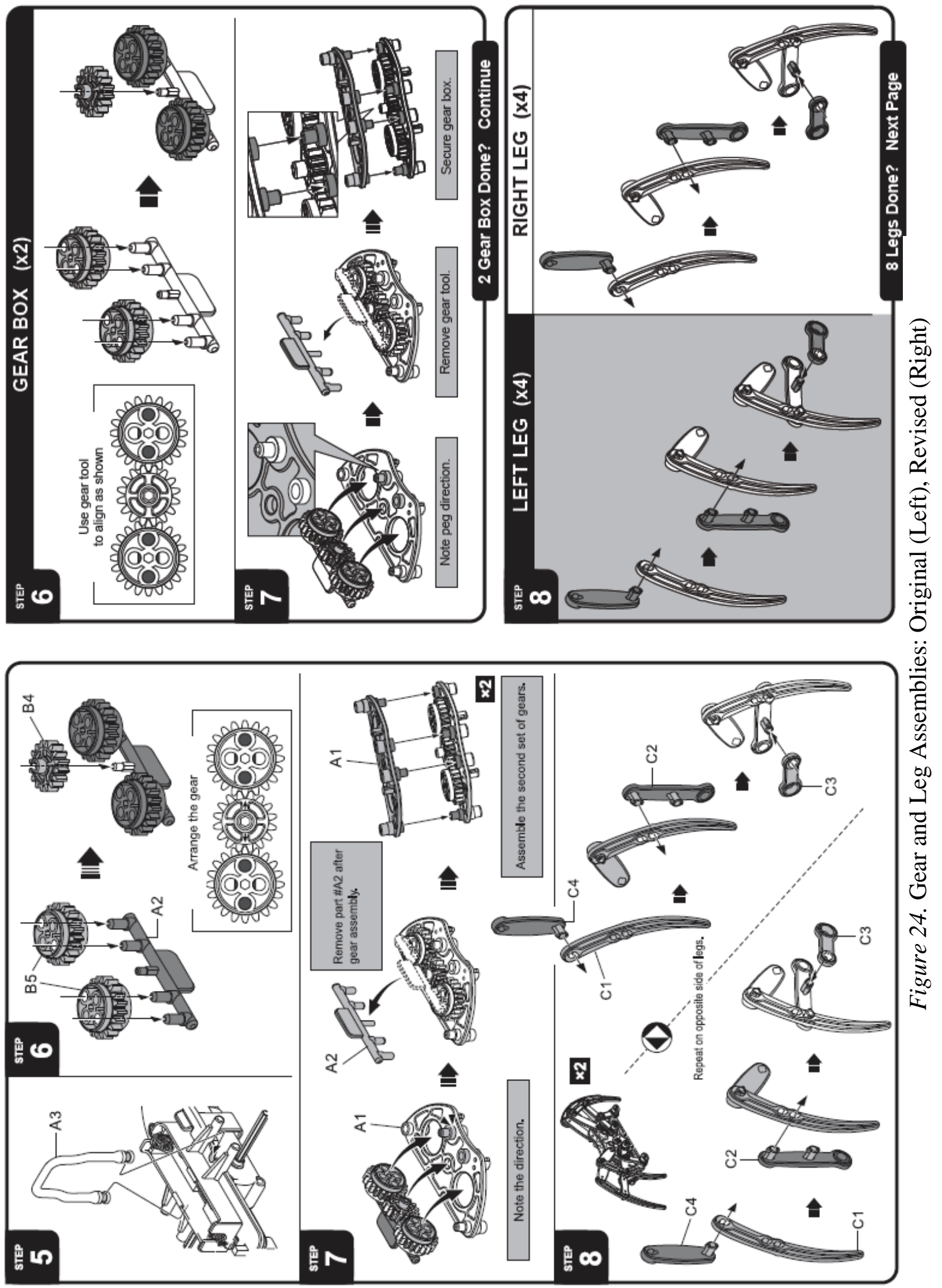




\section{Step 9}

Step 9 ranked 11 of 18 with a slightly good score overall of 0.267 . Usability was slightly good at 0.450 and desirability was slightly poor at -0.100 (See Table 13 ).

Table 13

Step 9 Scores

\begin{tabular}{|l|ccc|}
\hline \multirow{2}{*}{ Step 9 } & Usability & Desirability & Overall \\
\cline { 2 - 4 } & 0.450 & -0.100 & 0.267 \\
\hline
\end{tabular}

While Step 9 shows a single leg assembly being placed on to the gear box, in actuality, the step requires a sequence of attaching parts together, turning them to a correct orientation, then securing the parts with a peg. That was reflected in each of the reader's experiences. As Reader 2 stated,

I didn't realize that once you put it on it would swivel around because I was thinking it would hold him place. So the angle that I have to put this on for the others to fit on doesn't match the pegs on the other side, it doesn't fit. So once I realized I can put it on and it move the leg, then it made sense.

Also, all of the readers had some period of trial and error when choosing between short and long pegs, and assembling the left and right legs to the correct sides of the gear box. Both these issues express a lack of clarity in differentiating parts and a break in logical flow by requiring users to bridge the gap between the beginning and end of the leg assembly.

An image of the peg used in the assembly image was highlighted and described so that users could reference the part. A callout was also used to show the 'twisting' motion that would have to take place to complete the assembly step. The peg was moved into the line of action of the assembly to make the image more concise. Also, the whole step was mirrored to depict the right leg being assembled instead of the left. This is because the last leg that is assembled from 
Step 8 is a right so the part last touch would be the next part used in the order of the steps. The revised manual (shown on right) shows all the changes mentioned (See Figure 25).

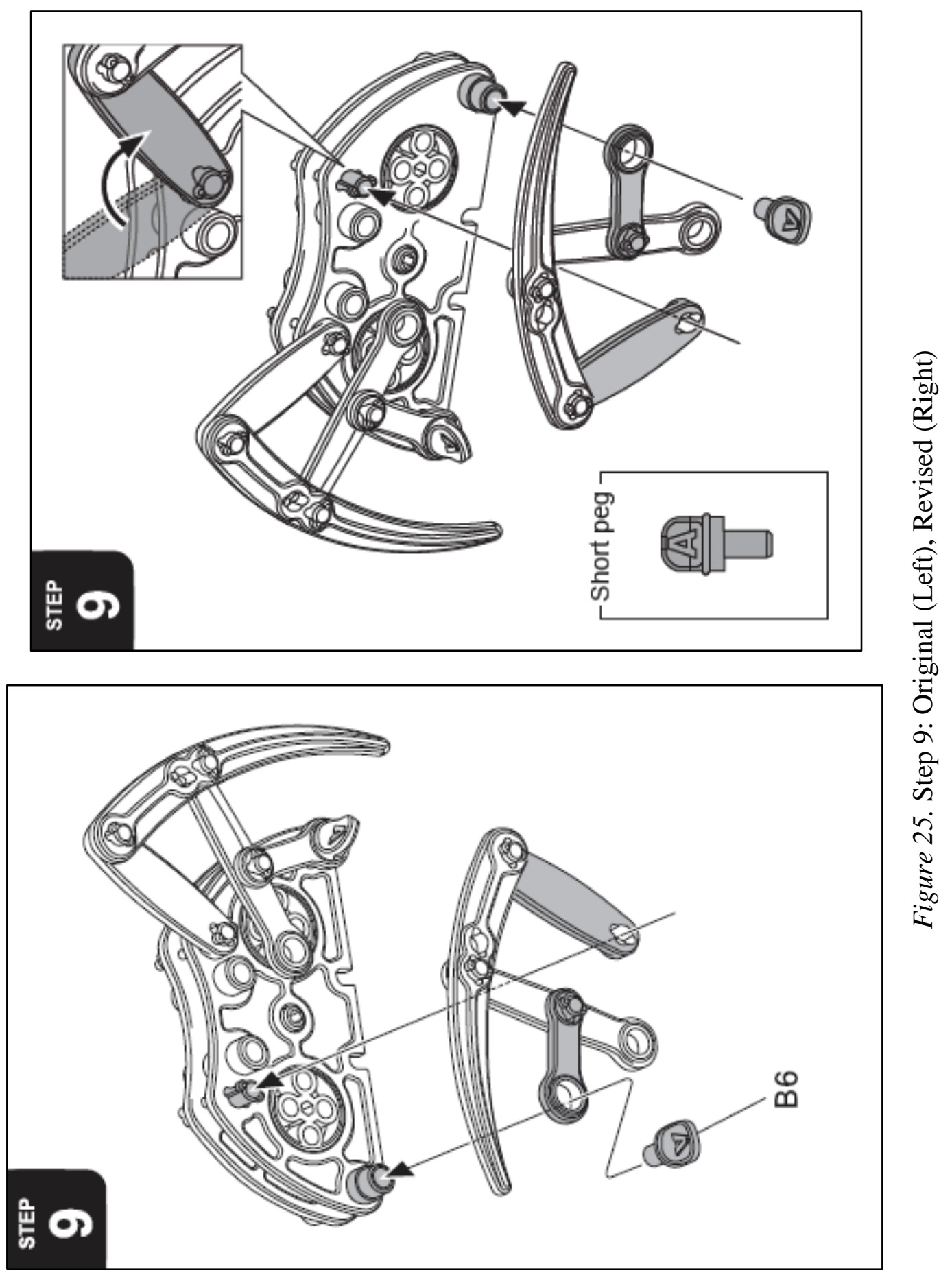




\section{Step 10}

Step 10 ranked 11 of 18 with a slightly good score overall of 0.633 . Usability was good at 1.050 and desirability was poor at -1.200 (See Table 14).

Table 14

Step 10 Scores

\begin{tabular}{|c|ccc|}
\hline \multirow{2}{*}{ Step 10 } & Usability & Desirability & Overall \\
\cline { 2 - 4 } & 1.050 & -1.200 & 0.633 \\
\hline
\end{tabular}

Step 10’s only issues were that the peg size was not easily discernable and some readers over looked the peg placement diagram. While the desirability was significantly negative, the comments did not indicate why there was such a low score. Step 10 was revised to include an image of the long peg similar to step 9. As a poka yoke technique, having the two steps next to each other would allow the reader to compare the pegs side by side immediately providing instant feedback to the correct peg locations. The peg placement chart was also highlighted with color to draw attention to that necessary detail. Finally, the image was mirrored to match Step 9 and document consistency was applied. The revised manual (shown on right) shows all the changes mentioned (See Figure 26). 


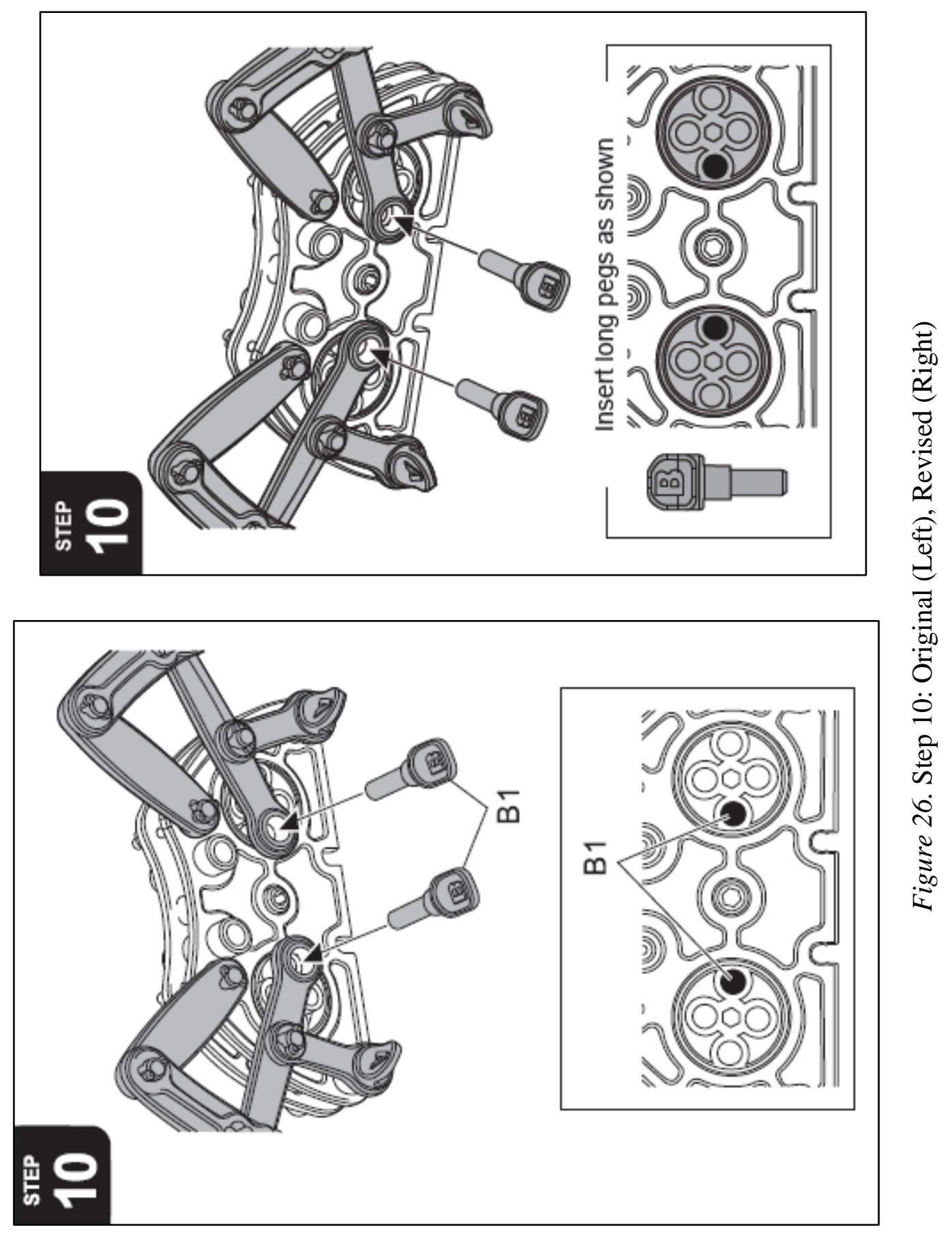




\section{Step 11}

Step 11 ranked 15 of 18 with a slightly good score overall of 0.133 . Usability was slightly good at 0.400 and desirability was slightly poor at -0.400 (See Table 15 ).

Table 15

Step 11 Scores

\begin{tabular}{|c|ccc|}
\hline \multirow{2}{*}{ Step 11 } & Usability & Desirability & Overall \\
\cline { 2 - 4 } & 0.400 & -0.400 & 0.133 \\
\hline
\end{tabular}

The most common reaction to Step 11 was that it was simply a repeat of Step 9. It was noted that some though that it was opposite side of the assembly described in Steps 9 and 10, and others thought that it was describing a new separate assembly. In either case, readers thought that the step was repetitive and only referenced Step 9 for assembly. This is an example of perceived uselessness.

Rather than omitting the step, the 'flip over' header in Step 4 was used to show that the assembly of the legs on to the gear box should continue until it is fully complete. The entire image was mirrored to show that it's the opposite side and the color scheme was flipped to differentiate Step 11 from Step 9. The revised manual (shown on right) shows all the changes mentioned (See Figure 27). 


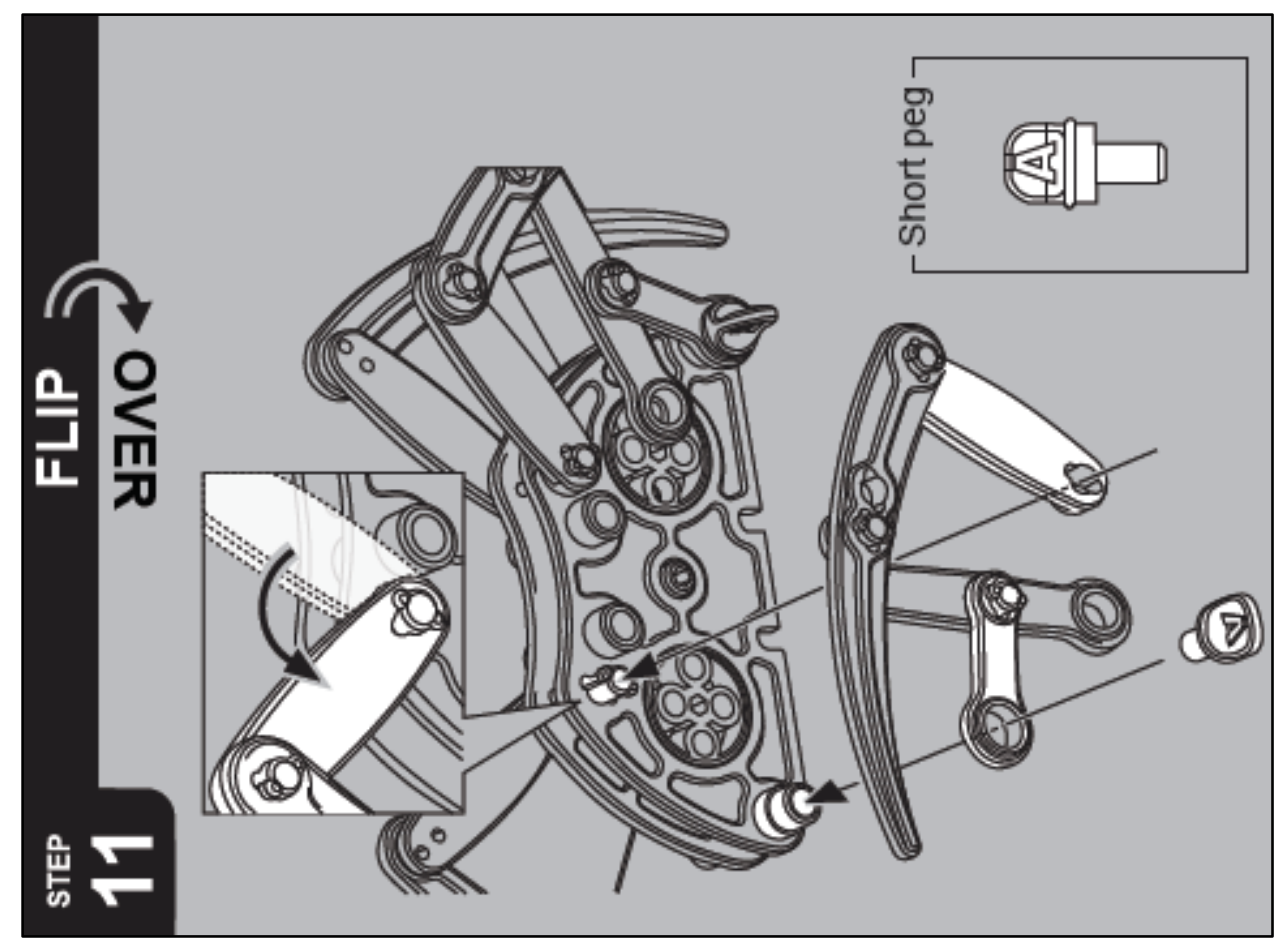

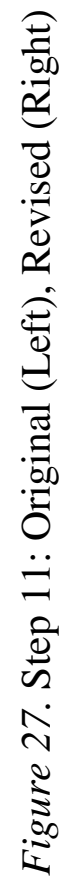

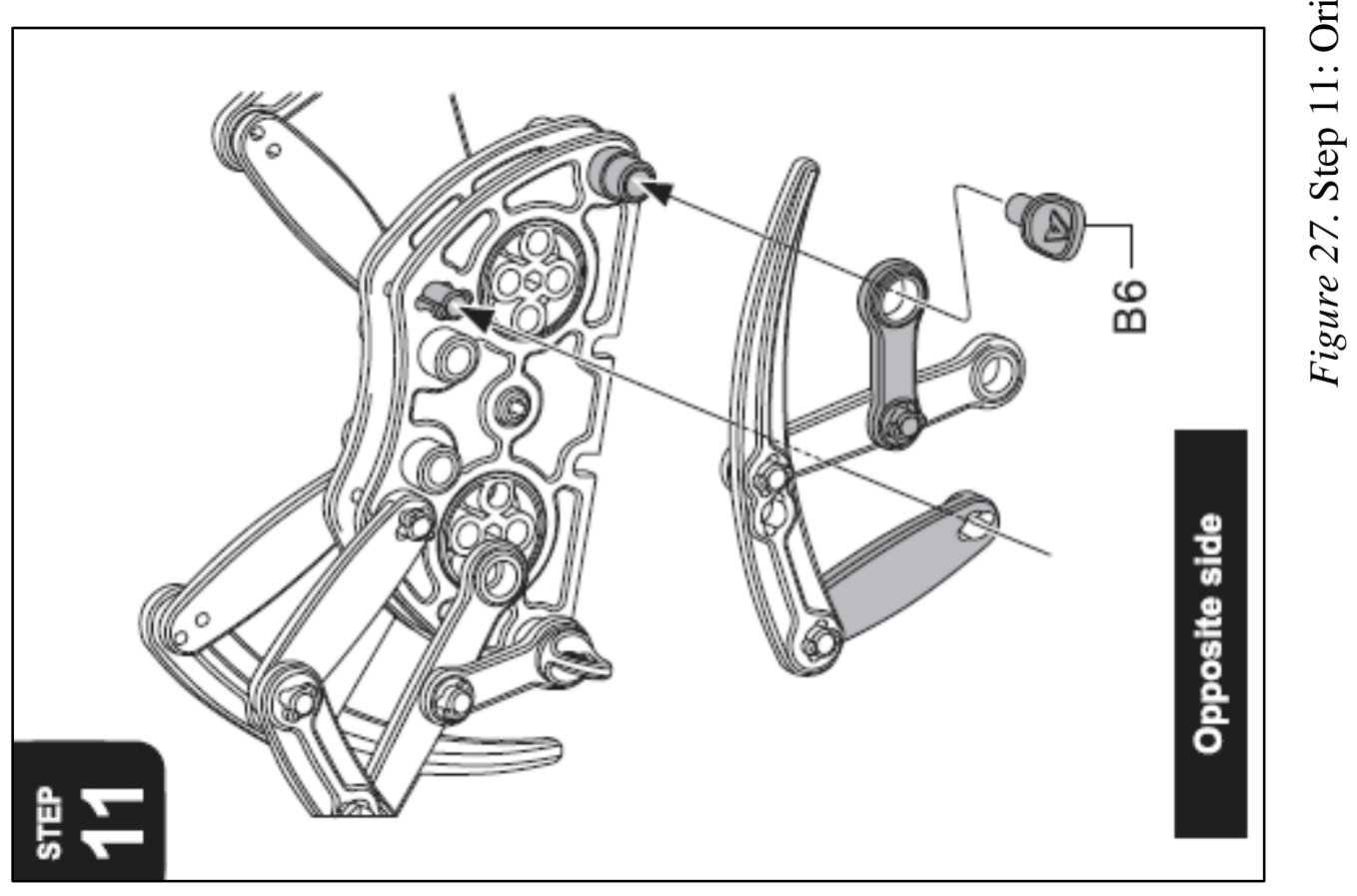




\section{Step 12}

Step 12 ranked 9 of 18 with a slightly good score overall of 0.500 . Usability was good at 1.050 and desirability was slightly poor at -0.600 (See Table 16).

Table 16

Step 12 Scores

\begin{tabular}{|c|ccc|}
\hline \multirow{2}{*}{ Step 12} & Usability & Desirability & Overall \\
\cline { 2 - 4 } & 1.050 & -0.600 & 0.500 \\
\hline
\end{tabular}

Similar to Step 11, Step 12 was dismissed for being a repeat of Step 10. However, even though the steps were regarded as the same, the usability was still scored in the good range, and the desirability was only slightly poor as compared to Step 10's solid poor scoring. It would have been expected that the steps would have either been identical in all categories, or Step 12 would have been scored much worse. Nevertheless, the same strategy from Step 11 was applied to Step 12. The revised manual (shown on right) shows all the changes mentioned (See Figure 28). 

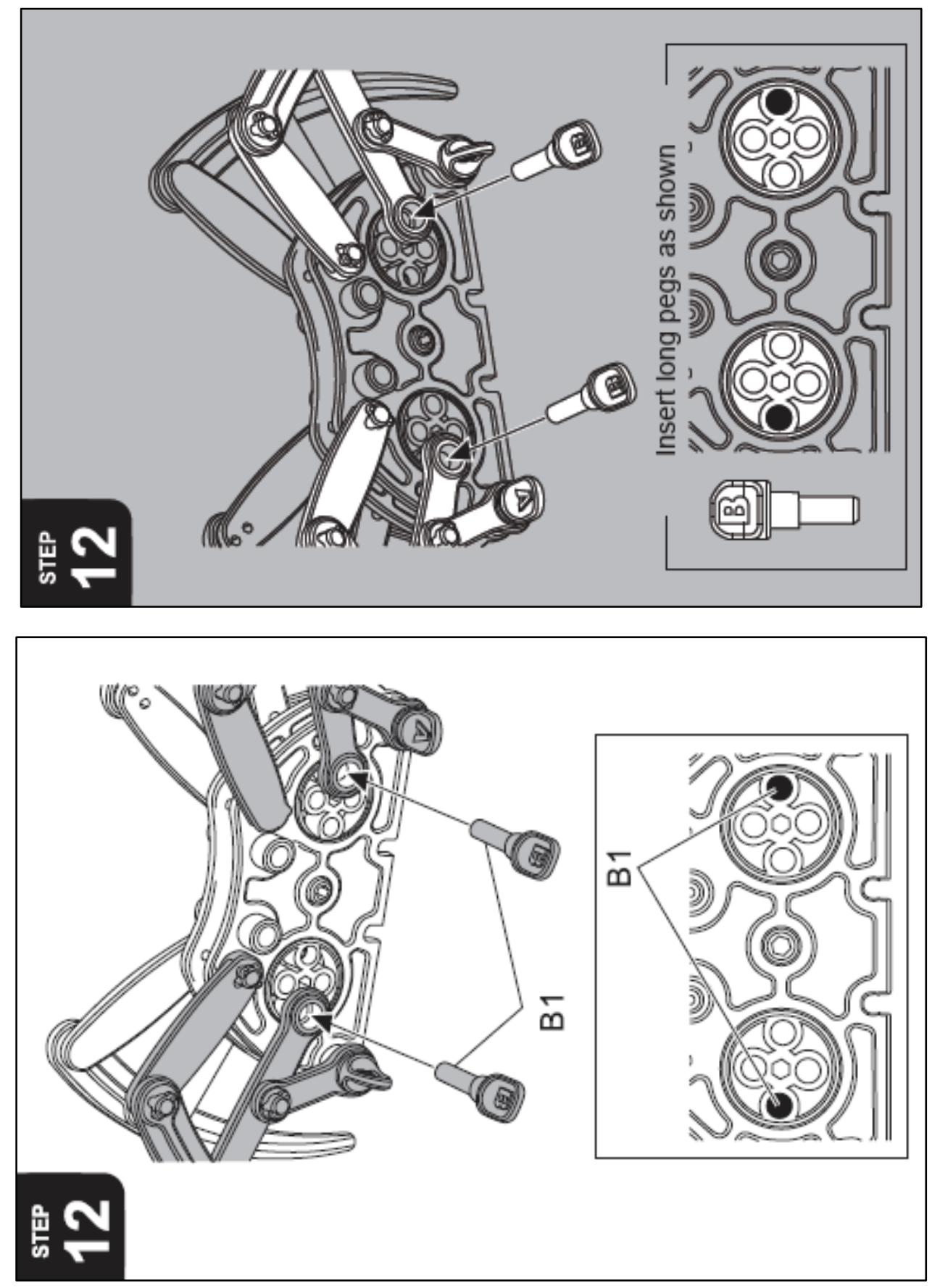

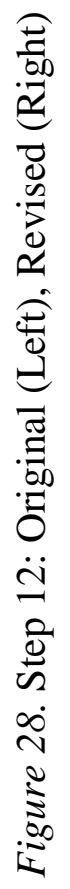


On another note, all readers failed to complete the two required leg units before moving on to the next page. While the requirement is stated in Step 8, everyone failed to remember the note and had to search the instruction manual before deciding to return to the leg assembly. The poke yoke prompt to encourage inspection was included along with a header to group Steps 9 through 12 into a subassembly group. The revised manual (shown on right) shows page organization (See Figure 29). 


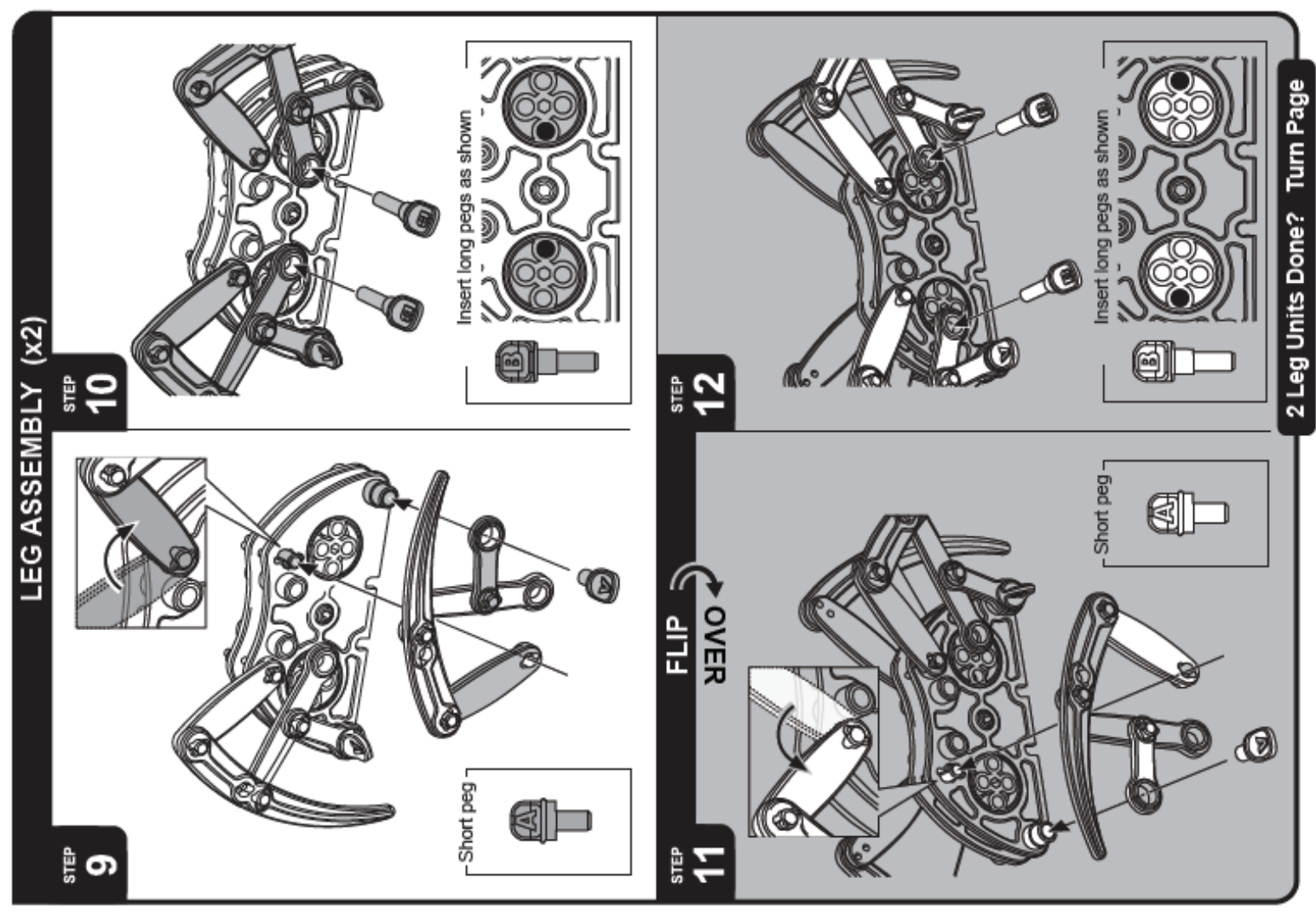

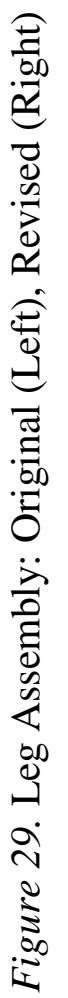

음을

呂
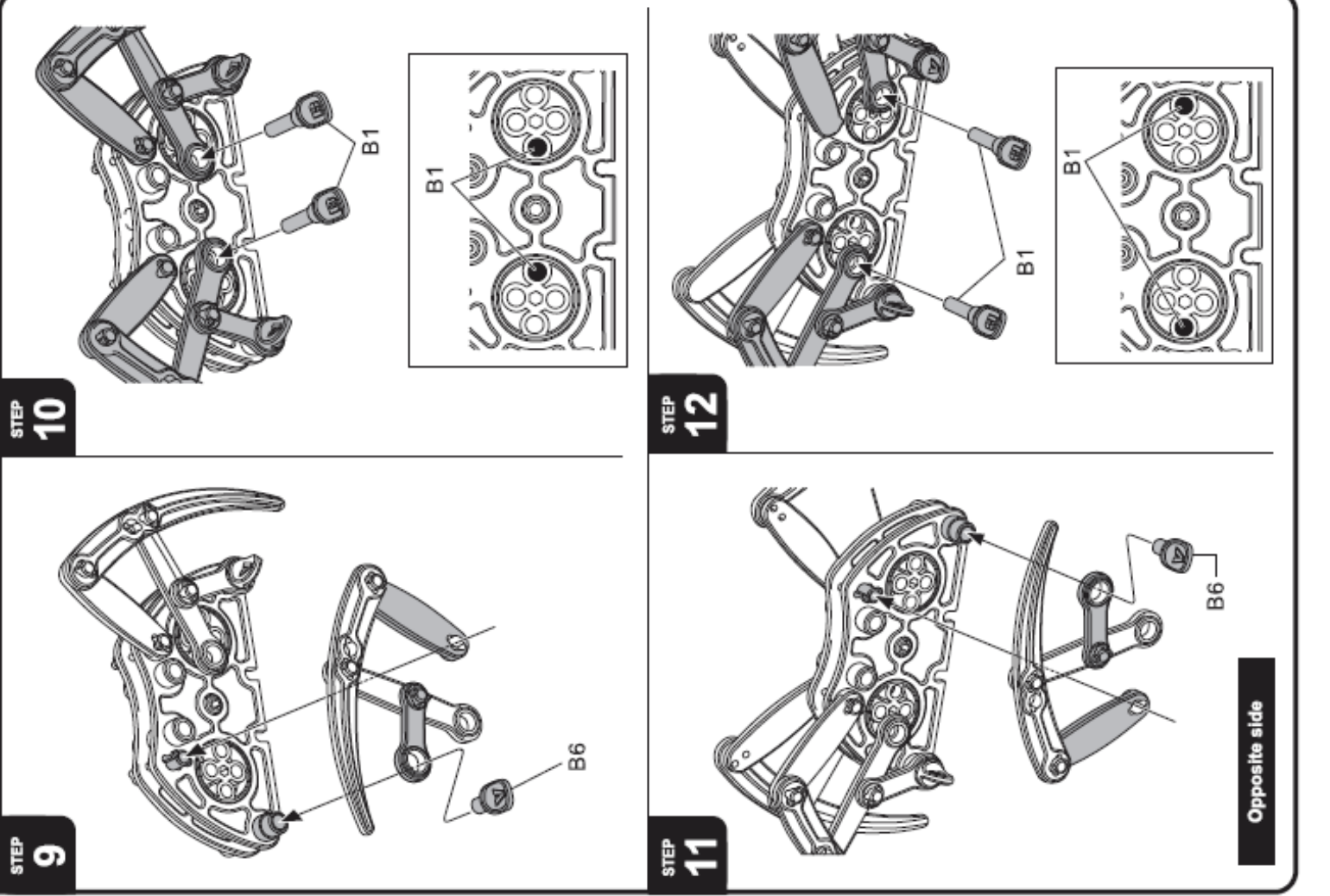


\section{Step 13}

Step 13 ranked 1 of 18 with a good score overall of 1.867 . Usability was good at 2.600 and desirability was slightly poor at 0.400 (See Table 17).

Table 17

Step 13 Scores

\begin{tabular}{|c|ccc|}
\hline \multirow{2}{*}{ Step 13} & Usability & Desirability & Overall \\
\cline { 2 - 4 } & 2.600 & 0.400 & 1.867 \\
\hline
\end{tabular}

Step 13 best exemplified a usable and desirable step in the instruction manual by providing a meaningful task that users could enjoy during assembly and could complete through clear, concise directions. While the secondary 'top view' image and textbox did not help any of the readers, these aspects were ignored for the excitement of seeing the toy finally come together. As Reader 4 said, “Step 13 [was one of my top three best]. That's the end and that's when everything comes together and that's when you get to see your work.”

One reader was confused by the additional image, so it was removed so that the main image could be enlarged. Between this step and the completion of the project, no time was provided for the battery to be placed in the motor unit. So, a battery was depicted in Step 13. The revised manual (shown on bottom) shows all the changes mentioned (See Figure 30). 

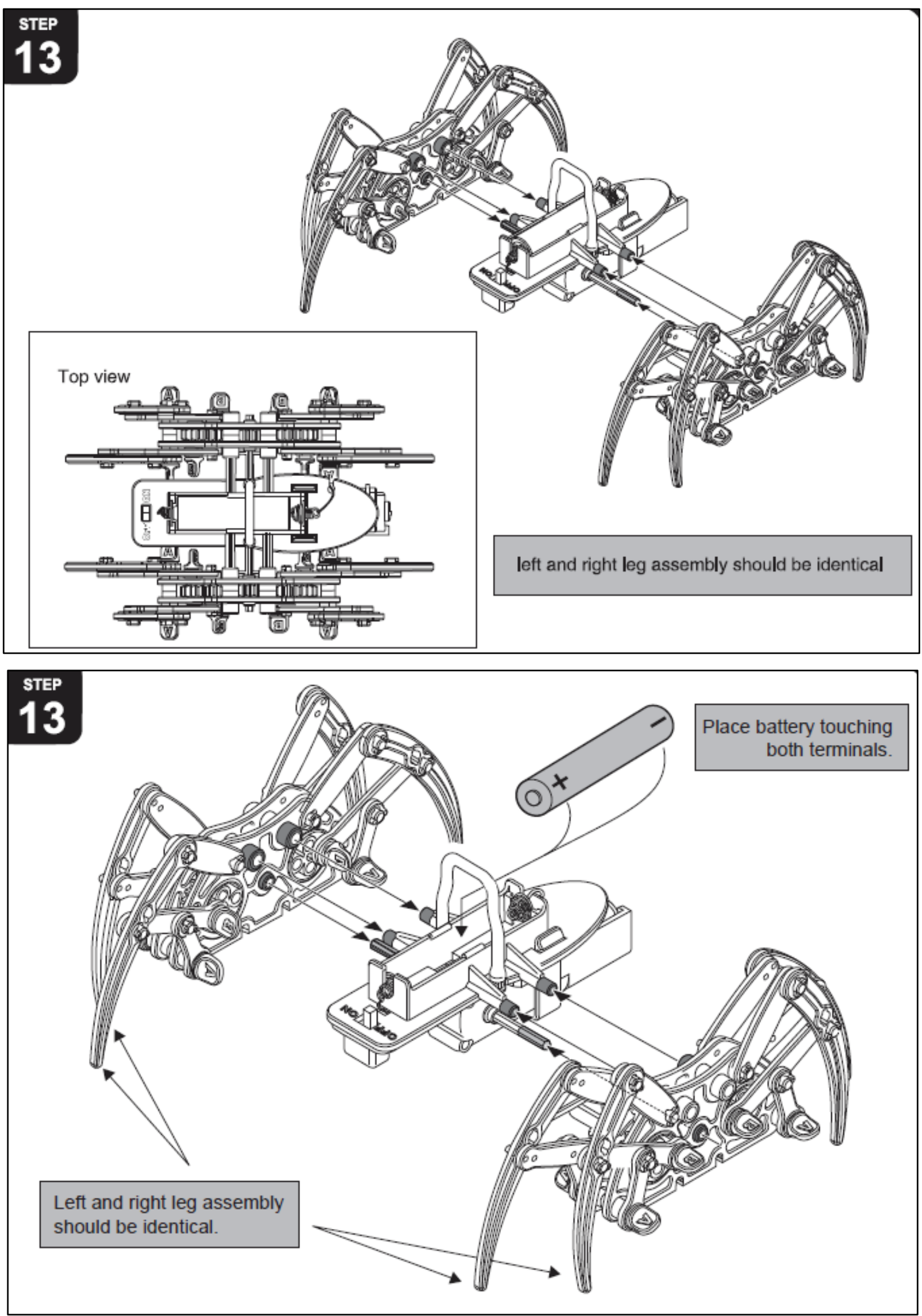

Figure 30. Step 13: Original (Top), Revised (Bottom) 


\section{Step 14}

Step 14 ranked 4 of 18 with a good score overall of 1.267 . Usability was good at 2.500 and desirability was slightly poor at -1.200 (See Table 18).

Table 18

Step 14 Scores

\begin{tabular}{|c|ccc|}
\hline \multirow{2}{*}{ Step 14 } & Usability & Desirability & Overall \\
\cline { 2 - 4 } & 2.500 & -1.200 & 1.267 \\
\hline
\end{tabular}

Feedback for Step 14 was not consistent among readers, but document consistency was implemented into the step. Also, detail was reduced in the image and a note on the purpose of the step was included. A second half of the step includes instruction on turning on the toy spider. In this case, a celebratory “COMPLETE!” was added to emphasize final task completion. The revised manual (shown on bottom) shows all the changes mentioned (See Figure 31). 

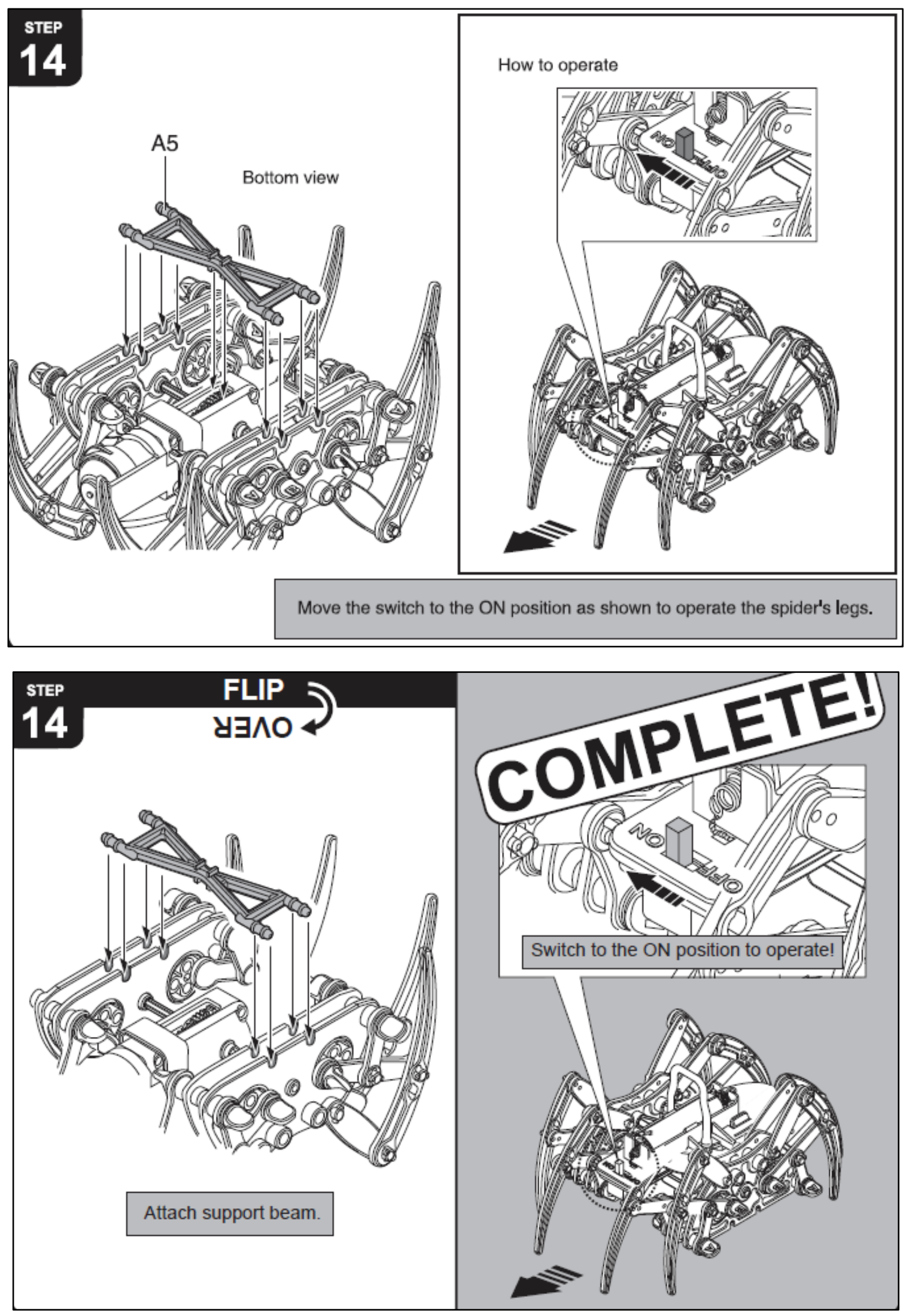

Figure 31. Step 14: Original (Top), Revised (Bottom) 


\section{Modifications page}

The modifications page ranked 17 of 18 with a slightly poor score overall of -0.100 . Usability was slightly good at 0.200 and desirability was slightly poor at -0.700 (See Table 19).

Table 19

Modifications Page Scores

\begin{tabular}{|c|ccc|}
\hline \multirow{2}{*}{ Modifications Page } & Usability & Desirability & Overall \\
\cline { 2 - 4 } & 0.200 & -0.700 & -0.100 \\
\hline
\end{tabular}

Overall the content of the modification page was understood, but many of the readers reported that the page was misplaced. There was often confusion as readers were mid-assembly and were interrupted by a page of 'extra' steps that could be performed when the toy was complete. This speaks to document organization in which the logical flow of tasks is disrupted by a step that doesn’t logically come next. Also, a cutting guide provided to readers to accurately cut a rubber tube that could added to the toy for additional traction. While the text instructed readers to cut eight lengths, ten lengths were provided.

As a result, the modifications page was placed at the end of the full spider toy assembly and the tube step was slightly modified to make the in manual ruler functional for measuring and cutting the tube. It should be noted that the editable PDF provided by Five Below was missing this page. The missing page was reconstructed using a similar manual provided by NSI International, Inc. The revised manual (shown on right) shows all the changes mentioned (See Figure 32). 


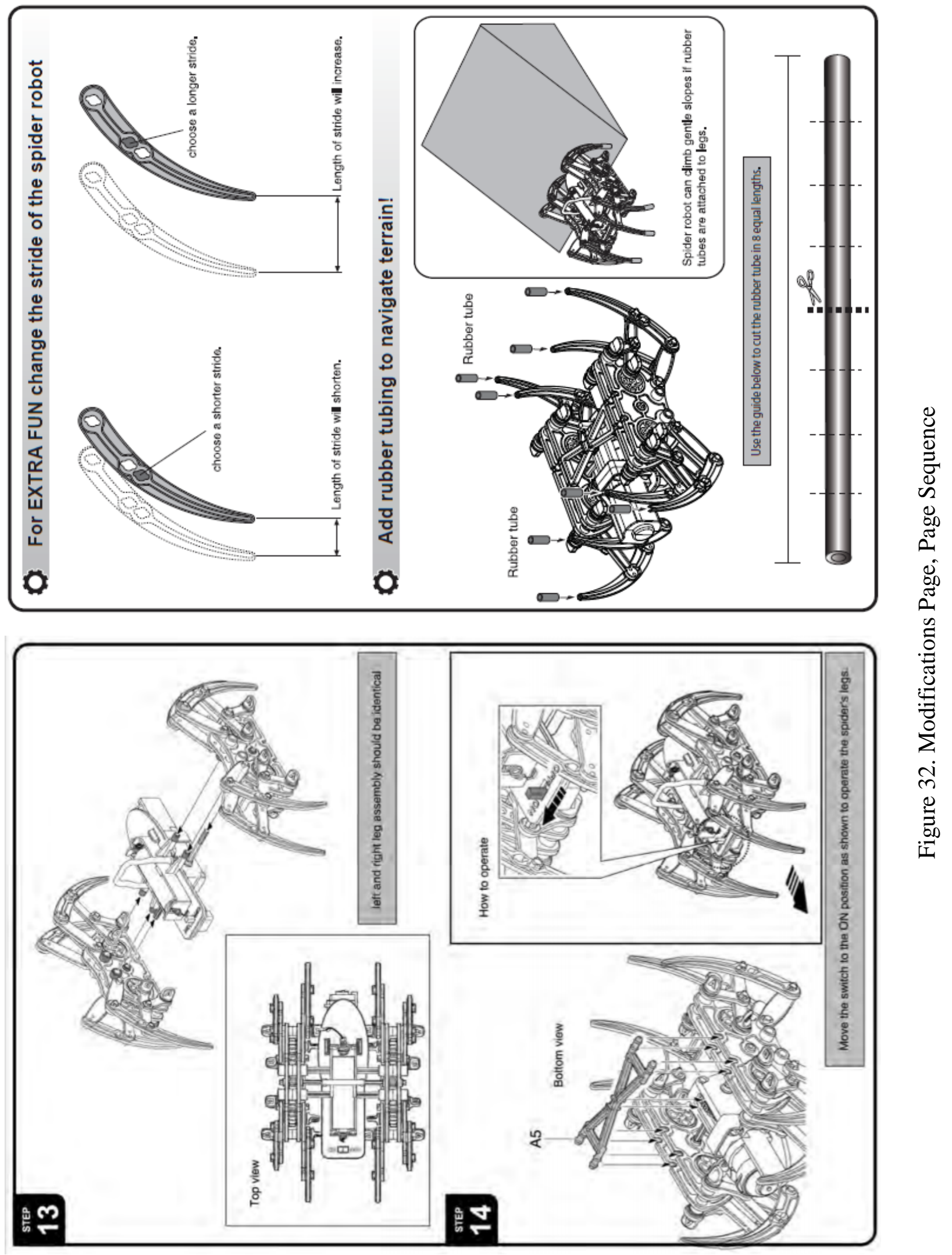




\section{Back page}

The back page ranked 18 of 18 with a slightly poor score overall of -0.200 . Usability was good at 1.100 and desirability was poor at -2.800 (See Table 20).

Table 20

Back Page Scores

\begin{tabular}{|c|ccc|}
\hline \multirow{2}{*}{ Back Page } & Usability & Desirability & Overall \\
\cline { 2 - 4 } & 1.100 & -2.800 & -0.200 \\
\hline
\end{tabular}

While many readers did not look at the back page, one reader noticed that the warning information on the back provided was not relevant showing that a stock paragraph had been used. If followed, a user might be able to open up the motor unit of the toy ultimately breaking the product. Changes were made to reflect the specific case of this toy.

With the unused white space, a note was made about extra parts that could be expected after the assembly process was completed. A simple marketing element was also included to promote novelty that might lead to further engagement with the product brand. The revised manual (shown on right) shows all the changes mentioned (See Figure 33). 


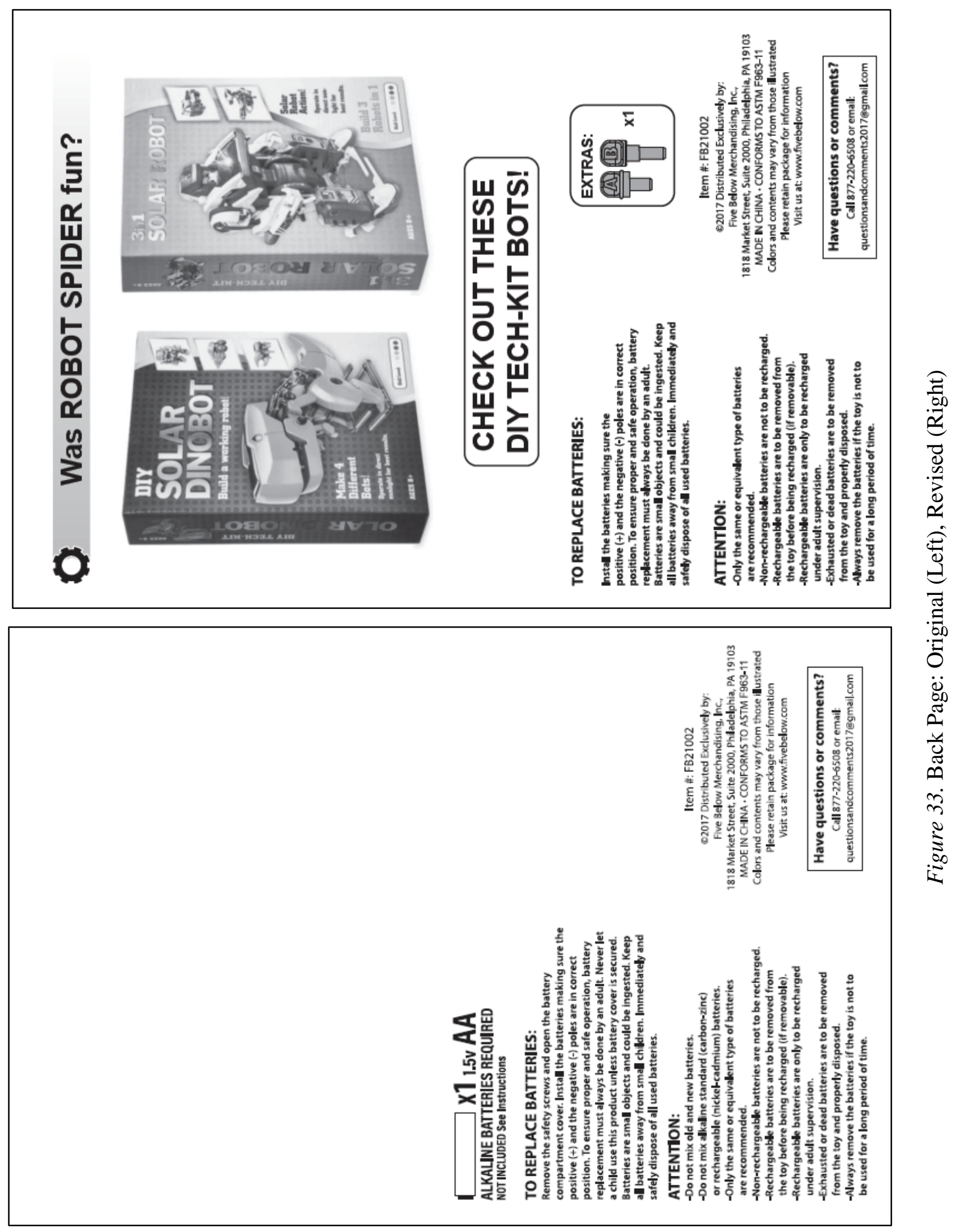




\section{Phase 3: Evaluate Redesign and Compare with Initial Product}

Upon completion of the redesign, A usability test and interview were conducted under the same parameters as the test for the original manual. Like the original manual, data for the overall manual scoring, step rankings, and itemized question scores were tabulated for the revised instruction manual. The full revised manual results may be viewed in Appendix K. Specifically, comments by specific participants were reorganized to only show step specific designation

\section{Dependent t-test}

\section{Overall scores}

A Dependent t-test statistical procedure was used to determine if statistical differences existed between the means of the overall scale scores for the original (Group 1) and revised (Group 2) instruction manuals. Plots containing both original and revised manual data show difference between each one’s performance. Statistical significance calculated and described visually through the use of error bars. Table 21 and Figure 34 show these results.

Table 21

Overall Scales Comparison

\begin{tabular}{lcc}
\hline Scale & $\begin{array}{c}\text { Original Manual } \\
M_{\mathrm{G} 1}\end{array}$ & $\begin{array}{c}\text { Revised Manual } \\
\mathrm{M}_{\mathrm{G} 2}\end{array}$ \\
\hline Attractiveness & -0.13 & 0.90 \\
Perspicuity & -0.05 & -0.25 \\
Efficiency & 0.60 & 0.25 \\
Dependability & 0.85 & 0.80 \\
Stimulation & 0.40 & 1.25 \\
Novelty & 0.65 & 0.85 \\
\hline
\end{tabular}




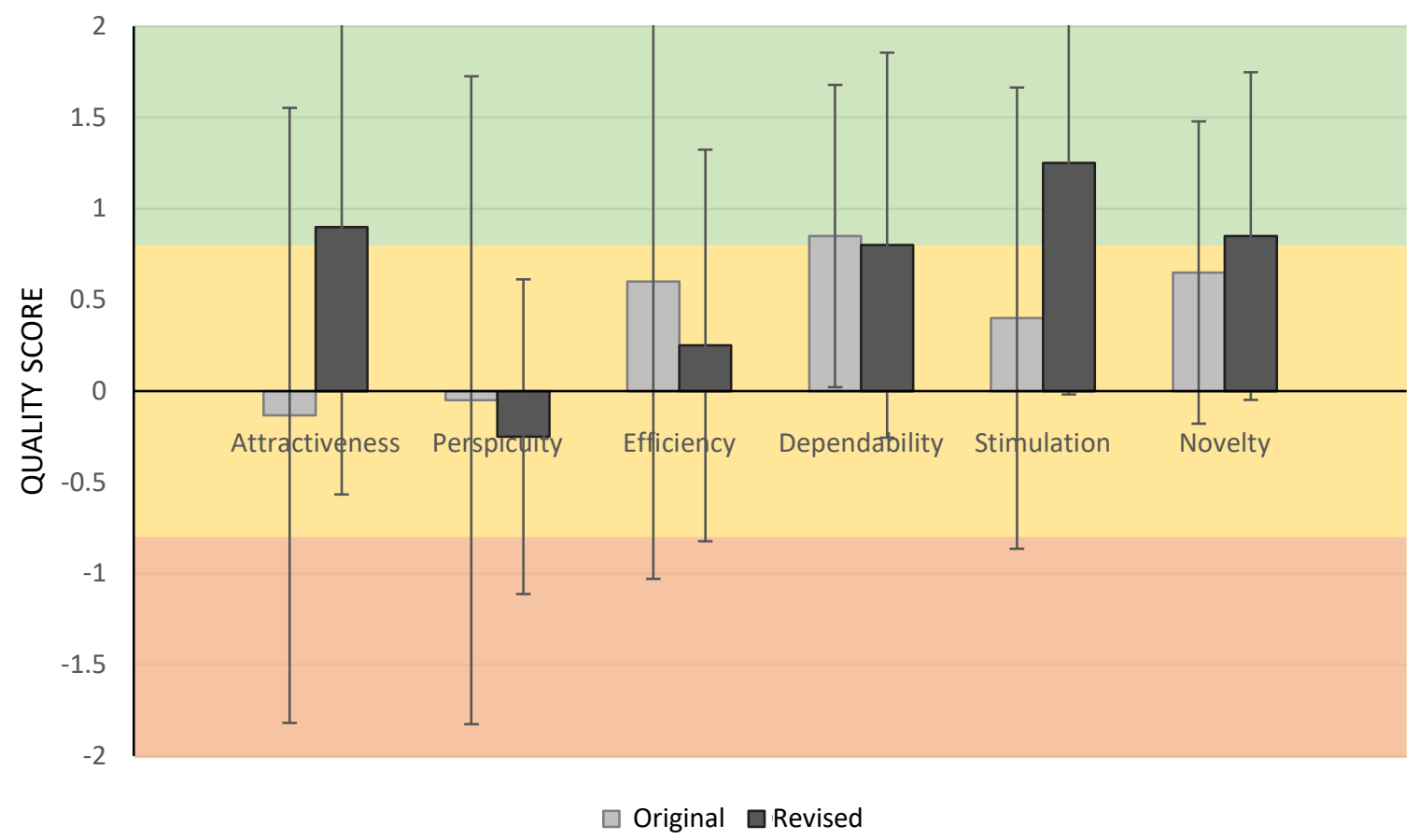

Figure 34. Scale Scores Comparison

The general trend in the data shows that there was an overall increase in the attractiveness of the revised manual compared to the original manual as well as increases in both desirable scales. There was, however, a decrease in each of the usability scales with exception dependability which remained roughly the same. It should be noted that in most cases, results were not statistically significant. This was expected due to the nature of sampling a group of participants less than 30. By visual inspection, scales whose error bars are contained in a single region (all in the good (green) zone, etc.) provide insights beyond the exact population being sampled. Similarly with product comparison, two products whose error bars do not overlap are statistically different from each other. The UEQ does provide suggested population sizes to achieve results applicable to a normal curve. Then again, in terms of this case study the data provides specific useful insights. The trend of comparative scores was simplified in Table 22 and 
Figure 35. Because the components of usability and desirability were not statistically significant, overall significance was not measured.

Table 22

Overall Scores Comparison

\begin{tabular}{lcc}
\hline \multirow{2}{*}{ Score } & Original Manual & Revised Manual \\
& $\mathrm{M}_{\mathrm{G} 1}$ & $\mathrm{M}_{\mathrm{G} 2}$ \\
\hline Attractiveness & 0.9 & -0.13333 \\
Usability & 0.266667 & 0.466667 \\
Desirability & 1.05 & 0.525 \\
\hline
\end{tabular}

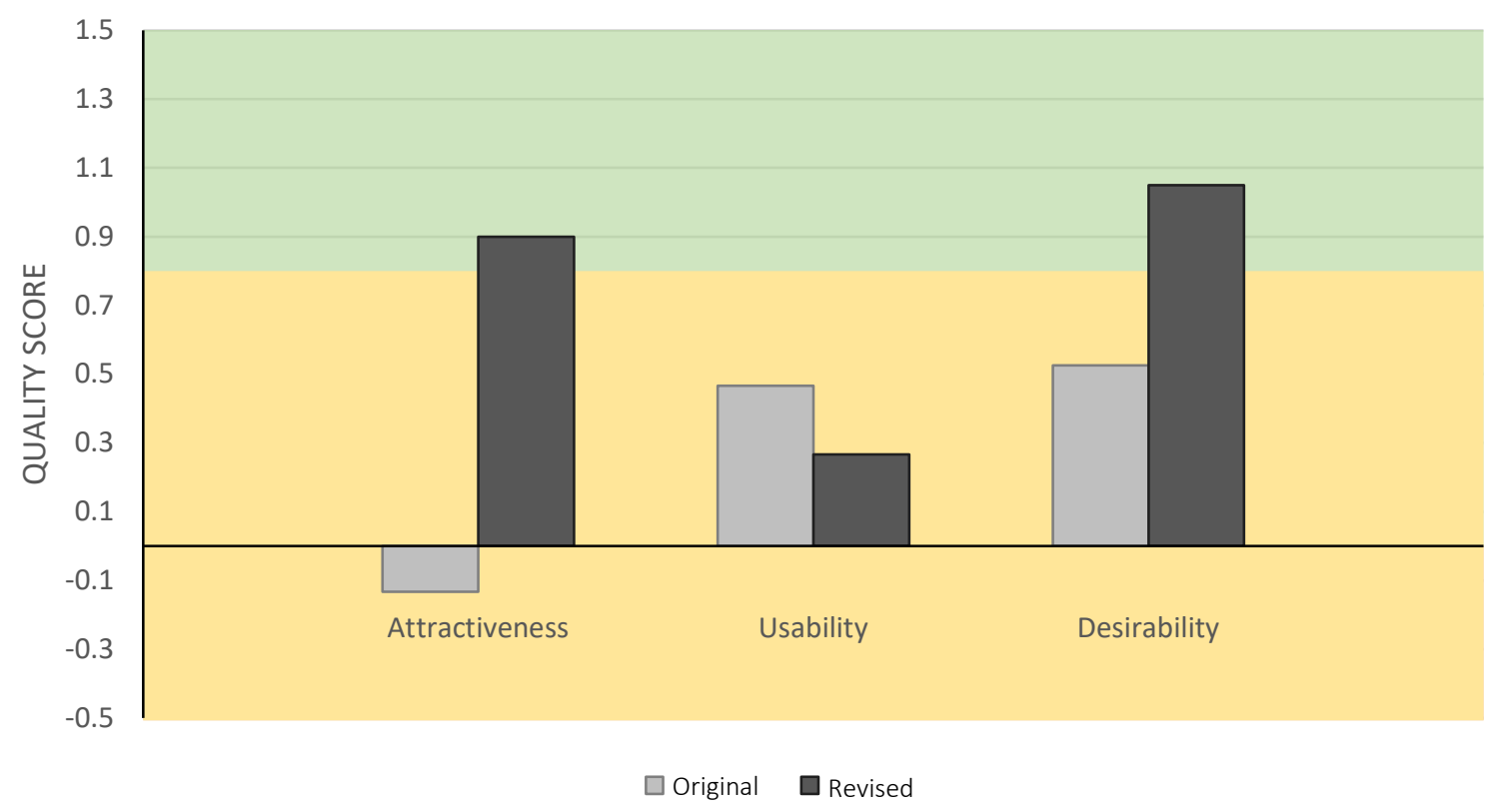

Figure 35. Overall Scores Comparison

\section{Step Rankings}

A Dependent t-test was also conducted for each set of individual step rankings.

Comparisons for overall performance (Figure 36), usability (Figure 37), and desirability (Figure 38) were shown below. An evaluation of these results will be explained in the following section. Significant differences are noted, but figures may be seen in Appendix L for clarity.

Notable significant differences overall were seen in the Modifications Page and Back Page. 


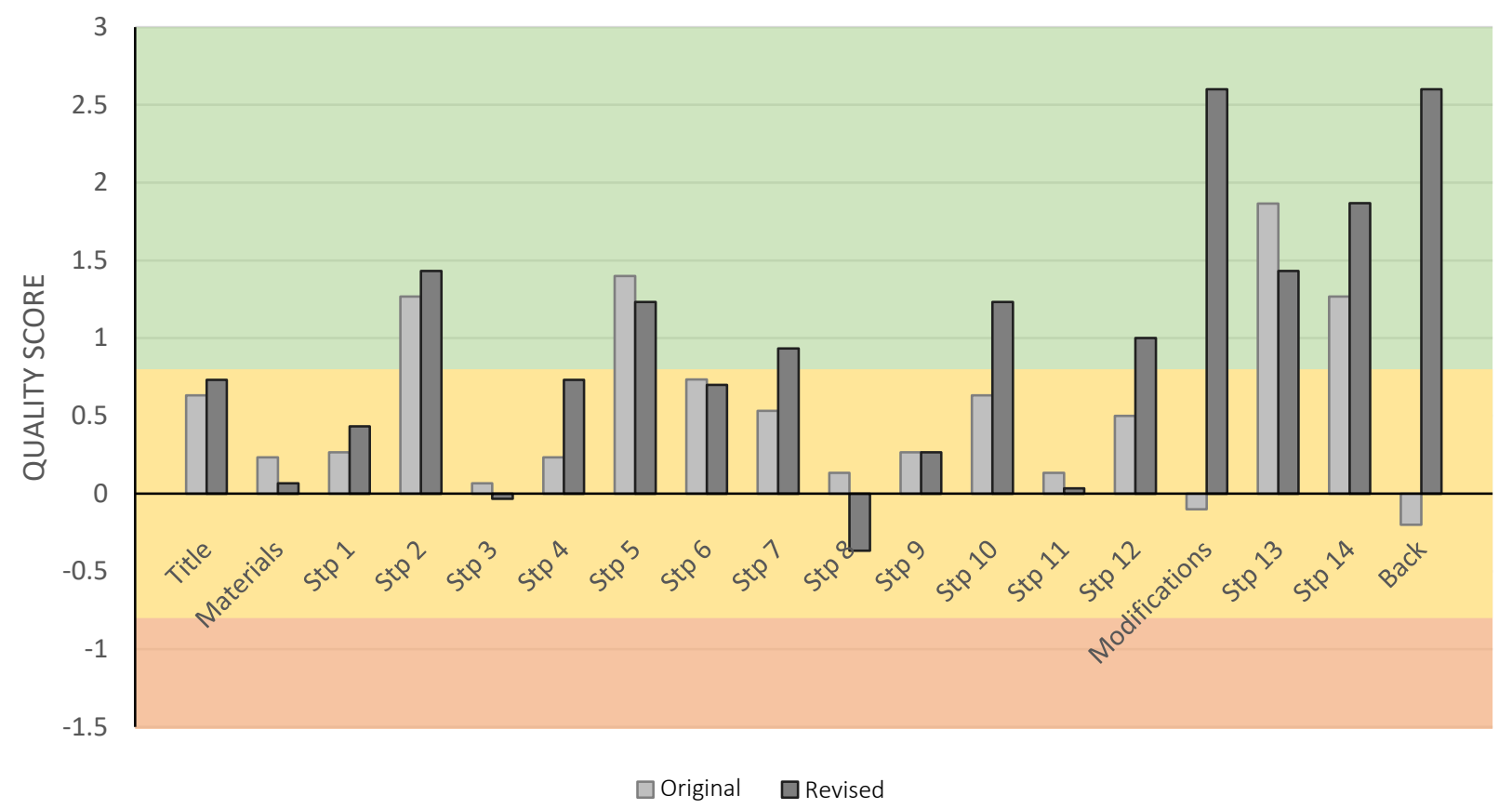

Figure 36. Overall Steps Comparison

Significant differences in usability were seen in the Modifications Page and Step 13.

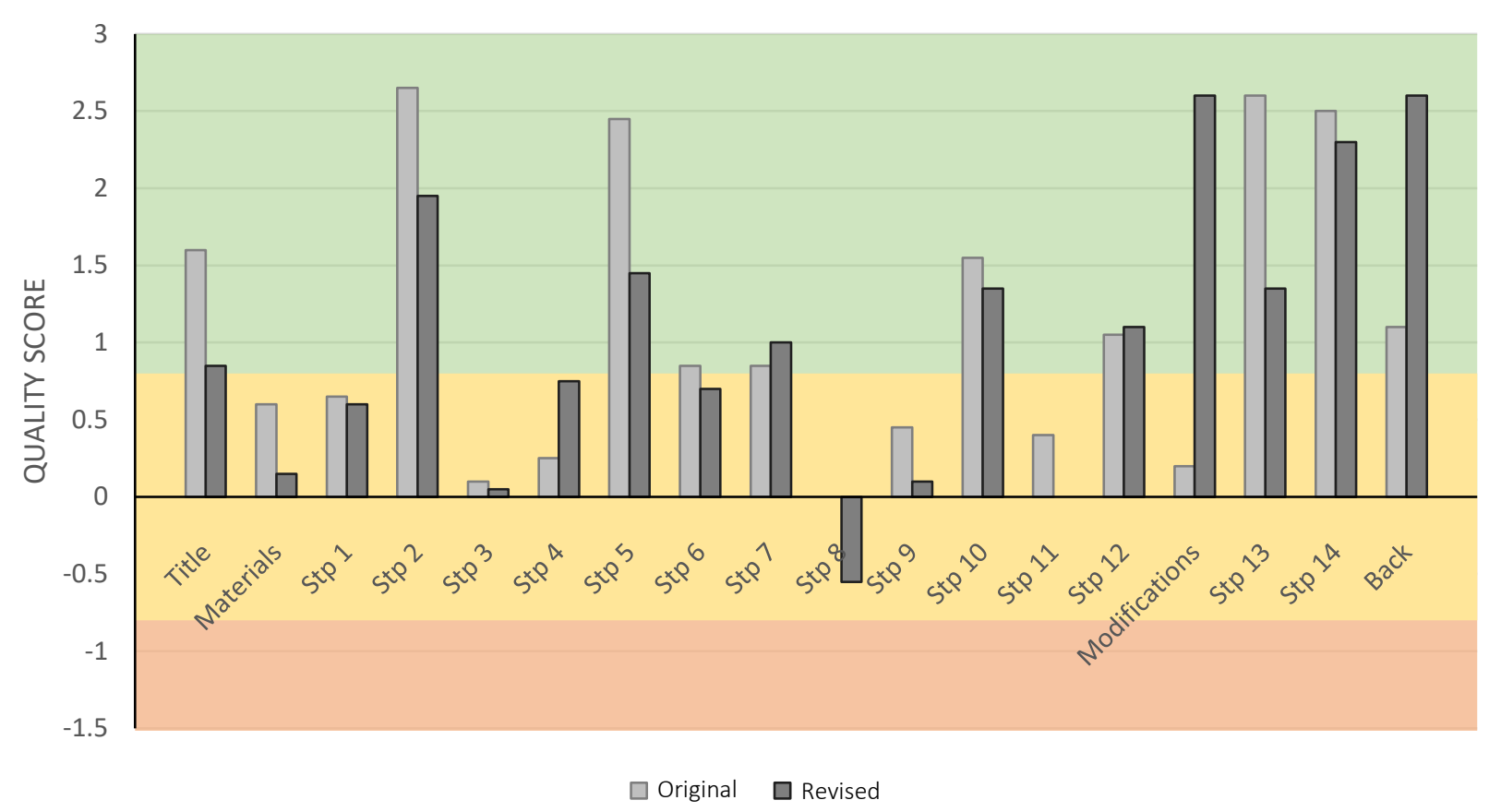

Figure 37. Usability Steps Comparison

Significant difference in desirability were seen in the modifications page and back page. 


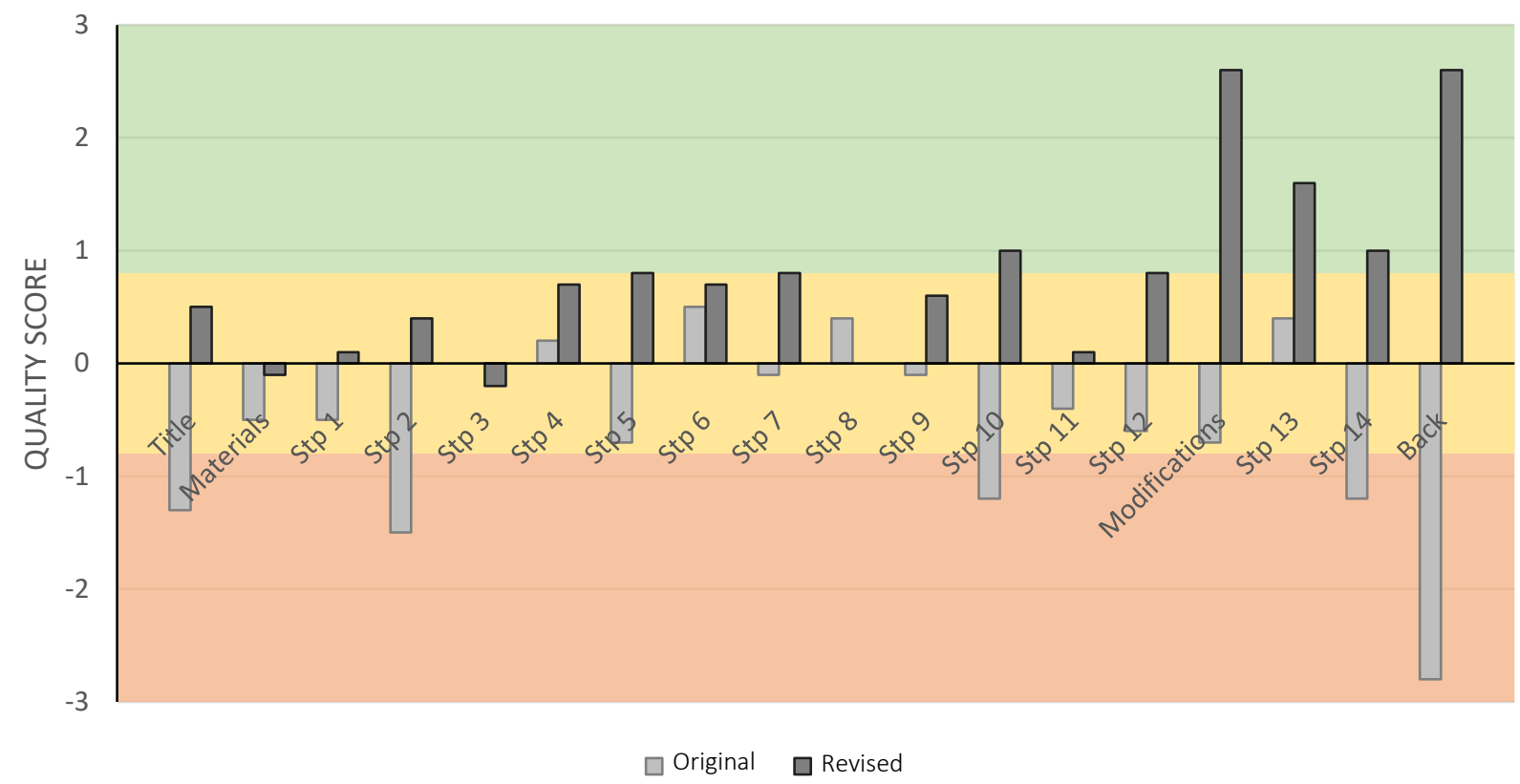

Figure 38. Desirability Steps Comparison

\section{Step comparison evaluations}

The successful implementation of design revisions to a step was based on the results of the overall step ranking (the average of usability and desirability scores) (See Figure 39).

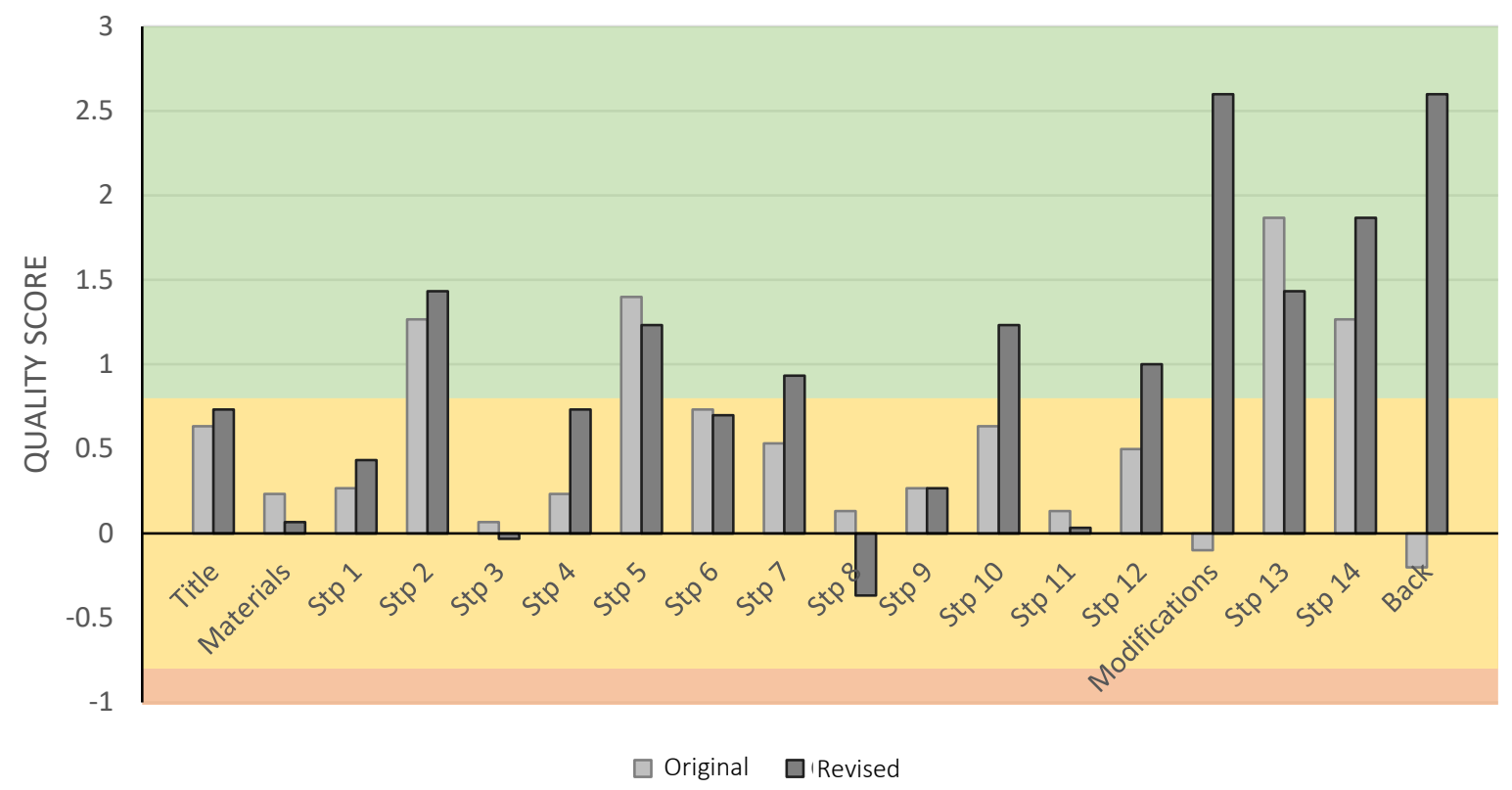

Figure 39. Overall Steps Comparison 
In general, design revisions resulted in slight improvement or slight decline by averages differing within the same quality zone; remaining the approximately the same where averages remained relatively close independent of design revisions; improved where averages increased from a lower quality zone to a high one; and in one case declined where an average decreased from a higher quality zone to a lower one. Overall improvements or lack thereof were determined using the comparative data and qualitative data from the second round of testing. While the comparative data shows differences in general scores, the interviews and observations help determine if users were expressing similar concerns before the redesign or if new issues resulted from the redesign. Either of these cases would suggest that some poka yoke strategies were not successful or not correctly implemented and the specific visual elements were not effective.

\section{Title and materials page: basis for no change}

The title page and materials page experienced little or no change during the redesign. This was confirmed in the scoring where the title page improved 0.100 points and the materials page decreased 0.166 points (See Table 23).

Table 23

Title and Materials Overall Score Differences

\begin{tabular}{lccc}
\hline \multicolumn{1}{c}{ Step } & Original Manual & Revised Manual & Difference \\
& $\mathrm{M}_{\mathrm{G} 1}$ & $\mathrm{M}_{\mathrm{G} 2}$ & $\Delta \mathrm{M}$ \\
\hline Title & 0.633 & 0.733 & 0.100 \\
Materials & 0.233 & 0.067 & -0.166 \\
\hline
\end{tabular}

Due to the nature of these mean differences, step which exhibited mean differences less than $0.200(\Delta \mathrm{M} \leq \pm 0.200)$ were considered to have neither improved or decreased. 


\section{Steps exhibiting no change}

Steps exhibiting no change were reported in Table 24 below.

Table 24

No Change Overall Score Differences

\begin{tabular}{lccc}
\hline & Original Manual & Revised Manual & Difference \\
& M $_{\mathrm{G} 1}$ & $\mathrm{M}_{\mathrm{G} 2}$ & $\Delta \mathrm{M}$ \\
\hline Step 1 & 0.267 & 0.433 & 0.166 \\
Step 2 & 1.267 & 1.433 & 0.166 \\
Step 3 & 0.067 & -0.033 & -0.100 \\
Step 5 & 1.400 & 1.233 & -0.167 \\
Step 6 & 0.733 & 0.700 & -0.033 \\
Step 9 & 0.267 & 0.267 & 0.000 \\
Step 11 & 0.133 & 0.033 & -0.100 \\
Step 13 & 1.867 & 1.433 & -0.434 \\
\hline
\end{tabular}

\section{Step 1}

Step 1 changes primarily consistency of document consistency edits and while there was a slight increase in the step scoring $(\Delta \mathrm{M}=+0.166)$, no additional feedback was provided to support an increase or decrease in the step effectiveness.

Step 2

Similarly, Step 2 only was modified by document consistency edits and there was no feedback regarding the step.

\section{Step 3}

In Step 3, there was a slight decrease in the score $(\Delta M=-0.100)$ leading the step to be most exactly neutral overall $(M=-0.033)$ even though specific changes had been made. The poka yoke strategy was to group the components of the step together to help identify the two 
major tasks in the step. As Reader 8 said, "You had to pay very careful attention and stare at the diagram to make sure that everything on your part matching what their picture was.” The statement summarizes comments made by the first group indicating that issues in the step had not been resolved. Also, noted confusion in recognizing the switch because it was not color coded, this was a mistake by the designer by overlooking that detail.

\section{Step 5}

Step 5 exhibited no change with a slight decrease in score $(\Delta \mathrm{M}=-0.167)$. While group 1 participants did not note issues with the step, the revised manual group raised question of the purpose of the piece and issues on image size. When reviewed the designer found the step image had actually been decreased in size slightly compared to the original. There were some negative comments in which it was two reader's preference that the step be placed at the end of the assembly process or combined with the installation of the battery.

Step 6

In Step 6, readers were better able to identify that the step was focused on the use of the gear tool. Two readers did, however, have trouble identifying the tool and tried to reference the tools list in the materials page. In terms of poka yoke, the additional information did not aid readers in quickly recognizing the requirements to complete the ask as readers reported. The mixed positive and negative comments resulted in a slightly decreased score $(\Delta M=-0.033)$.

\section{Step 9}

Step 9 presented issues in the original manual by not indicating well which peg size was needed and the overall assembly sequence. In the revision, most readers understood the same message from Step 9, but the message was incorrect. Most readers attempted to attached the leg assembly upside down. While many secondary issues were addressed successfully, greater 
insight was gained as to a deeper clarity issue than was communicated in the first round of testing. Poka yoke successes were seen with greater part identification, but the main issue of the step remained resulting in no score $(\Delta \mathrm{M}=0.000)$ change for the step.

\section{Step 11}

Step 11 in the original manual was considered useless because the repetitive step did not provide new information. The redesign of the step was considered to be faulty on the part of the designer because the use of color coding (applying a gray infill to the entire image) was reported to be unclear by readers. Greater insight was found where two readers stated that the showing a fully assembled leg in the image helped the reader complete the task. The slight decrease in overall score $(\Delta \mathrm{M}=-0.100)$ may suggest that the poor use of color made small impact if any on the perceived usefulness of the repetitive step.

\section{Step 13}

Although Step 13 was the first ranked step from the original manual, efforts were taken to raise its moderate desirability score to improve the overall manual desirability. Readers of the revised manual noted various issues with placing the battery and clarity issues with the words and pictures. It unclear why the readers noted these issues since the original manual did not address assembly of the battery and was much smaller. The decrease in usability of the step may have been for the pointed mentioned, but the usability score of the original Step 13 was exceedingly at 2.600 and was still strong after the revision at 1.350 . The desirability did improve significantly with an increase of 1.200 . The difference in the two scores ultimately resulted in a decrease of the overall score $(\Delta \mathrm{M}=-0.434)$. The decrease in overall score s not indicative of readers thoughts because the lower usability score was still a strong positive score. 


\section{Steps exhibiting score increase}

Steps exhibiting positive change were reported in Table 25.

Table 25

Score Increase Overall Differences

\begin{tabular}{lccc}
\hline \multicolumn{1}{c}{ Step } & Original Manual & Revised Manual & Difference \\
& $\mathrm{M}_{\mathrm{G} 1}$ & $\mathrm{M}_{\mathrm{G} 2}$ & $\Delta \mathrm{M}$ \\
\hline Step 4 & 0.233 & 0.733 & 0.500 \\
Step 7 & 0.533 & 0.933 & 0.400 \\
Step 10 & 0.633 & 1.233 & 0.600 \\
Step 12 & 0.500 & 1.000 & 0.500 \\
Modifications & -0.100 & 2.600 & 2.700 \\
Step 14 & 1.267 & 1.867 & 0.600 \\
Back & -0.200 & 2.600 & 2.800 \\
\hline
\end{tabular}

Step 4

In Step 4, there was a positive increase of $0.500(\Delta \mathrm{M}=0.500)$ bring the overall score close to a good quality score. Two readers did experience difficulties relating to the context of the step where not knowing that the parts were preparing for the battery assembly brought about confusion. The 'flip over' header, image size, and emphasized callouts were all sighted as helpful elements.

\section{Step 7}

In Step 7, two issues of clarity of important details and step progression were solved through simplifying the step layout and emphasizing important details through the use of callouts. In terms of poka yoke, a final callout depicted the proper orientation of a detail that would otherwise result in an incorrect assembly. The overall score raised 0.400 points $(\Delta \mathrm{M}=$ 0.400) improve Step 7’s quality to a good rating. 


\section{Step 10}

Step 10 was highly usable in the first manual but greatly lacked in terms of desirability. While readers from both tests did not comment on their attitudes towards it, desirability increased 1.800 points significantly contributing to Step 10's 0.600 increase $((\Delta \mathrm{M}=0.600)$ into the good quality score zone. The most notable change was the poka yoke implementation of the long peg image to help readers compare it to the peg used in step 9. If the revision did not expressly affect stimulation or novelty, it did incur a positive attitude towards the step overall.

\section{Step 12}

Concerning Step 12, readers mostly likely applied their opinions of Step 10 to this step since they were so similar. In the same pattern as Steps 9 and 11, the repetitive steps (like Steps 11 and 12) received slightly lower scores compared to the steps that they repeat. It is expected that readers tended to apply their opinions of the first steps to the repeated steps while maintaining the notion that the repetitive steps are useless. As a result, Steps 11 and 12 scored between 0.100 and 0.250 less overall then their repeated counterparts.

\section{Modifications page}

The modifications page originally was placed before the end of the toy assembly which was noted by all readers of the first group. While some slight changes were made to the wording and ruler on the page, the rearranging of page to the end of the manual is the expected cause of the 2.700 increase $(\Delta \mathrm{M}=2.700)$ in overall scoring. Putting optional steps before the completion of the main assembly proved to be a major issue among readers.

\section{Step 14}

In Step 14, original manual readers did not understand the purpose of the step. This point speaks to desirability in that the step did not provide value to the experience. By including a 
short description and a header signifying the completion of the assembly, the desirability increased by 2.200 contributing to an overall score increase of $0.600(\Delta M=0.600)$.

\section{Back page}

In most cases, the back page was only referenced by group 1 readers for the purpose of filling out the questionnaire, or glanced at to acknowledge the fact that there was a back page at all. In the revised manual, readers eventually made their way to the back page. One reason for this could be because the original manual ended the manual with the final step, readers naturally ended the reading of the manual. In the manual revision, the modification page did not provide a natural end which may have prompted readers to continue inspecting the document. Concerning the content of the back page, only two readers from group 1 read the safety information on the back page. In the revised manual, a marketing element was included to draw interest into other products in the toy's franchise. A note was also included about extra parts that should be left over from the assembly. With these things in mind, the improved 2.800 points $(\Delta M=2.800)$ to increase the quality from slightly poor to good.

\section{Steps exhibiting score decrease}

The step that exhibited a negative change was reported in Table 26.

Table 26

Score Decrease Overall Differences

\begin{tabular}{cccc}
\hline \multirow{2}{*}{ Step } & Original Manual & Revised Manual & Difference \\
& $\mathrm{M}_{\mathrm{G} 1}$ & $\mathrm{M}_{\mathrm{G} 2}$ & $\Delta \mathrm{M}$ \\
\hline Step 8 & 0.133 & -0.367 & -0.500 \\
\hline
\end{tabular}

Step 8 was considered to be the most difficult step among all readers and was the only step in the revised manual to report a true slightly poor quality score. Original manual readers’ 
main issue was that they were unsure how many times to repeat the leg assembly. Readers would often build two or four of the eight total legs and move on to the next step. Readers also reported anxiety from the step looking overwhelming. The strategy of the designer was to simplify the step by directly noting the number of legs needed to be built, separating the image into two manageable sections, and contrast the left and right assemblies.

The revised manual readers were inconsistent in the issues faced in the step but were consistent in their dissatisfaction. Two common issues were that readers were simply unable to correctly assemble the legs and other readers were able to assemble the legs but forgot which legs were in the 'left' orientation and which ones were 'right.' As a result, Step 8 decreased $0.500(\Delta \mathrm{M}=-0.500)$. from slightly good to slightly poor quality. 


\section{CHAPTER V}

\section{Conclusions and Discussion}

\section{Implications of Themes on User Experience}

This research provides 12 themes that describe the components of user experience (usability and desirability) in terms of instruction manuals as a communication tool. Effective communication is dependent on the sender (designer), channel (instruction manual), and receiver (customer) (Shannon \& Weaver, 1998).

Eight of the themes (step images, color coding, image size, word usage, part mirroring, step progression, document organization, and perceived uselessness) were primarily functional topics that described the instruction manual's ability to present a logical sequence of tasks that would lead to a meaningful result. The pragmatic quality of these themes first promoted the usability of the instruction manual, and secondly, may have provided visually beautiful pictures that are pleasing or desirable. As Reader 8 said,

I think there's more to it because it's also hard to figure out what they're trying to tell you in these pictures like what are you trying to tell me here?

The other four themes (confidence, deeper knowledge of task, perceived correct implementation, and task completion) were primarily reflective topics that describe readers reactions to their own ability to understand a logical sequence of tasks that would lead to a meaningful result. The hedonic quality of these themes promoted the desirability of the instruction manual by affirming readers’ intelligence, expectations, and capabilities. As Reader 2 said,

It was overall kind of empowering because I didn't think that highly of my ability to put together a... an electronic anything, so yeah. 


\section{Successful Poka Yoke Implementations}

Poka yoke is a technique that prompts a user to conduct 'source inspection.' This means that users will repeatedly prompted to check their work to ensure that mistakes do not go unnoticed to a point where correction is costly. Two main source inspection prompts are to make the user to prepare parts for assembly so parts not forgotten or incorrect, and features of the product are designed to prevent the user from moving forward if a mistake was made.

In terms of instruction manuals, the poka yoke technique was successfully applied in the following ways:

- Details were highlighted in the form of callouts reinforce possible mistakes. The longer a mistake goes undetected, the greater impact it may have on a user's confidence to complete the project.

- $\quad$ Steps were grouped in subassemblies to provide when a new task begins and ends. Grouped tasks provide context for a sequence of steps and provide stimulation when a full subassembly is complete.

\section{Study Limitations, Inconsistencies, and Personal Biases}

\section{Context}

This study analyzed the user experience aspect of instruction manual using a limited sample size and it used the product genre of mechanical toy assembly to make assertions of general assembly situations. The nature of this study dictates that all results only directly applicable to the DIY Tech-Kit Robot Spider. Although themes, design methodology, and explicit visual design elements are encouraged to be tested for other populations and assembly genres. 


\section{Supporting literature}

Concerning literature review, many of the core instruction design studies as well as concepts of user experience stem from the fields of computer science and from computer interaction design. The most developed instruction manual research found stemmed from the studies on teaching new computer users how to use word processors and email. The original development of the UEQ and UEQ-S was for the analysis of digital computer interfaces.

\section{Experiment design}

The DIY Tech-Kit Robot Spider was selected because the assembly required a variety of instructional situations that could be used to conduct further research.

An aim of the study was to be cost effective in the design of the experiment. Only a single toy was purchased for testing to act as a single 'prototype' that might be used by industry professionals for testing a product. As a result, the toy originally comes with the plastic parts molded into sheets in which users have to break the part out to begin assembly. This step was omitted as 10 toys would have been needed to be purchased to study this situation. In the later trials, some electrical leads were pulled out from the toy that required to operate the toy. Although, the toy was fixed before the end of participants' assembly period, that experience may have influenced their feedback compared to other participants.

Also, participants who finished the assembly incorrectly were prompted to troubleshoot the toy to determine their mistake. In cases where participants were not able to find the mistake, the experimenter aided in the troubleshooting process. The experiment did not account for failed attempts or a percentage of accuracy for each trial. 
Some design aspects such as document consistency were not directly quantifiable as the UEQ-S only measured the quality of individual steps. It is believed that overall document design strategies affected the results of each step.

\section{Personal biases}

As the designer, the experimenter limited design options to directly reflect feedback from readers, apply the concepts of poka yoke, and directly influence usability and desirability. The aim of the experimenter was to present the information of the original manual in a more direct and clear way. As a result, the experimenter attempted to improve on his perceived strategy of the manual. In this way, the manual could be analyzed as a revision where steps were directly comparable instead of a new manual overall. Supporting the notion that industry professionals may have limited resources, design options that would increase cost such as the addition of color, increased page count, or manual redesign from scratch was omitted.

Also, the experimenter assumed that participants' deviation from tasks described in the instruction manual were considered negative or incorrect.

\section{Design Suggestions}

The following design suggestions were noted during the study for making a significant impact on the instruction manual revision:

1. Maintain task oriented progression by completing the general project and then provide opportunities to make changes. Group 1 participants were confused when they were prompted with toy modifications before they completed the toy.

2. Provide a note for expected extra parts. Group 1 participants noted concern that there were extra parts and Group 2 participants using the revised manual said that the extra parts note helped affirm correct assembly. 
3. Do not leave white space. The back page of the manual in this case study was a final opportunity to engage the reader. A marketing element provided increased desirability.

4. Use callouts to highlight single important notes. Callouts improved the important features required for correct assemble in Step 7.

5. A picture is worth a thousand words, but the reader only needs ten. Reduce fine details on complex parts or zoom in on important elements of a larger image to help readers quickly identify the main message (See Step 14).

6. Provide a brief parts list in a step where part identification is important. In Step 10, short and long pegs are easily mistakable.

7. Some participants favorite steps were because it helped them complete a task they didn’t think that they could do. Steps that affirm user’s abilities promotes desirability.

\section{Future Studies}

Throughout the course of this study, the researcher developed questions or ideas from different observations that prompted further scrutiny outside the scope of this study. These questions and ideas are listed below:

- Would breaking parts out of a mold sheet improve part recognition during assembly?

- Conduct an industry review of instruction manual to determine strategies, industry standards, and effective design elements.

- Develop UEQ for instruction manuals to provide benchmarking analysis for designers.

- Can individuals who use instruction manual be classified into profiles? What design elements can be implemented to best fit each user's needs?

- Are there preliminary steps (such as looking at the box, or prereading the manual) that can improve the product assembly experience? 


\section{REFERENCES}

Bernhardt, S. A. (1986). Seeing the Text. College Composition and Communication, 66-78.

Booth, P. A. (1991). Errors and theory in human-computer interaction. Acta Psychologica, 6996.

Budiu, R. (2017, October 1). Quantitative vs. Qualitiative Usability Testing. Retrieved from Nielsen Norman Group.

Carroll, J. M., Smith-Kerker, P. L., Ford, J. R., \& Mazur-Rimetz, S. A. (1987). The Minimal Manual. Human-Computer Interaction, 123-153.

Crossman, E. R. (1959). A Theory of the Acquisition of Speed-Skill. Ergonomics, 153-166.

De Fazio, T. L., \& Whitney, D. E. (1987). Simplified Generation of all Mechanical Assembly Squences. IEEE Journal of Robotics and Automation, 640-658.

Egeth, H. E., \& Yantis, S. (1997). Visual Attention: Control, Representation, and Time Course. Annual Review of Psychology, 269-297.

Erlandson, R. F., Noblett, M. J., \& Phelps, J. A. (1998). Impacts of a Poke-Yoke Device on Job Performance of Individuals with Cognitive Impairmnets. IEEE Transactions on Rehabilitation Engineering, 269-276.

Feiereisen, S., Wong, V., \& Broderick, A. J. (2008). Analogies and Mental Simulations in Learning for Really New Products: The Role of Visual Attention. The Journal of Product Innovation Management, 593-607.

Fisher, M. (1999). Process improvement by poka-yoke. Work Study, 264-266.

FiveBelow. (2017). DIY Tech-Kit Robot Spider Assembly \& Instructions. PA.

Interaction Design Foundation. (2018, January 10). Key Questions in User Experience design Usability vs Desirability. Retrieved from Interaction Design Foundation. 
Ivankova, N. V., Creswell, J. W., \& Stick, S. L. (2006). Using Mixed-Methods Squesntial Explanatory Design: From Theory to Practice. Feild Methods, 3-20.

Karwowski, W., Lee, W., Jamaldin, B., Gaddie, P., Jang, R.-l., \& Alqesaimi, K. K. (1999). Beyond psychophysics: the need for a cognitive engineering approach to setting limits in manual lifting tasks. Ergonomics, 40-60.

Kostelnick, C. (1996). Supra-Textual Design: The Visual Retoric of Whole Documents. Technical Communication Quarterly, 9-33.

Kovacevic, D., Brozovic, M., \& Mozina, K. (2016). Improving visual search in instruction manuals using pictograms. Ergonomics, 1405-1419.

Lang, A. R., Martin, J. L., Sharples, S., \& Crow, J. A. (2013). The effect of design on the usability and real workld effectiveness of medical devices: A case study with adolescent users. Applied Ergonomics, 799-810.

Laugwitz, B., Held, T., \& Schrepp, M. (2008). Contruction and Evaluation of a User Experience Questionnaire. HCI and Usability for Education and Work, 63-76.

Lazonder, A. W., \& Van Der Meij, H. (1995). Error-information in tutorial documentation: Supporting users' errors to facilitate initial skill learning. International Journal of Human-Computer Studies, 185-206.

Lim, J. T., \& Hoffmann, E. R. (2015). Strategies in performing a manual assembly task. International Journal of Industrial Ergonomics, 121-129.

MacLeod, L. G., \& Morrison, G. R. (1998). Narrative Versus Step-by-Step Instructions for Computer Procedures. Proceedings of Selected Research and Development Presentations at the National Convention of the Association for Educational Communications and Technology, 255-259. 
Manning, F. (2015, July 22). What customers actually buy, and why it's not your product. Retrieved from GfK Insights Blog.

Martin, P. Y., \& Turner, B. A. (1986). Grounded Theory and Organizational Research. The Journal of Applied Behavioral Science, 141-157.

Mayer, R. E., \& Moreno, R. (1998). A cognitive Theory of Multimedia Learning: Implications for Design Principles. Journal of Educational Psycholoty, 358-368.

Nielsen, J. (2012, June 4). How Many Test Users in a Usability Study? Retrieved from Nielsen Norman Group.

Schrepp, M., Hinderks, A., \& Thomaschewski, J. (2017). Design and Evaluation of a Short Version of the User Experience Questionnaire (UEQ-S). International Journal of Interactive Multimedia and Artificial Intelligence, 103-108.

Shannon, C., \& Weaver, W. (1998). The mathematical Theory of Communication. Universirt of Illinois press.

Urata, T. (2004). Step-by-Step Visual Manuals: Design and Development. TechTrends, 31-34.

Valeriano, L. L. (1994, Dec 15). Design: Loved the present. Hated the Manual. Wall Street Journal.

Van der Meij, H., \& Carroll, J. M. (1995). Principles and Heuristics for designing Minimalist Instruction. Technical Communication, 243-261.

Weiss, E. H. (1991). How to write usable user documentation. Phoenix, AZ: Oryx. 


\section{APPENDICES}




\section{APPENDIX A: Cover Letter}

\section{Dear Participant,}

This letter is a request for you to take part in a research project to assess the impact of poka yoke on the effectiveness and user experience of instruction manuals. The purpose of this study is to explore insights that can aid information designers and product developers on using industrial manufacturing techniques to provide better product experiences for customers. This project is being conducted by Ephraim Pittore, BSME in the Davis College of Agriculture, Natural Resources and Design at WVU with supervision of Dr. Chris Haddox, an assistant professor in the School of Design and Community Development. This study is research in partial fulfillment for a Master's Degree in Design and Merchandising. Your participation in this project is greatly appreciated and will take approximately 60 - 75 minutes to participate an assembly exercise using an instruction manual and complete a questionnaire and interview. The study will take place in the Engineering Sciences Building (ESB) G70. Participants should have little to no experience playing with mechanical toys such as Lego, K'nex, or other assembly based toys.

Your involvement in this project will be kept as confidential as legally possible. The assembly exercise and interview will be video and audio recorded. All audio will be destroyed following their transcription. Some video maybe made anonymous for presentation purposes, but all written and recorded data will not be identifiable. You must be 18 years of age or older to participate. I will not ask any information that should lead back to your identity as a participant. Your participation is completely voluntary. You may skip any question or task that you do not wish to answer or perform and you may discontinue at any time. Your class standing, grades, or job will not be affected if you decide either not to participate or to withdraw. West Virginia University's Institutional Review Board acknowledgement of this project is on file.

I hope that you will participate in this research project, as it could be beneficial in understanding the impact of manufacturing techniques on instruction manuals and user experience. Thank you very much for your time. Should you have any questions about this letter or the research project, please feel free to contact Ephraim Pittore at (304) 963-0327 or by e-mail at eapittore@mix.wvu.edu or Dr. Chris Haddox at (304) 293-3657 or by email at chris.haddox@mail.wvu.edu.

Thank you for your time and help with this project.

Sincerely,

Ephraim Pittore 


\section{APPENDIX B: UEQ Descriptive Survey}

\section{Please make your evaluation now.}

For the assessment of the product, please fill out the following questionnaire. The questionnaire consists of pairs of contrasting attributes that may apply to the product. The circles between the attributes represent gradations between the opposites. You can express your agreement with the attributes by ticking the circle that most closely reflects your impression.

\section{Example:}

$$
\text { unattractive } \bigcirc \quad \bigcirc \quad \bigcirc \quad \bigcirc \quad \otimes \quad \bigcirc \quad \text { attractive }
$$

This response would mean that you rate the application as more attractive than unattractive.

Please decide spontaneously. Don't think too long about your decision to make sure that you convey your original impression.

Sometimes you may not be completely sure about your agreement with a particular attribute or you may find that the attribute does not apply completely to the particular product. Nevertheless, please tick a circle in every line.

It is your personal opinion that counts. Please remember: there is no wrong or right answer! 
Please assess the product now by ticking one circle per line.

\begin{tabular}{|c|c|c|c|c|c|c|c|c|}
\hline & 1 & 2 & 3 & 4 & 5 & 6 & & \\
\hline annoying & $\bigcirc$ & O & O & 0 & 0 & ○ & enjoyable & 1 \\
\hline not understandable & O & 0 & O & 0 & O & O & understandable & 2 \\
\hline dull & O & 0 & O & O & O & O & creative & 3 \\
\hline difficult to learn & 0 & 0 & 0 & 0 & 0 & 0 & easy to learn & 4 \\
\hline inferior & 0 & 0 & 0 & 0 & 0 & 0 & valuable & 5 \\
\hline boring & $\bigcirc$ & O & ○ & $\bigcirc$ & O & O & exciting & 6 \\
\hline not interesting & 0 & $\bigcirc$ & 0 & 0 & O & 0 & interesting & 7 \\
\hline unpredictable & $\bigcirc$ & 0 & ○ & $\bigcirc$ & ○ & O & predictable & 8 \\
\hline slow & 0 & 0 & 0 & 0 & 0 & 0 & fast & 9 \\
\hline conventional & O & 0 & 0 & $\bigcirc$ & O & 0 & inventive & 10 \\
\hline obstructive & 0 & 0 & 0 & 0 & 0 & 0 & supportive & 11 \\
\hline bad & O & O & O & $\bigcirc$ & O & O & good & 12 \\
\hline complicated & O & 0 & O & $\bigcirc$ & O & 0 & easy & 13 \\
\hline unlikable & O & 0 & O & $\bigcirc$ & $\bigcirc$ & 0 & pleasing & 14 \\
\hline usual & 0 & 0 & O & 0 & O & 0 & cutting edge & 15 \\
\hline unpleasant & $\bigcirc$ & $\bigcirc$ & O & $\bigcirc$ & ○ & O & pleasant & 16 \\
\hline not secure & 0 & 0 & 0 & 0 & 0 & 0 & secure & 17 \\
\hline demotivating & $\bigcirc$ & $\bigcirc$ & ○ & $\bigcirc$ & ○ & $\bigcirc$ & motivating & 18 \\
\hline fails expectations & ○ & 0 & 0 & $\bigcirc$ & 0 & O & meet expectations & 19 \\
\hline inefficient & $\bigcirc$ & $\bigcirc$ & ○ & $\bigcirc$ & ○ & O & efficient & 20 \\
\hline confusing & $\bigcirc$ & $\bigcirc$ & O & $\bigcirc$ & O & O & clear & 21 \\
\hline impractical & $\bigcirc$ & $\bigcirc$ & O & $\bigcirc$ & 0 & 0 & practical & 22 \\
\hline cluttered & 0 & $\bigcirc$ & 0 & 0 & 0 & 0 & organized & 23 \\
\hline unattractive & $\bigcirc$ & 0 & 0 & $\bigcirc$ & $\bigcirc$ & O & attractive & 24 \\
\hline unfriendly & $\bigcirc$ & $\bigcirc$ & 0 & $\bigcirc$ & 0 & 0 & friendly & 25 \\
\hline conservative & 0 & 0 & 0 & 0 & 0 & 0 & innovative & 26 \\
\hline
\end{tabular}


Rate each step of the instruction manual by filling out the table for each step.

Title Page

\begin{tabular}{|r|llllll|l|l|}
\hline obstructive & $\bigcirc$ & $\bigcirc$ & $\bigcirc$ & 0 & $\bigcirc$ & $\bigcirc$ & supportive \\
\hline complicated & $\bigcirc$ & $\bigcirc$ & $\bigcirc$ & $\bigcirc$ & $\bigcirc$ & $\bigcirc$ & easy \\
\hline inefficient & $\bigcirc$ & $\bigcirc$ & $\bigcirc$ & $\bigcirc$ & $\bigcirc$ & $\bigcirc$ & efficient \\
\hline confusing & $\bigcirc$ & $\bigcirc$ & $\bigcirc$ & $\bigcirc$ & $\bigcirc$ & $\bigcirc$ & clear \\
\hline boring & $\bigcirc$ & $\bigcirc$ & $\bigcirc$ & $\bigcirc$ & $\bigcirc$ & $\bigcirc$ & exciting \\
\hline not interesting & $\bigcirc$ & $\bigcirc$ & $\bigcirc$ & $\bigcirc$ & $\bigcirc$ & $\bigcirc$ & interesting \\
\hline
\end{tabular}

STEP 1

\begin{tabular}{|c|c|c|c|c|c|c|}
\hline obstructive & 00 & 0 & O & O & & supportive \\
\hline complicated & 00 & O & 0 & 0 & 0 & easy \\
\hline inefficient & 00 & 0 & 0 & 0 & 0 & efficient \\
\hline confusing & 00 & 0 & 0 & 0 & 0 & clear \\
\hline boring & 00 & O & 0 & 0 & 0 & exciting \\
\hline not interesting & 00 & 0 & 0 & O & O & interesting \\
\hline
\end{tabular}

STEP 3

\begin{tabular}{|c|c|c|}
\hline obstructive & 000000 & supportive \\
\hline complicated & 000000 & easy \\
\hline inefficient & 000000 & efficient \\
\hline confusing & 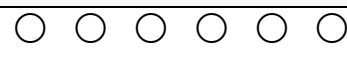 & clear \\
\hline boring & $0 \quad 0 \quad 0 \quad 0 \quad 00$ & exciting \\
\hline not interesting & 000000 & interesting \\
\hline
\end{tabular}

STEP 5

\begin{tabular}{|c|c|c|c|c|c|c|}
\hline obstructive & 00 & 0 & O & 0 & & supportive \\
\hline complicated & 00 & 0 & O & 0 & 0 & easy \\
\hline inefficient & $\mathrm{O} O$ & 0 & 0 & O & 0 & efficient \\
\hline confusing & 00 & 0 & O & 0 & 0 & clear \\
\hline boring & 00 & 0 & 0 & 0 & O & exciting \\
\hline not interesting & 00 & 0 & O & 0 & 0 & interesting \\
\hline
\end{tabular}

STEP 7

\begin{tabular}{|r|llllll|l|}
\hline obstructive & $\bigcirc$ & $\bigcirc$ & $\bigcirc$ & $\bigcirc$ & $\bigcirc$ & $\bigcirc$ & supportive \\
\hline complicated & $\bigcirc$ & $\bigcirc$ & $\bigcirc$ & $\bigcirc$ & $\bigcirc$ & $\bigcirc$ & easy \\
\hline inefficient & $\bigcirc$ & $\bigcirc$ & $\bigcirc$ & $\bigcirc$ & $\bigcirc$ & $\bigcirc$ & efficient \\
\hline confusing & $\bigcirc$ & $\bigcirc$ & $\bigcirc$ & $\bigcirc$ & $\bigcirc$ & $\bigcirc$ & clear \\
\hline boring & $\bigcirc$ & $\bigcirc$ & $\bigcirc$ & $\bigcirc$ & $\bigcirc$ & $\bigcirc$ & exciting \\
\hline not interesting & $\bigcirc$ & $\bigcirc$ & $\bigcirc$ & $\bigcirc$ & $\bigcirc$ & $\bigcirc$ & interesting \\
\hline
\end{tabular}

Materials Page

\begin{tabular}{|r|llllll|l|l|}
\hline obstructive & $\bigcirc$ & $\bigcirc$ & $\bigcirc$ & $\bigcirc$ & $\bigcirc$ & $\bigcirc$ & supportive \\
\hline complicated & $\bigcirc$ & $\bigcirc$ & $\bigcirc$ & $\bigcirc$ & $\bigcirc$ & $\bigcirc$ & easy \\
\hline inefficient & $\bigcirc$ & $\bigcirc$ & $\bigcirc$ & $\bigcirc$ & $\bigcirc$ & $\bigcirc$ & efficient \\
\hline confusing & $\bigcirc$ & $\bigcirc$ & $\bigcirc$ & $\bigcirc$ & $\bigcirc$ & $\bigcirc$ & clear \\
\hline boring & $\bigcirc$ & $\bigcirc$ & $\bigcirc$ & $\bigcirc$ & $\bigcirc$ & $\bigcirc$ & exciting \\
\hline not interesting & $\bigcirc$ & $\bigcirc$ & $\bigcirc$ & $\bigcirc$ & $\bigcirc$ & $\bigcirc$ & interesting \\
\hline
\end{tabular}

STEP 2

\begin{tabular}{|c|c|c|c|c|c|c|}
\hline obstructive & & $\mathrm{O}$ & $\mathrm{OO}$ & 0 & O & supportive \\
\hline complicated & O & O & 00 & 0 & $\mathrm{O}$ & easy \\
\hline inefficient & 0 & O & $\mathrm{OC}$ & 0 & O & efficient \\
\hline confusing & 0 & O & $\mathrm{OC}$ & $\mathrm{O}$ & O & clear \\
\hline boring & 0 & O & $\mathrm{OC}$ & 0 & 0 & exciting \\
\hline not interesting & 0 & O & $\mathrm{OC}$ & 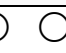 & $\mathrm{O}$ & interesting \\
\hline
\end{tabular}

\section{STEP 4}

\begin{tabular}{|c|c|c|c|c|c|c|}
\hline obstructive & 00 & O & 0 & 0 & & supportive \\
\hline complicated & 00 & O & O & 0 & O & easy \\
\hline inefficient & 00 & $\mathrm{O}$ & O & 0 & 0 & efficient \\
\hline confusing & 00 & 0 & $\mathrm{O}$ & 0 & 0 & clear \\
\hline boring & 00 & $\mathrm{O}$ & 0 & $\mathrm{O}$ & $\mathrm{O}$ & exciting \\
\hline not interesting & 00 & 0 & 0 & 0 & 0 & interesting \\
\hline
\end{tabular}

\section{STEP 6}

\begin{tabular}{|c|c|c|}
\hline obstructive & 000000 & supportive \\
\hline complicated & $\begin{array}{lllllll} & 0 & 0 & \circ & 0 & 0\end{array}$ & easy \\
\hline inefficient & 000000 & efficient \\
\hline confusing & 000000 & clear \\
\hline boring & 000000 & exciting \\
\hline not interesting & 000000 & interesting \\
\hline
\end{tabular}

\section{STEP 8}

\begin{tabular}{|c|c|c|}
\hline obstructive & 000000 & supportive \\
\hline complicated & 000000 & Easy \\
\hline inefficient & 000000 & Efficient \\
\hline confusing & 000000 & Clear \\
\hline boring & 000000 & Exciting \\
\hline not & 000000 & interesting \\
\hline
\end{tabular}


STEP 9

\begin{tabular}{|r|llllll|l|}
\hline obstructive & $\bigcirc$ & $\bigcirc$ & $\bigcirc$ & $\bigcirc$ & $\bigcirc$ & $\bigcirc$ & supportive \\
\hline complicated & $\bigcirc$ & $\bigcirc$ & $\bigcirc$ & $\bigcirc$ & $\bigcirc$ & $\bigcirc$ & easy \\
\hline inefficient & $\bigcirc$ & $\bigcirc$ & $\bigcirc$ & $\bigcirc$ & $\bigcirc$ & $\bigcirc$ & efficient \\
\hline confusing & $\bigcirc$ & $\bigcirc$ & $\bigcirc$ & $\bigcirc$ & $\bigcirc$ & $\bigcirc$ & clear \\
\hline boring & $\bigcirc$ & $\bigcirc$ & $\bigcirc$ & $\bigcirc$ & $\bigcirc$ & $\bigcirc$ & exciting \\
\hline not interesting & $\bigcirc$ & $\bigcirc$ & $\bigcirc$ & $\bigcirc$ & $\bigcirc$ & $\bigcirc$ & interesting \\
\hline
\end{tabular}

STEP 11

\begin{tabular}{|r|llllll|l|}
\hline obstructive & $\bigcirc$ & $\bigcirc$ & $\bigcirc$ & $\bigcirc$ & $\bigcirc$ & $\bigcirc$ & supportive \\
\hline complicated & $\bigcirc$ & $\bigcirc$ & $\bigcirc$ & $\bigcirc$ & $\bigcirc$ & $\bigcirc$ & easy \\
\hline inefficient & $\bigcirc$ & $\bigcirc$ & $\bigcirc$ & $\bigcirc$ & $\bigcirc$ & $\bigcirc$ & efficient \\
\hline confusing & $\bigcirc$ & $\bigcirc$ & $\bigcirc$ & $\bigcirc$ & $\bigcirc$ & $\bigcirc$ & clear \\
\hline boring & $\bigcirc$ & $\bigcirc$ & $\bigcirc$ & $\bigcirc$ & $\bigcirc$ & $\bigcirc$ & exciting \\
\hline not interesting & $\bigcirc$ & $\bigcirc$ & $\bigcirc$ & $\bigcirc$ & $\bigcirc$ & $\bigcirc$ & interesting \\
\hline
\end{tabular}

STEP 14

\begin{tabular}{|r|llllll|l|}
\hline obstructive & $\bigcirc$ & $\bigcirc$ & $\bigcirc$ & $\bigcirc$ & $\bigcirc$ & $\bigcirc$ & supportive \\
\hline complicated & $\bigcirc$ & $\bigcirc$ & $\bigcirc$ & $\bigcirc$ & $\bigcirc$ & $\bigcirc$ & easy \\
\hline inefficient & $\bigcirc$ & $\bigcirc$ & $\bigcirc$ & $\bigcirc$ & $\bigcirc$ & $\bigcirc$ & efficient \\
\hline confusing & $\bigcirc$ & $\bigcirc$ & $\bigcirc$ & $\bigcirc$ & $\bigcirc$ & $\bigcirc$ & clear \\
\hline boring & $\bigcirc$ & $\bigcirc$ & $\bigcirc$ & $\bigcirc$ & $\bigcirc$ & $\bigcirc$ & exciting \\
\hline not interesting & $\bigcirc$ & $\bigcirc$ & $\bigcirc$ & $\bigcirc$ & $\bigcirc$ & $\bigcirc$ & interesting \\
\hline
\end{tabular}

Step Modifications

\begin{tabular}{|r|llllll|l|}
\hline obstructive & $\bigcirc$ & $\bigcirc$ & $\bigcirc$ & $\bigcirc$ & $\bigcirc$ & $\bigcirc$ & supportive \\
\hline complicated & $\bigcirc$ & $\bigcirc$ & $\bigcirc$ & $\bigcirc$ & $\bigcirc$ & $\bigcirc$ & easy \\
\hline inefficient & $\bigcirc$ & $\bigcirc$ & $\bigcirc$ & $\bigcirc$ & $\bigcirc$ & $\bigcirc$ & efficient \\
\hline confusing & $\bigcirc$ & $\bigcirc$ & $\bigcirc$ & $\bigcirc$ & $\bigcirc$ & $\bigcirc$ & clear \\
\hline boring & $\bigcirc$ & $\bigcirc$ & $\bigcirc$ & $\bigcirc$ & $\bigcirc$ & $\bigcirc$ & exciting \\
\hline not interesting & $\bigcirc$ & $\bigcirc$ & $\bigcirc$ & $\bigcirc$ & $\bigcirc$ & $\bigcirc$ & interesting \\
\hline
\end{tabular}

STEP 10

\begin{tabular}{|r|llllll|l|}
\hline obstructive & $\bigcirc$ & $\bigcirc$ & $\bigcirc$ & $\bigcirc$ & $\bigcirc$ & $\bigcirc$ & supportive \\
\hline complicated & $\bigcirc$ & $\bigcirc$ & $\bigcirc$ & $\bigcirc$ & $\bigcirc$ & $\bigcirc$ & easy \\
\hline inefficient & $\bigcirc$ & $\bigcirc$ & $\bigcirc$ & $\bigcirc$ & $\bigcirc$ & $\bigcirc$ & efficient \\
\hline confusing & $\bigcirc$ & $\bigcirc$ & $\bigcirc$ & $\bigcirc$ & $\bigcirc$ & $\bigcirc$ & clear \\
\hline boring & $\bigcirc$ & $\bigcirc$ & $\bigcirc$ & $\bigcirc$ & $\bigcirc$ & $\bigcirc$ & exciting \\
\hline not interesting & $\bigcirc$ & $\bigcirc$ & $\bigcirc$ & $\bigcirc$ & $\bigcirc$ & $\bigcirc$ & interesting \\
\hline
\end{tabular}

STEP 12

\begin{tabular}{|r|rlllll|l|}
\hline obstructive & $\bigcirc$ & $\bigcirc$ & $\bigcirc$ & $\bigcirc$ & $\bigcirc$ & $\bigcirc$ & supportive \\
\hline complicated & $\bigcirc$ & $\bigcirc$ & $\bigcirc$ & $\bigcirc$ & $\bigcirc$ & $\bigcirc$ & easy \\
\hline inefficient & $\bigcirc$ & $\bigcirc$ & $\bigcirc$ & $\bigcirc$ & $\bigcirc$ & $\bigcirc$ & efficient \\
\hline confusing & $\bigcirc$ & $\bigcirc$ & $\bigcirc$ & $\bigcirc$ & $\bigcirc$ & $\bigcirc$ & clear \\
\hline boring & $\bigcirc$ & $\bigcirc$ & $\bigcirc$ & $\bigcirc$ & $\bigcirc$ & $\bigcirc$ & exciting \\
\hline not interesting & $\bigcirc$ & $\bigcirc$ & $\bigcirc$ & $\bigcirc$ & $\bigcirc$ & $\bigcirc$ & interesting \\
\hline
\end{tabular}

STEP 13

\begin{tabular}{|r|llllll|l|}
\hline obstructive & $\bigcirc$ & $\bigcirc$ & $\bigcirc$ & $\bigcirc$ & $\bigcirc$ & $\bigcirc$ & supportive \\
\hline complicated & $\bigcirc$ & $\bigcirc$ & $\bigcirc$ & $\bigcirc$ & $\bigcirc$ & $\bigcirc$ & easy \\
\hline inefficient & $\bigcirc$ & $\bigcirc$ & $\bigcirc$ & $\bigcirc$ & $\bigcirc$ & $\bigcirc$ & efficient \\
\hline confusing & $\bigcirc$ & $\bigcirc$ & $\bigcirc$ & $\bigcirc$ & $\bigcirc$ & $\bigcirc$ & clear \\
\hline boring & $\bigcirc$ & $\bigcirc$ & $\bigcirc$ & $\bigcirc$ & $\bigcirc$ & $\bigcirc$ & exciting \\
\hline not interesting & $\bigcirc$ & $\bigcirc$ & $\bigcirc$ & $\bigcirc$ & $\bigcirc$ & $\bigcirc$ & interesting \\
\hline
\end{tabular}

Back Page

\begin{tabular}{|r|rlllll|l|}
\hline obstructive & $\bigcirc$ & $\bigcirc$ & $\bigcirc$ & $\bigcirc$ & $\bigcirc$ & $\bigcirc$ & supportive \\
\hline complicated & $\bigcirc$ & $\bigcirc$ & $\bigcirc$ & $\bigcirc$ & $\bigcirc$ & $\bigcirc$ & easy \\
\hline inefficient & $\bigcirc$ & $\bigcirc$ & $\bigcirc$ & $\bigcirc$ & $\bigcirc$ & $\bigcirc$ & efficient \\
\hline confusing & $\bigcirc$ & $\bigcirc$ & $\bigcirc$ & $\bigcirc$ & $\bigcirc$ & $\bigcirc$ & clear \\
\hline boring & $\bigcirc$ & $\bigcirc$ & $\bigcirc$ & $\bigcirc$ & $\bigcirc$ & $\bigcirc$ & exciting \\
\hline not interesting & $\bigcirc$ & $\bigcirc$ & $\bigcirc$ & $\bigcirc$ & $\bigcirc$ & $\bigcirc$ & interesting \\
\hline
\end{tabular}


Read and Answer each of the following questions concerning your demographics (circle one).

1. What is your gender?
a. Male
b. Female

2. What is your age?
a. $18-21$
b. $22-25$
c. $26-29$
d. $30-39$
e. $40-49$
f. 50 and above

3. Where is your hometown?
a. West Virginia
b. Virginia
c. Maryland
d. Pennsylvania
e. Other (Specify)

4. What is your race? (Please Specify)

5. Do you consider yourself an expert, hobbyist, or active user of toys or games such as Legos, K'nex, assembly toys, Minecraft, or other STEM toys?
a. Yes
b. No

6. Do you consider yourself an expert or hobbyist in car mechanics, electronics design, tinkering, construction, or any other technical fields?
a. Yes
b. No 
APPENDIX C: Interview and observation sheet

\section{Interview Questions}

\section{User Feedback}

1. What did you think about the experience?

2. How satisfied or dissatisfied were you with the instruction manual?

3. Were there any aspects of the manual that were particularly Useful, Unuseful? Why/Why not?

4. Were there any aspects of the manual that were particularly Enjoyable, Unenjoyable? Why/Why not?

5. Please rank the top 3 best steps and state why you chose them?

6. Please rank the top 3 worst steps and state why you chose them?

7. Is there anything you would like to say about the instruction manual or your experience?

\section{Observational Questions}

8. During the assembly process, I noticed that [Choose from list below] on step (\#), could you tell/show me what happened?

Observations for steps 1-14
a. Confusion
b. Frustration
c. Spent significant time
d. Repeatedly referenced
e. Did not reference
f. Skipped
g. Repeated

Asked for help/Required assistance 


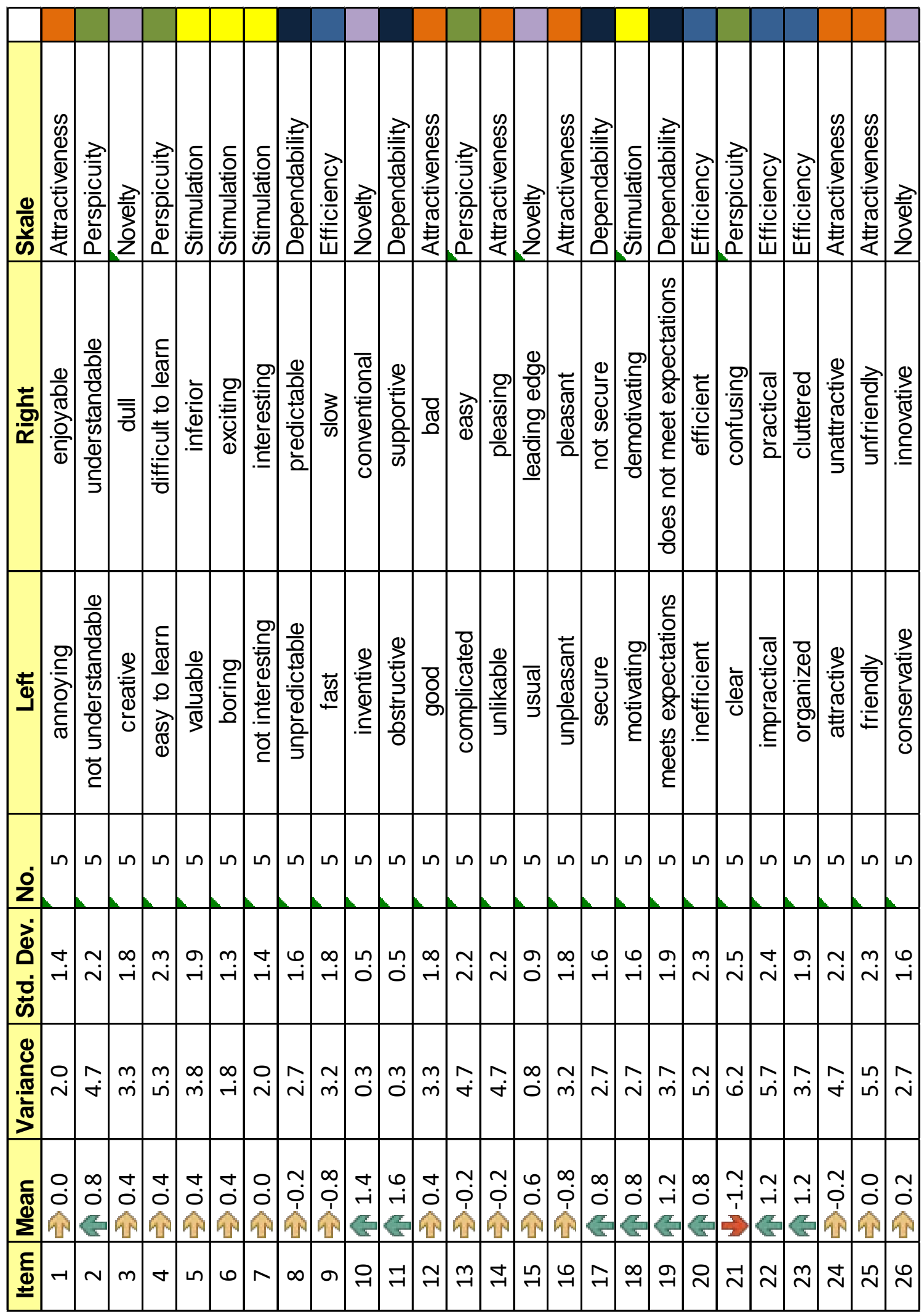




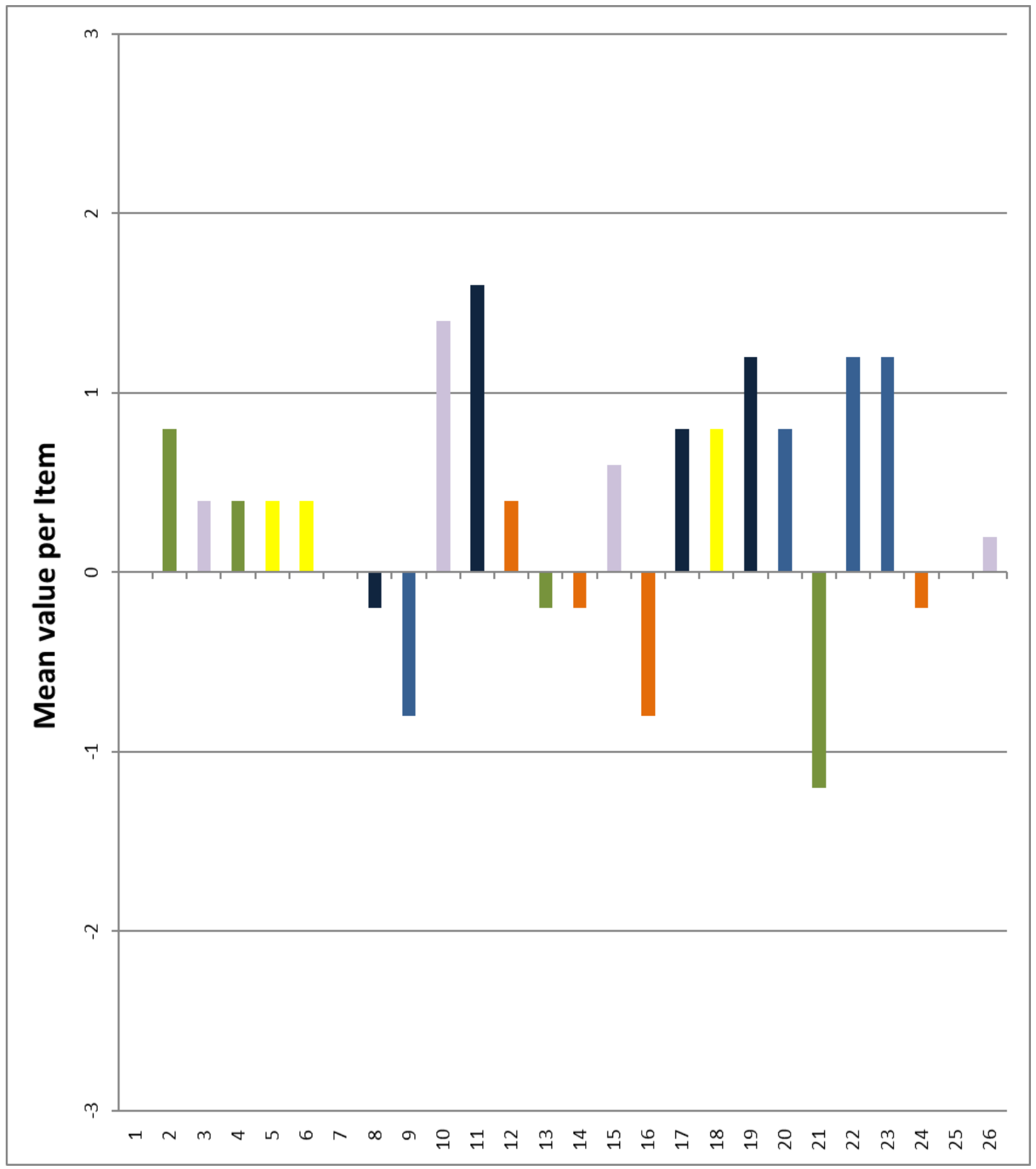




\begin{tabular}{|c|c|c|c|c|c|c|}
\hline \multicolumn{7}{|c|}{ Confidence interval $(\mathbf{p}=\mathbf{0 . 0 5}$ per item } \\
\hline Item & Mean & Std. Dev. & $\mathbf{N}$ & Confidence & \multicolumn{2}{|c|}{ Confidence interval } \\
\hline $\mathbf{1}$ & 0.000 & 1.414 & 5 & 1.240 & -1.240 & 1.240 \\
\hline $\mathbf{2}$ & 0.800 & 2.168 & 5 & 1.900 & -1.100 & 2.700 \\
\hline $\mathbf{3}$ & 0.400 & 1.817 & 5 & 1.592 & -1.192 & 1.992 \\
\hline $\mathbf{4}$ & 0.400 & 2.302 & 5 & 2.018 & -1.618 & 2.418 \\
\hline $\mathbf{5}$ & 0.400 & 1.949 & 5 & 1.709 & -1.309 & 2.109 \\
\hline $\mathbf{6}$ & 0.400 & 1.342 & 5 & 1.176 & -0.776 & 1.576 \\
\hline $\mathbf{7}$ & 0.000 & 1.414 & 5 & 1.240 & -1.240 & 1.240 \\
\hline $\mathbf{8}$ & -0.200 & 1.643 & 5 & 1.440 & -1.640 & 1.240 \\
\hline $\mathbf{9}$ & -0.800 & 1.789 & 5 & 1.568 & -2.368 & 0.768 \\
\hline $\mathbf{1 0}$ & 1.400 & 0.548 & 5 & 0.480 & 0.920 & 1.880 \\
\hline $\mathbf{1 1}$ & 1.600 & 0.548 & 5 & 0.480 & 1.120 & 2.080 \\
\hline $\mathbf{1 2}$ & 0.400 & 1.817 & 5 & 1.592 & -1.192 & 1.992 \\
\hline $\mathbf{1 3}$ & -0.200 & 2.168 & 5 & 1.900 & -2.100 & 1.700 \\
\hline $\mathbf{1 4}$ & -0.200 & 2.168 & 5 & 1.900 & -2.100 & 1.700 \\
\hline $\mathbf{1 5}$ & 0.600 & 0.894 & 5 & 0.784 & -0.184 & 1.384 \\
\hline $\mathbf{1 6}$ & -0.800 & 1.789 & 5 & 1.568 & -2.368 & 0.768 \\
\hline $\mathbf{1 7}$ & 0.800 & 1.643 & 5 & 1.440 & -0.640 & 2.240 \\
\hline $\mathbf{1 8}$ & 0.800 & 1.643 & 5 & 1.440 & -0.640 & 2.240 \\
\hline $\mathbf{1 9}$ & 1.200 & 1.924 & 5 & 1.686 & -0.486 & 2.886 \\
\hline $\mathbf{2 0}$ & 0.800 & 2.280 & 5 & 1.999 & -1.199 & 2.799 \\
\hline $\mathbf{2 1}$ & -1.200 & 2.490 & 5 & 2.183 & -3.383 & 0.983 \\
\hline $\mathbf{2 2}$ & 1.200 & 2.387 & 5 & 2.093 & -0.893 & 3.293 \\
\hline $\mathbf{2 3}$ & 1.200 & 1.924 & 5 & 1.686 & -0.486 & 2.886 \\
\hline $\mathbf{2 4}$ & -0.200 & 2.168 & 5 & 1.900 & -2.100 & 1.700 \\
\hline $\mathbf{2 5}$ & 0.000 & 2.345 & 5 & 2.056 & -2.056 & 2.056 \\
\hline $\mathbf{2 6}$ & 0.200 & 1.643 & 5 & 1.440 & -1.240 & 1.640 \\
\hline & & & & & & \\
\hline
\end{tabular}

\begin{tabular}{|l|c|c|c|c|c|c|}
\hline \multicolumn{7}{|c|}{ Confidence intervals $(\mathbf{p = 0 . 0 5 )}$ per scale } \\
\hline Scale & Mean & Std. Dev. & $\mathbf{N}$ & Confidence & Confidence interval \\
\hline Attractiveness & -0.133 & 1.924 & 5 & 1.686 & -1.819 & 1.553 \\
\hline Perspicuity & -0.050 & 2.026 & 5 & 1.776 & -1.826 & 1.726 \\
\hline Efficiency & 0.600 & 1.859 & 5 & 1.630 & -1.030 & 2.230 \\
\hline Dependability & 0.850 & 0.945 & 5 & 0.829 & 0.021 & 1.679 \\
\hline Stimulation & 0.400 & 1.443 & 5 & 1.265 & -0.865 & 1.665 \\
\hline Novelty & 0.650 & 0.945 & 5 & 0.829 & -0.179 & 1.479 \\
\hline
\end{tabular}


APPENDIX E: Individual Step Data Analysis For Original Manual

\begin{tabular}{|l|c|c|c|c|c|c|}
\hline \multicolumn{7}{|c|}{ Group 1 Steps } \\
\hline Steps & Overall Mear & \multicolumn{1}{|l|}{ Std. Dev. } & \multicolumn{3}{l|}{} & \\
\hline & & & & & & \\
\hline Title & 0.633 & 0.758 & 0.665 & -0.031 & 1.298 & 5 \\
\hline Materials & 0.233 & 1.847 & 1.619 & -1.386 & 1.852 & 5 \\
\hline Stp 1 & 0.267 & 1.539 & 1.349 & -1.083 & 1.616 & 5 \\
\hline Stp 2 & 1.267 & 0.435 & 0.381 & 0.886 & 1.648 & 5 \\
\hline Stp 3 & 0.067 & 1.942 & 1.702 & -1.636 & 1.769 & 5 \\
\hline Stp 4 & 0.233 & 1.588 & 1.392 & -1.159 & 1.625 & 5 \\
\hline Stp 5 & 1.400 & 0.863 & 0.756 & 0.644 & 2.156 & 5 \\
\hline Stp 6 & 0.733 & 1.690 & 1.481 & -0.748 & 2.215 & 5 \\
\hline Stp 7 & 0.533 & 1.876 & 1.644 & -1.111 & 2.178 & 5 \\
\hline Stp 8 & 0.133 & 1.386 & 1.215 & -1.082 & 1.349 & 5 \\
\hline Stp 9 & 0.267 & 1.750 & 1.534 & -1.268 & 1.801 & 5 \\
\hline Stp 10 & 0.633 & 1.592 & 1.395 & -0.762 & 2.028 & 5 \\
\hline Stp 11 & 0.133 & 2.066 & 1.811 & -1.678 & 1.944 & 5 \\
\hline Stp 12 & 0.500 & 1.130 & 0.991 & -0.491 & 1.491 & 5 \\
\hline Modification & -0.100 & 1.964 & 1.721 & -1.821 & 1.621 & 5 \\
\hline Stp 13 & 1.867 & 1.037 & 0.909 & 0.958 & 2.775 & 5 \\
\hline Stp 14 & 1.267 & 0.560 & 0.491 & 0.776 & 1.758 & 5 \\
\hline Back & -0.200 & 1.605 & 1.407 & -1.607 & 1.207 & 5 \\
\hline
\end{tabular}

\begin{tabular}{|c|c|c|c|c|c|c|c|c|c|}
\hline \multicolumn{5}{|c|}{ Group 1 Steps } & \multicolumn{5}{|c|}{ Group 1 Steps } \\
\hline Usability Mear & Std. Dev. & Confidence & Confider & Interval & Desirability Mea & Std. Dev. & Confidence & Confider & e Interval \\
\hline 1.600 & 0.548 & 0.480 & 1.120 & 2.080 & -1.300 & 1.987 & 1.742 & -3.042 & 0.442 \\
\hline 0.600 & 2.111 & 1.850 & -1.250 & 2.450 & -0.500 & 1.658 & 1.454 & -1.954 & 0.954 \\
\hline 0.650 & 1.506 & 1.320 & -0.670 & 1.970 & -0.500 & 1.803 & 1.580 & -2.080 & 1.080 \\
\hline 2.650 & 0.487 & 0.427 & 2.223 & 3.077 & -1.500 & 0.500 & 0.438 & -1.938 & -1.062 \\
\hline 0.100 & 2.051 & 1.798 & -1.698 & 1.898 & 0.000 & 1.768 & 1.549 & -1.549 & 1.549 \\
\hline 0.250 & 1.458 & 1.278 & -1.028 & 1.528 & 0.200 & 1.924 & 1.686 & -1.486 & 1.886 \\
\hline 2.450 & 0.512 & 0.449 & 2.001 & 2.899 & -0.700 & 1.565 & 1.372 & -2.072 & 0.672 \\
\hline 0.850 & 2.247 & 1.970 & -1.120 & 2.820 & 0.500 & 1.936 & 1.697 & -1.197 & 2.197 \\
\hline 0.850 & 2.111 & 1.850 & -1.000 & 2.700 & -0.100 & 1.817 & 1.592 & -1.692 & 1.492 \\
\hline 0.000 & 1.871 & 1.640 & -1.640 & 1.640 & 0.400 & 1.817 & 1.592 & -1.192 & 1.992 \\
\hline 0.450 & 2.003 & 1.756 & -1.306 & 2.206 & -0.100 & 2.247 & 1.970 & -2.070 & 1.870 \\
\hline 1.550 & 2.019 & 1.769 & -0.219 & 3.319 & -1.200 & 1.924 & 1.686 & -2.886 & 0.486 \\
\hline 0.400 & 2.578 & 2.259 & -1.859 & 2.659 & -0.400 & 1.342 & 1.176 & -1.576 & 0.776 \\
\hline 1.050 & 1.891 & 1.657 & -0.607 & 2.707 & -0.600 & 2.074 & 1.818 & -2.418 & 1.218 \\
\hline 0.200 & 2.087 & 1.829 & -1.629 & 2.029 & -0.700 & 1.789 & 1.568 & -2.268 & 0.868 \\
\hline 2.600 & 0.454 & 0.398 & 2.202 & 2.998 & 0.400 & 2.302 & 2.018 & -1.618 & 2.418 \\
\hline 2.500 & 0.586 & 0.514 & 1.986 & 3.014 & -1.200 & 1.924 & 1.686 & -2.886 & 0.486 \\
\hline 1.100 & 2.362 & 2.071 & -0.971 & 3.171 & -2.800 & 0.447 & 0.392 & -3.192 & -2.408 \\
\hline
\end{tabular}


APPENDIX F: Transcription for Original Manual

\section{GROUP 1 INTERVIEW \#1 (VERBAL RESPONCES)}

(00:08) Examiner: Okay, so the first question is, what did you think about the experience?

Participant: I would rather not do it.

(00:21) Examiner: Why would you say that?

Participant: It's not one of my strong suits. Having to tinker with something small, or follow specific directions and look at tiny pieces. It kind of produces anxiety in me.

(00:41) Examiner: So with that being said, how do you feel the instruction manual either did or did not help you through your pain of looking at small pieces?

Participant: Well yeah, it definitely helped because the pictures were really clear and if there was two sides to a piece they made sure to differentiate between which side of the piece was facing up or down. If I can't tell, I would probably panic and I would probably screw this up and I would have to go find someone else. I'm saying it was helpful and satisfying to how to finish but it was'nt enjoyable. But that's just my personality I don't think it's because an instruction manual.

(01:35) Examiner: So how satisfied or dissatisfied where you with instruction manual?

Participant: Very satisfied. There was only one or two times that I had to look closer if I was confused I had to look closer and I might realize I have confused something. [Reference Step 9 in manual] Like on Step 9, B6, I don't know how, I just missed it, I just didn't see it. And then I realized what is this little piece hanging here?

Participant: Or on the opposite side of the leg, [Reference Step 8 in manual] In Step 8, it took me a second to figure out what they meant. If the instruction manual was colored coded because the pieces are color coded that would have helped.

(02:30) Examiner: Okay, was there any aspects of the manual that were particularly useful? Maybe a step that really helped me.

Participant: I would have never figured out step 8. And steps 5 and 6 when you put the gears in the correct locations I don't think I would have figured that out.

Participant: Oh yeah and step 10,11, 12 when you're putting the legs together on the body part of the spider, one of them has to be up and the other one for it to function correctly because they can't all move at the same time. It has to alternate legs. I wouldn't have figured that out. They had to clearly me show me right here [Reference Step 11 in manual].

(03:50) Examiner: Then how about anything that was particularly unuseful? Or unclear?

Participant: Unuseful? Step 2 and step 5 seemed to useless. I think you need this, but maybe you can combine them with another step, because there's are four or five things to focus on in step 1 and then in step 2 there is just one little click and I'm like what? The step should be more balanced I guess, not similar amount of work for each step which made it a bit confusing. (04:40) Examiner: Were there any aspects of the manual that were particularly enjoyable?

Participant: As soon as I figured out the leg, the leg on the opposite side [Reference Step 8 in manual] I knew that I had to make three more pairs and that was kind of fun. Because I felt like I knew what I was doing at that point so I accelerated so that was kind of fun.

(05:15) Examiner: Okay are there any other ones that are particularly enjoyable?

Participant: Step 13, getting to actually put the two body parts with the with the legs attached on to the center piece that holds the battery. There's that sense of 'yes! I'm finished.' 
(05:40) Examiner: How about anything that was unenjoyable?

Participant: I don't understand electricity very well, so that part wasn't comfortable.

Examiner: What's step number was that?

Participant: Number 4. Especially if this is a kid's toy, say you're assembling it for your son and you have to twist the, I don't know how clear it is, twisting the metal threads on to the positive and negative terminal, if you mess up it could be exposed and dangerous and you could be easily electrocuted.

(06:55) Examiner: Okay so if you were to just say the best three steps what were they be?

Participant: I like step 7, putting the gears in place.

Participant: I didn't understand step 6, putting them on to the assembly piece, and I knew they weren't moving so I thought how are these gears going to move and then when you put it into the body piece and snap on the other side then it's so satisfying because then you're like, 'yes! that's where the gears are going to move now.'

Participant: So then, and then I guess on steps 10 and 12, hooking the legs into the gears. If you miss that part up, it's not going to be functional, and the idea of the moving of the gears and knowing that's what is going to create the forward movement was cool I don't know why, why is that really satisfying? The idea that that's what's going to make it function made it kinda fun. (08:59) Examiner: Okay and if you had to say the three worst steps.

Participant: 2, 5, and 14. They were the most boring.

(09:20) Examiner: And you said previously because there's too little to do? Almost seeming like there are meaningless?

Participant: Meaningless!

(09:40) Examiner: Is there anything else you would like to say about the instruction manual or your experience?

Participant: If it was color coded that would be cool, but I understand that that be a significant increase in price. I guess you could have at least differentiated by the shading on what was grey what was brown. You can tell all these parts are different colors but they're all gray here [Reference Step 8 in manual].

(10:20) Examiner: So, it's your preference for, to try to match the actual toy to the manual? Participant: Yeah.

Examiner: So if all the legs are gray, it would be nice if all these pieces were gray [Reference Step 8 in manual]?

Participant: Yeah, but I guess it's also nice they differentiate here [Reference Step 8 in manual] a little bit so they don't look all the same.

(11:00) Examiner: Any other comments that you have?

Participant: No.

(11:17) Examiner: I just have one more question, and it's just based off of my observation. During the assembly, I noticed on step number 4. I noticed you had some confusion there. Do you remember or could you tell what happened? In Step 4, you didn't know how to set the terminals into the body?

Participant: Yes it wasn't clear at first if you look inside the body [Reference Step 4 in manual] that there's a little space that the largest part of the terminal would have to slide into. Okay. (12:00) Examiner: On step number 6, you showed a little confusion with... 
Participant: Yeah, the gears weren't turning so I was like, I didn't realize this was in intermediate piece. I didn't realize A2 was an intermediate piece. But it says it in the next step [Reference Step 7 in manual], "remove, part A2 after gear assembly.”

(12:35) Examiner: Okay and then in 7, there was a little bit of confusion with having to flip over the body piece?

Participant: Yeah see [Reference Step 7 in manual], there's a raised Peg and a not raised peg and actually if you flip it over... no it's not the same because it's only on one of four of that so you have to know which one it is. And maybe if that little peg was highlighted that would help to show, 'Hey, im drawing attention to the fact that there's this little peg is here and it has to be in this direction.

(13:20) Examiner: And then Step 11 there's a little bit of confusion. Oh, what happened was, is you completed step 10 but you went to the next page a little bit confused on going between step 10 and step 11.

Participant: No, I was just referencing, where we going after? I realized I have another body pieces but it doesn't say anywhere to repeat the assembly again. So, I was looking to see, maybe it says it later[Reference Step extra step page in manual]. Am I allowed to go ahead and complete this step? or is it like, strategically coming later for a reason I don't know?

(15:00) Examiner: You repeatedly referenced the first page for the parts, on the front cover? Participant: Because, I wanted to double-check, for example B1 and B6 the pegs [Reference Step 10 in manual], B1 is longer than B6, but I wanted to double-check not just from these two steps and their pictures and their steps but the material options to make sure that I was seeing correctly.

(16:25) Examiner: And then finally the tube, you performed the tube cutting step a little different than maybe what it led on.

Participant: Well, it says 8 equal lengths [Reference extra step page in manual]. So if I fold it in half 1,2,3,5 times then I'm going to get almost the same result. And I don't have a ruler available to me, so it would take way too long to measure them out.

Examiner: Okay with that we are complete. 
GROUP 1 INTERVIEW \#2 (VERBAL RESPONCES)

(00:30) Examiner: The first question is what did you think about the experience?

Participant: It was overall kind of empowering because I didn't think that highly of my ability to put together a... an electronic anything, so yeah.

(00:50) Examiner: With that how did the instruction manual... Was that good ? Was it a good experience to work through?

Participant: Like the pictures were helpful. Like if it would have been descriptions, I would have been totally lost. So because I'm a visual learner, yeah. There were a couple of parts that were misleading though. so that's where maybe some more instruction... I don't know if it's answering another question that you have but... Like in step 8 cause it says[Reference Step 8 in manual], has a whole picture up there really tiny and it says "X2" but like I wasn't really paying attention to that part. I was paying more attention to what am I doing with each of these parts (leg assembly) so I feel like it should have said " $\mathrm{x} 4$ " so you'd be making four right legs and four left legs or whatever. That's more clear to me because later it's telling you how to hook it up to the thing[Reference Step 9 in manual], so I feel like there are parts where it alluded to future steps where you weren't quite there. So, it didn't seem quite relevant at that time.

Participant: Also, like with the same thing with the... [Reference Step extra step page in manual] I think the review part 'alternate modification steps' so like they put this before you're finished with the thing [Reference Step 13 in manual]. So I was confused because I was wondering if I was supposed to put these on first but then I realized it wasn't necessary so I finished it and then I went back and then put them on, yeah.

(02:30) Examiner: So it had that thing about the short stride longstride [Reference extra step page in manual]. So, I think it is symbols as the short stride. Would you have gone back and made it a long stride?

Participant: No because I think spiders are creepy. And even though I know it's not real it freaks me out when it walks so I personally wouldn't have but maybe a kid would.

(02:59) Examiner: So how satisfied or dissatisfied where you with instruction manual?

Participant: I would say pretty satisfied. It was better than most instruction manuals I've read.

(03:05) Examiner: What would you say was better than others?

Participant: I think a lot of it was the pictures and stuff, like just being clear about where... Especially with things that have mirror sides like both sides are the same, like being clear about this is what this side should look like and where it goes and this is what this side should look like and where it goes [Reference Step 9,11 in manual]. Because, I've put together bookshelves and things where I'll put things on backwards or whatever and I get you a letter step and I'm like 
'wait, this doesnt make sense' and then I have to go all the way back and restart it so I think it was pretty clear in how that goes about. Yeah, the order of operations I guess. For the most part.

(04:00) Examiner: So where there any aspects of the manual that were particularly useful?

Participant: I'd say the wire part [Reference Step 4 in manual] cause, like, I don't do anything electrical, if it would have just said 'hooked the wire to the terminal' I would have been like 'what does that mean?' so that was helpful to see it even to see how it was supposed to be wound around the terminal and just like putting the legs together [Reference Step 8 in manual] to have the pictures and stuff because I get really confused about my left and right so having the mirrored images were very useful.

(05:03) Examiner: What were aspects of the manual that are particularly unuseful?

Participant: I'd say the part where you put the gears on the little pegs [Reference Step 6 in manual]. I thought that was part of the machine, but then I was like but when I was like oh you're just using it took place it in these holes that are clearly yeah. It's not hard to figure out how they go in there. Maybe I shouldn't speak for everybody, but for me it's pretty clear how they would have sat inside the casing.

Participant: And then I think like parts like after that with attaching the legs some parts are necessary to repeat [Reference Step 9 in manual] but some are like putting the pegs inside to keep them secure, I feel like you don't need a whole another step to show you what that looks like [Reference Step 12 in manual] you could have been like 'repeat step 10 here.'

(05:57) Examiner: Could you say that one more time so steps 10 and 12 for repetitive[Reference Step 10,12 in manual]?

Participant: Yeah that's pretty... I can even see 9 and 11 [Reference Step 9,11 in manual]are kind of the same but they're showing you again on the opposite side this is what it look like so I can see where that is useful but 10 and 12 are literally just put a peg in a hole to put it in place [Reference Step 10,12 in manual]. I feel like once you do it once you kinda know how the other side goes.

(06:40) Examiner: Are there any aspects of the manual that are particularly enjoyable or fun?

Participant: I would say the whole leg assembly part because it was more engaging, multiple steps, and seeing it really come to life [Reference Step 8-12 in manual].

(07:10) Examiner: Okay and how about anything else on enjoyable?

Participant: No. I don't think so.

(07:30) Examiner: If you could rank the top three best steps whether is useful or helpful or fun or whatever? What would you say? 
Participant: Step 4. Step 8. And step 9.

Examiner: For step 4, what you said before where it did a really good job showing a not electrically inclined person how to connect wires?

Participant: Yes, I'd say that. And step 8 and 9 because the legs were, I mean they weren't, once you got the hang of it they weren't complicated but the first time through its a complicated process because there are so many little parts that goes into one leg, so that was helpful.

(08:45) Examiner: How about the three worst steps?

Participant: Probably step 6, for sure. That was my least favorite because it was kind of an unnecessary thing to do to make putting on the gears easier but it was just extra work that didn't need to happen. Step 12 because of it being repetitive. I don't know, like step 14 because I didn't know what the purpose of that was. Maybe it's like to stabilize it and hold it together but it's just like you finish the whole thing you get the battery in and then it's like 'oh, turn it upside down and put this thing on.' I didn't know what this was for or why I was doing it.

(10:20) Examiner: Is there anything else you would like to say about the instruction manual or your experience?

Participant: The last thing is, I never look at the back where it talks about batteries and things like that [Reference back cover in manual]. But for the purpose of reading it, I was kind of confused cause mentioned something about 'removing safety screws and open the battery compartment cover,' but like its uncovered. So, I am I supposed to flip it upside down and take it apart to replace the battery or what is it talking about? You can tell that some of this is a stock paragraph because it says do not mix old and new batteries but there's only one battery here so why would you do that? So I feel like it's lazy work on their part to slap on an all-encompassing battery warning.

(11:30) Examiner: Okay so the last part is I have a few questions during the assembly process I noticed that there's a little bit of confusion on step number 9 because I think it was the first time through you were trying to put the leg had a couple pieces and maybe you're either put all of these on at the same time [Reference Step 9 in manual] or maybe you had this left leg and was trying to put on the right leg?

Participant: I think I have the right leg at first and I got myself confused. But like, that peg on the top with the knobs on the side [Reference Step 9 in manual] that goes on the top part, I didn't realize that once you put it on it would swivel around because I was thinking it would hold him place. So the angle that I have to put this on for the others to fit on doesn't match the pegs on the other side, it doesn't fit. So once I realized I can put it on and it move the leg, then it made sense.

(12:40) Examiner: Step 12 there's a little confusion with: you did step 12 but you didn't know to repeat step 8 and you didn't know to go back to a so you moved on but then you're like 'wait a minute I have to go back.' 
Participant: That was the part where we were talking about instead of having that little picture of the spider put together [Reference Step 8 in manual] which you're not even at that point yet and having 'x2,' I would say like here is what this leg looks like assembled, do that ' $\mathrm{x} 4$.' And then over here say 'x2' with the whole body [Reference Step 10 in manual]. Because i'm a very literal person maybe somebody else would assume, 'oh, I have to do it again so lets do it now' but I was like, 'tell me to do it twice so I will do it twice.'

(13:45) Examiner: On step 14 you mentioned before the purpose of this piece. Were you also having trouble seeing it and where it went [Reference Step 14 in manual]?

Participant: I think it was like cause it said stick it down in there but some of these pieces throughout once you would push on it some then it would kind of slide in but it wasn't an easy click [Reference Step 14 in manual] so I was just thinking, 'am I going to break it when I push it in or do I need to put it in a different way?' And I didn't know what the piece was so I was wondering if I break it? And I think parts to in general when you have to cut the plastic pieces off sometimes the plastic pieces aren't quite rounded perfectly.

Examiner: So what did you end up doing did you just you just went for it and push the peace in there?

Participant: Yeah I think one side started to give and I was like, I'm going to assume that the other side is going to give by push hard enough [Referenced A2 gear assembly piece].

(15:00) Examiner: So how about the battery how did that work when you assembled it?

Participant: That was fun for the most part except the negative terminal was like squished when I put the battery and it got stuck and so wasn't touching this side so I kind of got scared that it put it in wrong but then I realized that it just need to be released on the one side [Reference spider toy battery terminals] and once I did that then it touched the other side. But that's like a typical battery so if you put batteries in before you would know how to do that. 
GROUP 1 INTERVIEW \#3 (VERBAL RESPONCES)

(00:05) Examiner: What did you think about the experience?

Participant: I'm happy I got it put together. But it's not something I would do in my spare time.

(00:20) Examiner: How would you say that the instruction manual help or didn't help your experience?

Participant: It helped because I wouldn't have known what to do without it.

(00:50) Examiner: How satisfied or dissatisfied were you with the instruction manual and why?

Participant: I was moderately satisfied if that's a good answer, because I didn't think that it was hard. But I definitely needed the instruction manual, but it wasn't the easiest thing in the world. Does that make sense?

(01:50) Examiner: Were there any aspects of the manual that were particularly useful?

Participant: I guess the pictures. Obviously that's all it is. The arrows. The labels are kind of pointless though, because there's no labels in the actual toy [Reference spider toy]. So A1, B3, that's not on the toy. The footnotes of stuff was good [Reference Step 7 in manual]. I overlooked them a couple of times but they were good.

(03:05) Examiner: Why do you think your overlooked them?

Participant: I never look at instructions so that just might be a me thing.

(03:25) Examiner: Were there any aspects of the manual that was particularly enjoyable?

Participant: Not really, there's not one part that particularly stood out.

(03:53) Examiner: Was there anything that was unenjoyable?

Participant: No.

(04:14) Examiner: Anything that made the instruction manual particularly enjoyable?

Participant: This isn't helpful [Reference materials page in manual], I don't know if it was helpful to other people but it wasn't helpful for me it more confused me than helped me.

Examiner: So, one thing I will say about that is that these pieces came like that but they popped out like that so I would have had to have bought ten toys for each person so they could pop it all out.

Participant: Well that just looks overwhelming to me. 
(05:30) Examiner: If you could rank the top three best steps for me and explain why?

Participant: Step 13. That's the end and that's when everything comes together and that's when you get to see your work. Step 6 . Because that's when you get to see all the little gears together. Probably step 3. I don't know, I kind of like dealing with the wire stuff.

(06:57) Examiner: Why do you like working with the wires?

Participant: It made me feel smarter.

(07:18) Examiner: Okay let's try ranking the top 3 worst steps.

Participant: 8. The pictures that it uses looks kind of confusing and overwhelming. The whole thing looks confusing [Reference Step 8 in manual]. At first glance at all looks overwhelming like, 'oh no, there's a lot to do.' But when you break it down there's not a whole lot because it's a repetitive step, but it makes it look like there's a lot more. Does that make sense? 7. Because the gears kept falling off. I didn't know if they were supposed to stick or not. And, 9 I guess. Because I got confused with the legs and how they were supposed to go on there.

(09:47) Examiner: On step number 6, I noticed that you had a little bit of confusion with the little tool [Reference Step 6 in manual]. I think because a knob was highlighted you thought I was an extra part?

Participant: Yes, I thought it was an extra part.

(10:20) Examiner: Why did you think I was in an extra part?

Participant: Because it was highlighted.

(10:29) Examiner: Do you have an idea of an improvement that could make it better?

Participant: I don't think it need to be highlighted at all(part A2, gear assembly tool). Because it doesn't even really look like the part. I don't know, I just got confused and it didn't look like anything like on the actual toy.

\section{(10:53) Examiner: Was an issue with color?}

Participant: Yes, there's an issue and color on the whole thing. There's some parts that are highlighted and some parts that aren't. Like at first you think that it's the difference between the gray parts and the brown parts because there's a bunch of this at the beginning but it's not.

(11:15) Examiner: Would you have preferred that the parts were the same color in the instruction manual as in the toy? At least different shading between light and dark?

Participant: Yes probably. 
(11:20) Examiner: Do you think it would help with this step [Reference Step 8 in manual] when it's colored in multiple pieces?

Participant: Yes, but I didn't pay attention to the coloring.

(12:00) Examiner: So on step number 8, it looks like you didn't know what the 'x2' was referring to right here [Reference Step 8 in manual]?

Participant: Yes, it said repeat on opposite sides and it shows two right here. So I'm thinking just only two, but it says times 2 [Reference Step 8 in manual]. So im thinking it only means 2. It's not really specifying to do it four times.

(12:40) Examiner: Would 'x2' have been better to be ' $x 4$ '?

Participant: Yes.

(12:50) Examiner: So on step 8 the first time around you only made three legs and then you moved on and then you had to come back and make a fourth leg?

Participant: Yeah, it's because I didn't know if I did it right and I didn't know if I was supposed to go ahead and assemble all the legs and that's when I saw the 'x2.' And maybe I assembled way too many for now.

(13:34) Examiner: Let's take a look at question 9. So on 9, the first time around you put the leg on wrong?

Participant: I put the leg on wrong because this was underneath [Reference Step 9 in manual] because at first I didn't see this part when I went over top and when you're snapping it on it feels like this part is going to break so I had to put underneath. So that's why I was confused.

(14:20) Examiner: So, let's look at Step 11. Step 11 is like step 9 and I noticed that on 11 you were assembling it upside down, as in this piece was assemble up here so it would swivel[Reference Step 11 in manual], but instead you were assembling it down here so it was locked in. Do you remember that at all?

Participant: Not really.

(15:00) Examiner: Another part with that was I noticed that you didn't really notice this step [Reference Step 11 in manual] too much, you referenced just referenced this one [Reference Step 9 in manual] instead?

Participant: Yes, I feel like this whole page is the same. I feel like these two steps, 9 and 10, are the same as 11 and 12 so I kept on referencing the first two steps. Because I didn't really feel like I needed the second. 
(15:30) Examiner: Finally, let's look at number 13. I noticed that you were a little confused on whether you should cut the tubes and put on the feet first or if you should assemble the spider first?

Participant: Yes, it doesn't say that this is extra [Reference extra step page in manual]. It just kind of goes into it so it was confusing at first.

(16:00) Examiner: So how could you have him prove that?

Participant: Well there could have been a header where it could show you that these are steps that you can do and that the steps are optional. Or you could put it at the end. So, you could switch these two pages.

(16:48) Examiner: So on Step 13, you put on the whole unit wrong you had to take them off and switch them around?

Participant: Yeah, cause these were too short [Reference the spider leg assemblies on the toy] for these ones so I had to take them off switch them and make sure that they were the same.

(17:05) Examiner: So how did you determine that you put them on wrong?

Participant: So, I saw that they were different lengths but here it says that they should be identical.

(17:20) Examiner: I wonder if identical is the right word because these are almost mirrored right? But you got it when it said identical. You got it? Did you reference the image at all[Reference Step 13 picture in box in manual]?

Participant: No, that's really confusing.

(17:55) Examiner: But the description was enough for you that it needed to be identical and you're able to figure it out?

Participant: Yeah.

(18:15) Examiner: Last thing is mentioning back to number 9. One of the things you said was, “That part sucks I feel like I'll break it?”

Participant: [Reference Step 9 in manual] So, when you snap this piece on to this piece it feels like it's going to snap it because this piece is sticking out on the plastic. Like, when you're pushing it on, the plastic is pushing on the plastic right here so it feels like it's going to break it. I didn't see any other way to do it. So, I kept pushing but it felt like I was going to break it. 
GROUP 1 INTERVIEW \#4 (VERBAL RESPONCES)

(00:15) Examiner: Question number 1 what did you think about the experience?

Participant: I thought it was not something that I'm used to, so a little difficult and a trick my mind a little bit. Thought-provoking we should say.

(00:40) Examiner: How did the instruction manual help this not 'used to' 'mind tricking process?'

Participant: I feel like it would be easier if they had captions for the pictures to help explain what to do. Sometimes the black and white line drawings are confusing. Just seeing what's supposed to be going where and when they flip it around you can't really tell when it's the opposite side when it's the black and white drawings.

(01:40) Examiner: How satisfied or dissatisfied with you where you with the instruction manual?

Participant: I was moderately dissatisfied. Because there are no words and it was confusing.

(02:25) Examiner: Were there any aspects of the manual that are particularly useful?

Participant: Something that was particularly useful was enlarging things like that[Reference Step 4 in manual].

(02:50) Examiner: Is there another place where there's call-outs might have been particularly useful?

Participant: I don't know. I don't think so.

Participant: These arrows were useful. Having this an arrow going from this hole to that hole was useful.

(03:36) Examiner: How about things that were unuseful?

Participant: Where you had to do legs on one side and it wasn't clear that you had to do the legs on the other side [Reference Step 11 in manual]. I don't really find whole pictures like this useful because there's so much going on that it doesn't makes sense [Reference Step 14 in manual].

(05:20) Examiner: How about aspects of the manual that were particularly enjoyable, something that was fun to do?

Participant: The first steps were enjoyable because before they got too complicated. Because they were easier. Like, put one piece on one piece[Reference Step 2 in manual]. Turning it on at the end. 
(06:26) Examiner: How about things that were unenjoyable?

Participant: The tedious things like attaching the legs to the right places and making sure that they're in the right position to attach to the right places (were unenjoyable).

(07:10) Examiner: Were there steps where maybe it was hard to understand what to do because you didn't know what the pieces did?

Participant: This one [Reference Step 7 in manual] the A2 piece was kind of confusing and I didn't understand what is was or know to take the A1 piece and put it on top. The A2 was confusing to me because it didn't make sense that it was just used to put the gears in.

(07:50) Examiner: What if on step 6, this A2 wasn't even here? What if it said gear tool or something like that? Do you think it would have helped?

Participant: Yes, definitely.

(08:35) Examiner: So, if you could rank the top three best steps in the manual what would they be?

Participant: Even though this was kind of confusing [Reference Step 8 in manual], I think it was a good one because it shows every little thing that needs to go exactly where with the arrows. So, I thought that was good. And it shows how to do it for both legs. Step 13 was pretty good because it showed you what you're doing in the whole step if that makes sense. It says you need to put these two legs onto the body with that picture [Reference Step 13 in manual].

Examiner: So that kind of help? You seeing what you were doing, but also you got ultimately that that was putting together the spider?

Participant: Yes.

(10:45) Examiner: So, what if for putting together let's say the leg assembly [Reference Step 8 in manual]there's all these different things that you're doing. So what if there is a picture of the spider and this whole section was highlighted so all these steps would help me build this piece?

Participant: Or if each leg was a different color and they colored them all with the pieces that they needed to be [Reference Step 8 in manual and picture on box].

Examiner: So, the first leg would be blue in the second leg would be yellow and then the leg assemblies would show where each colored leg needed to go [Reference Step 8 in manual].

Participant: Yes, I think it would have understood it more if it showed me where the blue leg was supposed to go and the yellow was supposed to go especially when you flip the body piece[Reference Step 8 in manual].

Participant: And step 4, they had the enlarged pictures that I said that I like. 
(12:20) Examiner: So what were the three worst steps?

Participant: Step 11. It's still not clear to me that that's the other side of the leg. And they kind of went from 9 and 10, putting the legs on the one side, and in Step 11 it only shows you how to put one leg on there. And then, in Step 12 it's done. Step 9 shows you how to put the first leg on and then both are magically on in step 10. In Step 11, one leg is being put on, but in step 12 they are magically on.

(13:55) Examiner: So you would have wanted to see each leg be on this be assembled? So what if step 9 showed both legs being assembled?

Participant: Yes. And [Reference Step 10 in manual] would be its own step still.

(14:45) Examiner: During the assembly process I noticed that you had some confusion in Step number 7? Confusion on the verbiage "assemble the second set of gears”?

Participant: Yes, it [the verbiage] was confusing because before, it was not clear but now I see that it's clear that there's two sets of them. That's another case it could be color coded.

Examiner: So now I realize that step 7, there is a picture with words, picture with words, picture without words, and then words with the tiny 'x2.' [Reference Step 7 in manual].

(15:50) Examiner: What ultimately happened was on step 7, there's an incorrect way of putting it together because you put part on the opposite direction. For some people it was enough to show that there's a highlighted pin but it wasn't for you?

Participant: Yes, I didn't notice that until the end. When this peg [Reference Step 7 in manual] was on the outside these things couldn't go into it [Reference toy spider].

(16:42) Examiner: Let's talk about number 8. On number 8, I'm not sure if you remember this or not, I wrote “did not follow through on direction of ' $\mathrm{x} 2$.'

Participant: Yes, I didn't even notice that until you pointed it out [direction dictating 'x2’].

(17:15) Examiner: Could you tell me what you were thinking? Or, I think I remember you put together this side and decide and then you moved on [Reference Step 8 in manual]. And then you move to step 9?

Participant: Yes, by looking at this picture I thought that there was only two sides to build.

(17:55) Examiner: On step 11, the first time through you went you skip steps 11 and 12 and then you flip the page?

Participant: Yes, these were the two other legs that I didn't know to make [Reference Step 11,12 in manual]. 
(18:55) Examiner: Can you recall what you were thinking during that time? You did step 9, you did step 10, then?

Participant: I was thinking that this was just the other[Reference Step 9, 10 in manual then the right side of the toy] I thought that the first two steps was the first set of legs and the second set of steps was the second set of legs [Reference Step 11,12 in manual then the left side of the toy].

(19:25) Examiner: One more question on 12. After finishing one of these you moved on?

Participant: Yes. 
GROUP 1 INTERVIEW \#5 (VERBAL RESPONCES)

(00:28) Examiner: Question number one what did you think about the instruction manual and your experience?

Participant: I would not do it again. I would not buy this for my child. In terms of this thing, it was very confusing. It says red wire and appoints the things, but there is two red wires and it doesn't tell me exactly what it needs to. It's very vague. And, I can see a kid getting frustrated and not liking science or wanting to do this because of it.

(01:05) Examiner: How satisfied or dissatisfied where you at the instruction manual?

Participant: Pretty dissatisfied, especially because I didn't have it right by the end. Even the box doesn't make sense because it says skill level and a bunch of colors, and I don't even know what that means. And, there's extra pieces and now it's kind of frustrating.

(01:55) Examiner: How about as a whole? What would you say about the instruction manual packet?

Participant: It was poor. I think Ikea does better. The directions were vague. They did not give me enough information to complete the tasks that were needed. They did not point to where I needed things to go. For instance, the wire got stuck because it didn't show me exactly where the wire needed to go. I saw this [Reference Step 6 in manual] but didn't understand what arrange the gear meant. Now that I see what the result is, now I understand it.

(02:50) Examiner: You didn't understand why each step was? So, for example, this says[Reference Step 6 in manual] place this gear here but I didn't know why? This might have contributed to why I noticed that you did one side incorrectly on step 6 ?

Participant: But the first time I had to go back and fix that, I forgot to go back and fix the second side.

(03:20) Examiner: And then the second time you pulled it apart and then just did the gears in which meant that you had to go back a third time and then adjust the gears again? So 'why?' is an important question you would say?

Participant: They also didn't differentiate between the short and a long [pegs]. If they were different colors and it showed on this, that would have made my life easier. Or, if the top of one of them were a triangle that would help. It says that there should be a letter on it, but I didn't even notice that there was a little ' $\mathrm{B}$ ' on the piece.

(4:10) Examiner: So, is there any aspects of the manual that were particularly useful?

Participant: I thought that I had done this correctly on [Reference Step 4 in manual] with the wiring, but then, it still wasn't right. So, I would have said that it was okay, but I still somehow mess it up so I don't really know. Like this whole first page wasn't too bad. I was able to stick 
with it for the first page. I do think if there was a wire cutter involved I would have given up: especially on my own.

(05:00) Examiner: So how about things that were particularly unuseful?

Participant: They should have made the ends fit for one side so I couldn't mess it up that badly. especially for a kid ages 8 and up, if I am with how many Masters degrees can't do this, how can an 8 year old child to do this? Especially the backwards leg, they don't really differentiate different sides very well. This picture is teeny tiny [Reference Step 8 in manual].

Examiner: Show mirroring?

Participant: Yes.

(05:55) Examiner: And what was teeny tiny?

Participant: The pictures showing how the mirroring was supposed to be.

(06:20) Examiner: Enjoyable parts of instruction manual?

Participant: I enjoyed watching it walk. That was probably the only enjoyable thing. But there is no congratulations at the end of the manual so I didn't get to enjoy it with the manual. There is no, “You win!” "You're done!” It was just how to operate and not electrocute yourself.

Participant: And this part [Reference extra step page in manual] really made me angry. I was three-fourths of the way done and then I came to this page which made me very angry. Because it's not a part of my outcome goal. They should have said, "for extra fun you can add tubes to make it crawl up things," not in the middle of the manual. I couldn't again figure out the "why?" there.

(07:39) Examiner: Please rank the top three best steps and why?

Participant: 14 was not bad. You know putting that little bottom part in. Because it shows the nice arrows going down into the slots. And that was the only step that was being shown. 2, 1 , and 2 were very easy. But, they are very easy things to show in comparison to some of the others. There are nice arrows showing you the directions. And the wire placements were nice.

(08:30) Examiner: So, I'm just curious for step 8. What do you think about those arrows?

Participant: There are terrible.

(08:40) Examiner: What makes them different? Lets say, 8, 9, and 10?

Participant: Those arrows [in step 8] did not compute in my mind so I can't '3D think' about it. If it showed the arrows going on an inch away then it would have [Reference Step 9 in manual]

... These arrows just made more sense to me[Reference Step 10 in manual]. These arrors are just 
coming from too far away. If there was like a 2 inch arrow going to put it on, that would make more sense to me [Reference Step 9 in manual]. I had actually looked at this to know what was going on [Reference Step 10 in manual] with seeing how this attached. Not, cause this doesn't... [Reference Step 9 in manual].

(09:55) Examiner: So, if you were to assemble the legs onto the body a combination of Step 8 and 9 that would have helped you?

Participant: Yes, I always do better if I think about the big picture if I add pieces to the big pictures instead of making small parts and then figuring out how the small parts go onto the big parts. So if I could do four of the same thing and then add longer parts it would have been easier.

Participant: This part showed me what I did wrong [Reference Step 10 in manual]. If it would have showed me this from the beginning, it probably would have helped me [Reference Step 6 in manual].

(11:20) Examiner: On step number six there should be some kind of explanation?

Participant: Yes, probably.

Participant: I didn't even look at this part [Reference Step 6 in manual]. I just assume that all four holes are the same. And I didn't understand what this was [Reference A2 gear assembly tool] I mean, I used it but then I started doing it without it.

(12:05) Examiner: Would it have helped if you had known that that piece was the "gear assembly tool?"

Participant: Yes. And also if it made it so the gears only fit on the way they were supposed to. But that's a design thing, not really what you need.

(12:45) Examiner: Let's rank the top 3 worst steps.

Participant: I really hated the legs. So you can just put one of the legs I guess. I didn't really understand that the legs had to face out. 8, 9, 11.

Examiner: So, at this point is there anything else you would like to say about the instruction manual or your experience?

Participant: No.

(13:50) Examiner: Did you have any frustration with 7?

Participant: No, because I didn't realize it was wrong. It's just "note that direction.” [Reference Step 7 in manual] I should have looked at it closer. I didn't know what "note the direction" meant. I see that it tells me to note the direction of holes, but it wasn't showing me specifically 
how the holes were supposed to be directed. It would have helped if it said to note the male versus female holes.

(14:20) Examiner: I noticed that you assembled the first one wrong and then you assemble the second one right, and then when you went on and you found out that there was an issue. Then, you assembled both of them. So what do you think about this highlighting[Reference Step 7 in manual]? Would there have been a way to better understand how to lay the body piece?

Participant: No, it shows it right here. I just missed it. Maybe if there's a way to more visually show the orientation [Reference Step 7 in manual]. Or possibly, made it a completely different step. I think I started looking at their legs and getting flustered.

Participant: I would make the legs on a different page for all the sections of steps together in a single page. All of this is on this side. And it would show what it looked like when I was done. And then you can move on to the next page and allow people to take a breath, before they move on to the real trouble.

(17:50) Examiner: So, you're saying it would be like: if it was on one page would be nice because everything you would have to do for that section would be with one page. So, you would like if the body steps were on one page and then here's what the whole thing should look like at the end. Here's what the body looks like before you're ready to move on to next page. And the same with the legs?

Participant: Yes.

(18:30) Examiner: Number 8 assembly image didn't make sense? So that guy right here [Reference Step 8 in manual].

Participant: Yes, I really didn't understand it because it's so little and there are knobs everywhere and I can't tell what the knobs are. And they even have letters on them, really tiny letters. It was just not helpful. It didn't help at all. And then "repeat on opposite side” of the legs: I was just a little confused too.

(19:25) Examiner: I noticed when you looked at step 9 you look at 10, 11, 12, and then you went back to step 9 ?

Participant: Yes, I didn't know what step number 9 was telling me, and again those are the arrow things, but when I look at step 10 and related it to the bigger part, that's when I figured out what was going on.

(20:00) Examiner: And after you assembled one of these units [Reference Step 12 in manual], you went on to the next page instead of assembling a second unit?

Participant: Yes, it never told me to assemble the second unit. It should show me two units and say that you're ready to move to the next page. It wants two units already. 
(20:45) Examiner: We didn't know what peg to use when it was time to use the pegs? So, is there's a better way to differentiate them?

Participant: Yes, it had labels on them but I didn't realize they said it and be on them. It was difficult to see. If it was colored or sized then that would help.

(21:15) Examiner: You had mentioned earlier that maybe the modifications page should be at the end and you said that maybe it should say, "for extra fun modifications are available?” Would you rather have the short side-long side step be at the beginning or just at the end?

Participant: No, it should be at the end. There's enough fun putting the modifications at the end and for extra fun you can modify it. The tube through me off not being the same color through. 
APPENDIX G: Themes Analysis Original Manual 


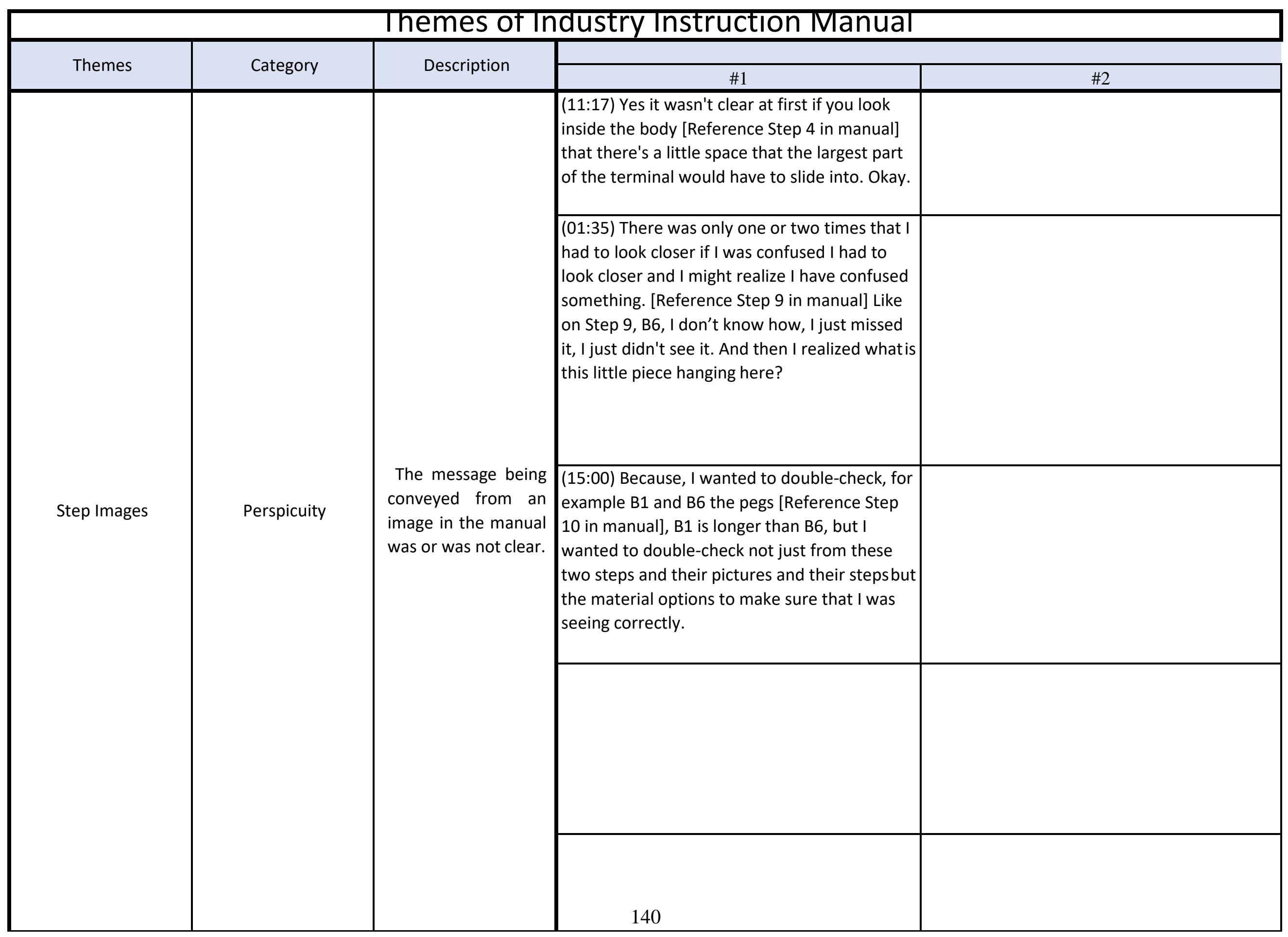




\section{Themes of Industry Instruction Mlanual}

\begin{tabular}{|c|c|c|}
\hline \multicolumn{3}{|c|}{ Supporting Data } \\
\hline$\# 3$ & $\# 4$ & $\# 5$ \\
\hline $\begin{array}{l}(01: 50) \text { I guess the pictures. Obviously that's all it } \\
\text { is. The arrows. }\end{array}$ & $\begin{array}{l}\text { (02:50) These arrows were useful. Having this an } \\
\text { arrow going from this hole to that hole was useful. }\end{array}$ & $\begin{array}{l}\text { (01:55) They did not point to where I needed things } \\
\text { to go. For instance, the wire got stuck because it } \\
\text { didn't show me exactly where the wire needed to } \\
\text { go. }\end{array}$ \\
\hline $\begin{array}{l}(07: 18) 9 \text { I guess. Because I got confused with the } \\
\text { legs and how they were supposed to go on there. }\end{array}$ & $\begin{array}{l}(03: 36) \text { I don't really find whole pictures like this } \\
\text { useful because there's so much going on that it } \\
\text { doesn't makes sense [Reference Step } 14 \text { in } \\
\text { manual]. }\end{array}$ & $\begin{array}{l}\text { (07:39) } 14 \text { was not bad. You know putting that little } \\
\text { bottom part in. Because it shows the nice arrows } \\
\text { going down into the slots. And that was the only } \\
\text { step that was being shown. } 2,1 \text {, and } 2 \text { were very } \\
\text { easy. But, they are very easy things to show in } \\
\text { comparison to some of the others. There are nice } \\
\text { arrows showing you the directions. And the wire } \\
\text { placements were nice. }\end{array}$ \\
\hline \multirow[t]{3}{*}{$\begin{array}{l}\text { (10:29) I don't think it need to be highlighted at } \\
\text { all(part A2, gear assembly tool). Because it doesn't } \\
\text { even really look like the part. I don't know, I just } \\
\text { got confused and it didn't look like anything like on } \\
\text { the actual toy. }\end{array}$} & $\begin{array}{l}\text { (08:35) Even though this was kind of confusing } \\
\text { [Reference Step } 8 \text { in manual], I think it was a good } \\
\text { one because it shows every little thing that needs } \\
\text { to go exactly where with the arrows. So, I thought } \\
\text { that was good. }\end{array}$ & $\begin{array}{l}\text { (08:40) Those arrows [in step 8] did not compute in } \\
\text { my mind so I can't ' } 3 D \text { think' about it. If it showed } \\
\text { the arrows going on an inch away then it would } \\
\text { have [Reference Step } 9 \text { in manual] ... These arrows } \\
\text { just made more sense to me[Reference Step } 10 \text { in } \\
\text { manual]. These arrors are just coming from too far } \\
\text { away. }\end{array}$ \\
\hline & $\begin{array}{l}\text { (15:50) Yes, I didn't notice that until the end. When } \\
\text { this peg [Reference Step } 7 \text { in manual] was on the } \\
\text { outside these things couldn't go into it [Reference } \\
\text { toy spider]. }\end{array}$ & $\begin{array}{l}\text { (14:20) No, it shows it right here. I just missed it. } \\
\text { Maybe if there's a way to more visually show the } \\
\text { orientation [Reference Step } 7 \text { in manual]. Or } \\
\text { possibly, made it a completely different step. I } \\
\text { think I started looking at their legs and getting } \\
\text { flustered. }\end{array}$ \\
\hline & & $\begin{array}{l}\text { (12:45) Participant: I really hated the legs. So you } \\
\text { can just put one of the legs I guess. I didn't really } \\
\text { understand that the legs had to face out. } 8,9,11 \text {. }\end{array}$ \\
\hline
\end{tabular}




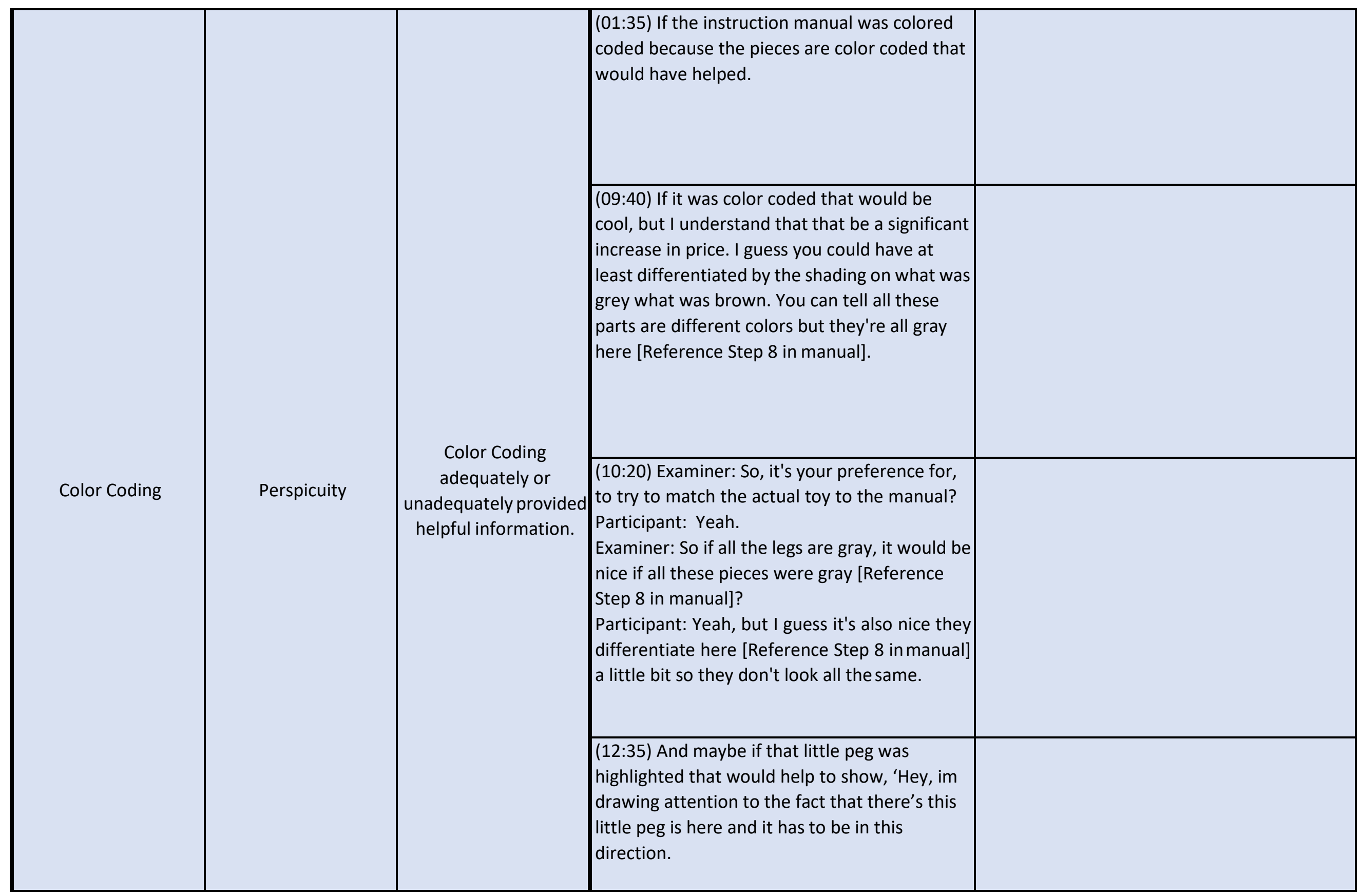




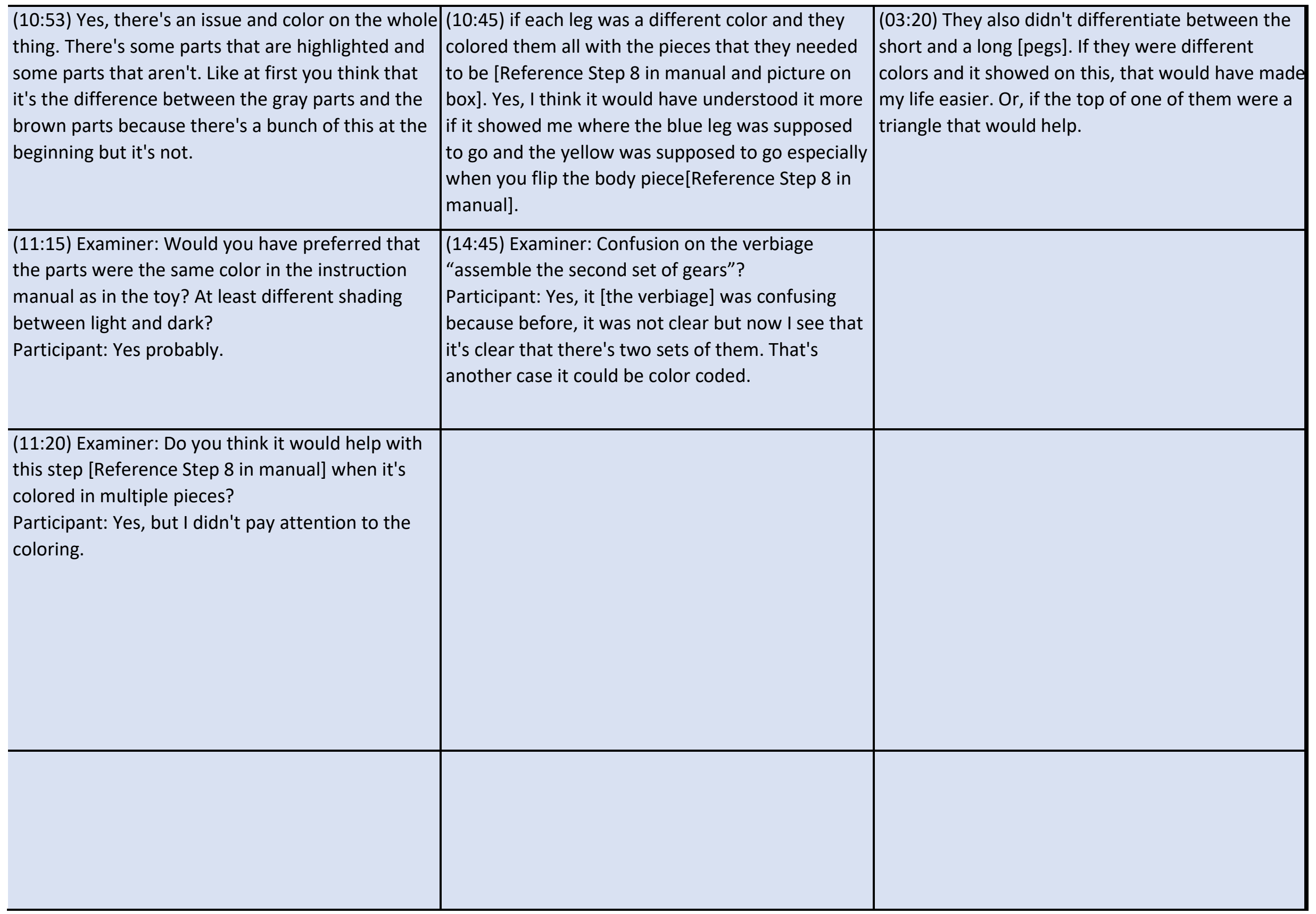




\begin{tabular}{|c|c|c|c|c|}
\hline \multirow[t]{2}{*}{ Task Completion } & Stimulation & \multirow[t]{2}{*}{$\begin{array}{c}\text { Sense of } \\
\text { progress/completition } \\
\text { or lack thereof affects } \\
\text { motivation and } \\
\text { interest. }\end{array}$} & $\begin{array}{l}\text { (00:41) I'm saying it was helpful and satisfying } \\
\text { to how to finish but it was'nt enjoyable. But } \\
\text { that's just my personality I don't think it's } \\
\text { because an instruction manual. } \\
\text { (5:15) Step } 13, \text { getting to actually put the two } \\
\text { body parts with the with the legs attached on } \\
\text { to the center piece that holds the battery. } \\
\text { There's that sense of 'yes! I'm finished.' }\end{array}$ & $\begin{array}{l}(06: 40) \text { I would say the whole leg assembly } \\
\text { part because it was more engaging, multiple } \\
\text { steps, and seeing it really come to life } \\
\text { [Reference Step } 8-12 \text { in manual]. }\end{array}$ \\
\hline & Novelty & & & \\
\hline \multirow[t]{2}{*}{ Percieved Uselessness } & \multirow[t]{2}{*}{ Efficiency } & $\begin{array}{c}\text { Information provided } \\
\text { caused unnecessary } \\
\text { effort or did not }\end{array}$ & $\begin{array}{l}(03: 50) \text { I think you need this, but maybe you } \\
\text { can combine them with another step, because } \\
\text { there's are four or five things to focus on in } \\
\text { step } 1 \text { and then in step } 2 \text { there is just one little } \\
\text { click and I'm like what? The step should be } \\
\text { more balanced I guess, not similar amount of } \\
\text { work for each step which made it a bit } \\
\text { confusing. }\end{array}$ & $\begin{array}{l}(05: 03) \text { I'd say the part where you put the } \\
\text { gears on the little pegs [Reference Step } 6 \text { in } \\
\text { manual]. I thought that was part of the } \\
\text { machine, but then I was like but when I was } \\
\text { like oh you're just using it took place it in these } \\
\text { holes that are clearly yeah. It's not hard to } \\
\text { figure out how they go in there. Maybe I } \\
\text { shouldn't speak for everybody, but for me it's } \\
\text { pretty clear how they would have sat inside } \\
\text { the casing. }\end{array}$ \\
\hline & & $\begin{array}{l}\text { provide additional } \\
\text { information. }\end{array}$ & $\begin{array}{l}(08: 59) 2,5 \text {, and } 14 \text {. They were the most } \\
\text { boring. }\end{array}$ & $\begin{array}{l}\text { (05:03) And then I think like parts like after } \\
\text { that with attaching the legs some parts are } \\
\text { necessary to repeat [Reference Step } 9 \text { in } \\
\text { manual] but some are like putting the pegs } \\
\text { inside to keep them secure, I feel like you } \\
\text { don't need a whole another step to show you } \\
\text { what that looks like [Reference Step } 12 \text { in } \\
\text { manual] you could have been like 'repeat step } \\
10 \text { here.' }\end{array}$ \\
\hline
\end{tabular}




\begin{tabular}{|c|c|c|}
\hline $\begin{array}{l}(00: 05) \text { I'm happy I got it put together. But it's not } \\
\text { something I would do in my spare time. }\end{array}$ & $(05: 20)$ Turning it on at the end. & $\begin{array}{l}\text { (01:05) Pretty dissatisfied, especially because I } \\
\text { didn't have it right by the end. }\end{array}$ \\
\hline $\begin{array}{l}(05: 30) \text { Step } 13 \text { [was one of my top three best]. } \\
\text { That's the end and that's when everything comes } \\
\text { together and that's when you get to see your work. }\end{array}$ & & $\begin{array}{l}(06: 20) \text { But there is no congratulations at the end } \\
\text { of the manual so I didn't get to enjoy it with the } \\
\text { manual. There is no, "You win!" "You're done!" It } \\
\text { was just how to operate }\end{array}$ \\
\hline $\begin{array}{l}\text { (05:30) Step } 6 \text { [was one of my top three best]. } \\
\text { Because that's when you get to see all the little } \\
\text { gears together. }\end{array}$ & & $\begin{array}{l}(06: 20) \text { I enjoyed watching it walk. That was } \\
\text { probably the only enjoyable thing. }\end{array}$ \\
\hline $\begin{array}{l}(01: 50) \text { The labels are kind of pointless though, } \\
\text { because there's no labels in the actual toy } \\
\text { [Reference spider toy]. So A1, B3, that's not on the } \\
\text { toy. }\end{array}$ & & $\begin{array}{l}(11: 20) \text { I didn't even look at this part [Reference } \\
\text { Step } 6 \text { in manual]. I just assume that all four holes } \\
\text { are the same. }\end{array}$ \\
\hline $\begin{array}{l}(15: 00) \text { Yes, I feel like this whole page is the same. I } \\
\text { feel like these two steps, } 9 \text { and } 10 \text {, are the same as } \\
11 \text { and } 12 \text { so I kept on referencing the first two } \\
\text { steps. Because I didn't really feel like I needed the } \\
\text { second. }\end{array}$ & & $\begin{array}{l}\text { (11:20) And I didn't understand what this was } \\
\text { [Reference A2 gear assembly tool] I mean, I used it } \\
\text { but then I started doing it without it. }\end{array}$ \\
\hline
\end{tabular}




\begin{tabular}{|c|c|c|c|c|}
\hline & & & & $\begin{array}{l}\text { (05:57) } 10 \text { and } 12 \text { are literally just put a peg in } \\
\text { a hole to put it in place [Reference Step } 10,12 \\
\text { in manual]. I feel like once you do it once you } \\
\text { kinda know how the other side goes. }\end{array}$ \\
\hline & & & & $\begin{array}{l}\text { (08:45) Probably step } 6 \text {, for sure. That was my } \\
\text { least favorite because it was kind of an } \\
\text { unnecessary thing to do to make putting on } \\
\text { the gears easier but it was just extra work that } \\
\text { didn't need to happen. } \\
(08: 45) \text { Step } 12 \text { because of it being repetitive. }\end{array}$ \\
\hline Percieved Uselessness & Efficiency & $\begin{array}{l}\text { Information provided } \\
\text { caused unnecessary } \\
\text { effort or did not } \\
\text { provide additional } \\
\text { information. }\end{array}$ & & $\begin{array}{l}\text { (10:20) I never look at the back where it talks } \\
\text { about batteries and things like that [Reference } \\
\text { back cover in manual]. But for the purpose of } \\
\text { reading it, I was kind of confused cause } \\
\text { mentioned something about 'removing safety } \\
\text { screws and open the battery compartment } \\
\text { cover,' but like its uncovered. So, I am I } \\
\text { supposed to flip it upside down and take it } \\
\text { apart to replace the battery or what is it } \\
\text { talking about? You can tell that some of this is } \\
\text { a stock paragraph because it says do not mix } \\
\text { old and new batteries but there's only one } \\
\text { battery here so why would you do that? So I } \\
\text { feel like it's lazy work on their part to slap on } \\
\text { an all-encompassing battery warning. }\end{array}$ \\
\hline Confidence & $\begin{array}{l}\text { Stimulation and } \\
\text { Dependability }\end{array}$ & $\begin{array}{l}\text { Information did or did } \\
\text { not affirm users' ability } \\
\text { to complete required } \\
\text { tasks. }\end{array}$ & $\begin{array}{l}(00: 21) \text { It's not one of my strong suits. Having } \\
\text { to tinker with something small, or follow } \\
\text { specific directions and look at tiny pieces. It } \\
\text { kind of produces anxiety in me. }\end{array}$ & $\begin{array}{l}(00: 30) \text { It was overall kind of empowering } \\
\text { because I didn't think that highly of my ability } \\
\text { to put together a... an electronic anything, so } \\
\text { yeah. }\end{array}$ \\
\hline
\end{tabular}




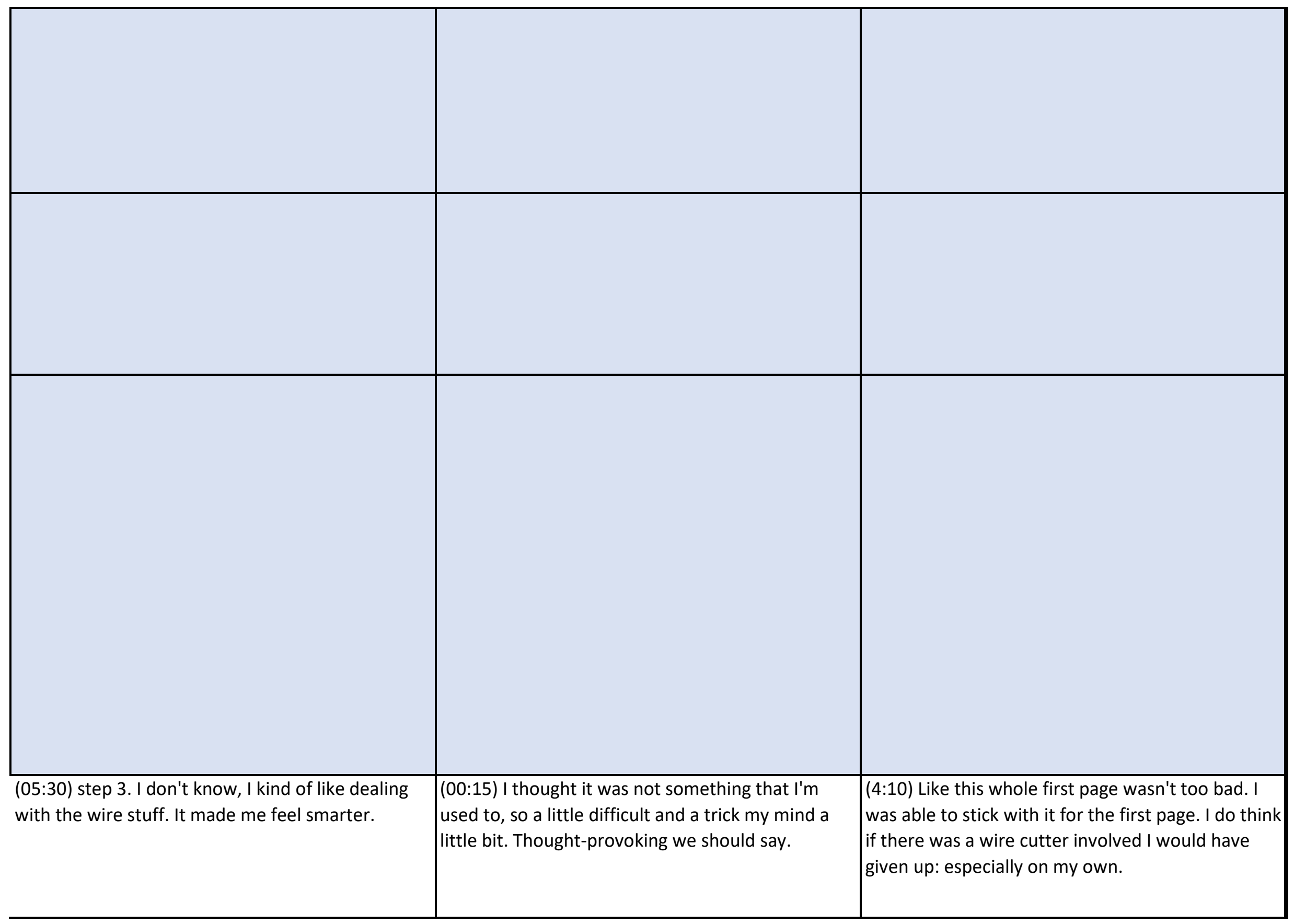




\begin{tabular}{|c|c|c|c|c|}
\hline \multirow{3}{*}{ Confidence } & Stimulation & \multirow{3}{*}{$\begin{array}{l}\text { Information did or did } \\
\text { not affirm users' ability } \\
\text { to complete required } \\
\text { tasks. }\end{array}$} & $\begin{array}{l}\text { (4:40) As soon as I figured out the leg, the leg } \\
\text { on the opposite side [Reference Step } 8 \text { in } \\
\text { manual] I knew that I had to make three more } \\
\text { pairs and that was kind of fun. Because I felt } \\
\text { like I knew what I was doing at that point so I } \\
\text { accelerated so that was kind of fun. }\end{array}$ & $\begin{array}{l}\text { (07:30) And step } 8 \text { and } 9 \text { because the legs } \\
\text { were, I mean they weren't, once you got the } \\
\text { hang of it they weren't complicated but the } \\
\text { first time through its a complicated process } \\
\text { because there are so many little parts that } \\
\text { goes into one leg, so that was helpful. }\end{array}$ \\
\hline & \multirow[t]{2}{*}{ Dependability } & & $\begin{array}{l}(05: 40) \text { I don't understand electricity very well, } \\
\text { so that part wasn't comfortable. }\end{array}$ & $\begin{array}{l}\text { (15:00) That was fun for the most part except } \\
\text { the negative terminal was like squished when I } \\
\text { put the battery and it got stuck and so wasn't } \\
\text { touching this side so I kind of got scared that it } \\
\text { put it in wrong but then I realized that it just } \\
\text { need to be released on the one side } \\
\text { [Reference spider toy battery terminals] and } \\
\text { once I did that then it touched the other side. } \\
\text { But that's like a typical battery so if you put } \\
\text { batteries in before you would know how to do } \\
\text { that. }\end{array}$ \\
\hline & & & $\begin{array}{l}\text { (00:41) If I can't tell, I would probably panic } \\
\text { and I would probably screw this up and I would } \\
\text { have to go find someone else. }\end{array}$ & \\
\hline $\begin{array}{l}\text { Deeper Knowledge of } \\
\text { Task }\end{array}$ & $\begin{array}{l}\text { Stimulation, Novelty, } \\
\text { Dependability }\end{array}$ & $\begin{array}{l}\text { Understanding of task } \\
\text { objective or purpose } \\
\text { did or did not provide } \\
\text { context or meet } \\
\text { expectations. }\end{array}$ & $\begin{array}{l}\text { (06:55) I didn't understand step } 6 \text {, putting } \\
\text { them on to the assembly piece, and I knew } \\
\text { they weren't moving so I thought how are } \\
\text { these gears going to move and then when you } \\
\text { put it into the body piece and snap on the } \\
\text { other side then it's so satisfying because then } \\
\text { you're like, 'yes! that's where the gears are } \\
\text { going to move now.' }\end{array}$ & $\begin{array}{l}(04: 00) \text { cause, like, I don't do anything } \\
\text { electrical, if it would have just said 'hooked the } \\
\text { wire to the terminal' I would have been like } \\
\text { 'what does that mean?' so that was helpful to } \\
\text { see it even to see how it was supposed to be } \\
\text { wound around the terminal and just like } \\
\text { putting the legs together [Reference Step } 8 \text { in } \\
\text { manual] }\end{array}$ \\
\hline
\end{tabular}




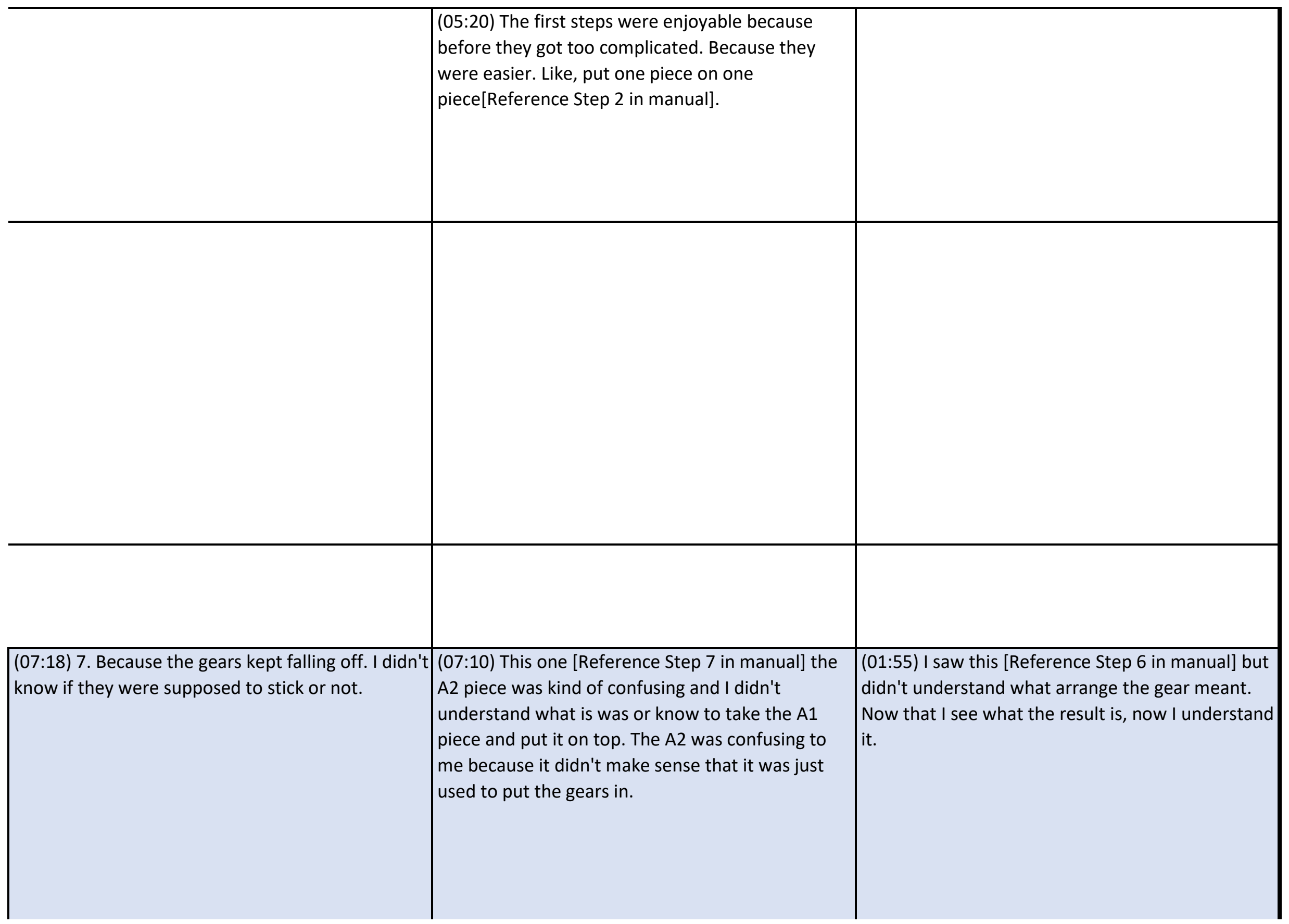




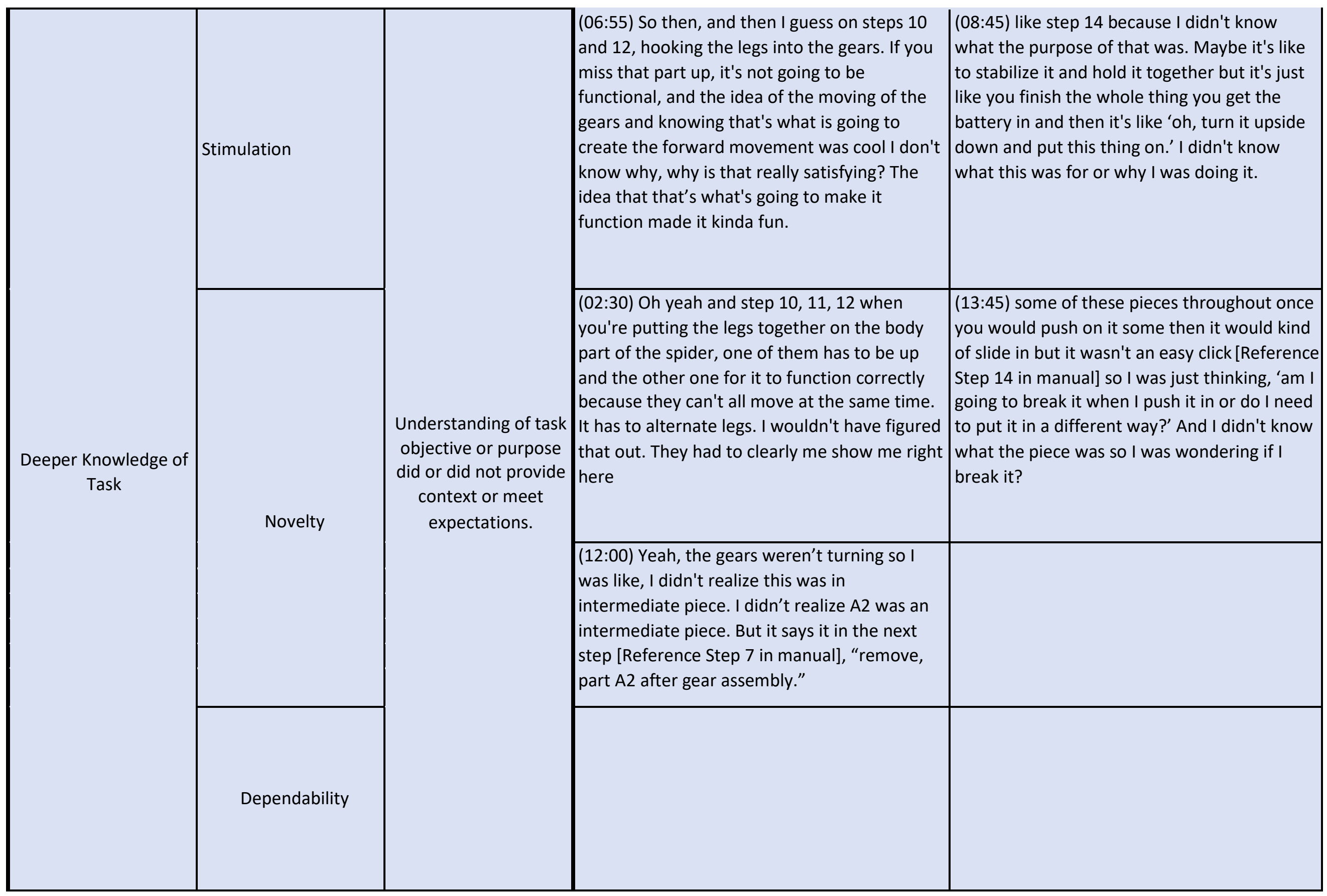




\begin{tabular}{|c|c|c|}
\hline 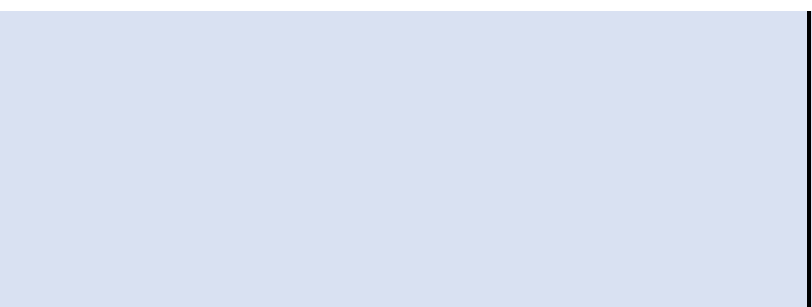 & $\begin{array}{l}(08: 35) \text { Step } 13 \text { was pretty good because it showed } \\
\text { you what you're doing in the whole step if that } \\
\text { makes sense. It says you need to put these two legs } \\
\text { onto the body with that picture [Reference Step } 13 \\
\text { in manual]. }\end{array}$ & $\begin{array}{l}(08: 40) \text { If there was like a } 2 \text { inch arrow going to put } \\
\text { it on, that would make more sense to me } \\
\text { [Reference Step } 9 \text { in manual]. I had actually looked } \\
\text { at this to know what was going on [Reference Step } \\
10 \text { in manual] with seeing how this attached. Not, } \\
\text { cause this doesn't... [Reference Step } 9 \text { in manual]. }\end{array}$ \\
\hline & & $\begin{array}{l}(09: 55) \text { Yes, I always do better if I think about the } \\
\text { big picture if I add pieces to the big pictures instead } \\
\text { of making small parts and then figuring out how } \\
\text { the small parts go onto the big parts. So if I could } \\
\text { do four of the same thing and then add longer } \\
\text { parts it would have been easier. }\end{array}$ \\
\hline & & $\begin{array}{l}\text { (09:55) This part showed me what I did wrong } \\
\text { [Reference Step } 10 \text { in manual]. If it would have } \\
\text { showed me this from the beginning, it probably } \\
\text { would have helped me [Reference Step } 6 \text { in } \\
\text { manual]. }\end{array}$ \\
\hline & & $\begin{array}{l}(11: 20) \text { And I didn't understand what this was } \\
\text { (19:25) Yes, I didn't know what step number } 9 \text { was } \\
\text { telling me, and again those are the arrow things, } \\
\text { but when I look at step } 10 \text { and related it to the } \\
\text { bigger part, that's when I figured out what was } \\
\text { going on. }\end{array}$ \\
\hline
\end{tabular}




\begin{tabular}{|c|c|c|c|c|}
\hline \multirow{2}{*}{$\begin{array}{l}\text { Percieved Correct } \\
\text { Implementation }\end{array}$} & \multirow[t]{2}{*}{ Dependability } & \multirow{2}{*}{$\begin{array}{l}\text { Belief that the user } \\
\text { performed task } \\
\text { correctly according to } \\
\text { the information } \\
\text { provided. }\end{array}$} & & $\begin{array}{l}\text { (13:45) some of these pieces throughout once } \\
\text { you would push on it some then it would kind } \\
\text { of slide in but it wasn't an easy click [Reference } \\
\text { Step } 14 \text { in manual] so I was just thinking, 'am I } \\
\text { going to break it when I push it in or do I need } \\
\text { to put it in a different way?' And I didn't know } \\
\text { what the piece was so I was wondering if I } \\
\text { break it? }\end{array}$ \\
\hline & & & & \\
\hline \multirow[t]{2}{*}{ Element, Image Size } & \multirow[t]{2}{*}{ Efficiency } & \multirow[t]{2}{*}{$\begin{array}{l}\text { Size of information did } \\
\text { or did not require } \\
\text { additional reivew to } \\
\text { understand its } \\
\text { message. }\end{array}$} & $\begin{array}{l}\text { (12:35) And maybe if that little peg was } \\
\text { highlighted that would help to show, 'Hey, im } \\
\text { drawing attention to the fact that there's this } \\
\text { little peg is here and it has to be in this } \\
\text { direction. }\end{array}$ & $\begin{array}{l}\text { (00:50) Like in step } 8 \text { cause it says[Reference } \\
\text { Step } 8 \text { in manual], has a whole picture up } \\
\text { there really tiny and it says "X2" but like I } \\
\text { wasn't really paying attention to that part. I } \\
\text { was paying more attention to what am I doing } \\
\text { with each of these parts (leg assembly) }\end{array}$ \\
\hline & & & & \\
\hline
\end{tabular}




\begin{tabular}{|l|l|l|}
\hline $\begin{array}{l}\text { (13:34) I put the leg on wrong because this was } \\
\text { underneath [Reference Step } 9 \text { in manual] because } \\
\text { at first I didn't see this part when I went over top } \\
\text { and when you're snapping it on it feels like this part } \\
\text { is going to break so I had to put underneath. So } \\
\text { that's why I was confused. }\end{array}$ & $\begin{array}{l}(4: 10) \text { I thought that I had done this correctly on } \\
\text { [Reference Step 4 in manual] with the wiring, but } \\
\text { then, it still wasn't right. So, I would have said that } \\
\text { it was okay, but I still somehow mess it up so I } \\
\text { don't really know. }\end{array}$ \\
\hline $\begin{array}{l}\text { (18:15) [Reference Step } 9 \text { in manual] So, when you } \\
\text { snap this piece on to this piece it feels like it's going } \\
\text { to snap it because this piece is sticking out on the } \\
\text { plastic. Like, when you're pushing it on, the plastic } \\
\text { is pushing on the plastic right here so it feels like } \\
\text { it's going to break it. I didn't see any other way to } \\
\text { do it. So, I kept pushing but it felt like I was going to } \\
\text { break it. }\end{array}$ & $\begin{array}{l}\text { (01:05) And, there's extra pieces and now it's kind } \\
\text { of frustrating. }\end{array}$ \\
\hline & $\begin{array}{l}\text { (02:25) Something that was particularly useful was } \\
\text { enlarging things like that[Reference Step 4 in } \\
\text { manual]. }\end{array}$ & $\begin{array}{l}\text { (03:20) They also didn't differentiate between the } \\
\text { short and a long [pegs]... It says that there should } \\
\text { be a letter on it, but I didn't even notice that there } \\
\text { was a little 'B' on the piece. }\end{array}$ \\
\hline
\end{tabular}




\begin{tabular}{|c|c|c|c|c|}
\hline Element, Image Size & Efficiency & $\begin{array}{l}\text { Size of information did } \\
\text { or did not require } \\
\text { additional reivew to } \\
\text { understand its } \\
\text { message. }\end{array}$ & & \\
\hline \multirow{3}{*}{$\begin{array}{l}\text { Document } \\
\text { Organization }\end{array}$} & \multirow{3}{*}{ Dependability } & \multirow{3}{*}{$\begin{array}{c}\text { Manual road map did } \\
\text { or did not provide easy } \\
\text { to-follow logical } \\
\text { progression. }\end{array}$} & $\begin{array}{l}\text { (13:20) No, I was just referencing, where we } \\
\text { going after? I realized I have another body } \\
\text { pieces but it doesn't say anywhere to repeat } \\
\text { the assembly again. So, I was looking to see, } \\
\text { maybe it says it later[Reference Step extra step } \\
\text { page in manual]. Am I allowed to go ahead and } \\
\text { complete this step? or is it like, strategically } \\
\text { coming later for a reason I don't know? }\end{array}$ & $\begin{array}{l}(12: 40) \text { That was the part where we were } \\
\text { talking about instead of having that little } \\
\text { picture of the spider put together [Reference } \\
\text { Step } 8 \text { in manual] which you're not even at } \\
\text { that point yet and having ' } x 2, \text {,' I would say like } \\
\text { here is what this leg looks like assembled, do } \\
\text { that ' } x 4 \text {.' And then over here say ' } x 2 \text { 'with the } \\
\text { whole body [Reference Step } 10 \text { in manual]. }\end{array}$ \\
\hline & & & & $\begin{array}{l}(00: 50) \text { Also, like with the same thing with } \\
\text { the... [Reference Step extra step page in } \\
\text { manual] I think the review part 'alternate } \\
\text { modification steps' so like they put this before } \\
\text { you're finished with the thing [Reference Step } \\
13 \text { in manual]. So I was confused because I was } \\
\text { wondering if I was supposed to put these on } \\
\text { first but then I realized it wasn't necessary so I } \\
\text { finished it and then I went back and then put } \\
\text { them on, yeah. }\end{array}$ \\
\hline & & & & $\begin{array}{l}(03: 05) \text { so I think it was pretty clear in how } \\
\text { that goes about. Yeah, the order of operations } \\
\text { I guess. For the most part. }\end{array}$ \\
\hline
\end{tabular}




\begin{tabular}{|c|c|c|}
\hline & & $\begin{array}{l}\text { (18:30) [Reference Step } 8 \text { in manual] Yes, I really } \\
\text { didn't understand it because it's so little and there } \\
\text { are knobs everywhere and I can't tell what the } \\
\text { knobs are. And they even have letters on them, } \\
\text { really tiny letters. It was just not helpful. It didn't } \\
\text { help at all. And then "repeat on opposite side" of } \\
\text { the legs: I was just a little confused too. }\end{array}$ \\
\hline $\begin{array}{l}\text { (07:18) The pictures that it uses looks kind of } \\
\text { confusing and overwhelming. The whole thing } \\
\text { looks confusing [Reference Step } 8 \text { in manual]. At } \\
\text { first glance at all looks overwhelming like, 'oh no, } \\
\text { there's a lot to do.' But when you break it down } \\
\text { there's not a whole lot because it's a repetitive } \\
\text { step, but it makes it look like there's a lot more. }\end{array}$ & $\begin{array}{l}\text { (17:55) Yes, these were the two other legs that I } \\
\text { didn't know to make [Reference Step } 11,12 \text { in } \\
\text { manual]. I was thinking that this was just the } \\
\text { other[Reference Step 9, } 10 \text { in manual then the right } \\
\text { side of the toy] I thought that the first two steps } \\
\text { was the first set of legs and the second set of steps } \\
\text { was the second set of legs [Reference Step } 11,12 \text { in } \\
\text { manual then the left side of the toy]. }\end{array}$ & $\begin{array}{l}\text { (14:20) I would make the legs on a different page } \\
\text { for all the sections of steps together in a single } \\
\text { page. All of this is on this side. And it would show } \\
\text { what it looked like when I was done. And then you } \\
\text { can move on to the next page and allow people to } \\
\text { take a breath, before they move on to the real } \\
\text { trouble. }\end{array}$ \\
\hline \multirow[t]{2}{*}{$\begin{array}{l}(15: 30) \text { it doesn't say that this is extra [Reference } \\
\text { extra step page in manual]. It just kind of goes into } \\
\text { it so it was confusing at first. Well there could have } \\
\text { been a header where it could show you that these } \\
\text { are steps that you can do and that the steps are } \\
\text { optional. Or you could put it at the end. So, you } \\
\text { could switch these two pages. }\end{array}$} & & $\begin{array}{l}(20: 00) \text { Yes, it never told me to assemble the } \\
\text { second unit. It should show me two units and say } \\
\text { that you're ready to move to the next page. It } \\
\text { wants two units already. }\end{array}$ \\
\hline & & $\begin{array}{l}(21: 15) \text { No, it should be at the end. There's enough } \\
\text { fun putting the modifications at the end and for } \\
\text { extra fun you can modify it. }\end{array}$ \\
\hline
\end{tabular}




\begin{tabular}{|c|c|c|c|c|}
\hline $\begin{array}{l}\text { Document } \\
\text { Organization }\end{array}$ & Dependability & $\begin{array}{l}\text { Manual road map did } \\
\text { or did not provide easy- } \\
\text { to-follow logical } \\
\text { progression. }\end{array}$ & & \\
\hline \multirow[t]{2}{*}{$\begin{array}{l}\text { Showing Sides or } \\
\text { Differentiating Parts }\end{array}$} & \multirow[t]{2}{*}{ Perspicuity } & \multirow[t]{2}{*}{$\begin{array}{l}\text { Image did or did not } \\
\text { provide complete } 3 \mathrm{D} \\
\text { information. }\end{array}$} & $\begin{array}{l}\text { (00:41) Well yeah, it definitely helped because } \\
\text { the pictures were really clear and if there was } \\
\text { two sides to a piece they made sure to } \\
\text { differentiate between which side of the piece } \\
\text { was facing up or down. }\end{array}$ & $\begin{array}{l}\text { (03:05) Especially with things that have mirror } \\
\text { sides like both sides are the same, like being } \\
\text { clear about this is what this side should look } \\
\text { like and where it goes and this is what this side } \\
\text { should look like and where it goes [Reference } \\
\text { Step } 9,11 \text { in manual]. }\end{array}$ \\
\hline & & & & $\begin{array}{l}(04: 00) \text { I get really confused about my left and } \\
\text { right so having the mirrored images were very } \\
\text { useful. }\end{array}$ \\
\hline \multirow{2}{*}{ Step Progression } & \multirow{2}{*}{ Dependabililty } & \multirow{2}{*}{$\begin{array}{l}\text { Steps or step images } \\
\text { did or did not provide } \\
\text { obvious next step. }\end{array}$} & & $\begin{array}{l}\text { (11:30) I didn't realize that once you put it on } \\
\text { it would swivel around because I was thinking } \\
\text { it would hold him place. So the angle that I } \\
\text { have to put this on for the others to fit on } \\
\text { doesn't match the pegs on the other side, it } \\
\text { doesn't fit. So once I realized I can put it on } \\
\text { and it move the leg, then it made sense. }\end{array}$ \\
\hline & & & & $\begin{array}{l}(00: 50) \text { That's more clear to me because later } \\
\text { it's telling you how to hook it up to the } \\
\text { thing[Reference Step } 9 \text { in manual], so I feel like } \\
\text { there are parts where it alluded to future steps } \\
\text { where you weren't quite there. So, it didn't } \\
\text { seem quite relevant at that time. }\end{array}$ \\
\hline
\end{tabular}




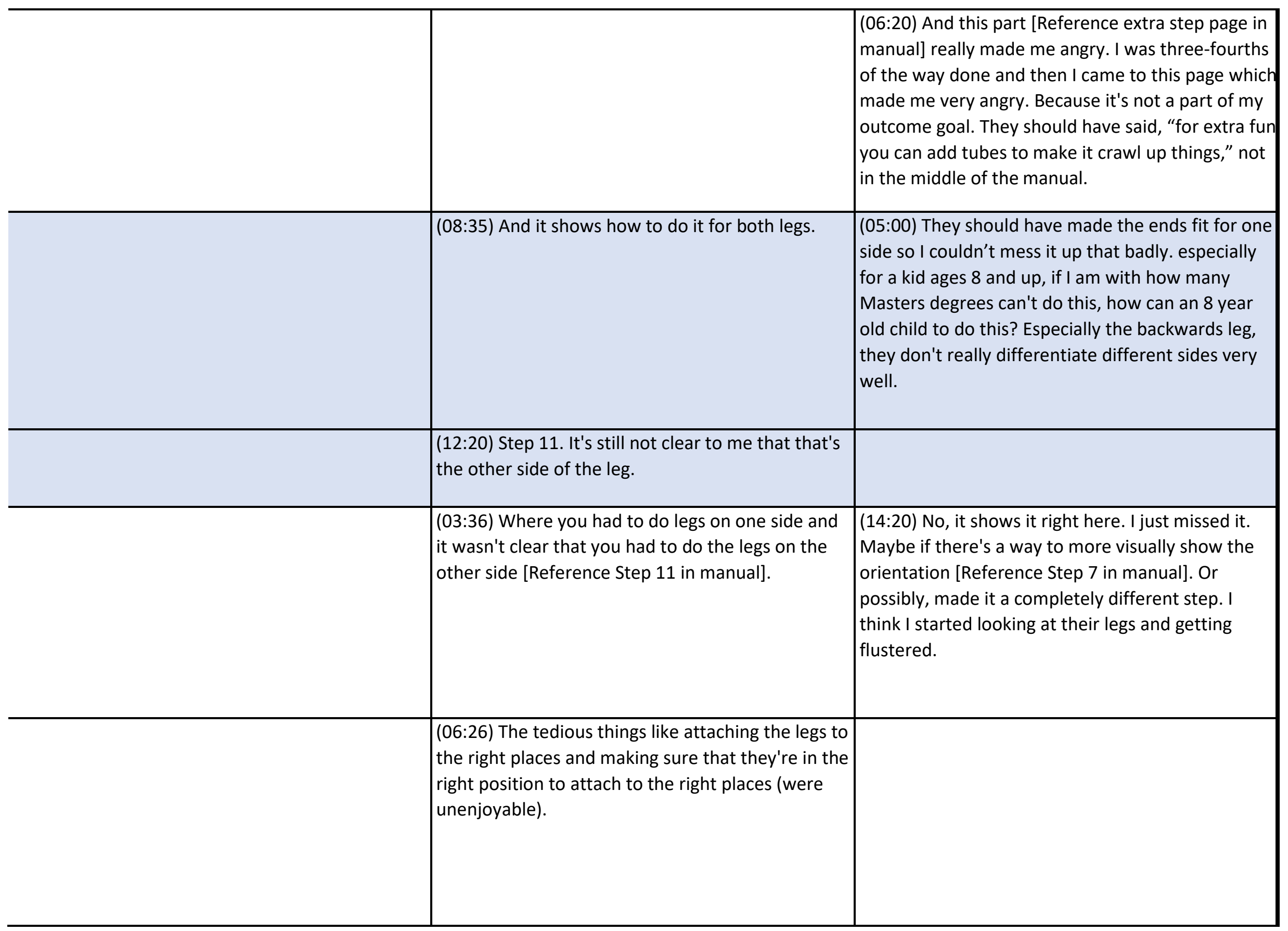




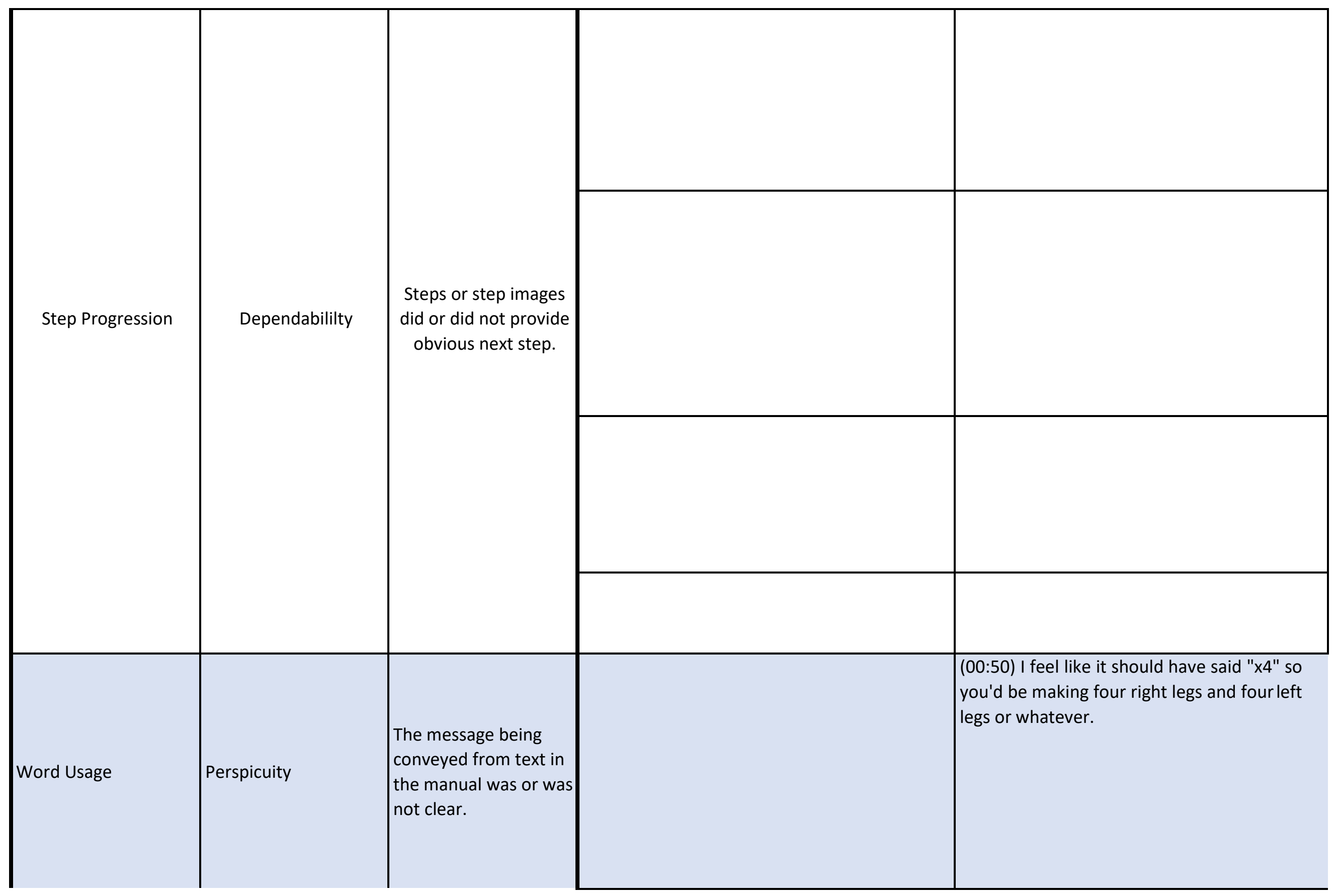


This one [Reference Step 7 in manual] the A2 piece was kind of confusing and I didn't

understand what is was or know to take the A1

piece and put it on top. The A2 was confusing to

me because it didn't make sense that it was just

used to put the gears in.

(12:20) they kind of went from 9 and 10, putting

the legs on the one side, and in Step 11 it only

shows you how to put one leg on there. And then,

in Step 12 it's done. Step 9 shows you how to put

the first leg on and then both are magically on in

step 10. In Step 11, one leg is being put on, but in

step 12 they are magically on.

(13:55) Examiner: So you would have wanted to

see each leg be on this be assembled? So what if

step 9 showed both legs being assembled?

Participant: Yes. And [Reference Step 10 in

manual] would be its own step still.

$(17: 15)$ by looking at this picture I thought that

there was only two sides to build.

(1:50) The footnotes of stuff was good [Reference Step 7 in manual]. I overlooked them a couple of times but they were good.
(00:40) I feel like it would be easier if they had captions for the pictures to help explain what to do. Sometimes the black and white line drawings are confusing. Just seeing what's supposed to be going where and when they flip it around you can't really tell when it's the opposite side when it's the black and white drawings.
(00:28) it was very confusing. It says red wire and appoints the things, but there is two red wires and it doesn't tell me exactly what it needs to. It's very vague. And, I can see a kid getting frustrated and not liking science or wanting to do this because of it. 


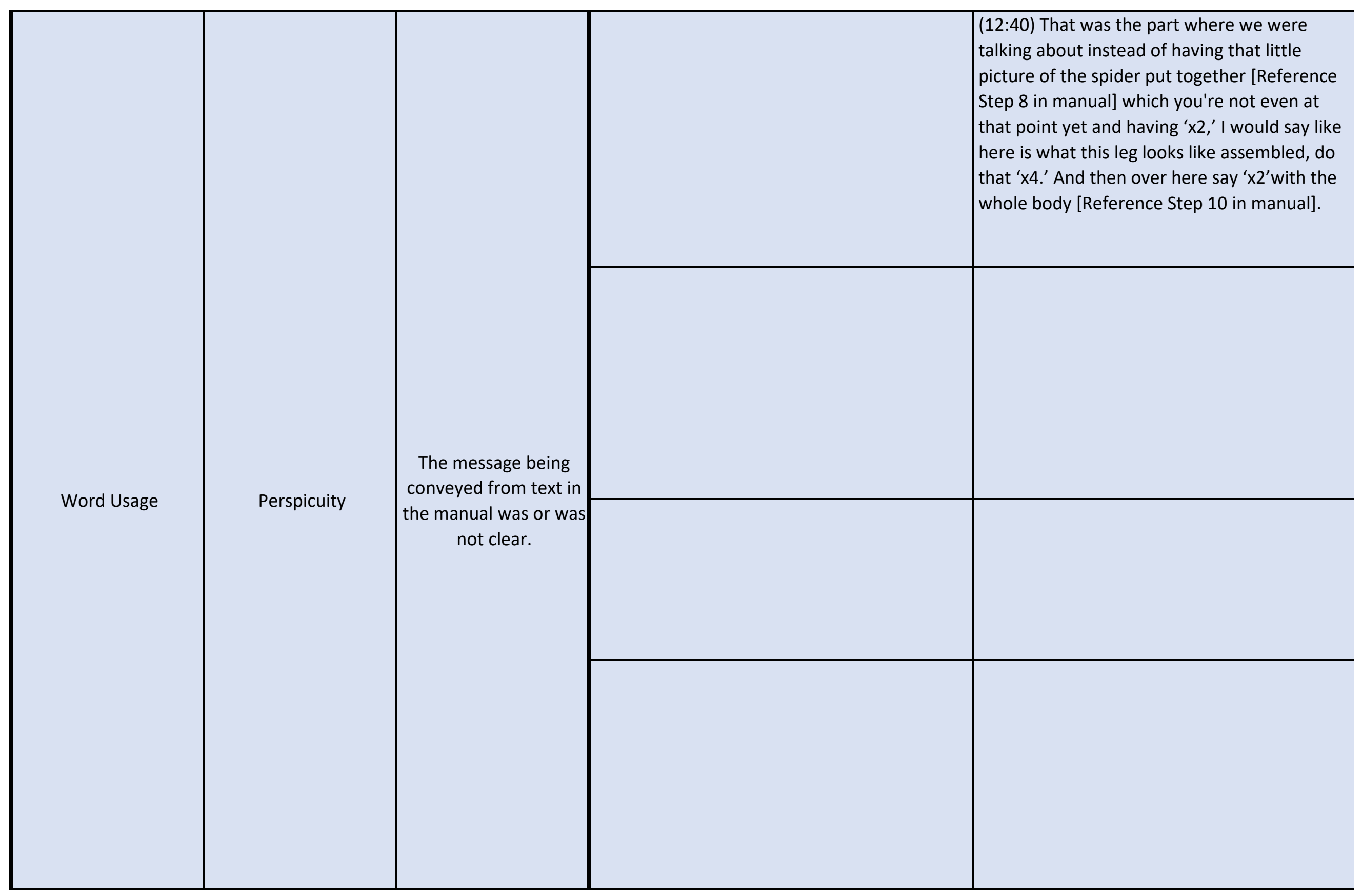




\begin{tabular}{|c|c|c|}
\hline $\begin{array}{l}(12: 50) \text { it said repeat on opposite sides and it } \\
\text { shows two right here. So I'm thinking just only two, } \\
\text { but it says times } 2 \text { [Reference Step } 8 \text { in manual]. So } \\
\text { im thinking it only means } 2 \text {. It's not really specifying } \\
\text { to do it four times. }\end{array}$ & $\begin{array}{l}\text { (01:40) I was moderately dissatisfied. Because } \\
\text { there are no words and it was confusing. }\end{array}$ & $\begin{array}{l}\text { (01:55) It was poor. I think lkea does better. The } \\
\text { directions were vague. They did not give me } \\
\text { enough information to complete the tasks that } \\
\text { were needed. }\end{array}$ \\
\hline & & $\begin{array}{l}\text { (06:20) And this part [Reference extra step page in } \\
\text { manual] really made me angry. I was three-fourths } \\
\text { of the way done and then I came to this page which } \\
\text { made me very angry. Because it's not a part of my } \\
\text { outcome goal. They should have said, "for extra fun } \\
\text { you can add tubes to make it crawl up things," not } \\
\text { in the middle of the manual. }\end{array}$ \\
\hline $\begin{array}{l}(17: 05) \text { l saw that they were different lengths but } \\
\text { here it says that they should be identical. }\end{array}$ & $\begin{array}{l}\text { (14:45) Examiner: Confusion on the verbiage } \\
\text { "assemble the second set of gears"? } \\
\text { Participant: Yes, it [the verbiage] was confusing } \\
\text { because before, it was not clear but now I see that } \\
\text { it's clear that there's two sets of them. That's } \\
\text { another case it could be color coded. }\end{array}$ & $\begin{array}{l}\text { (13:50) It's just "note that direction." [Reference } \\
\text { Step } 7 \text { in manual] I should have looked at it closer. } \\
\text { I didn't know what "note the direction" meant. I } \\
\text { see that it tells me to note the direction of holes, } \\
\text { but it wasn't showing me specifically how the holes } \\
\text { were supposed to be directed. It would have } \\
\text { helped if it said to note the male versus female } \\
\text { holes. }\end{array}$ \\
\hline & & $\begin{array}{l}\text { (18:30) [Reference Step } 8 \text { in manual] Yes, I really } \\
\text { didn't understand it because it's so little and there } \\
\text { are knobs everywhere and I can't tell what the } \\
\text { knobs are. And they even have letters on them, } \\
\text { really tiny letters. It was just not helpful. It didn't } \\
\text { help at all. And then "repeat on opposite side" of } \\
\text { the legs: I was just a little confused too. }\end{array}$ \\
\hline
\end{tabular}




\begin{tabular}{|c|c|c|c|c|}
\hline Overall Impressions & Attractiveness & $\begin{array}{c}\text { Did users like or dislike } \\
\text { the product? }\end{array}$ & 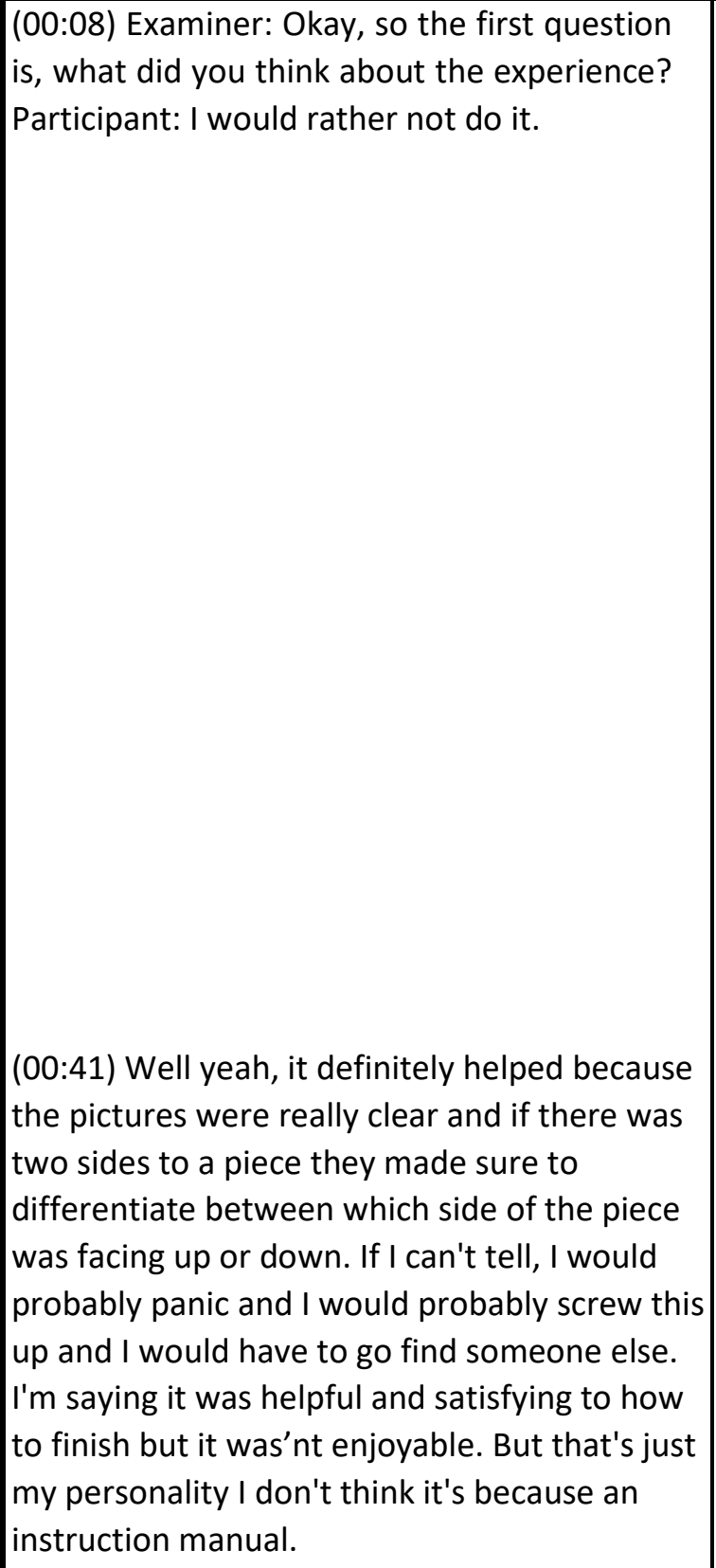 & $\begin{array}{l}\text { (02:59) I would say pretty satisfied. It was } \\
\text { better than most instruction manuals I've } \\
\text { read. I think a lot of it was the pictures and } \\
\text { stuff, like just being clear about where... } \\
\text { Especially with things that have mirror sides } \\
\text { like both sides are the same, like being clear } \\
\text { about this is what this side should look likeand } \\
\text { where it goes and this is what this side should } \\
\text { look like and where it goes [Reference Step } \\
9,11 \text { in manual]. Because, I've put together } \\
\text { bookshelves and things where I'll put things on } \\
\text { backwards or whatever and I get you a letter } \\
\text { step and I'm like 'wait, this doesnt make sense' } \\
\text { and then I have to go all the way back and } \\
\text { restart it so I think it was pretty clear in how } \\
\text { that goes about. Yeah, the order of operations } \\
\text { I guess. For the most part. } \\
\text { (00:30) It was overall kind of empowering } \\
\text { because I didn't think that highly of my ability } \\
\text { to put together a... an electronic anything, so } \\
\text { yeah. }\end{array}$ \\
\hline
\end{tabular}


(00:50) I was moderately satisfied if that's a good answer, because I didn't think that it was hard. But I definitely needed the instruction manual, but it wasn't the easiest thing in the world. Does that make sense?

(00:05) I'm happy I got it put together. But it's not something I would do in my spare time.
$(00: 15)$ I thought it was not something that I'm used to, so a little difficult and a trick my minda little bit. Thought-provoking we should say.

(01:40) I was moderately dissatisfied. Because there are no words and it was confusing.
(00:28) I would not do it again. I would not buy this for my child. In terms of this thing, it was very confusing. It says red wire and appoints the things, but there is two red wires and it doesn't tell me exactly what it needs to. It's very vague. And, I can see a kid getting frustrated and not liking science or wanting to do this because of it.

(01:05) Pretty dissatisfied, especially because I didn't have it right by the end. Even the boxdoesn't make sense because it says skill level and a bunch of colors, and I don't even know what that means. And, there's extra pieces and now it's kind of frustrating. 


\section{APPENDIX H: Themes Analysis Original Manual}

\begin{tabular}{|c|c|c|c|c|c|}
\hline \multicolumn{6}{|c|}{ Observations and Remarks On Manual Steps } \\
\hline Item & & & Observation & & Remark \\
\hline Step 1 & & & & & $\begin{array}{l}(07: 39) 1 \text {, and } 2 \text { were } \\
\text { very easy. But, they are } \\
\text { very easy things to show } \\
\text { in comparison to some of } \\
\text { the others. There are } \\
\text { nice arrows showing you } \\
\text { the directions. }\end{array}$ \\
\hline Step 2 & $\begin{array}{l}\text { Pulled wire out from } \\
\text { lead }\end{array}$ & & & & $\begin{array}{l}(03: 50) \text { I think you need } \\
\text { this, but maybe you can } \\
\text { combine them with } \\
\text { another step, because } \\
\text { there's are four or five } \\
\text { things to focus on in step } \\
1 \text { and then in step } 2 \\
\text { there is just one little } \\
\text { click and I'm like what? } \\
\text { The step should be more } \\
\text { balanced I guess, not } \\
\text { similar amount of work } \\
\text { for each step which made } \\
\text { it a bit confusing. }\end{array}$ \\
\hline Step 3 & $\begin{array}{l}\text { Didn't know how to } \\
\text { orient the part }\end{array}$ & Trouble using wires & $\begin{array}{l}\text { Did not recognize the } \\
\text { switch }\end{array}$ & $\begin{array}{l}\text { A lot of things going on in } \\
\text { image }\end{array}$ & $\begin{array}{l}(00: 30) \text { It was overall kind } \\
\text { of empowering because I } \\
\text { didn't think that highly of } \\
\text { my ability to put together } \\
\text { a... an electronic } \\
\text { anything, so yeah. }\end{array}$ \\
\hline Step 4 & $\begin{array}{l}\text { Didn't know to to set } \\
\text { terminals into body }\end{array}$ & $\begin{array}{l}\text { Didn't put terminals in } \\
\text { hole, went to step } 5 \text { for } \\
\text { confirmation }\end{array}$ & $\begin{array}{l}\text { Had to go to next step to } \\
\text { place the terminals }\end{array}$ & $\begin{array}{l}\text { Not clear where to slide } \\
\text { in terminals }\end{array}$ & $\begin{array}{l}(02: 25) \text { Something that } \\
\text { was particularly useful } \\
\text { was enlarging things like } \\
\text { that[Reference Step } 4 \text { in } \\
\text { manual]. }\end{array}$ \\
\hline Step 5 & $\begin{array}{l}\text { Didn't know to bend } \\
\text { piece and bring in }\end{array}$ & $\begin{array}{l}\text { Had to closely inspect } \\
\text { for detail }\end{array}$ & & & $\begin{array}{l}(08: 59) 2,5 \text {, and } 14 \text {. They } \\
\text { were the most boring. }\end{array}$ \\
\hline
\end{tabular}




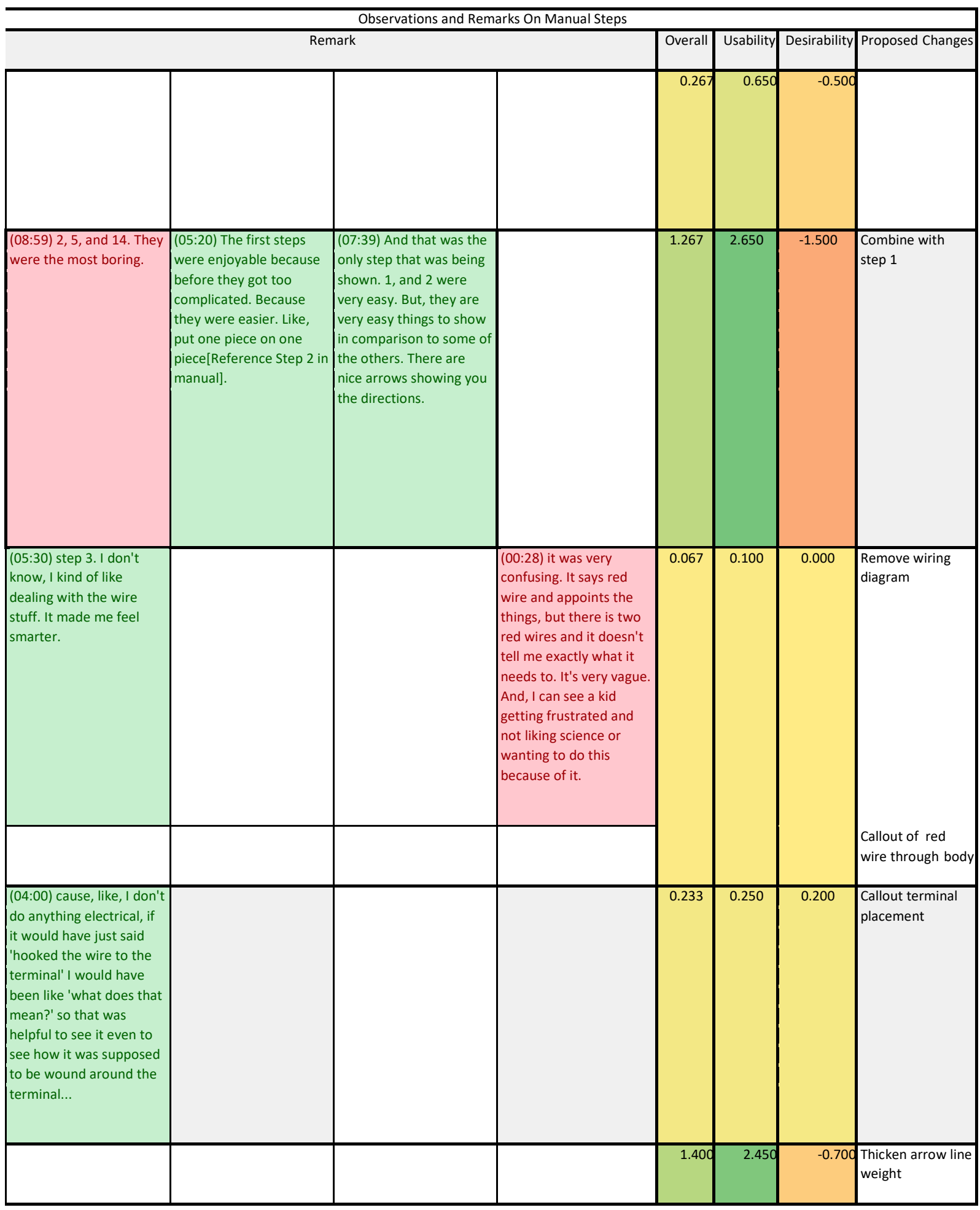




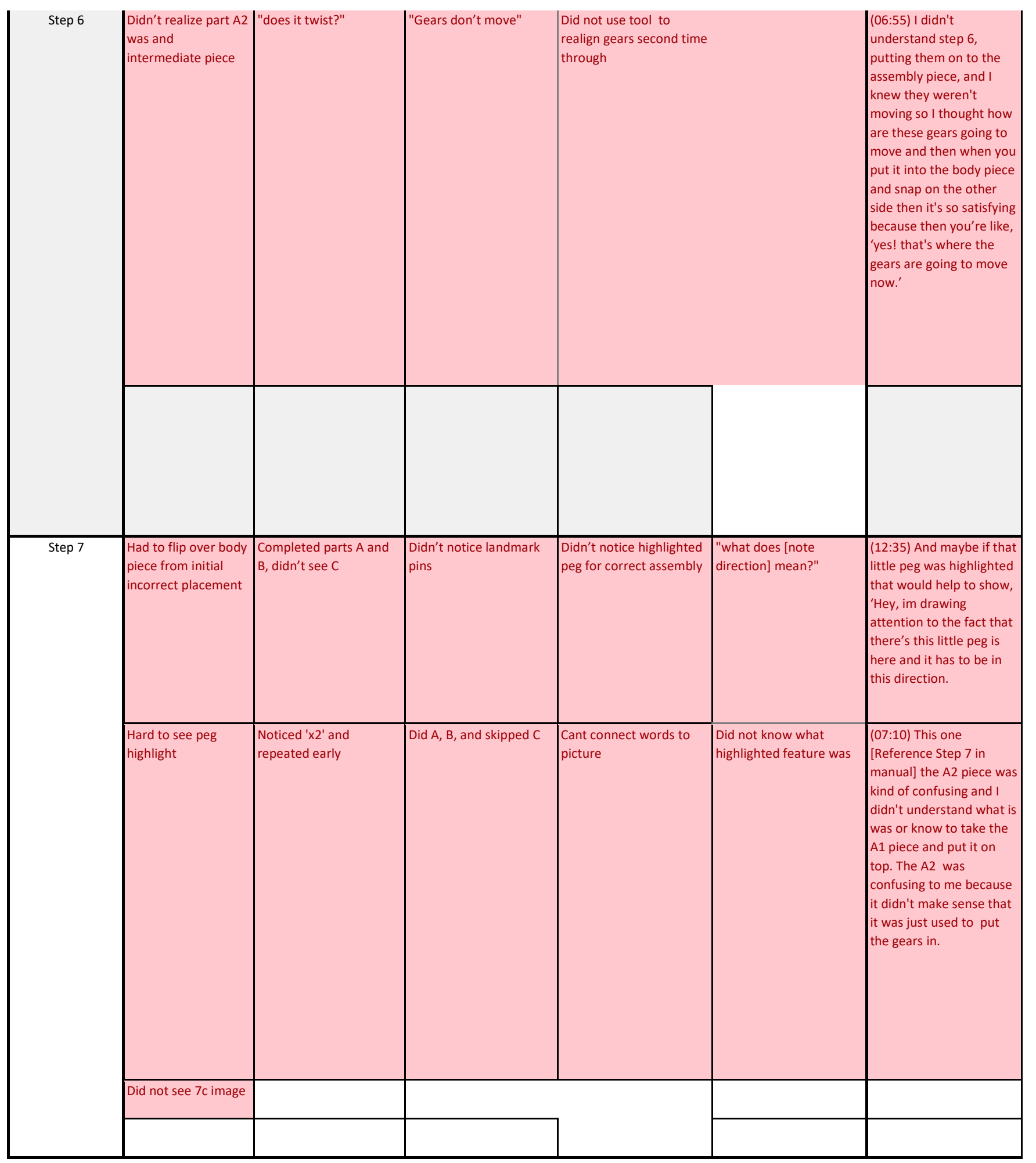




\begin{tabular}{|c|c|c|c|c|c|c|c|}
\hline $\begin{array}{l}(05: 03) \text { I'd say the part } \\
\text { where you put the gears } \\
\text { on the little pegs } \\
\text { [Reference Step } 6 \text { in } \\
\text { manual]. I thought that } \\
\text { was part of the machine, } \\
\text { but then I was like but } \\
\text { when I was like oh you're } \\
\text { just using it took place it } \\
\text { in these holes that are } \\
\text { clearly yeah. It's not hard } \\
\text { to figure out how they go } \\
\text { in there. Maybe I } \\
\text { shouldn't speak for } \\
\text { everybody, but for me it's } \\
\text { pretty clear how they } \\
\text { would have sat inside the } \\
\text { casing. }\end{array}$ & $\begin{array}{l}\text { (10:29) I don't think it } \\
\text { need to be highlighted at } \\
\text { all(part A2, gear } \\
\text { assembly tool). Because } \\
\text { it doesn't even really } \\
\text { look like the part. I don't } \\
\text { know, I just got confused } \\
\text { and it didn't look like } \\
\text { anything like on the } \\
\text { actual toy. }\end{array}$ & $\begin{array}{l}(05: 30) \text { Step } 6 \text { [was one } \\
\text { of my top three best]. } \\
\text { Because that's when you } \\
\text { get to see all the little } \\
\text { gears together. }\end{array}$ & $\begin{array}{l}(11: 20) \text { I didn't even look } \\
\text { at this part [Reference } \\
\text { Step } 6 \text { in manual]. I just } \\
\text { assume that all four } \\
\text { holes are the same. }\end{array}$ & 0.733 & 0.850 & 0.500 & $\begin{array}{l}\text { Name part A2 } \\
\text { "gear tool" }\end{array}$ \\
\hline & & & $\begin{array}{l}\text { (01:55) I saw this } \\
\text { [Reference Step } 6 \text { in } \\
\text { manual] but didn't } \\
\text { understand what } \\
\text { arrange the gear meant. } \\
\text { Now that I see what the } \\
\text { result is, now I } \\
\text { understand it. }\end{array}$ & & & & $\begin{array}{l}\text { Arrange to } \\
\text { highlight picture }\end{array}$ \\
\hline $\begin{array}{l}(16: 42) \text { I didn't even } \\
\text { notice that until you } \\
\text { pointed it out [direction } \\
\text { dictating ' } x 2^{\prime} \text { ]. }\end{array}$ & $\begin{array}{l}(07: 18) 7 \text {. Because the } \\
\text { gears kept falling off. I } \\
\text { didn't know if they were } \\
\text { supposed to stick or not. }\end{array}$ & $\begin{array}{l}(15: 50) \text { Yes, I didn't } \\
\text { notice that until the end. } \\
\text { When this peg } \\
\text { [Reference Step } 7 \text { in } \\
\text { manual] was on the } \\
\text { outside these things } \\
\text { couldn't go into it } \\
\text { [Reference toy spider]. }\end{array}$ & show $7 \mathrm{C}$ better visually & 0.533 & 0.850 & -0.100 & $\begin{array}{l}\text { Highlight A1 } \\
\text { placements by: } \\
\text { callout, improving } \\
\text { caption, arrow to } \\
\text { pin, Remove part } \\
\text { details }\end{array}$ \\
\hline $\begin{array}{l}\text { (14:45) Examiner: } \\
\text { Confusion on the } \\
\text { verbiage "assemble the } \\
\text { second set of gears"? } \\
\text { Participant: Yes, it [the } \\
\text { verbiage] was confusing } \\
\text { because before, it was } \\
\text { not clear but now I see } \\
\text { that it's clear that there's } \\
\text { two sets of them. That's } \\
\text { another case it could be } \\
\text { color coded. }\end{array}$ & $\begin{array}{l}\text { (1:50) The footnotes of } \\
\text { stuff was good } \\
\text { [Reference Step } 7 \text { in } \\
\text { manual]. I overlooked } \\
\text { them a couple of times } \\
\text { but they were good. }\end{array}$ & $\begin{array}{l}\text { (13:50) It's just "note } \\
\text { that direction." } \\
\text { [Reference Step } 7 \text { in } \\
\text { manual] I should have } \\
\text { looked at it closer. I } \\
\text { didn't know what "note } \\
\text { the direction" meant. I } \\
\text { see that it tells me to } \\
\text { note the direction of } \\
\text { holes, but it wasn't } \\
\text { showing me specifically } \\
\text { how the holes were } \\
\text { supposed to be directed. } \\
\text { It would have helped if it } \\
\text { said to note the male } \\
\text { versus female holes. }\end{array}$ & $\begin{array}{l}\text { (14:20) No, it shows it } \\
\text { right here. I just missed } \\
\text { it. Maybe if there's a } \\
\text { way to more visually } \\
\text { show the orientation } \\
\text { [Reference Step } 7 \text { in } \\
\text { manual]. Or possibly, } \\
\text { made it a completely } \\
\text { different step. I think I } \\
\text { started looking at their } \\
\text { legs and getting } \\
\text { flustered. }\end{array}$ & & & & $\begin{array}{l}\text { Improve captions } \\
\text { and placement }\end{array}$ \\
\hline & & & & & & & \begin{tabular}{|l} 
Change $x 2$ \\
direction \\
Improve step \\
progression
\end{tabular} \\
\hline
\end{tabular}




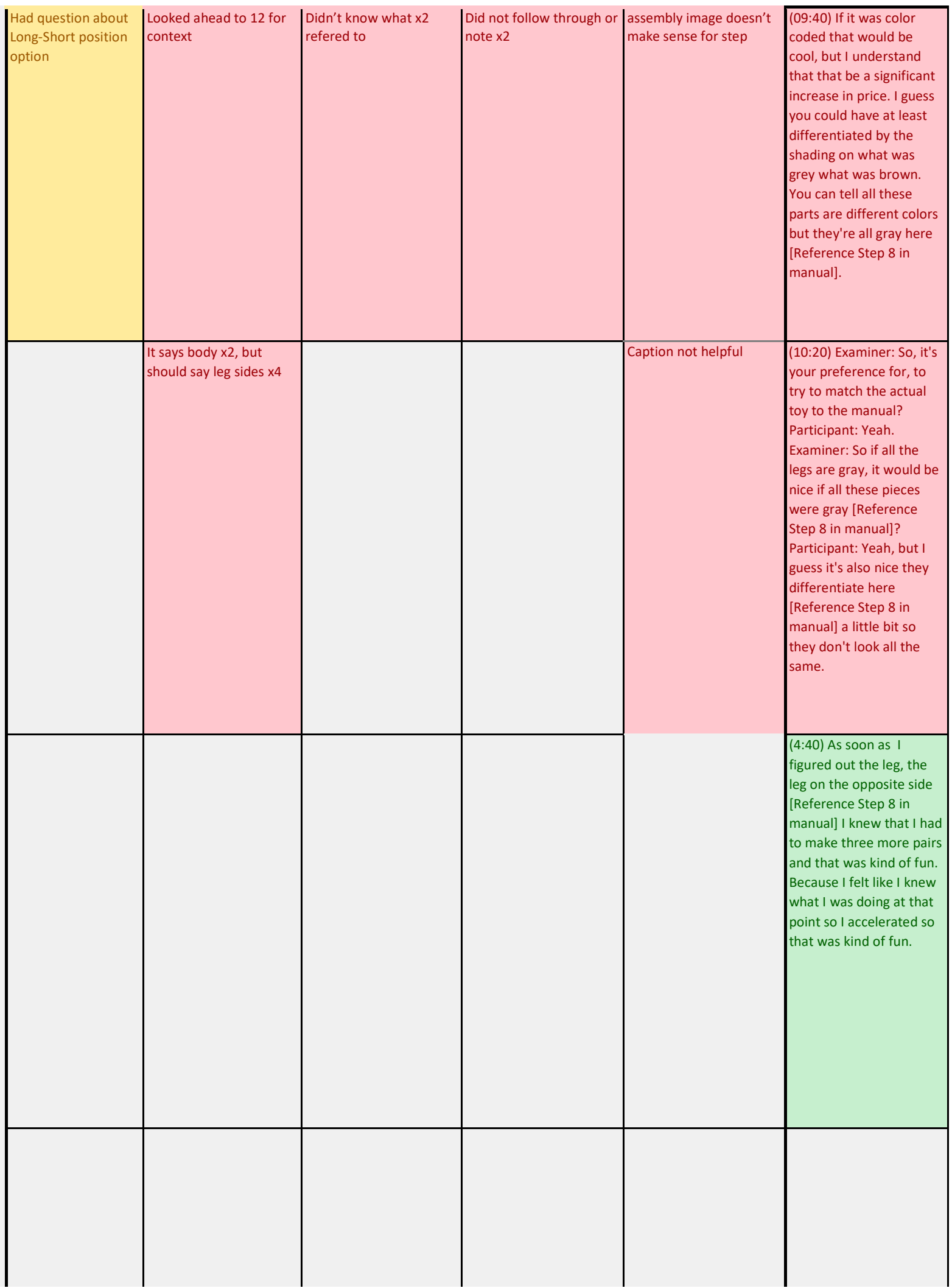




\begin{tabular}{|c|c|c|c|c|c|c|c|}
\hline $\begin{array}{l}(07: 30) \text { And step } 8 \text { and } 9 \\
\text { because the legs were, I } \\
\text { mean they weren't, once } \\
\text { you got the hang of it } \\
\text { they weren't complicated } \\
\text { but the first time through } \\
\text { its a complicated process } \\
\text { because there are so } \\
\text { many little parts that } \\
\text { goes into one leg, so that } \\
\text { was helpful. }\end{array}$ & $\begin{array}{l}\text { (07:18) The pictures that } \\
\text { it uses looks kind of } \\
\text { confusing and } \\
\text { overwhelming. The } \\
\text { whole thing looks } \\
\text { confusing [Reference } \\
\text { Step } 8 \text { in manual]. At first } \\
\text { glance at all looks } \\
\text { overwhelming like, 'oh } \\
\text { no, there's a lot to do.' } \\
\text { But when you break it } \\
\text { down there's not a whole } \\
\text { lot because it's a } \\
\text { repetitive step, but it } \\
\text { makes it look like there's } \\
\text { a lot more. }\end{array}$ & $\begin{array}{l}\text { color coding to show } \\
\text { where sub-assemblies of } \\
\text { legs go }\end{array}$ & $\begin{array}{l}\text { Assembly image too } \\
\text { small, not helpful }\end{array}$ & 0.133 & 0.000 & 0.400 & $\begin{array}{l}\text { Remove assembly } \\
\text { image }\end{array}$ \\
\hline $\begin{array}{l}\text { (00:50) I feel like it } \\
\text { should have said "x4" so } \\
\text { you'd be making four } \\
\text { right legs and four left } \\
\text { legs or whatever. }\end{array}$ & $\times 2$ should be $x 4$ & $\begin{array}{l}\text { (08:35) Even though this } \\
\text { was kind of confusing } \\
\text { [Reference Step } 8 \text { in } \\
\text { manual], I think it was a } \\
\text { good one because it } \\
\text { shows every little thing } \\
\text { that needs to go exactly } \\
\text { where with the arrows. } \\
\text { So, I thought that was } \\
\text { good. }\end{array}$ & $\begin{array}{l}(08: 40) \text { Those arrows [in } \\
\text { step 8] did not compute } \\
\text { in my mind so I can't '3D } \\
\text { think' about it. }\end{array}$ & & & & $\begin{array}{l}\text { Change } x 2 \\
\text { direction to } \\
\text { making } 8 \text { legs }\end{array}$ \\
\hline $\begin{array}{l}\text { (00:50) Like in step } 8 \\
\text { cause it says[Reference } \\
\text { Step } 8 \text { in manual], has a } \\
\text { whole picture up there } \\
\text { really tiny and it says } \\
\text { "X2" but like I wasn't } \\
\text { really paying attention to } \\
\text { that part. I was paying } \\
\text { more attention to what } \\
\text { am I doing with each of } \\
\text { these parts (leg } \\
\text { assembly) }\end{array}$ & $\begin{array}{l}\text { (12:50) it said repeat on } \\
\text { opposite sides and it } \\
\text { shows two right here. So } \\
\text { I'm thinking just only } \\
\text { two, but it says times } 2 \\
\text { [Reference Step } 8 \text { in } \\
\text { manual]. So im thinking it } \\
\text { only means } 2 \text {. It's not } \\
\text { really specifying to do it } \\
\text { four times. }\end{array}$ & $\begin{array}{l}\text { (10:45) if each leg was a } \\
\text { different color and they } \\
\text { colored them all with the } \\
\text { pieces that they needed } \\
\text { to be [Reference Step } 8 \\
\text { in manual and picture on } \\
\text { box]. Yes, I think it would } \\
\text { have understood it more } \\
\text { if it showed me where } \\
\text { the blue leg was } \\
\text { supposed to go and the } \\
\text { yellow was supposed to } \\
\text { go especially when you } \\
\text { flip the body } \\
\text { piece[Reference Step } 8 \text { in } \\
\text { manual]. }\end{array}$ & $\begin{array}{l}\text { (18:30) [Reference Step } \\
8 \text { in manual] Yes, I really } \\
\text { didn't understand it } \\
\text { because it's so little and } \\
\text { there are knobs } \\
\text { everywhere and I can't } \\
\text { tell what the knobs are. } \\
\text { And they even have } \\
\text { letters on them, really } \\
\text { tiny letters. It was just } \\
\text { not helpful. It didn't help } \\
\text { at all. And then "repeat } \\
\text { on opposite side" of the } \\
\text { legs: I was just a little } \\
\text { confused too. }\end{array}$ & & & & $\begin{array}{l}\text { Segment step to } \\
\text { make look simpler }\end{array}$ \\
\hline & & & $\begin{array}{l}\text { (05:00) This picture is } \\
\text { teeny tiny [Reference } \\
\text { Step } 8 \text { in manual]. The } \\
\text { pictures showing how } \\
\text { the mirroring was } \\
\text { supposed to be. }\end{array}$ & & & & $\begin{array}{l}\text { Address } \\
\text { color/shading }\end{array}$ \\
\hline
\end{tabular}




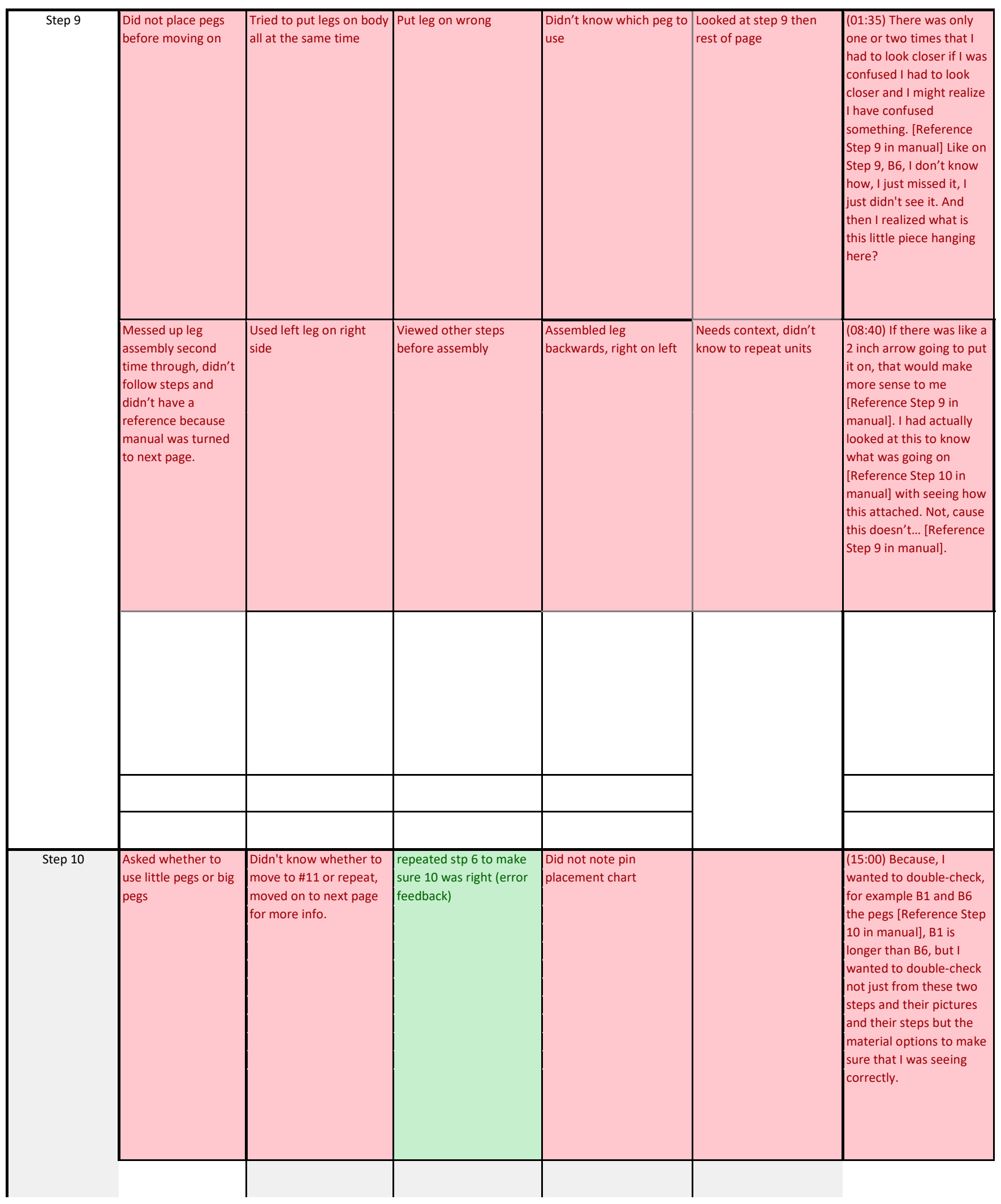




\begin{tabular}{|c|c|c|c|c|c|c|c|}
\hline $\begin{array}{l}\text { (07:30) And step } 8 \text { and } 9 \\
\text { because the legs were, I } \\
\text { mean they weren't, once } \\
\text { you got the hang of it } \\
\text { they weren't complicated } \\
\text { but the first time through } \\
\text { its a complicated process } \\
\text { because there are so } \\
\text { many little parts that } \\
\text { goes into one leg, so that } \\
\text { was helpful. }\end{array}$ & $\begin{array}{l}\text { "that part sucks, I feel } \\
\text { like youll break it" }\end{array}$ & $\begin{array}{l}(12: 20) \text { they kind of went } \\
\text { from } 9 \text { and } 10 \text {, putting } \\
\text { the legs on the one side, } \\
\text { and in Step } 11 \text { it only } \\
\text { shows you how to put } \\
\text { one leg on there. And } \\
\text { then, in Step } 12 \text { it's done. } \\
\text { Step } 9 \text { shows you how to } \\
\text { put the first leg on and } \\
\text { then both are magically } \\
\text { on in step } 10 . \text { In Step } 11 \text {, } \\
\text { one leg is being put on, } \\
\text { but in step } 12 \text { they are } \\
\text { magically on. }\end{array}$ & $\begin{array}{l}\text { Show } 2 \text { completed units } \\
\text { then move to next page }\end{array}$ & 0.267 & 0.450 & -0.100 & $\begin{array}{l}\text { number assembly } \\
\text { of each joint, or } \\
\text { hierarchy to show } \\
\text { steps on assembly }\end{array}$ \\
\hline \multirow[t]{3}{*}{$\begin{array}{l}(11: 30) \text { I didn't realize } \\
\text { that once you put it on it } \\
\text { would swivel around } \\
\text { because I was thinking it } \\
\text { would hold him place. So } \\
\text { the angle that I have to } \\
\text { put this on for the others } \\
\text { to fit on doesn't match } \\
\text { the pegs on the other } \\
\text { side, it doesn't fit. So } \\
\text { once I realized I can put it } \\
\text { on and it move the leg, } \\
\text { then it made sense. }\end{array}$} & $\begin{array}{l}\text { (13:34) I put the leg on } \\
\text { wrong because this was } \\
\text { underneath [Reference } \\
\text { Step } 9 \text { in manual] } \\
\text { because at first I didn't } \\
\text { see this part when I went } \\
\text { over top and when } \\
\text { you're snapping it on it } \\
\text { feels like this part is } \\
\text { going to break so I had to } \\
\text { put underneath. So that's } \\
\text { why I was confused. }\end{array}$ & $\begin{array}{l}\text { (13:55) Examiner: So you } \\
\text { would have wanted to } \\
\text { see each leg be on this } \\
\text { be assembled? So what if } \\
\text { step } 9 \text { showed both legs } \\
\text { being assembled? } \\
\text { Participant: Yes. And } \\
\text { [Reference Step } 10 \text { in } \\
\text { manual] would be its } \\
\text { own step still. }\end{array}$ & $\begin{array}{l}(08: 40) \text { If it showed the } \\
\text { arrows going on an inch } \\
\text { away then it would have } \\
\text { [Reference Step } 9 \text { in } \\
\text { manual]. These arrors } \\
\text { are just coming from too } \\
\text { far away. }\end{array}$ & & & & $\begin{array}{l}\text { Show twisting of } \\
\text { joint to proper } \\
\text { placement }\end{array}$ \\
\hline & & & $\begin{array}{l}\text { (12:45) Participant: I } \\
\text { really hated the legs. So } \\
\text { you can just put one of } \\
\text { the legs I guess. I didn't } \\
\text { really understand that } \\
\text { the legs had to face out. } \\
8,9,11 \text {. }\end{array}$ & & & & $\begin{array}{l}\text { Manual goes from } \\
\text { working on left leg } \\
\text { (8) to assembling } \\
\text { right leg (9). } \\
\text { Confusing... }\end{array}$ \\
\hline & & & & & & & $\begin{array}{l}\text { Consider flipping } \\
\text { step } 9 \\
\text { make image } \\
\text { elements closer }\end{array}$ \\
\hline $\begin{array}{l}\text { (02:30) Oh yeah and step } \\
10,11,12 \text { when you're } \\
\text { putting the legs together } \\
\text { on the body part of the } \\
\text { spider, one of them has } \\
\text { to be up and the other } \\
\text { one for it to function } \\
\text { correctly because they } \\
\text { can't all move at the } \\
\text { same time. It has to } \\
\text { alternate legs. I wouldn't } \\
\text { have figured that out. } \\
\text { They had to clearly me } \\
\text { show me right here }\end{array}$ & & $\begin{array}{l}\text { (03:20) They also didn't } \\
\text { differentiate between } \\
\text { the short and a long } \\
\text { [pegs]. If they were } \\
\text { different colors and it } \\
\text { showed on this, that } \\
\text { would have made my life } \\
\text { easier. Or, if the top of } \\
\text { one of them were a } \\
\text { triangle that would help. }\end{array}$ & $\begin{array}{l}(08: 40) \text { These arrows } \\
\text { just made more sense to } \\
\text { me[Reference Step } 10 \text { in } \\
\text { manual]. }\end{array}$ & 0.633 & 1.550 & -1.200 & Include caption \\
\hline
\end{tabular}




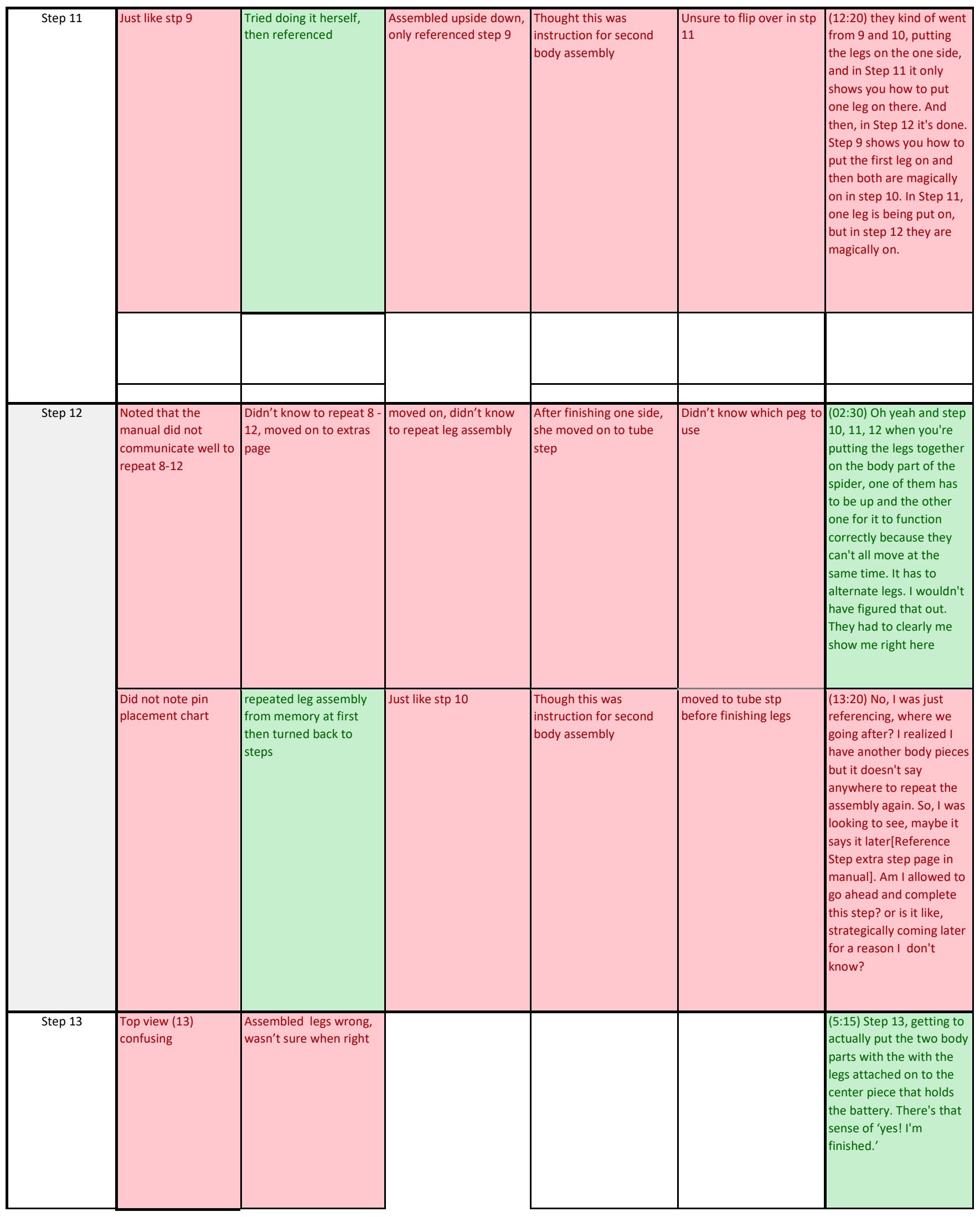




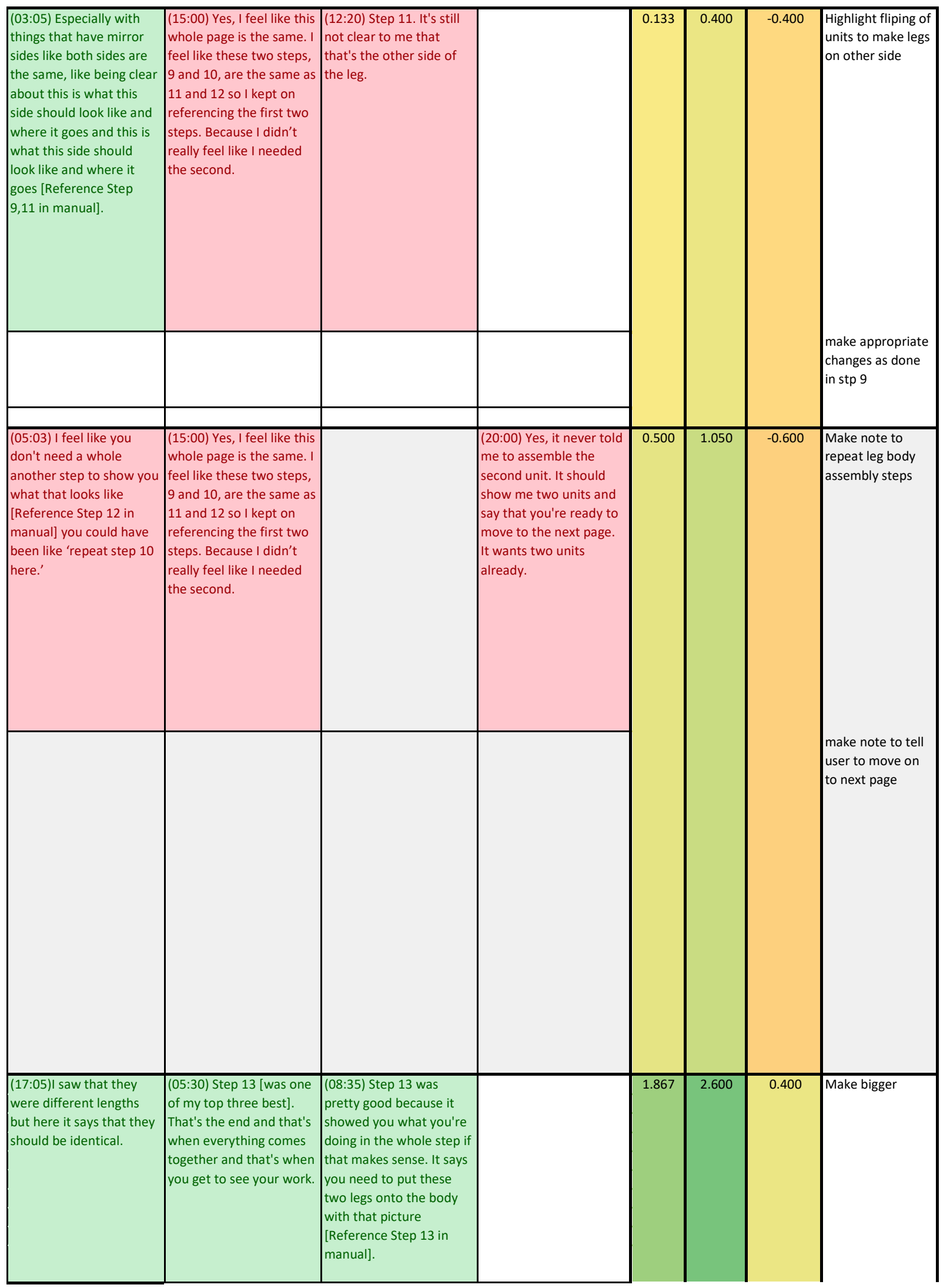




\begin{tabular}{|c|c|c|c|c|c|c|}
\hline Step 14 & & & & & & $\begin{array}{l}(08: 59) 2,5 \text {, and } 14 \text {. They } \\
\text { were the most boring. }\end{array}$ \\
\hline \multicolumn{7}{|l|}{ Title } \\
\hline \multirow[t]{2}{*}{ Materials } & $\begin{array}{l}\text { Refers to page to } \\
\text { check parts }\end{array}$ & & & & & \\
\hline & $\begin{array}{l}\text { Had to make sure } \\
\text { parts were right } \\
\text { needed to see part in } \\
\text { picture }\end{array}$ & & & & & \\
\hline \multirow[t]{3}{*}{ Modifications } & $\begin{array}{l}\text { Halving the tube to } \\
\text { create } 8 \text { equal units } \\
\text { was more } \\
\text { comfortable than } \\
\text { cutting } 8 \text { units across }\end{array}$ & $\begin{array}{l}\text { Wasn't sure to do step } \\
13 \text { or tube first }\end{array}$ & $\begin{array}{l}\text { confused on whether to } \\
\text { do tube first, or } 13\end{array}$ & $\begin{array}{l}\text { Did not use ruler in } \\
\text { manual }\end{array}$ & $\begin{array}{l}\text { I want the steps to } \\
\text { complete first, not the } \\
\text { options }\end{array}$ & $\begin{array}{l}\text { Switch Mods with stp 13- } \\
14\end{array}$ \\
\hline & $\begin{array}{l}\text { Didn't notice the the } \\
\text { tube cutting image } \\
\text { was a ruler }\end{array}$ & $\begin{array}{l}\text { Halved the tube to get } 8 \\
\text { pieces }\end{array}$ & Used ruler in tube step & on extras, confused & $\begin{array}{l}\text { Noted, "these wont be } \\
\text { exact" }\end{array}$ & \\
\hline & $\begin{array}{l}\text { Conducted tube step } \\
\text { before assembling } \\
\text { whole spider }\end{array}$ & $\begin{array}{l}\text { Didn't know manual was } \\
\text { a ruler }\end{array}$ & & & & \\
\hline
\end{tabular}




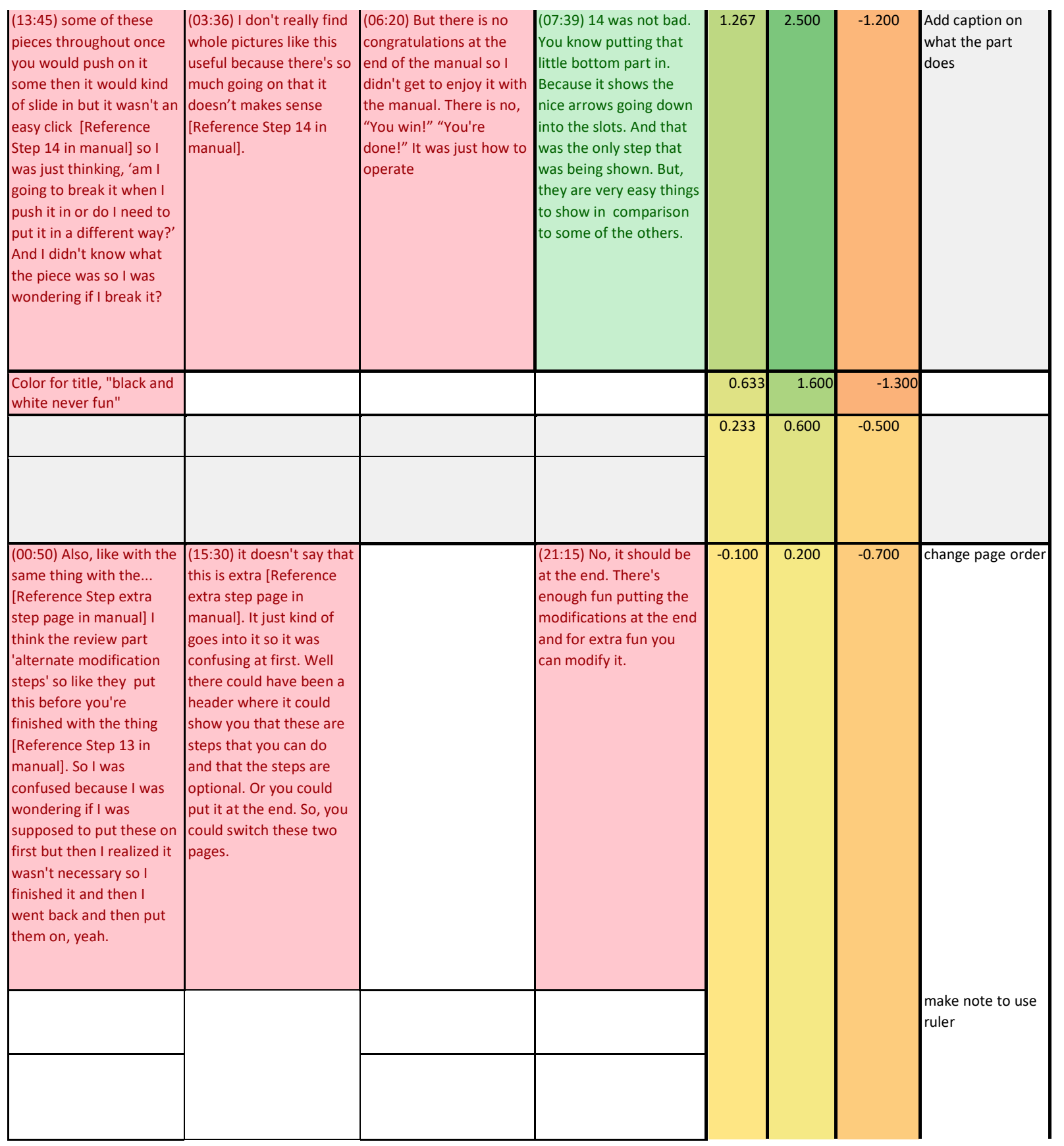




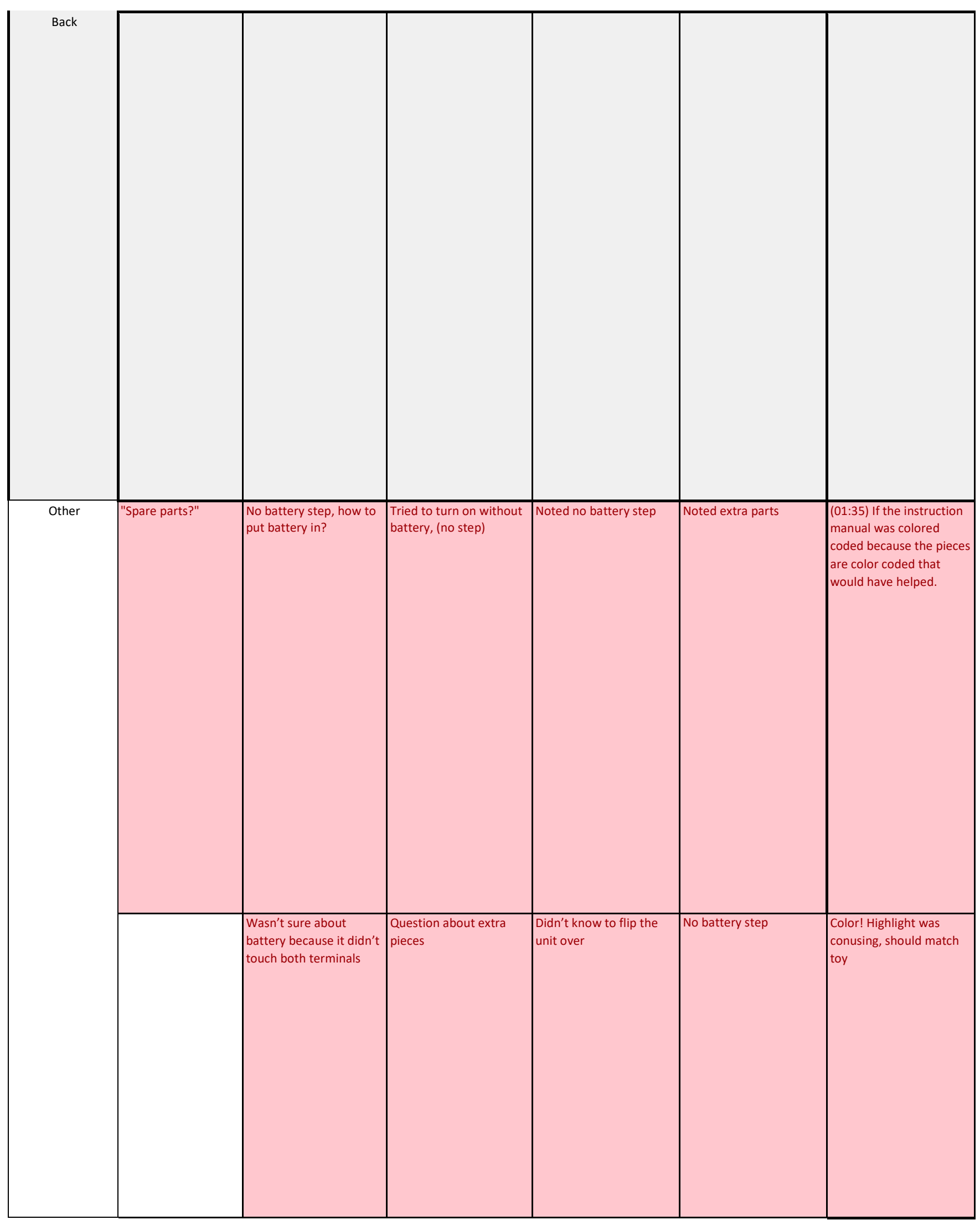




\begin{tabular}{|c|c|c|c|c|c|c|c|}
\hline $\begin{array}{l}(10: 20) \text { I never look at } \\
\text { the back where it talks } \\
\text { about batteries and } \\
\text { things like that } \\
\text { [Reference back cover in } \\
\text { manual]. But for the } \\
\text { purpose of reading it, I } \\
\text { was kind of confused } \\
\text { cause mentioned } \\
\text { something about } \\
\text { 'removing safety screws } \\
\text { and open the battery } \\
\text { compartment cover,' but } \\
\text { like its uncovered. So, I } \\
\text { am I supposed to flip it } \\
\text { upside down and take it } \\
\text { apart to replace the } \\
\text { battery or what is it } \\
\text { talking about? You can } \\
\text { tell that some of this is a } \\
\text { stock paragraph because } \\
\text { it says do not mix old and } \\
\text { new batteries but there's } \\
\text { only one battery here so } \\
\text { why would you do that? } \\
\text { So I feel like it's lazy work } \\
\text { on their part to slap on }\end{array}$ & & & & -0.200 & 1.100 & -2.800 & fix page dialog \\
\hline $\begin{array}{l}(15: 00) \text { That was fun for } \\
\text { the most part except the } \\
\text { negative terminal was } \\
\text { like squished when I put } \\
\text { the battery and it got } \\
\text { stuck and so wasn't } \\
\text { touching this side so I } \\
\text { kind of got scared that it } \\
\text { put it in wrong but then I } \\
\text { realized that it just need } \\
\text { to be released on the one } \\
\text { side [Reference spider } \\
\text { toy battery terminals] } \\
\text { and once I did that then } \\
\text { it touched the other side. } \\
\text { But that's like a typical } \\
\text { battery so if you put } \\
\text { batteries in before you } \\
\text { would know how to do } \\
\text { that. }\end{array}$ & $\begin{array}{l}(10: 53) \text { Yes, there's an } \\
\text { issue and color on the } \\
\text { whole thing. There's } \\
\text { some parts that are } \\
\text { highlighted and some } \\
\text { parts that aren't. Like at } \\
\text { first you think that it's } \\
\text { the difference between } \\
\text { the gray parts and the } \\
\text { brown parts because } \\
\text { there's a bunch of this at } \\
\text { the beginning but it's } \\
\text { not. }\end{array}$ & $\begin{array}{l}\text { (02:50) These arrows } \\
\text { were useful. Having this } \\
\text { an arrow going from this } \\
\text { hole to that hole was } \\
\text { useful. }\end{array}$ & $\begin{array}{l}\text { Put sub assemblies on } \\
\text { their own pages }\end{array}$ & & & $\begin{array}{l}\text { have notes } \\
\text { on when to } \\
\text { turn the } \\
\text { page }\end{array}$ & Add battery step \\
\hline $\begin{array}{l}\text { (01:50) The labels are } \\
\text { kind of pointless though, } \\
\text { because there's no labels } \\
\text { in the actual toy } \\
\text { [Reference spider toy]. } \\
\text { So A1, B3, that's not on } \\
\text { the toy. }\end{array}$ & $\begin{array}{l}\text { (11:15) Examiner: Would } \\
\text { you have preferred that } \\
\text { the parts were the same } \\
\text { color in the instruction } \\
\text { manual as in the toy? At } \\
\text { least different shading } \\
\text { between light and dark? } \\
\text { Participant: Yes } \\
\text { probably. }\end{array}$ & $\begin{array}{l}\text { (00:40) I feel like it would } \\
\text { be easier if they had } \\
\text { captions for the pictures } \\
\text { to help explain what to } \\
\text { do. Sometimes the black } \\
\text { and white line drawings } \\
\text { are confusing. Just seeing } \\
\text { what's supposed to be } \\
\text { going where and when } \\
\text { they flip it around you } \\
\text { can't really tell when it's } \\
\text { the opposite side when } \\
\text { it's the black and white } \\
\text { drawings. }\end{array}$ & $\begin{array}{l}\text { show completed sub } \\
\text { assemblies }\end{array}$ & & & \begin{tabular}{|l|} 
add sub \\
assembly \\
completion \\
notes
\end{tabular} & note extra parts \\
\hline
\end{tabular}




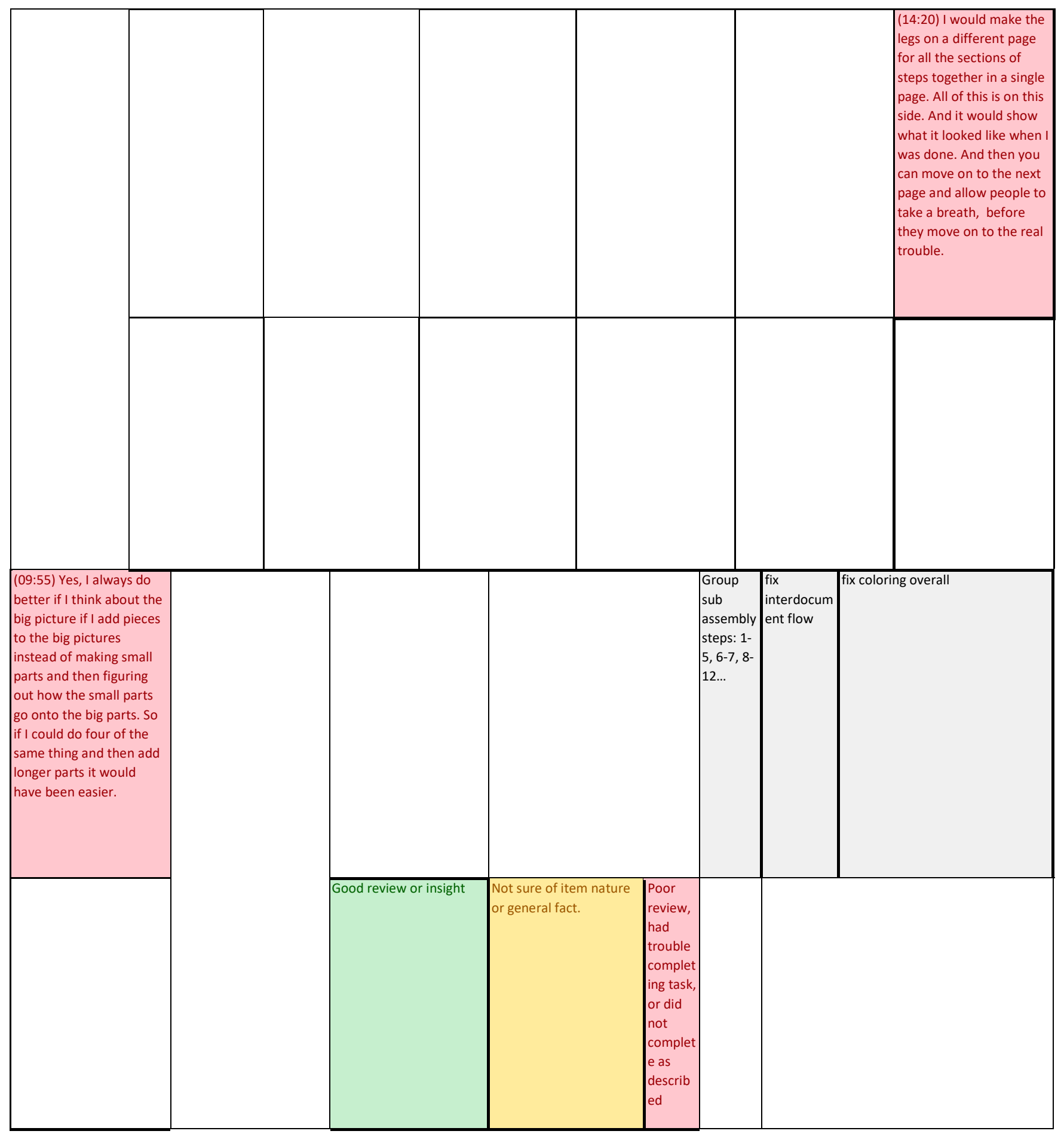




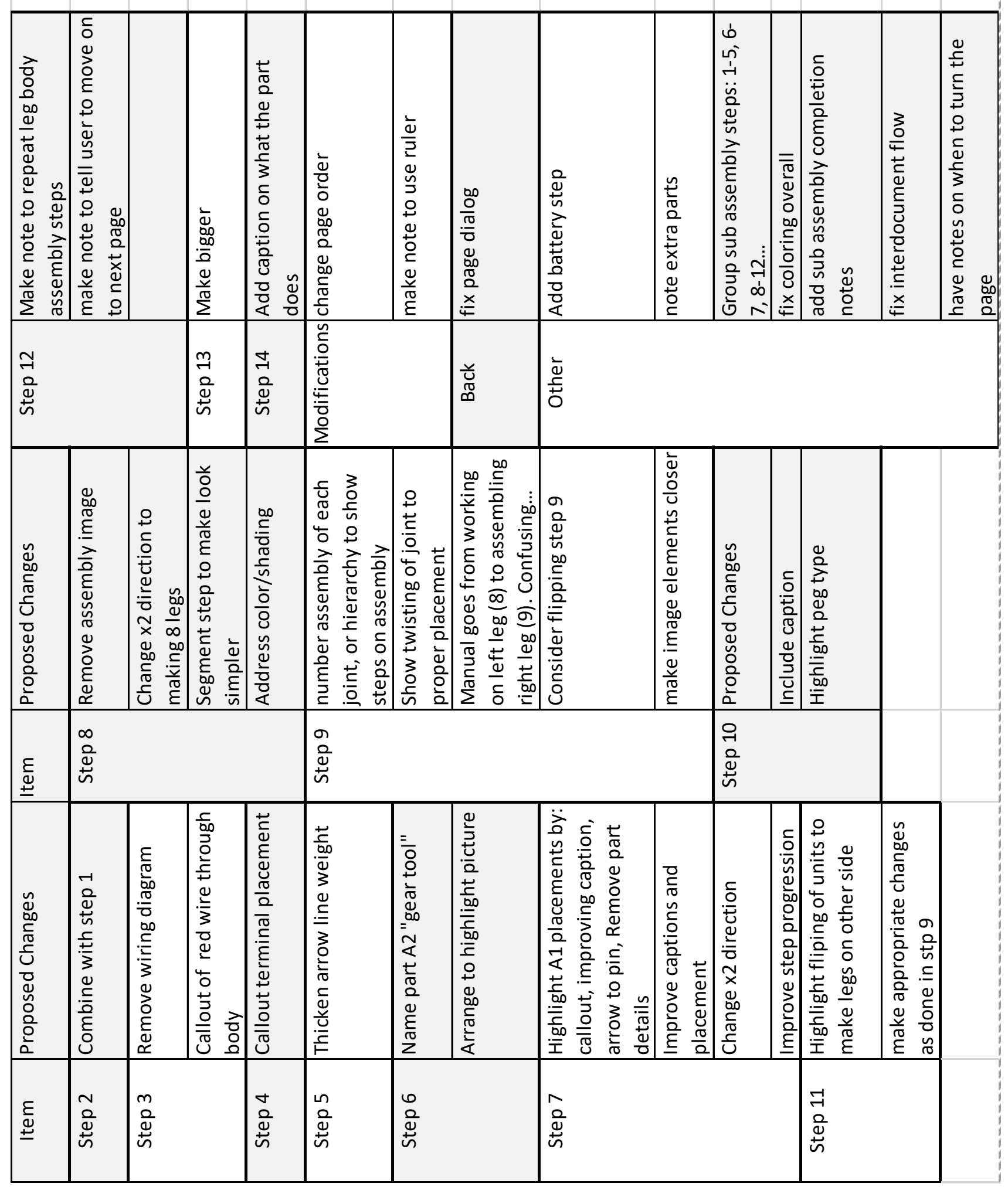


APPENDIX I: Original Instruction Manuals

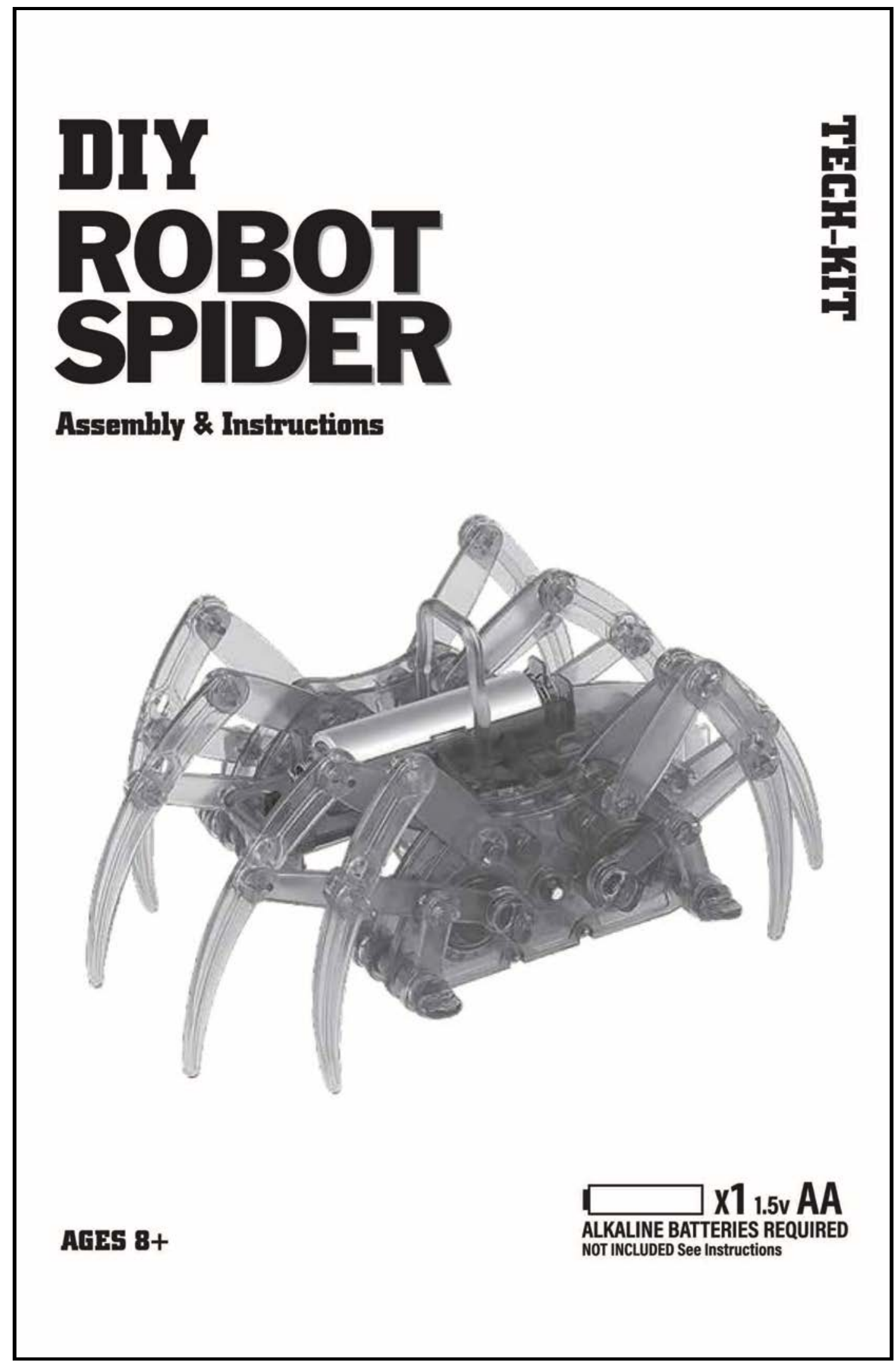




\section{DIY \\ ROBOT \\ SPIDER}

Dechanical Parts List \& Tool You May Need:
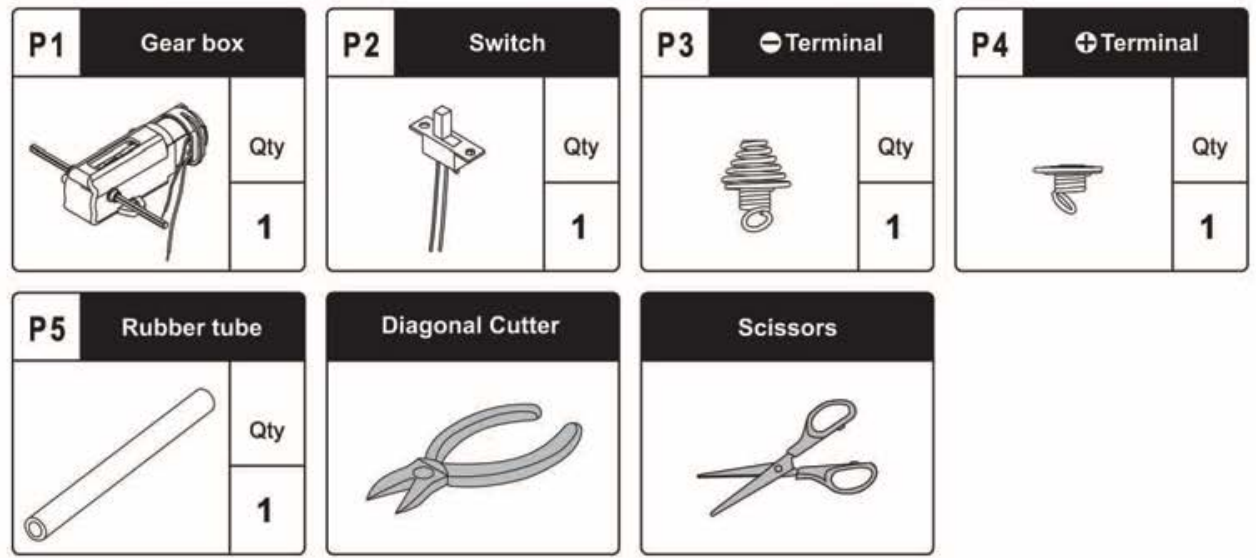

\section{Q Plastic Parts:}

Cut up the plastic parts in succession as shown.
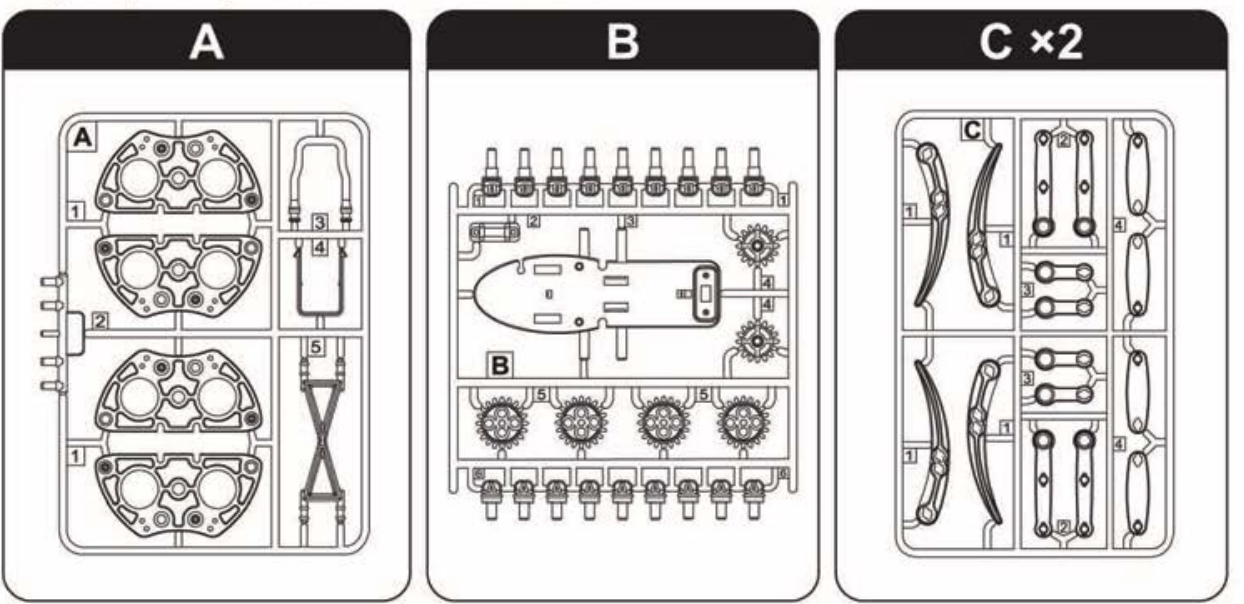


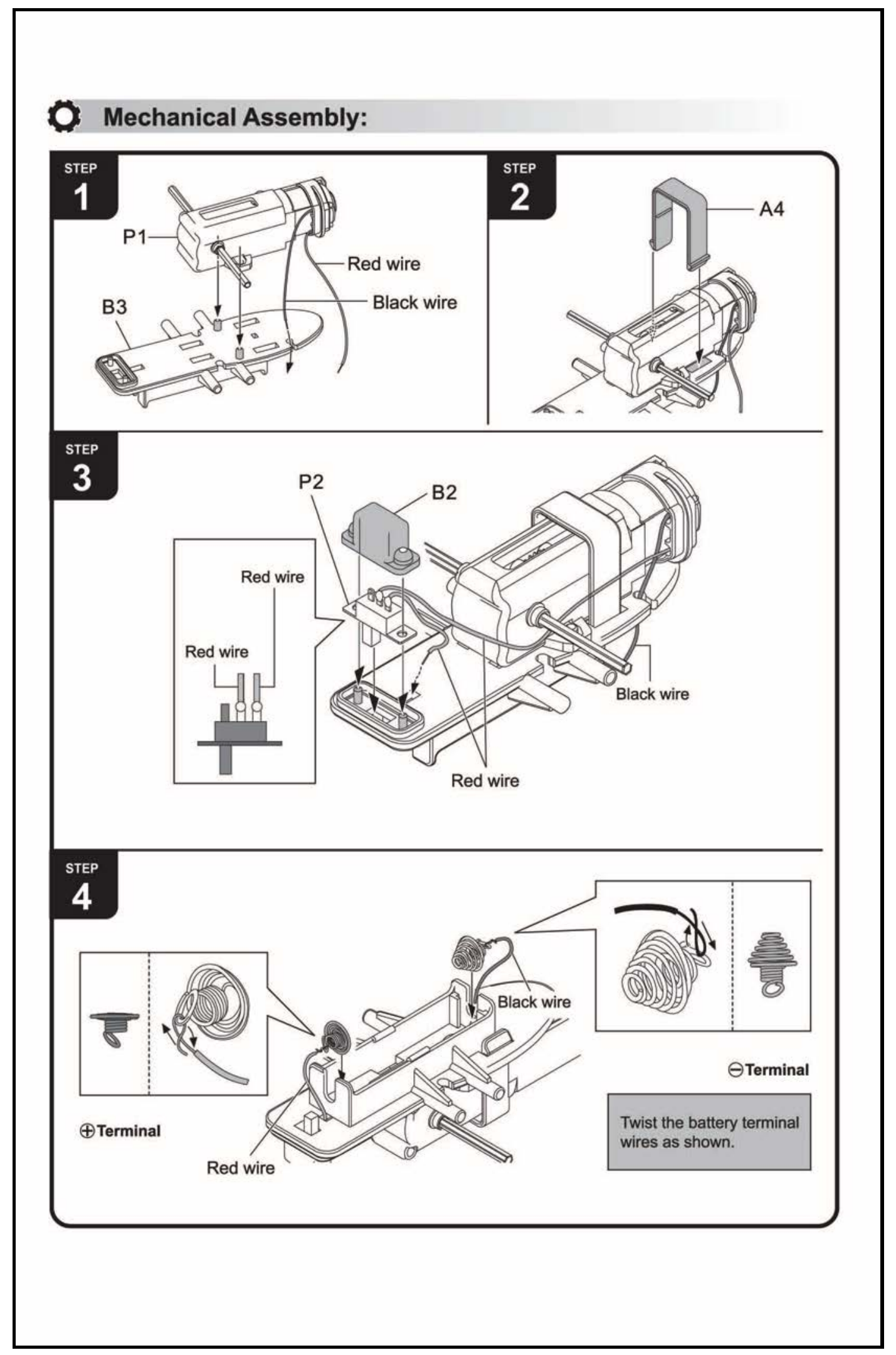




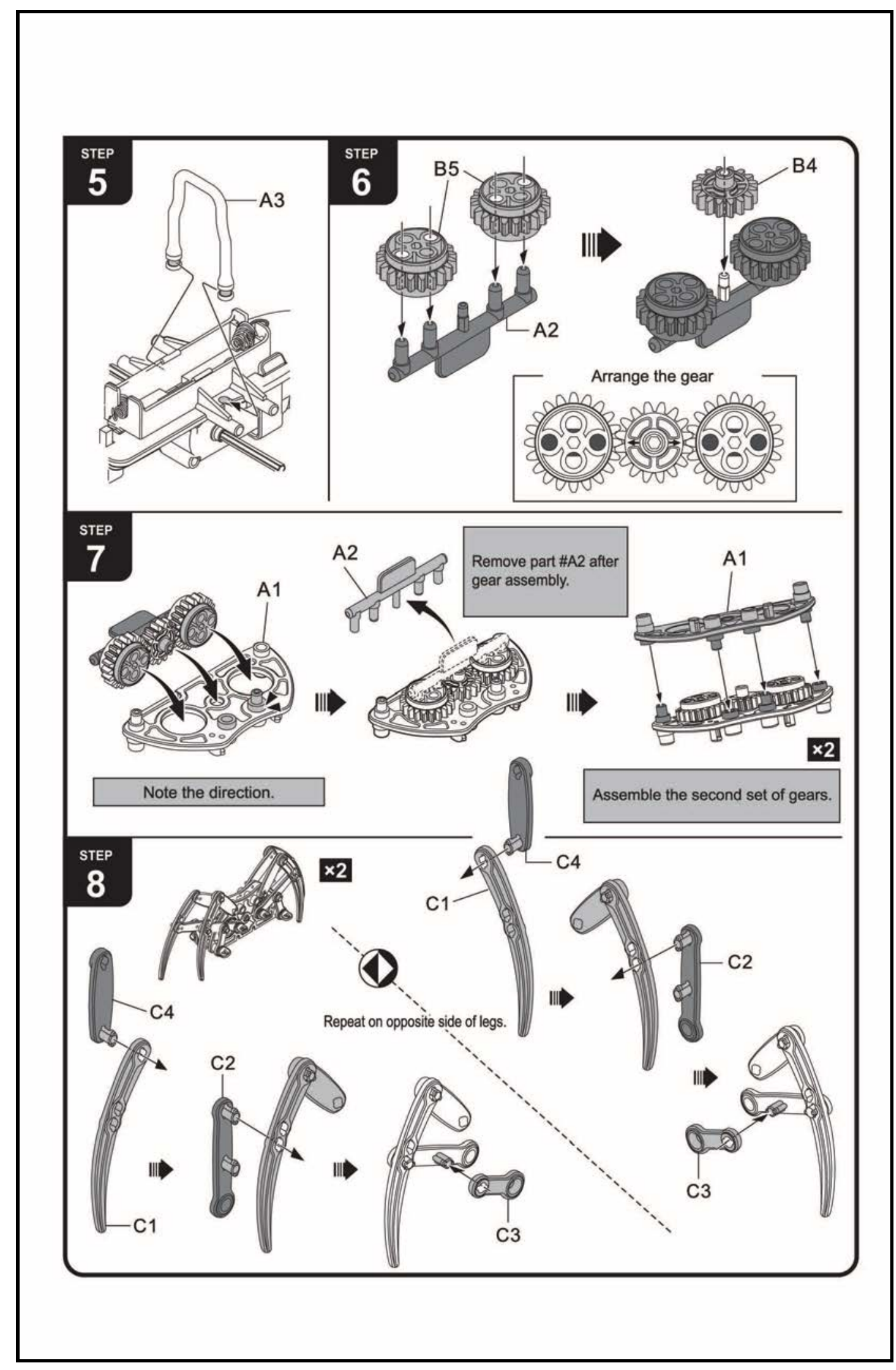




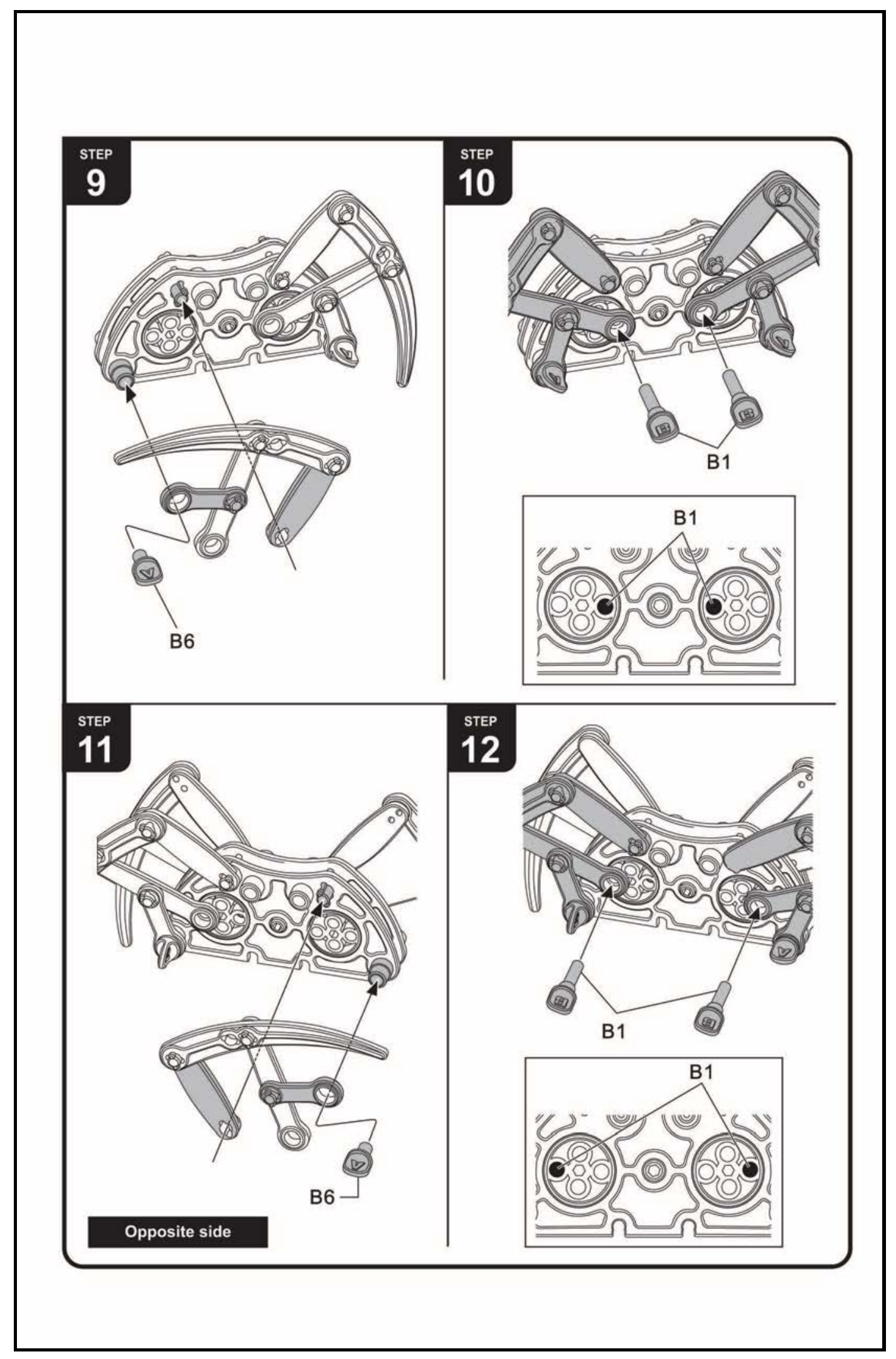




\section{Change the stride length for the spider robot as shown}
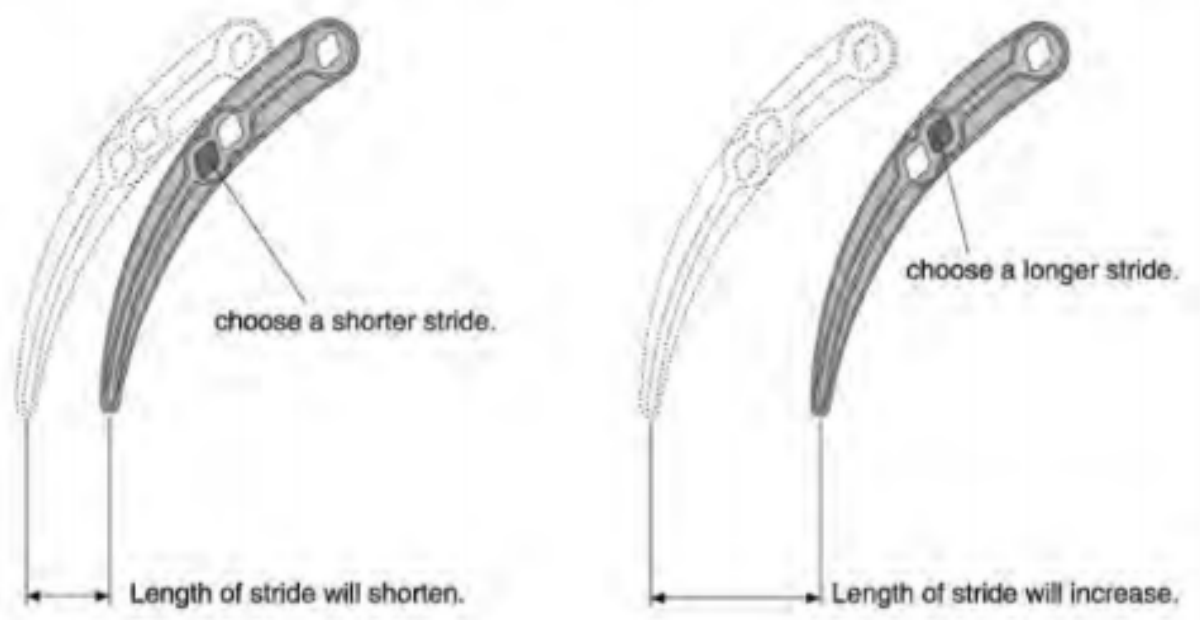

\section{Q Insert the rubber tube}
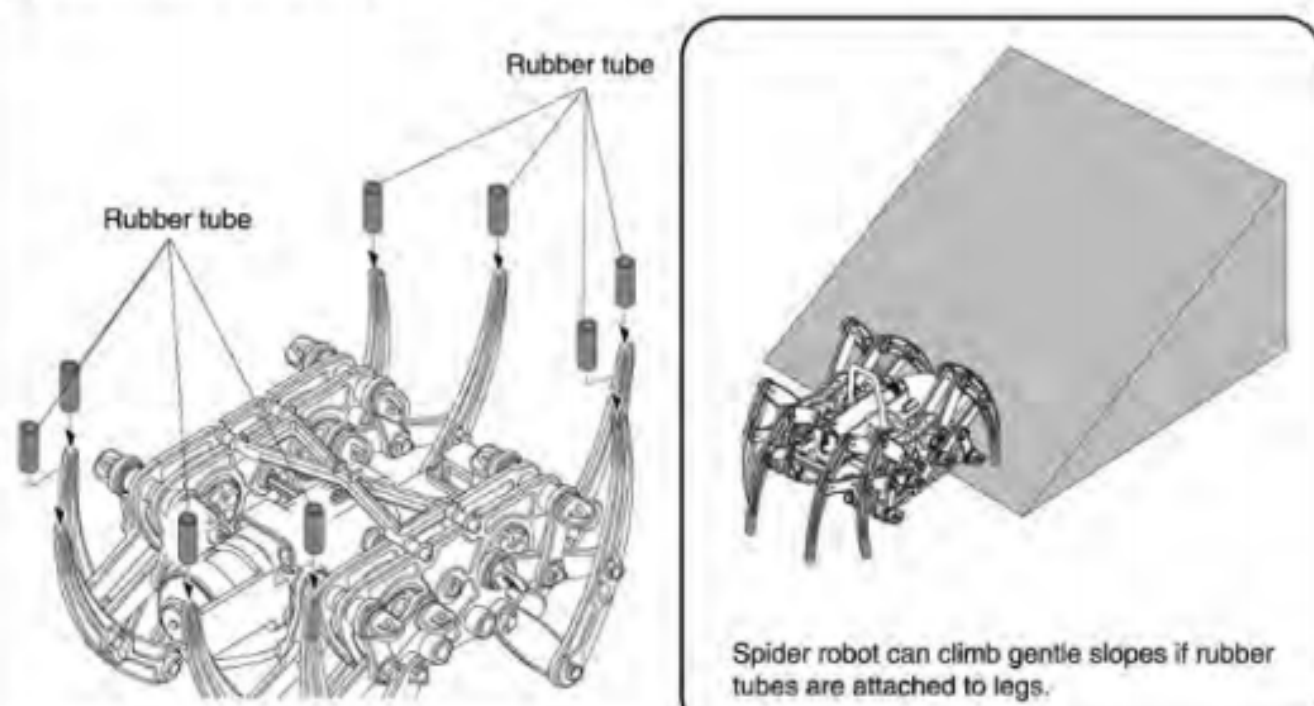

Spider robot can climb gentle slopes if rubber tubes are attached to legs.

Cut the rubber tube in 8 equal lengths (as shown) and attach to legs.

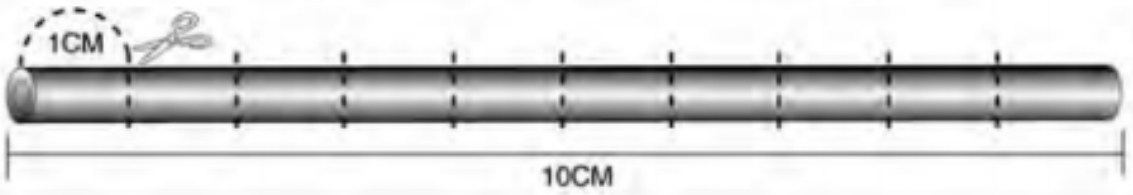




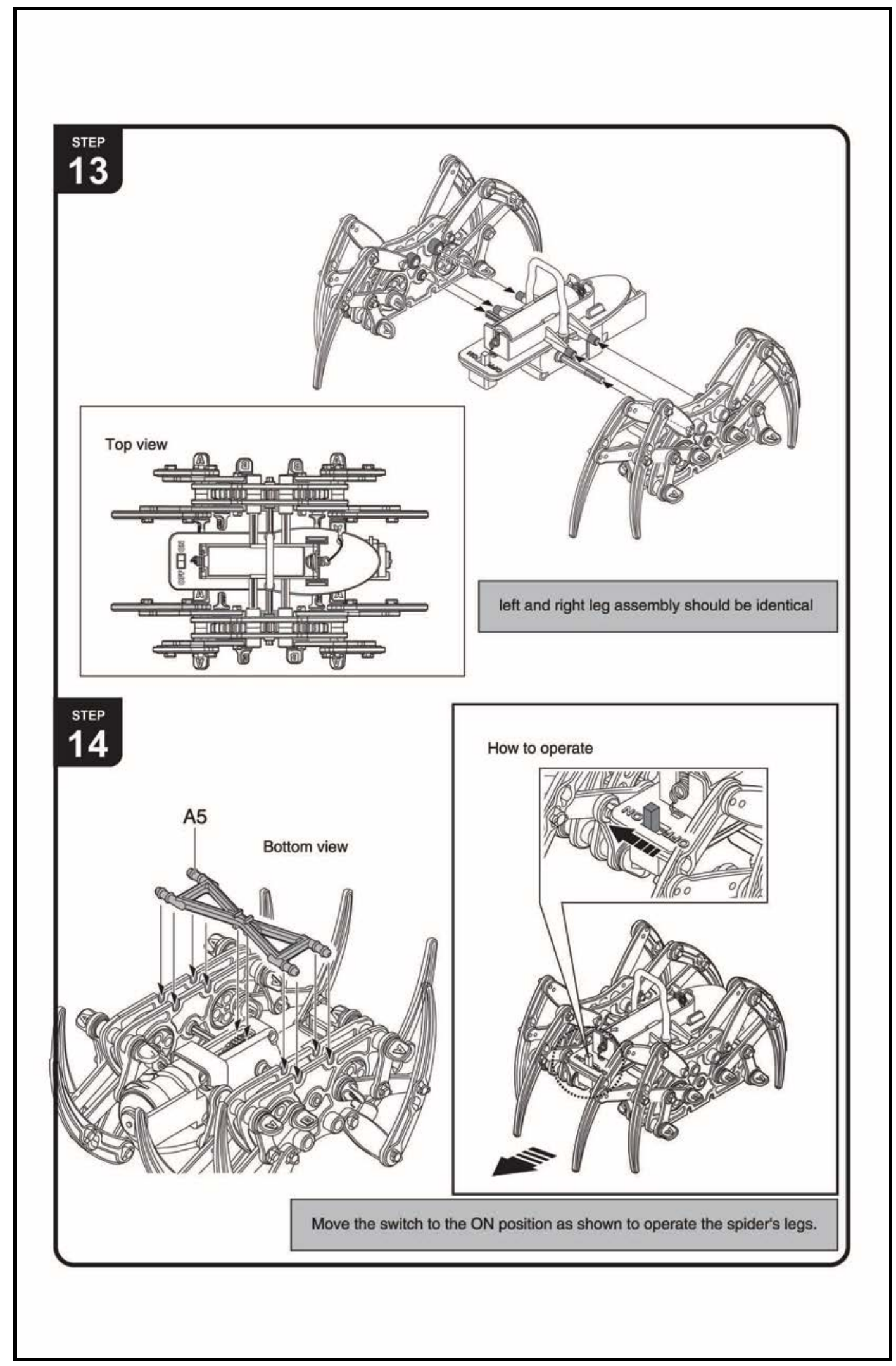


TO REPLACE BATTERIES:

Remove the safety screws and open the battery

compartment cover. Install the batteries making sure the positive $(+)$ and the negative $(-)$ poles are in correct position. To ensure proper and safe operation, battery replacement must always be done by an adult. Never let a child use this product unless battery cover is secured. Batteries are small objects and could be ingested. Keep all batteries away from small children. Immediately and safely dispose of all used batteries.

\section{ATTENTION:}

-Do not mix old and new batteries.

-Do not mix alkaline standard (carbon-zinc) or rechargeable (nickel-cadmium) batteries. -Only the same or equivalent type of batteries are recommended.

-Non-rechargeable batteries are not to be recharged. -Rechargeable batteries are to be removed from the toy before being recharged (if removable).

-Rechargeable batteries are only to be recharged under adult supervision.

-Exhausted or dead batteries are to be removed

from the toy and properly disposed.

-Always remove the batteries if the toy is not to be used for a long period of time.
Item \#: FB21002

O2017 Distributed Exclusively by: Five Below Merchandising, Inc.,

1818 Market Street, Suite 2000, Philadelphia, PA 19103 MADE IN CHINA • CONFORMS TO ASTM F963-11

Colors and contents may vary from those illustrated

Please retain package for information Visit us at: www.fivebelow.com

Have questions or comments? Call 877-220-6508 or email: questionsandcomments2017@gmail.com 

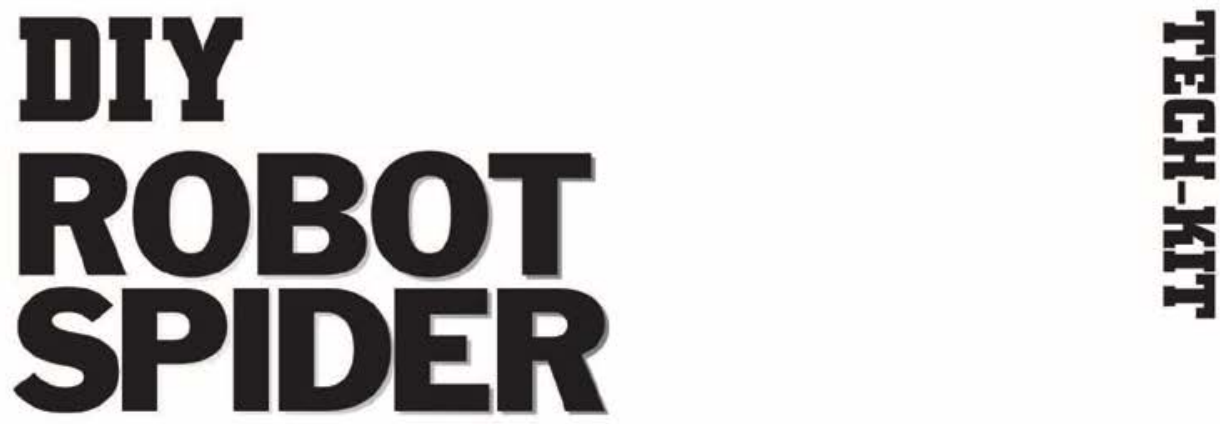

Assembly \& Instructions

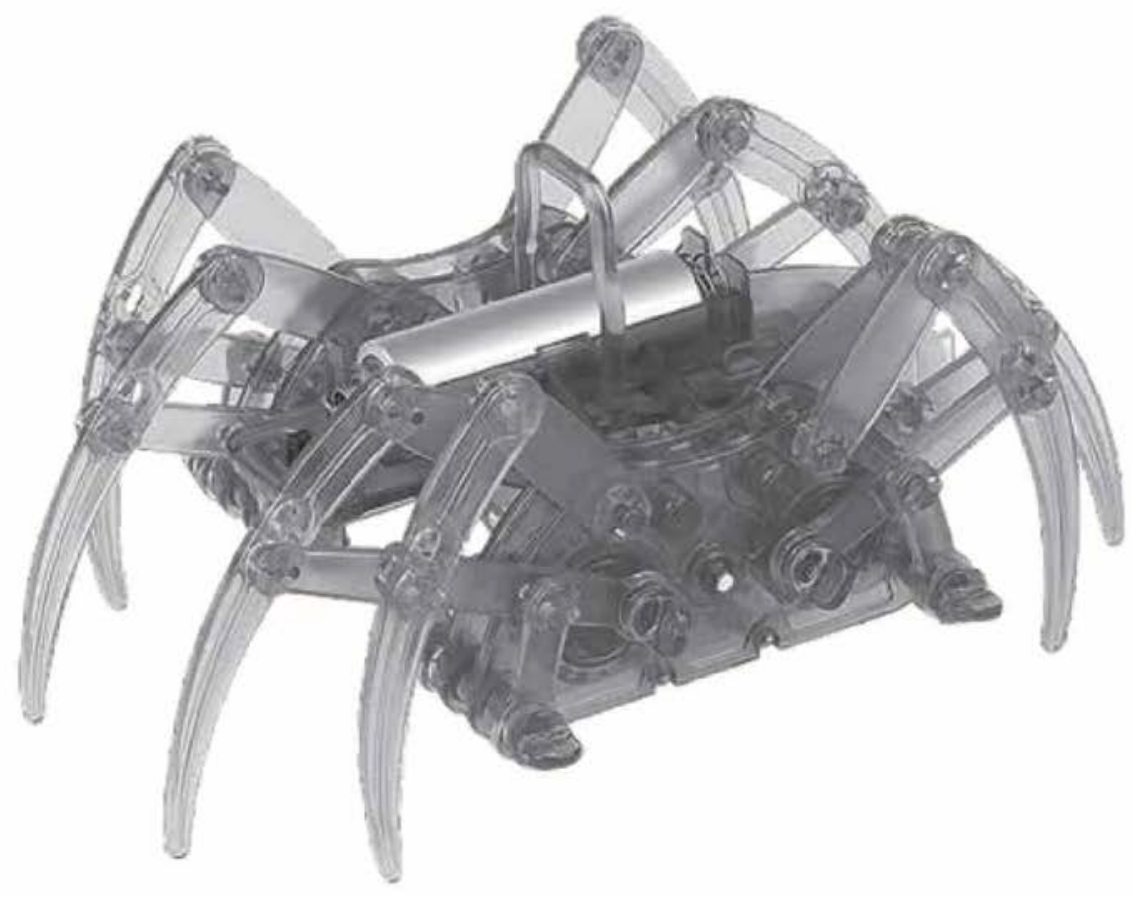

AGES 8+ 


\section{DIY \\ ROBOT \\ SPIDER}

a Mechanical Parts List \& Tool You May Need:
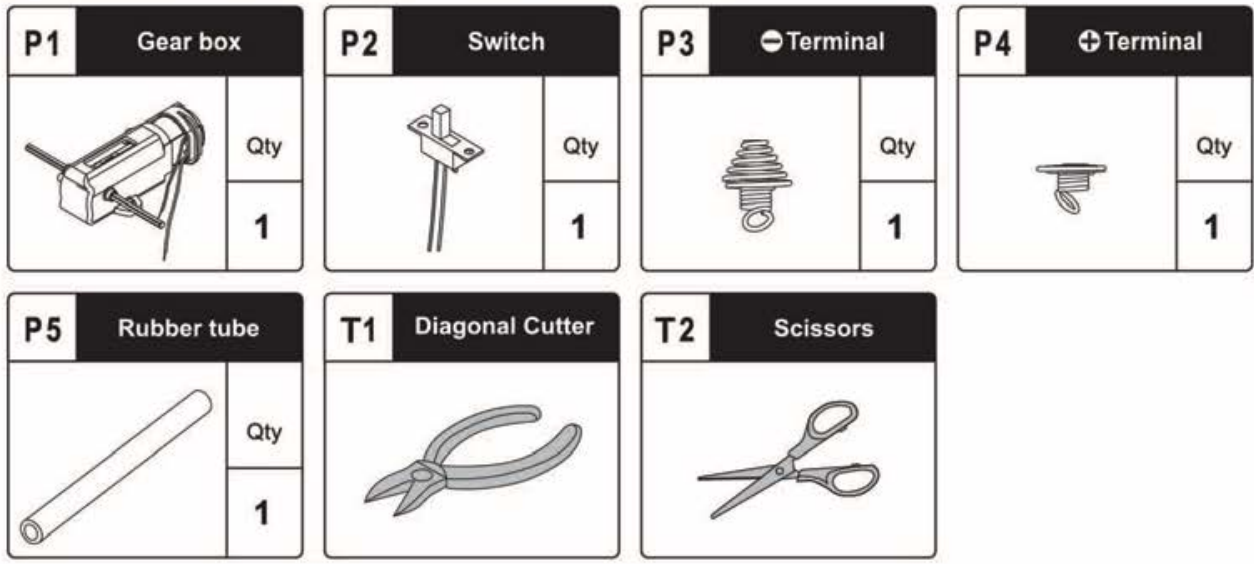

\section{Plastic Parts:}

Cut up the plastic parts in succession as shown.
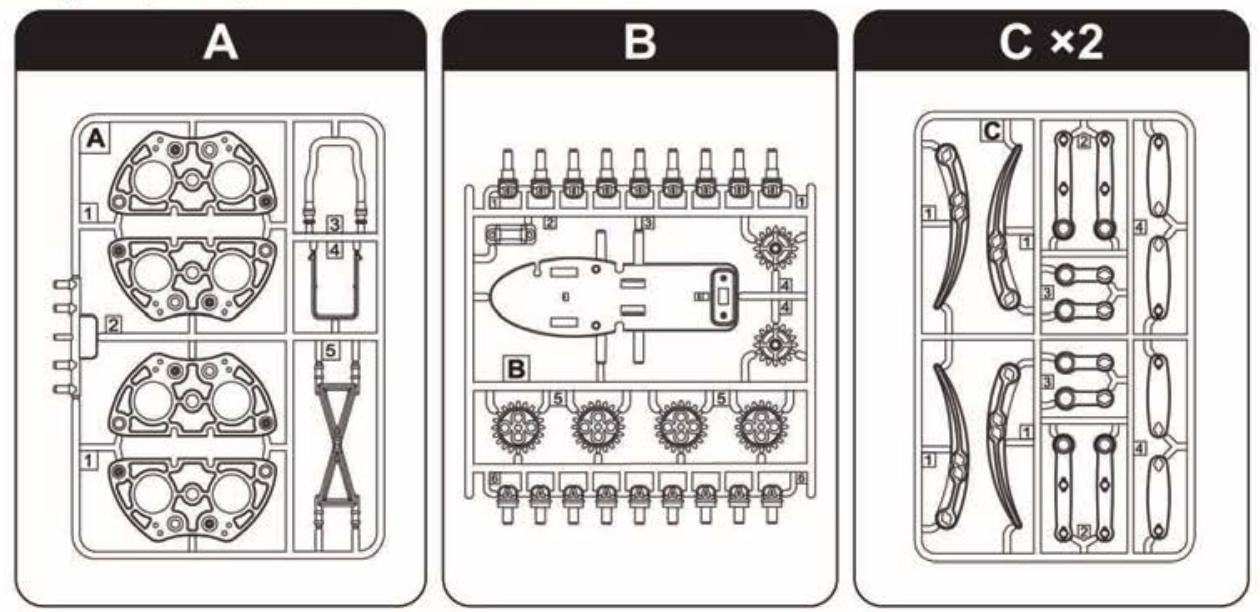


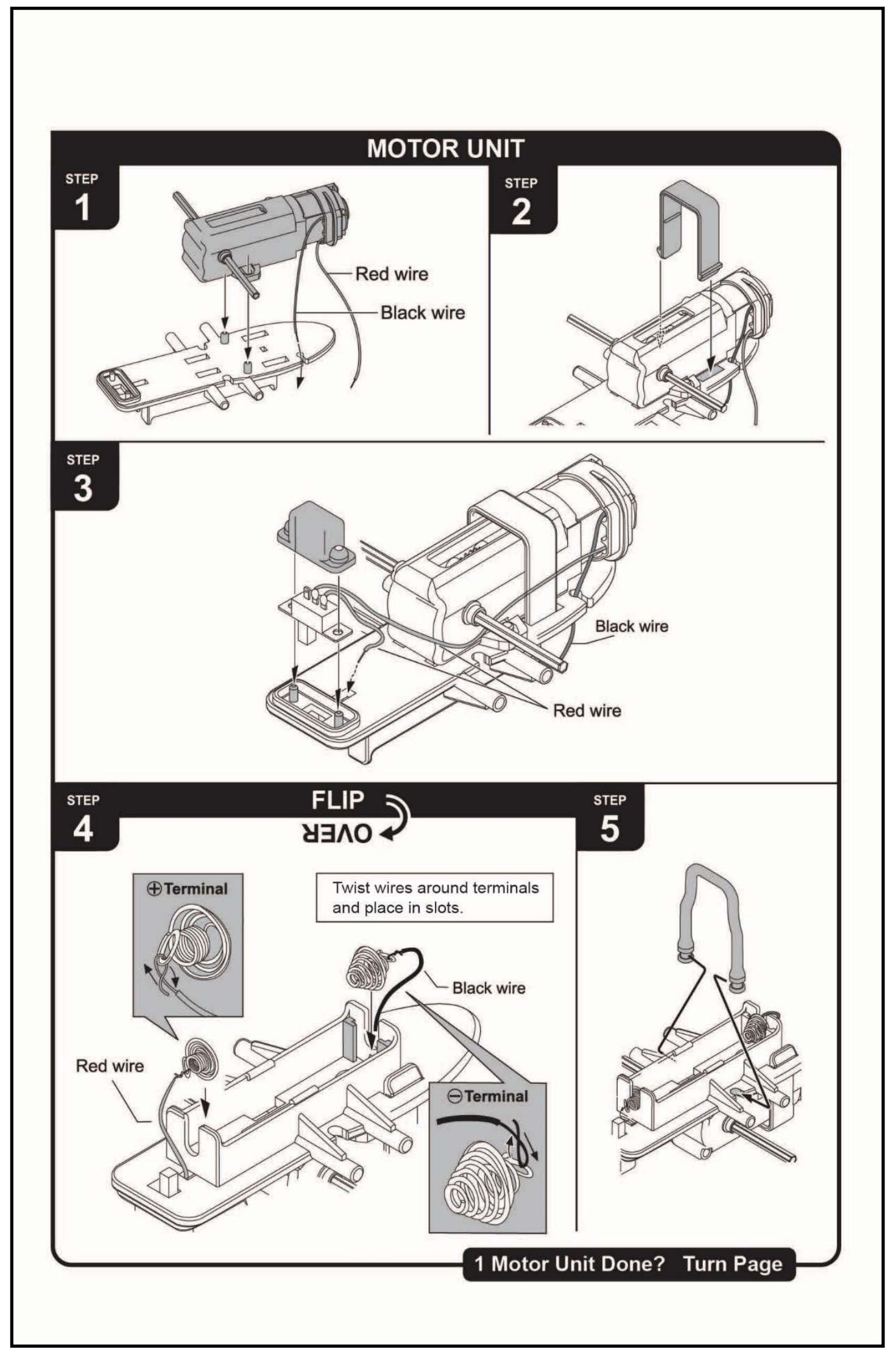




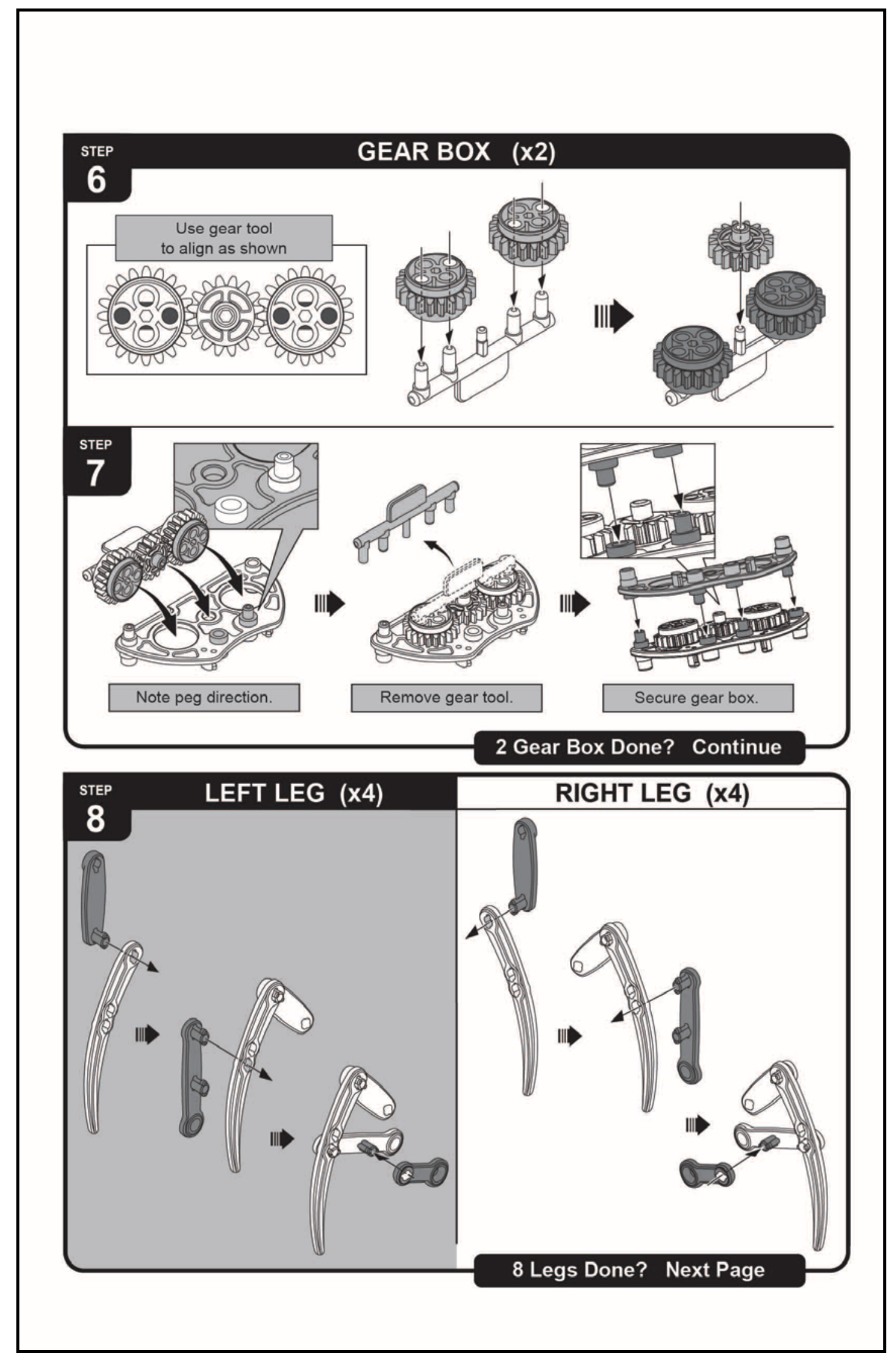




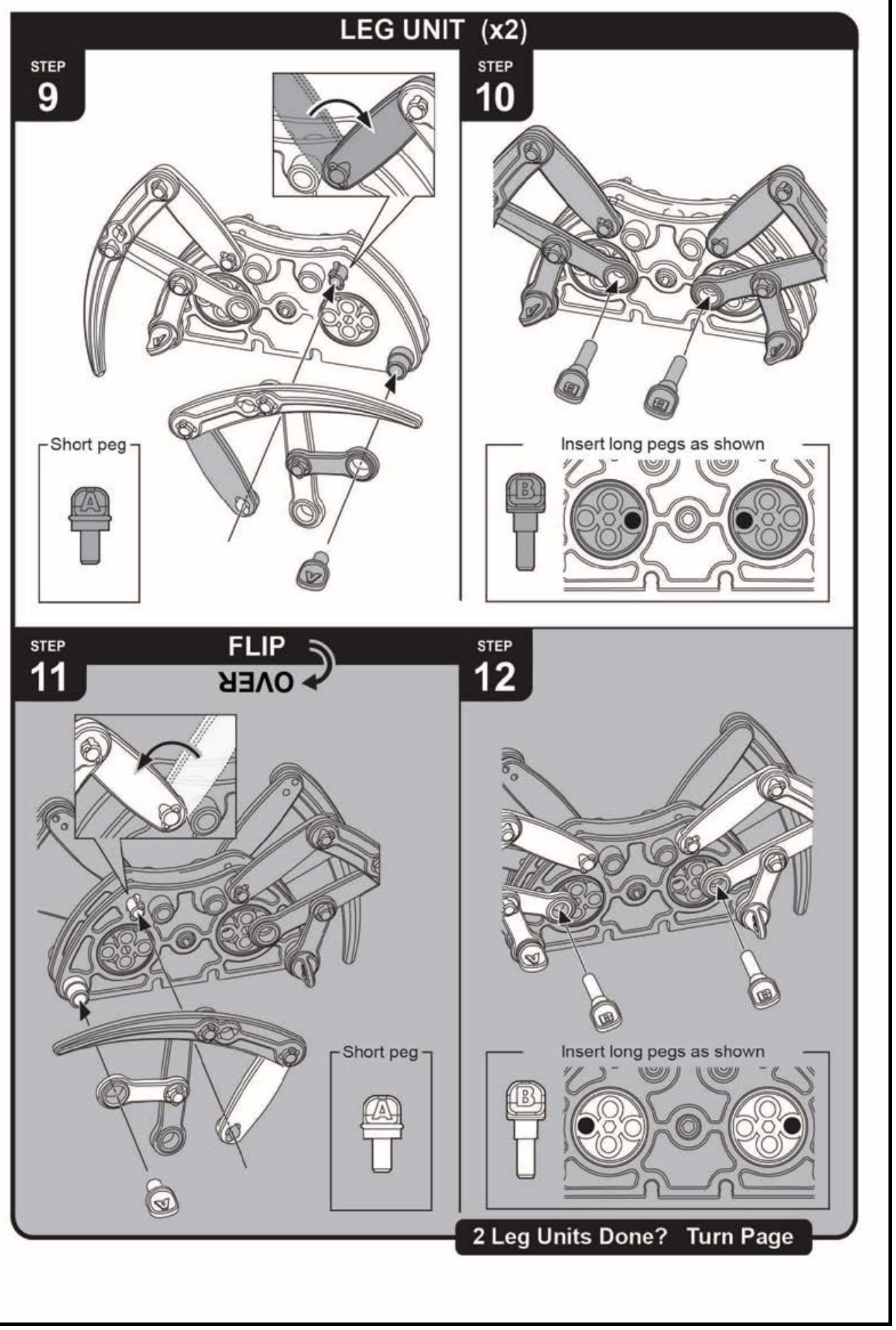




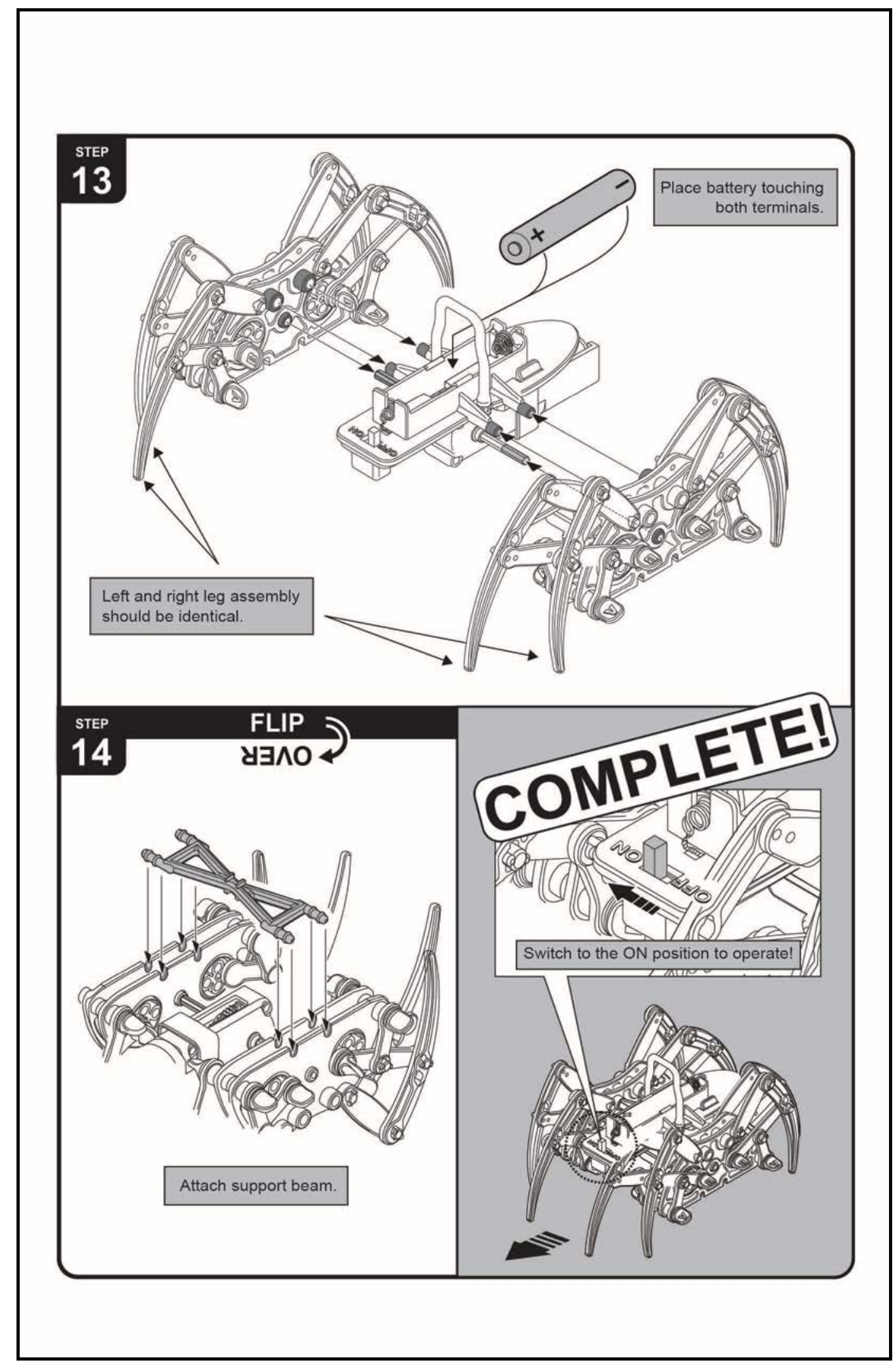




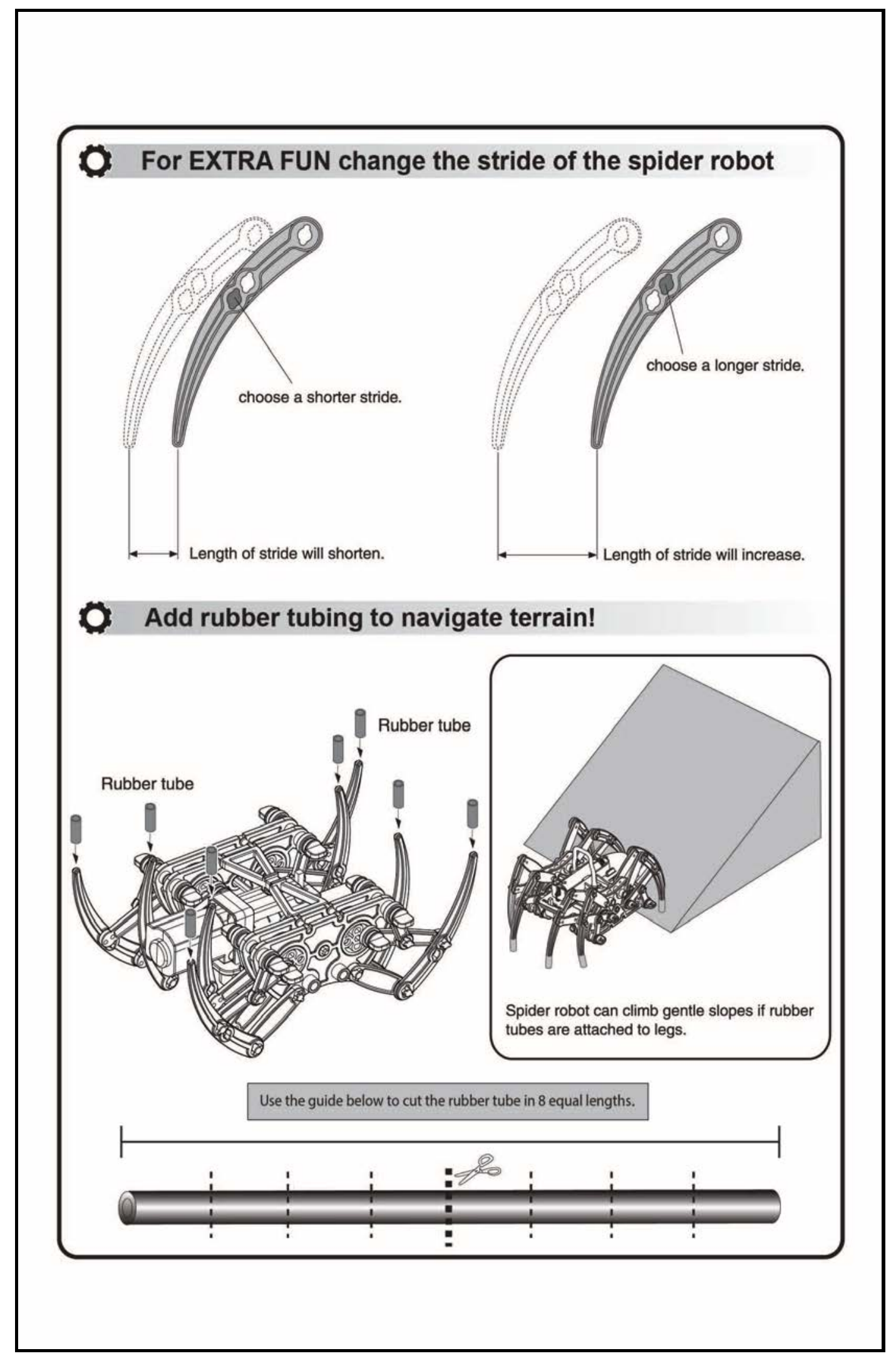




\section{Was ROBOT SPIDER fun?}
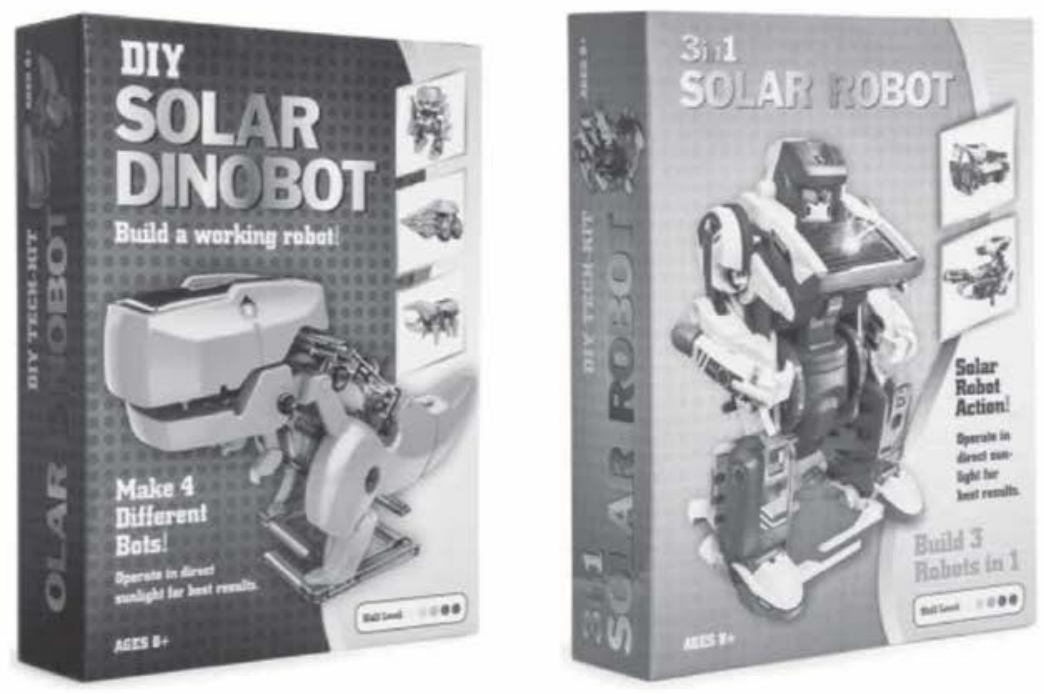

\section{CHECK OUT THESE DIY TECH-KIT BOTS!}

\section{TO REPLACE BATTERIES:}

Install the batteries making sure the

positive $(+)$ and the negative $(-)$ poles are in correct position. To ensure proper and safe operation, battery replacement must always be done by an adult.

Batteries are small objects and could be ingested. Keep all batteries away from small children. Immediately and safely dispose of all used batteries.

\section{ATTENTION:}

-Only the same or equivalent type of batteries are recommended.

-Non-rechargeable batteries are not to be recharged.

-Rechargeable batteries are to be removed from the toy before being recharged (if removable). -Rechargeable batteries are only to be recharged under adult supervision.

-Exhausted or dead batteries are to be removed from the toy and properly disposed.

-Always remove the batteries if the toy is not to be used for a long period of time.

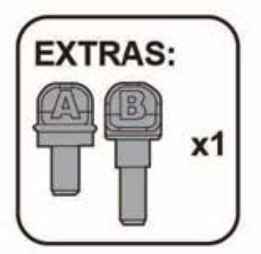

Item \#: FB21002

O2017 Distributed Exclusively by: Five Below Merchandising, Inc.,

1818 Market Street, Suite 2000, Philadelphia, PA 19103 MADE IN CHINA - CONFORMS TO ASTM F963-11

Colors and contents may vary from those illustrated Please retain package for information

Visit us at: www.fivebelow.com

\begin{tabular}{|c|}
\hline Have questions or comments? \\
Call $877-220-6508$ or email: \\
questionsandcomments2017@gmail.com
\end{tabular}


APPENDIX K: Revised Instruction Manual Quantitative and Qualitative Data

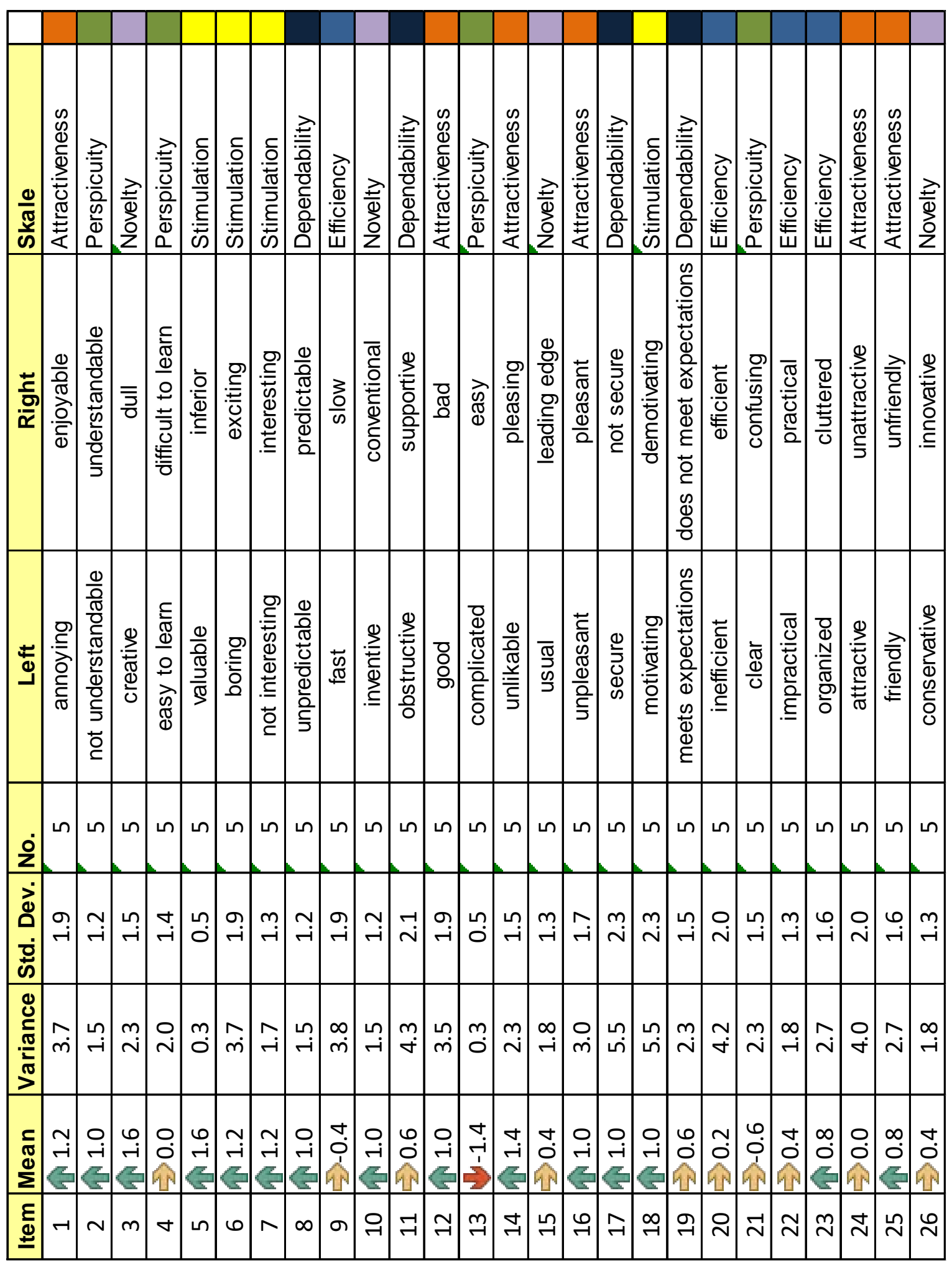




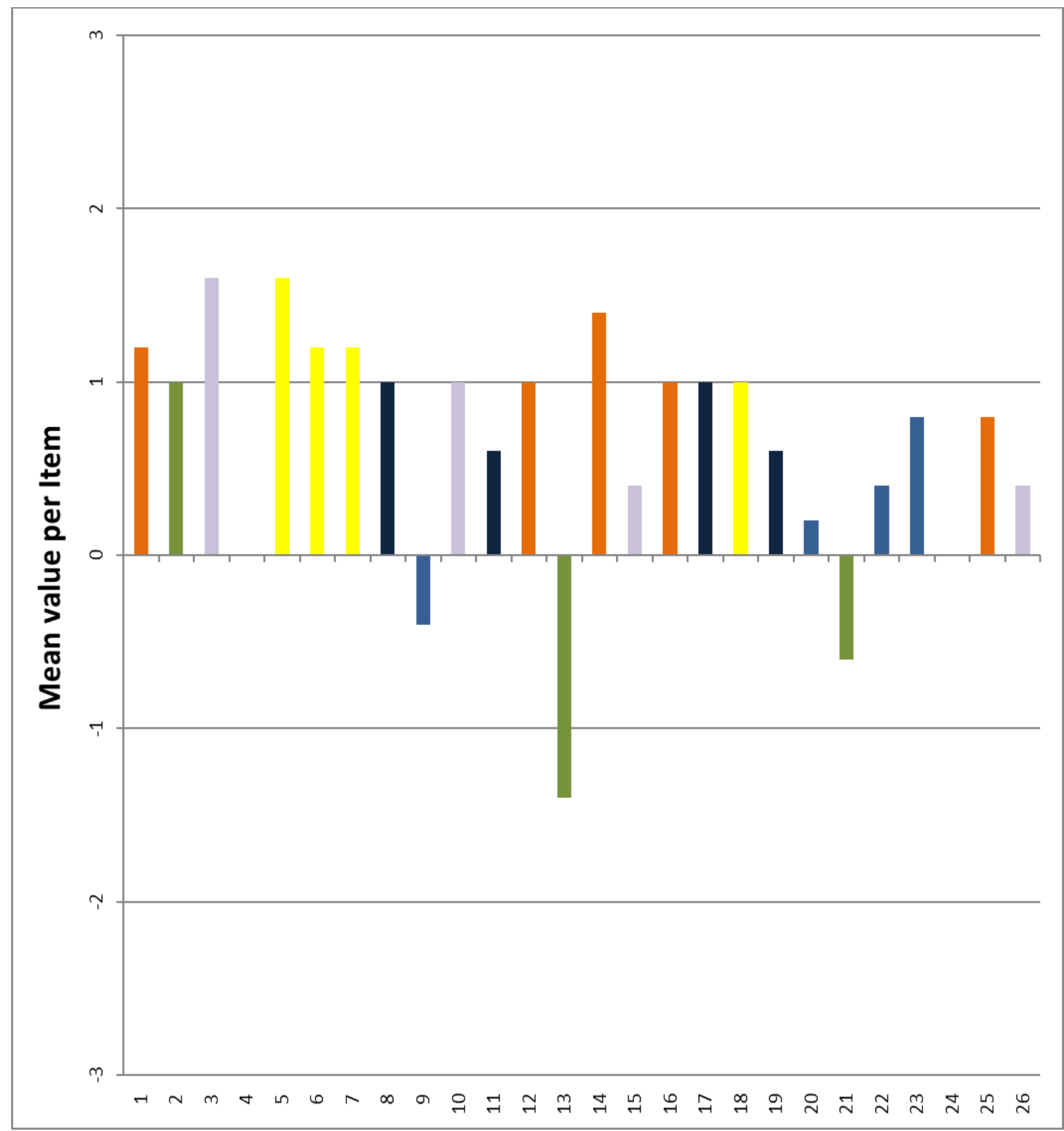




\begin{tabular}{|c|c|c|c|c|c|c|}
\hline \multicolumn{7}{|c|}{ Confidence interval $(\mathbf{p}=\mathbf{0 . 0 5})$ per item } \\
\hline Item & Mean & Std. Dev. & $\mathbf{N}$ & Confidence & \multicolumn{1}{c|}{ Confidence interval } \\
\hline $\mathbf{1}$ & 1.200 & 1.924 & 5 & 1.686 & -0.486 & 2.886 \\
\hline $\mathbf{2}$ & 1.000 & 1.225 & 5 & 1.074 & -0.074 & 2.074 \\
\hline $\mathbf{3}$ & 1.600 & 1.517 & 5 & 1.329 & 0.271 & 2.929 \\
\hline $\mathbf{4}$ & 0.000 & 1.414 & 5 & 1.240 & -1.240 & 1.240 \\
\hline $\mathbf{5}$ & 1.600 & 0.548 & 5 & 0.480 & 1.120 & 2.080 \\
\hline $\mathbf{6}$ & 1.200 & 1.924 & 5 & 1.686 & -0.486 & 2.886 \\
\hline $\mathbf{7}$ & 1.200 & 1.304 & 5 & 1.143 & 0.057 & 2.343 \\
\hline $\mathbf{8}$ & 1.000 & 1.225 & 5 & 1.074 & -0.074 & 2.074 \\
\hline $\mathbf{9}$ & -0.400 & 1.949 & 5 & 1.709 & -2.109 & 1.309 \\
\hline $\mathbf{1 0}$ & 1.000 & 1.225 & 5 & 1.074 & -0.074 & 2.074 \\
\hline $\mathbf{1 1}$ & 0.600 & 2.074 & 5 & 1.818 & -1.218 & 2.418 \\
\hline $\mathbf{1 2}$ & 1.000 & 1.871 & 5 & 1.640 & -0.640 & 2.640 \\
\hline $\mathbf{1 3}$ & -1.400 & 0.548 & 5 & 0.480 & -1.880 & -0.920 \\
\hline $\mathbf{1 4}$ & 1.400 & 1.517 & 5 & 1.329 & 0.071 & 2.729 \\
\hline $\mathbf{1 5}$ & 0.400 & 1.342 & 5 & 1.176 & -0.776 & 1.576 \\
\hline $\mathbf{1 6}$ & 1.000 & 1.732 & 5 & 1.518 & -0.518 & 2.518 \\
\hline $\mathbf{1 7}$ & 1.000 & 2.345 & 5 & 2.056 & -1.056 & 3.056 \\
\hline $\mathbf{1 8}$ & 1.000 & 2.345 & 5 & 2.056 & -1.056 & 3.056 \\
\hline $\mathbf{1 9}$ & 0.600 & 1.517 & 5 & 1.329 & -0.729 & 1.929 \\
\hline $\mathbf{2 0}$ & 0.200 & 2.049 & 5 & 1.796 & -1.596 & 1.996 \\
\hline $\mathbf{2 1}$ & -0.600 & 1.517 & 5 & 1.329 & -1.929 & 0.729 \\
\hline $\mathbf{2 2}$ & 0.400 & 1.342 & 5 & 1.176 & -0.776 & 1.576 \\
\hline $\mathbf{2 3}$ & 0.800 & 1.643 & 5 & 1.440 & -0.640 & 2.240 \\
\hline $\mathbf{2 4}$ & 0.000 & 2.000 & 5 & 1.753 & -1.753 & 1.753 \\
\hline $\mathbf{2 5}$ & 0.800 & 1.643 & 5 & 1.440 & -0.640 & 2.240 \\
\hline $\mathbf{2 6}$ & 0.400 & 1.342 & 5 & 1.176 & -0.776 & 1.576 \\
\hline & & & & & & \\
\hline
\end{tabular}

\begin{tabular}{|l|c|c|c|c|c|c|}
\hline \multicolumn{7}{|c|}{ Confidence intervals $(\mathbf{p}=\mathbf{0 . 0 5})$ per scale } \\
\hline Scale & Mean & Std. Dev. & $\mathbf{N}$ & Confidence & \multicolumn{2}{|c|}{ Confidence interval } \\
\hline Attractiveness & 0.900 & 1.673 & 5 & 1.467 & -0.567 & 2.367 \\
\hline Perspicuity & -0.250 & 0.984 & 5 & 0.863 & -1.113 & 0.613 \\
\hline Efficiency & 0.250 & 1.225 & 5 & 1.074 & -0.824 & 1.324 \\
\hline Dependability & 0.800 & 1.204 & 5 & 1.055 & -0.255 & 1.855 \\
\hline Stimulation & 1.250 & 1.447 & 5 & 1.268 & -0.018 & 2.518 \\
\hline Novelty & 0.850 & 1.025 & 5 & 0.898 & -0.048 & 1.748 \\
\hline
\end{tabular}




\begin{tabular}{|c|c|c|c|c|c|c|}
\hline \multicolumn{7}{|c|}{ Group 2 Steps } \\
\hline Steps & Overall Mea & Std. Dev. & Confidence & Confidenc & nterval & $\mathrm{N}$ \\
\hline Title & 0.733 & 2.136 & 1.873 & -1.139 & 2606 & 5 \\
\hline Materials & 0.067 & 1.978 & 1.733 & -1.667 & 1.800 & 5 \\
\hline Stp 1 & 0.433 & 1.931 & 1.693 & -1.260 & 2.126 & 5 \\
\hline Stp 2 & 1.433 & 1.078 & 0.944 & 0.489 & 2.378 & 5 \\
\hline Stp 3 & -0.033 & 2.155 & 1.889 & -1.922 & 1.856 & 5 \\
\hline Stp 4 & 0.733 & 0.535 & 0.469 & 0.264 & 1.202 & 5 \\
\hline Stp 5 & 1.233 & 1.025 & 0.898 & 0.335 & 2.132 & 5 \\
\hline Stp 6 & 0.700 & 1.761 & 1.544 & -0.844 & 2.244 & 5 \\
\hline Stp 7 & 0.933 & 0.955 & 0.837 & 0.097 & 1.770 & 5 \\
\hline Stp 8 & -0.367 & 2.364 & 2.072 & -2.439 & 1.706 & 5 \\
\hline Stp 9 & 0.267 & 2.070 & 1.815 & -1.548 & 2.081 & 5 \\
\hline Stp 10 & 1.233 & 1.470 & 1.289 & -0.055 & 2.522 & 5 \\
\hline Stp 11 & 0.033 & 2.849 & 2.497 & -2.464 & 2.531 & 5 \\
\hline Stp 12 & 1.000 & 2.297 & 2.014 & -1.014 & 3.014 & 5 \\
\hline Modifications & 2.600 & 0.303 & 0.265 & 2.335 & 2.865 & 5 \\
\hline Stp 13 & 1.433 & 0.384 & 0.336 & 1.097 & 1.770 & 5 \\
\hline Stp 14 & 1.867 & 0.730 & 0.640 & 1.227 & 2.507 & 5 \\
\hline Back & 2.600 & 0.548 & 0.480 & 2.120 & 3.080 & 5 \\
\hline
\end{tabular}

\begin{tabular}{|c|c|c|c|c|c|c|c|c|c|}
\hline \multicolumn{5}{|c|}{ Group 2 Steps } & \multicolumn{5}{|c|}{ Group 2 Steps } \\
\hline Usability Mear & Std. Dev. & Confidence & Confidenc & nterval & Desirability Mea & Std. Dev. & Confidence & Confidenc & terval \\
\hline 0.850 & 2.205 & 1.933 & -1.083 & 2.783 & 0.500 & 2.092 & 1.833 & -1.333 & 2.333 \\
\hline 0.150 & 1.989 & 1.743 & -1.593 & 1.893 & -0.100 & 2.074 & 1.818 & -1.918 & 1.718 \\
\hline 0.600 & 2.309 & 2.024 & -1.424 & 2.624 & 0.100 & 1.817 & 1.592 & -1.492 & 1.692 \\
\hline 1.950 & 0.716 & 0.627 & 1.323 & 2.577 & 0.400 & 2.074 & 1.818 & -1.418 & 2.218 \\
\hline 0.050 & 2.355 & 2.064 & -2.014 & 2.114 & -0.200 & 1.823 & 1.598 & -1.798 & 1.398 \\
\hline 0.750 & 0.771 & 0.675 & 0.075 & 1.425 & 0.700 & 1.095 & 0.960 & -0.260 & 1.660 \\
\hline 1.450 & 1.255 & 1.100 & 0.350 & 2.550 & 0.800 & 2.019 & 1.769 & -0.969 & 2.569 \\
\hline 0.700 & 1.718 & 1.505 & -0.805 & 2.205 & 0.700 & 1.891 & 1.657 & -0.957 & 2.357 \\
\hline 1.000 & 1.031 & 0.903 & 0.097 & 1.903 & 0.800 & 1.304 & 1.143 & -0.343 & 1.943 \\
\hline-0.550 & 2.280 & 1.999 & -2.549 & 1.449 & 0.000 & 2.739 & 2.400 & -2.400 & 2.400 \\
\hline 0.100 & 2.226 & 1.951 & -1.851 & 2.051 & 0.600 & 1.949 & 1.709 & -1.109 & 2.309 \\
\hline 1.350 & 1.636 & 1.434 & -0.084 & 2.784 & 1.000 & 1.541 & 1.351 & -0.351 & 2.351 \\
\hline 0.000 & 2.894 & 2.537 & -2.537 & 2.537 & 0.100 & 2.837 & 2.487 & -2.387 & 2.587 \\
\hline 1.100 & 2.382 & 2.088 & -0.988 & 3.188 & 0.800 & 2.168 & 1.900 & -1.100 & 2.700 \\
\hline 2.600 & 0.518 & 0.454 & 2.146 & 3.054 & 2.600 & 0.418 & 0.367 & 2.233 & 2.967 \\
\hline 1.350 & 0.518 & 0.454 & 0.896 & 1.804 & 1.600 & 0.418 & 0.367 & 1.233 & 1.967 \\
\hline 2.300 & 1.095 & 0.960 & 1.340 & 3.260 & 1.000 & 1.414 & 1.240 & -0.240 & 2.240 \\
\hline 2.600 & 0.548 & 0.480 & 2.120 & 3.080 & 2.600 & 0.548 & 0.480 & 2.120 & 3.080 \\
\hline
\end{tabular}


(00:20) Examiner: What did you think about the experience?

Participant: I started off very intimidated by all the little pieces but once I got the feel for what I was doing it was okay to replicate.

(00:43) Examiner: How satisfied or dissatisfied were you with instruction manual?

Participant: [Referenced Materials Page] So I like that it has the parts list that was important for me, as far as the mechanical parts . The plastic parts, I didn't understand any of it. I hardly looked at it, I didn't even know it was looking at, because there in a pile. This piece [Referenced Step 5] I wasn't sure cause it was in the pile. What I should have done is I should have spread out all out first so that was probably my fault. [Referenced Step 6,10,12] And I think some of the things, like the shorts pegs in the long pegs, where you put these gears and I didn't pay attention to that and if I would have looked at it it would have made it much more helpful for me.

Examiner: Why do you think that is?

Participant: [Referenced Step 6,10,12] I was looking at the picture and I wasn't looking at the boxes. and so yeah so thats probably... it says in here like in three different places where to put the those gears or where to put the legs in and I didn't look at any of those three. So, my eyes were drawn to the big what it's supposed to look like.

(02:05) Examiner: How about if you just would have like overall, we're going to be driving the steps little bit later, overall would you consider this manual yes yes this is a good manual or no I'd rather have something else .

Participant: Yeah, I think it was good I think it was a little confusing like I said at the beginning when I started off actually I was fine until I got to the leg assembly [Referenced Step 8]and then I really couldn't tell until I got it on wrong that these were on the wrong side. So because they need to be... and when you look at the arrows you can tell they need to be the other side and then the last piece needs to be on the other side. But, I couldn't tell that until I put it on that I can't assemble it because these things were in the way. So then I just had to replicate the same thing I had done.

Examiner: So, once you saw one you were able to build off of that one?

Participant: Yeah, and I didn't even really look at... well, I did but that's probably why I didn't notice this part because I was thinking about replicating those legs. It does say right there times for but again just looking at the big picture of stuff.

(03:27) Examiner: With that actually, I'll come back to that later cuz that's something I want to ask you about. So let's talk about, well maybe we're here, any aspects of the manual that were particularly useful: a couple of things that really got me where I needed to go?

Participant: The flip over was totally helpful cuz I would have been confused if it didn't say flip over it. Seems like a small thing but it makes a huge difference because then I know what I'm 
looking at so that was really helpful. After I noticed the short peg-long peg differentiation that was useful too.

(04:17) Examiner: So how about unuseful things? Thinks that were maybe looked over or just..

Participant: yeah well, [Referenced Step 4] these things I didn't understand what I was supposed to do. If maybe it said 'for the batteries,' then I would have said oh okay that's the positive and negative for the batteries but I didn't know what that was when I was putting it in. Then again you're talking to someone who doesn't know much about assembling things.

(04:58) Examiner: Then also I believe while you're doing it you had mentioned 'oh I need the battery' and then you kind of flipped asking where this whole battery thing was?

Participant: That was on this page towards the end [Referenced Step 13] cuz I couldn't if the battery is on the top or the bottom of the spider. And I guess I could have done back and looked at the picture [Referenced Title] and then that but while I was looking here, I had to figure out if the batteries on the top of the bottom I don't think that was a thing.

(05:31) Examiner: So this is just a question, do what I have made sense to do the batteries and the terminals together? At the beginning?

Participant: At the beginning? I don't think I would have wanted to put the battery in while I was assembling it because it would have kept them falling out and would have driven me crazy. So it's just a matter of I just need to figure out where the battery is going and that thing [Referenced Step 5] I don't know I didn't know what that thing was.

(06:08) Examiner: So with that, if that one you weren't sure about the piece and you had the tube and then you thought 'maybe its the tube' and then you just said it to the side. So, when did you realize that...?

Participant: When it was left over cause it was sitting there and it was there. Cause again, it is back here but again I didn't have them laid out like this. I just started grabbing stuff and putting stuff together. Where in reality, people would normally, it would come like this so you would look at it and make sure they have all the parts.

(06:44) Examiner: Okay that's all good.

Participant: I think that makes a big difference, when out of the box it's like this [Referenced Materials Page] and you can see everything labeled, pile some people would lay it all out make sure looks like this. I just start grabbing.

(07:04) Examiner: That is one difference instead of buying a bunch of these I had to because they shall come in a big sheet and you step allow so that might be...

Participant: Well there are some people like my husband he would lay all these pieces out first and make sure that you need it whereas I just started grabbing so this probably two different ways of doing it. 
(07:32) Examiner: Let's talk about aspects of the manual that particularly enjoyable?

Participant: Nice to see what the end result is supposed to look like [Referenced Title]. I think that's important, right at the beginning, yep. I need to know where I'm going with this thing. And really the pictures were very helpful. I think that just being able to look and even though it was a little difficult to figure out where the like pieces were supposed to go, once I was able to figure out the first one then all made sense. So I think the pictures were good.

(08:11) Examiner: Is there anything else about the picture or literally any ink on the page?

Participant: [Referenced Step 14] This is fun seeing that your complete, to know that you are done, turn on. If it didn't work I would have been really mad but yeah. I like that ta-da part of it. This actually was helpful to the ruler and scissors thing [Referenced Extras Page]. Does it really climb things when it has the... have you tried it on an incline?

\section{(09:00) Examiner: Where there any other enjoyable aspects?}

Participant: Yeah, turning it on and it worked. That was the biggest that was the funnest thing for me that was the exciting part.

(09:21) Examiner: Anything else?

Participant: [Referenced Back Page] This was good to know because I did have extra parts and I don't know if it says that in the beginning that you'll have parts. But, that's kind of nice to know because I got kinda concerned when I saw these two extra parts, I was like, 'I did I forget to put something on?' But, when I turn to the back and saw that I might actually be helpful to put closer to the front so you know that you have these extras.

(09:50) Examiner: So let's talk about some unenjoyable aspects.

Participant: The only unenjoyable was not knowing what that thing was [Referenced Step 5] and knowing that I had putting the leg pieces on backwards and then I had to take it off and reassemble after but it was just the one leg [Referenced Step 9], but after that it was very clear you know they were trying to show how the legs are supposed to be assembled other than that no everything was good.

(10:26) Examiner: Let's rank the top three best steps and why you would choose those three.

Participant: Well the top best step is turning it on and it works by far the top[Referenced Step 14]. This is a good step [Referenced Step 6] this piece shows how to put the gear together and slide them right in. The gear tool is good, thats the best way to explain put them in there make them work so that's a good step.

(11:13) Examiner: Quick question on that, what if it didn't say gear tool? Would you have...

Participant: I wouldn't have had any idea what this is for. I would have thought you was a leftover piece or I probably would have thrown it away thinking it was just holding something together do you know what I mean? Cuz that's what my initial thought was when I first saw it. 
[Referenced Step 1,3] The wires were actually easier than I thought they're going to be because I first thought 'wires' I was like, 'oh no I have to figure out where these wires have to go.' It was easier than I thought. I just didn't know where what the terminals were.

(12:20) Examiner: So how about the worst three steps if you had to do your bottom three?

Participant: [Referenced Step 5] Bottom three, again figuring out step 5 figuring out what that piece was in step 5 knowing what that was. I don't know if there really was anything else besides the fact I can figure out what it was everything else was okay.

(13:10) Examiner: Is there anything else you'd like to say about the instruction manual or your experience?

Participant: Its probably more my... cuz everybody else does it differently... I think that if I were to do it again or were to get some advice on reading instruction manual, I would read the manual first and then go back and start putting things together because I just saw step one and I just started doing step one whereas if I would have read their first I would have been a lot easier because I would have seen where the pegs were and where everything goes.

Examiner: So maybe that speaks a little bit to context?

Participant: Well somewhere on here it should say, 'recommended read instruction manual before beginning assembly' and so that way it would make more sense to me but everybody's learning styles are different to so you can put it on there 10 different places and people still probably wouldn't read it.

(14:17) Examiner: I'm just going to ask you one more and that's a multi question part. I'm just going to step through some of the observations that I had and see what you were thinking. So first we're going to start with step number 4, it seemed at first that you didn't know how to twist the wires on to the terminals? What were you thinking there?

Participant: Well I wasn't thinking that was where the battery goes. I didn't know what I was doing and so and um yeah. [Referenced Step 4] And I don't know if it says anywhere the actual battery case. so I was putting it in there know what I was doing so I didn't know if the wire was supposed to go all the way through but then once I said I wrapped all the way around okay.

Examiner: So when you knew that show the battery goes here if you didn't know what these metal things we're at first?

Participant: I didn't know what those things were at first. And it does say positive and negative terminal but that didn't mean anything to me.

Examiner: So when you knew that the battery terminal went there then you're like 'oh I know what these things are.'

Participant: Yes then I knew right away that they just needed to snap in and that's where the battery needed to go. 
(15:34) Examiner: And the second part that is you didn't know to set the terminals, there are these little slots for them. And, eventually you got them in the slots but maybe at first you didn't know to slide them in there?

Participant: No, and I couldn't tell picture if it was supposed to... and then again I didn't know that that's where the battery is going so I didn't know if it had to lay in there there or what was happening... But it does say place in slots.

Examiner: Then I noticed in step 5 maybe you looked at the picture and thought, 'oh they're attached.’

Participant: Right.

(16:09) Examiner: Now let's step down to step number 7. You mentioned well... you said I'm looking for three things, do you remember saying that or what you were thinking when you first saw it?

Participant: Those little gears I think in Step 6... no I have the gear some step 6.

Examiner:And after you said that you were looking at these body pieces right here. I'm not sure what you were thinking... what I kind of thought was oh these were three pieces you're putting together instead of...

Participant: The gears in the two sides?

Examiner: Yes instead of subsequent steps... do you remember anything about that?

Participant: No I don't.

(16:56) Examiner: So then at the top of number 6 it says... what does this mean to you?

Participant: So all I was doing was lining up the gears.

Examiner: So how about actually above step 6?

Participant: You mean where it says 'x2?' Yeah, I was only doing one at a time. I did the same thing down here. I didn't even look at the ' $\mathrm{x} 4$.'

(17:28) Examiner: And then the notes at the bottom of each section, what do you think about those?

Participant: Gearbox no... I didn't... I'll be honest with you, I didn't read much. I was mostly looking at the pictures. Yeah, and that's how I missed a lot of this stuff: short peg-long peg, a lot of that stuff. I was just basically looking at the pictures.

(18:05) Examiner: Just an in general, I noticed that you built one of everything and then once you finished you were like, 'now I can go back to the beginning and do it all again.' So you would say that was kind of your strategy, 'let me be building up?' 
Participant: No, I wouldn't say that was a strategy. I just didn't look at the 'times' how many of I needed to do. I just did picture, build, picture, build, picture, built.

(18:26) Examiner: In step 8, you actually assembled two left legs instead of a left and a right. And then, in Step 9 you put the left leg on the left spot, then you put a left light on the right spot and then you're like 'oh wait something doesn't look right.'

Participant: Yeah and then I had to flip the around, because I had the pegs or whatever these things were on the opposite side and it wouldn't attach. So then I realized oh these all have to be on the same side and so then when I went back, after I did the first legs then I was like okay this is how the legs go together. So I was really 'picture, built' exactly.

(19:13) Examiner: Another note was that, after you built the first leg and attached it working with this one, instead of referencing the manual you referenced the actual part. So is that your preference? 'I already have one so I'm going to look what I've already that done.'

Participant: Yes, one already work so I figured that I'll just going to go like that so I didn't look at the manual again.

(19:44) Examiner: Then in step 10, noticed that more legs were needed when you got to step number 11 because you only have the two, so then you reference a toy to be able to build more legs.

Participant: I just kept on repeating what I had done rather than looking at the manual.

(20:05) Examiner: Step 12, I noticed that instead of putting on both legs: instead of putting on this leg and this leg and putting one on, You built this leg and then you put the short peg and a long peg in so it's almost like you combined step 9 and 10 to do the left side then the right side and then move on?

Participant: Yes.

(20:39) Examiner: Also you didn't notice the headers or footers, but you did notice the 'flip'. Do you have an idea of why?

Participant: I don't know, I don't know if it was just the arrow that grabbed my attention or that I knew that it didn't look like what I was working on so I knew that something had to happen. But, the flip over was really helpful even though I didn't really read a lot of the rest of it. It just kind of drew my attention for some reason.

(21:31) Examiner: Would you say that it didn't really make sense to going to make two of these things, then make 8 legs and then I'm going to have all these little assemblies together and then build them all into one big thing? Your preference was to build this thing and then I'm going to build onto it and on here and on here and on here.

Participant: Yes and then just built on to that side. And I don't know if that's... the steps are helpful too but it does tell you which are right and left but once I had it right I just went ahead and do the same thing over again rather than referring back to the manual. 
(22:00) Examiner: Then on step number 13, that's when you figure it out step number 5 to put this little guy on?

Participant: Yeah, because it was left. Because I didn't see it initially.

(22:31) Examiner: And then it was hard to get the battery in their right because there's these weird little knobby things?

Participant: Yeah, I don't think I had all of these backside of push these things back. I needed to push these back a little further because they kept on flopping out.

(22:55) Examiner: There's a note that said 'left and right leg assembly should be identical.’ Did you understand what that was saying?

Participant: In so much that as assembly wise, I didn't even notice that these were identical until... well until you pointed it out. Because identical to me that they should be walking the same way, just that the assembly should be identical I guess.

(23:33) Examiner: There's just some slight confusion at step 13 thing where you're looking at the step and you were kind of getting these pieces together, you saw flip over you flipped it over and then you started to assemble these?

Participant: Yeah, I was just trying to get that thing I was trying to align the top holes. I had it upside down...

Examiner: I think I see it right now this piece it to come out of place.

Participant: Yeah something was crooked.

Examiner: Anything that you would like to say?

Participant: It's funny because when you go back and read I'm realizing' oh yeah now I'm understanding what that meant' 'should be identical' and if it didn't work walking in circles or whatever it would cause you to go back and noticed that stuff that's why because those legs are aligned properly. 
Group 2 Trial \#7 (VERBAL RESPONCES)

(00:10) Examiner: What you think about the experience?

Participant: It's more of a first kind of for me. It's not exactly a first but kind of first. So I'm not into do-it-yourself and all those kind of things.

Examiner: So, your experience of your, like, first major DIY thing, was it good was it bad?

Participant: It was good since at the end I was able to complete it.

(01:04) Examiner: Anything else with experience overall?

Participant: I thought some of the steps were confusing.

(01:15) Examiner: So how about just overall how satisfied or dissatisfied where you with the instruction manual?

Participant: Do you have a scale or... On a scale of 7 where 7 is fully satisfied, I'd be a 4 because of some of the steps that are not clear and not a 1 because most of them were clear.

(02:18) Examiner: Let's hone in on some of the specifics, was there any aspects that were particularly useful?

Participant: Yeah there was a differentiation in the color. most of the time it was right but at times was not. Suppose I need to make a sub assembly, that's two or more parts and those parts are being different colors. So that was helping. In Step 7, there should have been a dark color if you see here [Reference Step 1]. I thought most of the times, this one meant a dark color and this one meant light color.

(03:50) Examiner: So it was your preference that the colors of the instruction manual would similarly match the colors of the toy?

Participant: Yes. If in one step there's a number of parts, if they differentiated these parts the different colors in might help.

Examiner: So do you mean like a hierarchy like this card place going into this other colored piece?

Participant: Yes. What they have done is every time whatever they already have is in white and what needs to be assembled is in the darker color.

Examiner: Is that a good thing or a bad thing?

Participant: Good at times, bad times because then they're able to differentiate it from what they already have and what needs to be assembled. 
Examiner: Could you show me example for that helped?

Participant: In the first few steps.

Examiner: How about a time where it wasn't so good?

Participant: Step 7, because I was looking for a base with a light color and then in Step 10 I thought that the legs would be in the light color as well.

(06:15) Examiner: How about some aspects of a particularly unuseful?

Participant: There's this one [Reference Step 13], the battery, and I believe for the left and right leg [Reference Step 8] because you cannot actually differentiate between them. If you just have the sub-assembled parts you won't be able to differentiate between them. Maybe they could have said left leg and right leg into 4 in the manual. I mean to say why do they have to have two different?

Examiner: So you're trying to say maybe all eight like should just be the same and then you can put them on.

Examiner: Okay anything else?

Participant: I think this, I don't find this use of gear tool very helpful [Reference Step 6]. Initially, I thought that when I you use this gear tool to fix the gears and the body it would get fixed and that very moment but that didn't happen.

(08:15) Examiner: How about any other aspects of instruction manual that are particularly useful or unuseful?

Participant: This thing, the Step 8, it was very useful but I didn't follow it and I messed up.

Examiner: So it was useful but you didn't follow it, what do you think that is?

Participant: This thing, I meant to say that, this part would get under the longer part and I didn't follow that at times. So sometimes the part was on top of that. So it was very clear but I missed on that.

Examiner: So you said it was very clear but...

Participant: Yes but I missed it.

Participant: So one other thing, what does this thing do? It should ideally support this thing?

Examiner: I think the purpose is to keep the two legs on so the legs don't fall out this way.

(10:06) Examiner: So how about aspects of the manual that were particularly enjoyable? 
Participant: So you want to know about some specific things? So there is moments when I was confused which is the positive and which is the negative one among these terminals. But, then I figured out there is a clear picture negative is bigger. So these details were enjoyable. And for these wires, how they will go. I meant to say like the red wire goes in there, black wire goes other way.

Examiner: So you like the wiring?

Participant: Yes. Even securing the gearbox. So initially I thought that the gears in the gearbox was loose but once I was able to have this covered up and secured they were tight.

\section{Examiner: Was it nice to know that oh okay if it's together?}

Participant: Yes, and like most of the parts were snap fits so that was also good so there was no loosening or tightening things. When you can feel that when you use a when you use the snap fit you know intuitively whether it's been done right or not.

\section{(12:30) Examiner: Any other in enjoyable aspects?}

Participant: Another enjoyable aspect was when I was putting the... this thing (leg) with the gear... in Step 9 step 10 ...was enjoyable because once you were done with that and then you're moving it you could see the legs expanding and contracting... it appeared cool.

\section{(13:50) Examiner: How about unenjoyable aspects?}

Participant: I thought that after doing two of these [Referencing Step 8] I would be able to do other 6 on my own and remember but that was not happening. I'd have to look again and again and even then I did some mistakes. And, of course, use of this gear tool.

Examiner: So you thought I was supposed to work one way but it didn't work how you thought?

Participant: I think one can fix with the hands, the gears. They don't need to use the gear tool.

Examiner: How about any other unenjoyable aspects?

Participant: Everything else was enjoyable.

(15:25) Examiner: Now we're going to rank the top three best steps and state why you chose them.

Participant: First, Step 10 as I told you because after the step there's no confusion in that. And once it was done you could see the legs expanding and contracting. Step 3, because it showed how the wires... getting there.

Examiner: So you liked how the wires were clearly placed? 
Participant: And step 7.

Examiner: For the same reason that you got to say before that you saw the gearbox coming together?

Participant: Yes.

Examiner: Now let's choose our three least favorite or worst steps.

Participant: First one was step 8, although they clearly mentioned since I messed up I'll say step 8. Step 6 because that was not needed. Step 11, I meant to say, it wasn't bad but among all of those since I already made a mistake in step $8 \ldots$.

Examiner: So Step at 8 just made Step 11 worse?

Participant: Yes.

(19:00) Examiner: Anything else youd like to say about the instruction manual or your experience?

Participant: I think overall it is good.

(19:30) Examiner: So last thing I'm going to ask is, based off of some of my observations I'm going to ask you a couple of things. So first you looked through the whole manual before building. So why did you do that?

Participant: Just to know the sequence... like...

Examiner: Just to know where you're going?

(20:00) Examiner: In Step1 when you're putting together this little motor thing, you put it on the other way, so what do you think was going on there?

Participant: I thought that was the only way initially, but then I saw that this part is going into the other end but for me was changed by 180 degree.

(20:35) Examiner: You had mentioned on step 4, the positive and negative terminal terminals did not come intuitively. What were you thinking there?

Participant: So, at times they're pretty similar. Maybe there's some objects when they're similar, the positive and the negative look similar. It depends on where you're connect them. So I thought they're going to be the same. I thought there was no difference. And even this picture it's somewhat clear but this has a side view... like this is a front view and this is a back view, so if they would have used a front view here it would have been less confusing. 
(21:35) Examiner: So how about these two pictures right here? Would it have helped if these two pictures were with them? Would this have helped?

Participant: But then you wouldn't have known how the wire got to get into this thing.

Examiner: So what if this picture in this picture is right next to it would that have helped?

Participant: Yes that would help, although they've already written positive and negative terminal here even then that might have helped.

(22:14) Examiner: And then you had also mentioned how maybe you had some confusion on this step but then again you also really enjoyed it? Can you describe why? Why do you think that is? It's confusing but you also enjoyed it?

Participant: The confusion was intuitively I thought they were similar, but just after looking at the actual parts I found that they were different. And then I saw here so they very have little details about that so in that sense it was both confusing and interesting.

Examiner: So working out it in your head, 'oh this is how it works.' You like that aspect of figuring out?

Participant: Yes.

(23:08) Examiner: So let's look at number 5. You asked, 'why do we need this part?' Did you kind of figure out later on that it was a place to hold the spider? Or maybe you just figured it out?

Participant: Yes I just figured it out now. Maybe you could merge inserting this battery in here and then doing it. What kind of thing would help rather than would help more as compared to putting the holder first and then the battery.

(24:15) Examiner: Let's look at number 6. You thought the manual up to this point was color coded by parts rather than being this hierarchy of dark parts going into light parts. Would you have preferred that that all dark pieces were brown and all light pieces were gray on the toy? Or did you like that it kind of showed that the highlighted pieces were the pieces moving around?

Participant: Initially, I thought I would have preferred that, but then it would have been too complicated. Because to have whatever your assembled you see both colors than it would have been confusing.

Examiner: So part color would have been your preference?

Participant: Yes.

(25:22) Examiner: So on to number 7, you thought that when assembling the gears that the gear should have clicked in or been secured somehow? 
Participant: A similar snap-fit kind of thing that we had for the rest of assembly.

Examiner: But it wasn't, so maybe you were trying different pieces to see if they would fit? And then you didn't use the gear tool again the second time because you felt like you didn't really needed it?

Participant: Yes, it's saved some time.

(26:00) Examiner: On Step 8, you built two left legs and they were right and then you build a couple more legs and they were wrong, and then you ended up building 6 left legs and 2 right legs. Do you remember any of that? There was a little bit of struggle going on there.

Participant: I was not able to differentiate between the left and right.

Examiner: Why is that? Is because the pictures look too similar?

Participant: So what I tried was I kept these on top of each other and all eight appeared the same.

Examiner: So it's hard to tell because of these pictures this piece is behind this piece but also this piece is behind this piece. So maybe feel like holding a piece this way maybe you'll assemble them all kind of like this.

(27:11) Examiner: So 9 we had some trouble on part 9. Maybe because we had some trouble with step eight. So there's some trouble putting the legs on. One consistent which I want to ask you about is that the way that the picture shows is that this piece is assembled above the body, but every time you assembled it below. It's really hard because this piece was running into this knob. Do you remember that? So, every time you push it in you mentioned, 'is it supposed to make that sound?' Just because you were trying to assemble it down it was making that sound instead of assembling over top?

Examiner: The way that the instruction manual says it shows that this piece comes on right here snaps and then comes down. But then you preferred to do it this way. So why do you think it was your preference to put it on this way?

Participant: So that would have been better but that's what this is trying to show?

Examiner: So if you didn't see it that way, what would be a good way to show this thing coming up and over as compared to...

Participant: Maybe could break the step up into 9A and 9B, where you show first this thing going in and then the second one going in.

Examiner: So maybe there's too many things going on?

Participant: Yes. 
(29:35) Examiner: I noticed the first time you were use the pegs you tried twisting the pegs into the hole instead of pushing. Is that what you thought at first, that work like a screw? When did you find out otherwise?

Participant: Because it didn't have the threads on.

(29:54) Examiner: On step 10, you were confused on the orientation of these holes do you remember that? What do you think was going on there?

Participant: I thought on one of these, there should only been one hole. I meant to say, looking at the picture I understood as three should be filled in and only I was trying to figure out.

(30:37) Examiner: On number 11, didn't finish unit number 1 moved on unit number 2. So when you were assembling you made some legs you put legs on this one and then you set it down and then you went on to the next one. Instead of, making all four legs and then moving to the next one. Do you remember that?

Participant: Here it says leg unit into two, so I went to 9 then 10 and then because her same color. I thought like let me let me go and do the second unit.

Examiner: So, you were thinking it was saying, 'do 9,10,9,10’ and then it said, '11,12,11,12.'

(31:27) Examiner: So, during the 8,9,10 process I think that after I got one leg on your reference a toy more than your reference the manual? So you when you were building the part you were looking at the parts to determine... Why do you think that is?

Participant: Just looking at what I did because the first leg came out right. So I thought I've already done it so if I see it again I would be able to know if it's right or not

(32:17) Examiner: So it seems like the strategy you had was assemble all the assemblies, make all these and then assemble all those, and then assemble all the sub-assemblies which I believe is what the manual saying. But, you weren't able to find out if you did something wrong until it was time to apply them. Do you think it was good to assemble all the legs and bodies and then bring them together?

Participant: I think the strategy was right but I think I missed out.

(33:31) Examiner: Let's turn to the next page, and then you mentioned why the battery last? And why did you say that again? What was the reason?

Participant: I believe that since they, let me call it the holder, maybe it's comparatively more difficult to put in the battery now like even if you say if you say get the other way what happens if you put in the battery before? In step 5 you put in the battery and then you put in the holder so then it's not going to make any difference. Now [Referencing Step 13] it's more difficult to put the battery because you have to get past the holder. 
(34:32) Examiner: So you mentioned that there is extras. Do you think that maybe the project wasn't done or something was wrong because there's extra parts?

Participant: The way that I was going I thought that maybe I missed, but then I thought that since this was kind of symmetric since everything should have been a multiples of 2, then I thought that maybe these are the extras. Otherwise if there was four two of each then I might have thought that that maybe I had missed somewhere.

(35:20) Examiner: On this step right here on the tube cutting step, I noticed you would fold a piece and cut it, fold a piece and then cut it?

Participant: I wanted to make them equal.

Examiner: So folding was an obvious...

Participant: I didn't see any marks on the tube.

(35:49) Examiner: So one of the thing, I noticed that after you assembled step 14 then you went over here and went ahead to the extra page before turning it on. Why do you think that was?

Participant: I thought that this was a very obvious so I didn't even look at this page. Once I was done I didn't saw the complete and have to start playing with it. I thought that might be the obvious last step.

Examiner: So when you saw the two you already knew that... 


\section{(00:05) Examiner: What did you think about the experience?}

Participant: It was... I was very intimidated by all the parts and pieces but when you're actually got into going step-by-step it wasn't as bad as I thought it was going to be. I will say that I was much more careful with this then I would have been if I was doing this at home because it was in this setting. I may have gone a little bit quicker and glazed over couple other things at home I was being a little more careful looking at the steps.

\section{(00:55) Examiner: How satisfied or dissatisfied with the instruction manual?}

Participant: I was just not, it could have been far better than what it was. So I wasn't completely disgusted with its there are instruction manuals that I've seen that are far worse. I think that having some words was helpful more words would have been more helpful. There were areas that were slightly confusing to me.

(01:39) Examiner: So let's talk about some aspects of the manual may be a specific step but I'm looking for just more general aspects of the manual that were particularly useful.

Participant: The words, I like words. Like Step 7, 'note peg direction' alerting you as to which direction pieces need to come in because I found step 8 to be particularly confusing where you had a note the direction of the legs so that this leg was bending this way and this leg was bending this way.

\section{Examiner: It would have been better to somehow point that out?}

Participant: Because if I did this at home I probably would have ended up with 8 left legs. So that part was particularly confusing. Yes, words. Words are useful, especially alerting you to the little intricacies of which direction thinks need to go. They also talked about the gear tool but nowhere in the document does it tell you what the gear tool was. so I thought that was unhelpful.

\section{(02:59) Examiner: So how about unuseful things? I know you just mentioned one...}

Participant: Yes, gear tool. Step 11 and 12, I'm assuming that because the gray is the reverse, looking at the left and right leg one that also appears to be one it appears to be how they demarcated that. I found that to be kind of confusing it also made the pictures very difficult to see because they grayed them out. Basically when I came to steps 11 or 12, I had already done steps 9 and 10 so I already knew to do so Step 11 or 12 weren't really steps that I looked at. Probably because you couldn't see the picture that good. The support beam was actually, not confusing, but it's hard to see on steps 13 or 14 where are you had to pay really close attention to where the arrows are pointing to because there's a lot going on in that picture. So, you can't really see even what they're pointing at because there's so much detail and so many little things and when you got to the support beam step when I slide the thing together I put the two leg units as close as possible. But to really get the support beam to click in, you had to move the pieces out a 
little bit. It wasn't confusing, it just wasn't helpful. See to get it to click in the grooves, and I may have put it together wrong.

(04:30) Examiner: So they're just off one. so you're kind of mentioning with the details hard to see but there's actually saying that there's actually four points the click on but you actually got one, two three, four, five, and six, but then one was missing.

(04:45) Examiner: You said there's so much going on it's hard to focus in on the details?

Participant: So they have all every single detail in every single leg in the picture. It would have been more useful to me to have a more zoomed in look on the exact step of what I'm doing. So, instead of having all the legs and all the body parts, to see the little section of what I was supposed to be putting together. So because it's so tiny, if I was just a little grandma that cant see very good there's no way that would be doing this.

(05:20) Examiner: Is there any more unuseful aspects?

Participant: I don't think I don't mean this is better than once I've seen I think I've mentioned the ones that stood out to me.

(05:40) Examiner: So let's talk about particularly enjoyable aspects, we already talked about functionality but what about particularly enjoyable?

Participant: The end result was enjoyable. I felt successful that was able to follow the manual and get the thing put together. Once I figure it out the gear part that was fairly enjoyable process of repeating the steps. let's see the leg unit I could have cared less for that wasn't helpful...

(6:18) Examiner: Leg unit meaning this one? [Referenceing Step 8] Why was that not enjoyable?

Participant: Because the picture was confusing and it took me awhile to get... I like to be able to look at something and understand it quickly and do it. This is not quick to do. Yeah, I wouldn't classify this whole project much of it as enjoyable.

\section{(06:48) Examiner: So what about unenjoyable aspects?}

Participant: Well let's begin with putting together the motor unit. You have to be very cognizant of how these little arrows like the red wire you're not supposed stick anywhere. Initially, I thought you had to stick them both down in the groove and then you get over to this [Referencing Step 3]. You had to pay very careful attention and stare at the diagram to make sure that everything on your part matching what their picture was. Putting together the battery pieces was not complicated, I wouldn't call it enjoyable.

Participant: The legs, we talked about the legs, that was just not fun to figure out because there's a lot of different components and making sure each component was put on there the exact specific way every single time you did it. So I kept on having refer back to the pictures and look 
and make sure, and referred a bunch of pictures and it took me forever to put the legs together because I had to keep staring and confirming that I had it all put together right because I know that if I screwed that up I wouldn't get it my spider. Once you got to the leg unit and once you got it figured out and then were able to repeat the process that wasn't as challenging. The flipping over part we talked about how that wasn't very fun.

Participant: And then this last part on how to stick it together. That, I didn't really look at the picture because I didn't find the picture overly useful so I just kind of figured it out and then went from there.

(08:17) Examiner: Okay now let's rank the top three best steps if you had to choose 3.

Participant: Yes I will definitely. Let's see the gearbox step number 6 then 7 . The clarity of it, once I figured out what the gear tool was which it wasn't complicated because I looked at the pictures once we got that, that was a very simplistic step. And then 7 also was pretty simple of how to put that together. And then it was nice that you had that they indicated that you have to do that two times in two different... come up with two things. And then I would say the next wannabe number 4 . That had to be be fairly straight forward on how to put the black wires and the red wires and the two different size terminals. It's nice that they zoomed in on that aspect of it.

\section{(09:25) Examiner: So now let's try the bottom three steps.}

Participant: Let's see absolute worst, 11 and 12 and it wasn't because the content of the step. I dont know what the heck is happening in these pictures. It was very clear to me, 9 and 10 was very clear as to what I was supposed to do when I stared at the picture. When they reversed the picture then grayed it out, I can't even... my brain can't grasp what is happening... what they're trying to communicate to me.

\section{(10:14) Examiner: Is that because it's harder to see to dark?}

Participant: It's harder to see... yeah, pictures indicate where they overlap is supposed to be on top I figured that out on my own because the picture was not exactly clear. And when I'm looking at just when you're looking at it it just kind of hard to understand what they're trying to communicate to you.

(10:36) Examiner: So do you think it would have helped if it was the same color scheme as here? Or is there more to it?

Participant: I think there's more to it because it's also hard to figure out what they're trying to tell you in these pictures like what are you trying to tell me here?

Examiner: So you got nine?

Participant: Yes I got nine, I made sure my leg was pointed in the right direction and then I stuck them on like the picture told me to. Just kind of when they flip it over... maybe my brain 
doesn't work in reverse because it's hard...and they don't have a picture of a whole leg for Step 11 or step 12. So on step 9 the show a whole picture of the entire leg on the thing that I was able to reference and I think that's part of the problem with Step 11. There's no picture of an entire leg already on the unit for me to mirror.

(11:37) Examiner: So you like having 'I'm see what's going on but I also can see what I should be having?'

Participant: Having what the end result is supposed to be because then I was looking at the box a couple of times... I have one more rank?

\section{(11:52) Examiner: Yes I have one more question, was this box up here useful?}

Participant: No, the most useful part of this was just seeing how it's supposed to be on there when I'm done.

Participant: Did I tell you 8 yet? So step number 8 is the next one. It wasn't a hundred percent clear the difference between right and left. So I kind of had to ascertain that myself of here's how the left leg is different from the right leg. 'oh' they're pointing and different directions and 'oh' the pieces fit on there differently.

(12:57) Examiner: So at this time is there anything else you'd like to say about the instruction manual?

Participant: Let's see I can give you some feedback. Yes, in places where things are tricky for example back to the leg part. It's helpful to give me a heads up of 'here is where you might get confused and here's what you might do to avoid putting it together wrong.' So note the direction of the leg. A note, 'note the direction of the peg' like it was so nice when they mention 'note the direction' here. Yes, that was very helpful.

(13:40) Examiner: What if it had said ‘note leg direction' here would that have been helpful?

Participant: Yes, that would have been very helpful.

Participant: Over here where it said, 'note right and leg assemblies are identical.' That was very helpful because if I did not have it I would have been staring at the page for really like time and would have been like which one of these goes where. Instead they told me exactly that they're exactly the same so they just go on there. So places where I needed to be aware of something is different this piece versus this piece enough... to get me to really study the picture that would be helpful and that is helpful. So that's my feedback.

(14:22) Examiner: So the last question is going to be based off to some things I noticed. So one of the first things that you did was flipped to the book real quick to see what's going on, why?

Participant: Because of my life skills of test-taking you always look through the whole test before you take it. 
(15:08) Examiner: So on step number 5 you had mentioned you said that picture isn't clear?

Participant: No, I couldn't tell where... I knew this piece but I cant see where the little grooves were in the picture the details... it was too scanned out. It's too... it's not zoomed in enough. If they would have showed me the arm and then the peg I was to put it in that would have been more clear.

(15:37) Examiner: Number 6, you had mentioned gear tool...

Participant: Yeah what the heck is a gear tool? Is that... even in the picture it's kind of unclear because is this a piece of the thing? Is this the tool? So I went to this page cause usually in the parts they'll tell you, 'you have 12 little screws, you have16 flat screws.' But they didn't identify this thing anywhere.

Examiner: So it would have helped if you had seen this before somewhere?

Participant: Right, if they would have identified it that's why I flipped back to the parts page because a lot of times in a manual they list out that you had you know, ' 4 of this piece, 3 of this piece and oh this is what this piece is. Nahh.'

(16:35) Examiner: So you put the battery in early, so you know the battery had to go in there so you just put it in there?

Participant: Yes, I knew what I had to do so I just wanted it to be out of my way.

(16:51) Examiner: On step 8, after you reference that one you reference that one to see that it was correct so you believe that your part was more correct than the manual?

Participant: Yeah, yes, yes.

Participant: Well it's partly because it's easier to look at the finished product of what you have than it is to look at these hard to see pictures. That is what part of that was all about.

(17:22) Examiner: So whether you noticed this or not, when you're assembling the left like you actually assembled a right leg and then when you assemble the right you actually assembled the left leg. Then when you went to assemble it so you were kind of crossing over. Did you notice that?

Participant: No, I just knew that I have four of one kind and for the other kind.

Examiner: So that was enough that you had four of each piece?

Participant: So I figure it out that these ones are curving this way and these ones are coming this way and so yeah this was not a very useful picture for me. 
(18:05) Examiner: Then on step 8 you did... you were pretty quick on getting... assembling up to this step where you had this little assembly of the three pieces but in that last piece you had to look at for a little while kind of to see how that piece... What were you thinking there?

Participant: Its confusing a little bit cuz it's hard to tell where they want this last little piece for me because up here this piece has three things here but then when you come down here there's only one piece. So what are they talking about because in this picture there are two pegs but now they only have one peg? duh they put it together, but it's still... This might have been more useful as a combined step where you show the thing with the arrow going into that hole and then this coming over top and plugging into there. That's where my brain got confused.

\section{(19:00) Examiner: So is that your preference that maybe it doesn't have to be three steps?}

Participant: Yes yes yes yes yes. Yeah, cuase repeating this and the second picture is where it got confusing for me. And they're trying to do that with, see, manuals do it different ways... Sometimes they do combined it into one and everything has arrows on how you sticking together. In this one they're trying to do things with graying, like the colors, which wasn't useful for me at all... that they grayed stuff out and are trying to send you messages with the coloring. Maybe if it was a color manual I could have figured that out and they don't even say anywhere... Like, they don't give you instructions on how to use the instructions, right? So when things are gray, it means something in here which it took me 3, 4, 5 pages to figure that out.

(19:52) Examiner: So is that your preference... So the way I would describe this is like a color hierarchy of, okay, dark to light sort of thing. But it is your preference that 'im working with and brown pieces so it would be nice if in the manual it was gray and brown.'

Participant: Yes. That would have been very helpful for me... Like Legos... Legos are like that.

(20:23) Examiner: So then we're going to move on to step number 9. You had said it's nice that the pegs are shown like short versus long.

Participant: Yes, in the real world I would have been like, 'oh a peg psht' and then I would have been like 'shit' I got the wrong one. And then, I would have gotten it back out and they got a new one so yeah it's nice that they indicated that yeah with words.

(20:51) Examiner: Then unsure about the third hole... so you put these two pieces, the dark ones, on well and then you were looking at this one well I'm not...

Participant: So I'm looking at this step wanting to put this on somewhere looking at this step. So then I'm like 'where the hell is that supposed to go?' So then I had to come over here to the step to see that step. It might have been more helpful to have all the steps for this particular piece, this leg piece, all in one step. Yeah so I'm not like, 'oh, where is that supposed to go?'

(21:30) Examiner: So you were working on step 9 but you're looking at step 10?

Participant: Yes I wanted to know how to put the whole leg on... 
Examiner: And it be complete.

Participant: Yes yes yes. Partly because I wanted to make sure that... I got this part in on the right place and then where does this part go? So this helps confirm that I put this piece in correctly.

(22:18) Examiner: So you said that you put this piece on and by putting these pieces on you would know that this first step was correct?

Participant: Yes when I had all three pieces attached then it would confirm that I attach them all correctly. So when I finish step nine I still have a piece to attach and I don't know if I did step 9 right or not until I can attach that one. Because I thought it was a little confusing on where the little piece went as compared to the big piece.

(22:52) Examiner: Okay then you mentioned in step 9 and10, you had said, "I did it once, twice shouldn't be too bad.” So you're just thinking like I feel like I've been at right, I can do it again.

Participant: So they were two leg units, so leg units were times two and then when I got to the flip it over part I just thought, 'Nope. I'm just going to mirror what I did up here and not look at this confusing picture.'

(23:20) Examiner: So I noticed that you did steps 9 and 10 and steps 9 and 10 and then you technically did steps $11,12,11,12$. And then you said steps 11 and 12 were a little less clear and you said before because it was too dark and what else did you say?

Participant: There is not a full completed leg on any of these pictures like there is up here.

(23:49) Examiner: So it was your preference that you would have it show how it goes on and how it looks complete and it provides you a reference.

Participant: Yes.

Participant: I think that's how I was like, 'what the heck is going on here?' because they say flip over but then they have... this picture is almost the same as this picture up there but this one down here is not because all the legs are cut off. I don't know why they did that because if they just to finish off that leg...

Examiner: So if they would have provided your context that would have been good?

(24:33) Examiner: So I think you had pretty much completed both sides and then you said, 'if they all like the same then they're either all right or all wrong.' So at that point you weren't exactly sure if there are right or not?

Participant: Right, because I know I wasn't finished completely and so I have the two leg units then they look the same so they were either all correct or all incorrect and so I wouldn't know until I got to Step 13 and put it all together. Because, I've had that happen before, 'well they all 
look the same so they should be right,' and then they're not and then I didn't have a completed... once I turn the page I did have a completed unit to look at, but prior to that there was no full picture but the darn thing was supposed to look like once I was done. And so, once I got to the next page it was a do-or-die.

Examiner: So you're going to be either super excited or super frustrated.

(25:34) Examiner: I noticed another thing that you did was as you finish you both of the leg units you were turning the little gears...

Participant: Yes, to confirm that it worked. That was how I knew that when I got to the end of assembling the leg units I tested them out. That's how I knew that either screw them all up or are they were all right so that's how I felt pretty confident that they were going to work.

(25:59) Examiner: So when you turned to the end pages you had looked at step 14, you start a step 14, and then you went to the extra page and then you went to Step 13. So what were you thinking there?

Participant: Well I was looking to see how the legs were going to go on, how the leg units were go on to the motor unit and try to figure out how... looking ahead how they work together.

(26:30) Examiner: So you wanted to see a completed picture and how they came together?

Participant: Yeah, I like to see examples of how things are supposed to be.

Participant: I was also probably looking to the end to see, 'are we almost done?'

(26:53) Examiner: So at that point you had kind of reached like, 'okay it's time to finish this up... okay it's time to wrap this up.'

(27:02) Examiner: Okay on step 14, this is the second to last note you had placed the piece on wrong but you know was it the same issue of kind of we have a picture that was to zoomed out, the details are too small, it's just a matter of too much information and too small of a picture?

Participant: Yes, so I stop looking at the picture and then assembled the step the best that I could figure it out by not looking at the picture.

(27:29) Examiner: And then the final thing is we did the tube step where were they we cut the little tube so you use the roller and you kind of laid it there and you were snipping the pieces?

Participant: In the real world I wouldn't have done that. I would have just eyeballed it and that's why I said they should have come with pre-cut ones or something. They could have designed that far better. I think this is janky and cheap.

(28:04) Examiner: Is there anything else you would like to say. 
Participant: It wasn't as bad as I thought I was going to be. It was very intimidating looking at all the pieces and the parts and the box, and I was like, 'oh gosh, can I do this?'

(28:17) Examiner: But then after completing it...

Participant: Am I smarter than an eight-year-old? I'm must be.

(28:23) Examiner: One note, we didn't talk about this much, [referenced step 14 complete step]. Was this a good step? A good completion step?

Participant: No.

(28:33) Examiner: How about the back?

Participant: Well, my kids are really into dinosaurs. So it's like man, maybe that would be fun to make since I succeeded at this one that one might be fun too. Who knows? I wasn't completely disenfranchised with the whole project so I might have been interested with one of these when I got the end. Like I said, it wasn't nearly as bad as I anticipated. 


\section{(00:07) Examiner: So what did you think about the experience?}

Participant: It was fun. I did, like, find it enjoying to, like, find it enjoying to try to figure it out and, like, a challenge and there's an end product which is satisfying. So yeah, I liked it.

\section{(00:28) Examiner: How satisfied or dissatisfied where you with instruction manual?}

Participant: For the most part, like I could... actually... I think if I hadn't had your help... well, I guess I figured it out how... It wasn't that clear when it came to wiring the battery[Reference Step 4]. Although like the other parts that were pretty clear. There are a couple of things I was confused about. So, overall I would say slightly dissatisfied. Mainly only because of this part [Reference Step 4] cause I didn't realize there was specific way that the wire had to be twisted.

(01:18) Examiner: Aspects of the manual are particularly useful? So now we can get a little more specific.

Participant: The arrows were super helpful, because especially... I don't know, there's so many things in here they have to connect and put it in and so many little holes and knobs and stuff so it just helped for it to be specific about where exactly things go. Where it did have words, the order. I think, yeah, the words were helpful and the labeling of red wire, black wire[Reference Step 3]. So where there were word instructions and labels that was helpful. Cause, I like to read things and obviously this isn't color so you have to know which one's red and which one's black. These little pictures were helpful[Reference Step 8]. I thought they're very clear. Like if I had words I think it would have been confusing because it was more like a simple step just seeing which piece gets in which hole.

\section{(03:14) Examiner: Let's talk about unuseful aspects.}

Participant: So maybe I know on the parts, it lists some of the things but like if there's a list of what part was what. Mainly because the gear tool I was confused initially I thought since there's two gearboxes there would be two of these [Reference Step 6] because I didn't know if they were just a tool. So maybe labeling evening if was just had shown this was the gear tool. So that wasn't super helpful... So then step 4, it was... if I looked and really thought then, 'okay that's the direction of the arrows,' but initially the directions just say, 'twist wires around terminals.' So that's not very specific. If it even said, 'make sure the directions shown' that would have been helpful. I don't know for the most part the rest of it was okay... I wouldn't put some of the steps in the order that they were. I would I just would combine these two [Referencing step 9 and 10] because in my mind I was like, 'okay, put one peg and put the other peg in but its not showing it in this picture so I was confused and I had to go to the next one.

(05:12) Examiner: Let's move on to aspects of the instruction manual that particularly enjoyable.

Participant: I like to doing the little gearbox thing. I don't know why, well where it said note peg direction that was helpful. I don't know, its just satisfying I think. It was the first part, besides the 
motor unit, that was the first part when I was like, 'oh, I put it together and I can see where it's going.' And also when you're attaching in Step 13, I could see, 'oh it's a spider I can see it now.' I don't know that's it I guess.

\section{(06:11) Examiner: Now let's talk about some unenjoyable aspects.}

Participant: Step 4, maybe because I'm just not inclined to understand wiring and stuff. Like I was confused initially because the little terminals, I guess. I didn't realize that they sat in the little slots like it was in the photo. Well it does say place in slots so maybe I didn't read it well enough. And then of course I was confused by the... I thought I did the wiring right because I thought it was simple. But I didn't realize it had to be in this direction and had to look this way and stuff. [Reference Step 8] This part was just tedious to do and step eight regardless of instruction manual.

(07:27) Examiner: So it was clear, you said it was clear, but you didn't like the tediousness of... Ok, these have to go in certain holes... Was having to do it eight times? Was that tedious?

Participant: Yeah, I think just the repetition. Also on this step [Reference Step 8], I was a little confused... so are the parts on the left leg going to be different than the parts and right leg and then I realize that it's just the direction it was in.

(08:05) Examiner: How about let's rank our top 3 best steps and state why?

Participant: I think in the beginning step well I don't know... I like the first step because maybe because it was the start and it was clear and it was the first thing I had to do before it really got complicated. And.. in my mind, I lump all of these steps together as one[Reference Step 9-12]. 9 and 10 are the exact same thing as 11 and 12 just on the opposite side. And like I said, I would have lumped these together so I did like putting the legs on because I saw how it worked and I would see the aligning and the turning of those things to make the legs move so I was like okay that's cool. And I like 13 cause it was like putting it together. We had made the motor unit and the legs and the gear boxes and stuff so it was putting it all together.

(09:44) Examiner: So on the opposite side, we're going to do our least three favorite or bottom three steps.

Participant: I didn't like 4 and I didn't like 8 just because it was tedious.

Examiner: And 4 was for the reason as you said before that it wasn't specific on the wires?

Participant: Yeah. And I would just say 5 because I forgot it.

Examiner: Why do you think that is?

Participant: I don't know why I forgot it.

Examiner: Do you think you just overlooked it? 
Participant: I thought okay well I'm done putting these things in so now. I just thought I was done with the motor unit.

Examiner: So you felt a completion there?

Participant: Yeah I felt completion (on step 4) and felt like I could move on. Maybe step 5 should have been at the end because like I feel like it's a finishing touch... like this is put on it at the end [Reference Step 14] and then that would be put on at the end. So I think it was just the placement of that step so I finished the motor unit and I just thought I was ready to move on so I completely overlooked it.

(11:23) Examiner: So is there anything else that you would like to say about the instruction manual or your experience?

Participant: It was fun honestly. Overall, I enjoy doing it. I felt like I accomplished something. It was frustrating when I got all the way to the end and it wouldn't work and then I thought that I had done this but then it wasn't working. So it was frustrating to have to go back and figure it out but then when I did pinpoint what was wrong there was a sense of accomplishment when it started working again.

(12:15) Examiner: So you would say that although you made it to the end and you didn't get that what you're expecting of it working, it was worth it like it, was worth it to go back and check the parts.

Participant: Yeah, I would have been annoyed if it didn't work it. Would have bothered me. I would been like, 'what's wrong with it' and I would want to go back and figure it out. So I wouldn't just stop it just because it didn't work I think I'd be frustrated if I couldn't figure it out.

(12:32) Examiner: So the last question is multi-part. I'm just going to go through some of my observations and just ask what were you doing there were thinking there. And I just might repeat some of the things that you said. The first thing that you said was, 'I like the written instructions better than the photos' so what's your preference to be able to...

Participant: Well I think I need both. I wouldn't pick one over the other. I need them in conjunction. I definitely couldn't do written instructions without pictures.

Examiner: So it's the difference between step 1 and 2... I understand that 2 maybe it made sense...

Participant: I don't think 2 would need words actually.

Examiner: But Step 5 it's a little... you're able to understand what was going on in Step 2 but then 5 was a little different?

Participant: I don't know why maybe it's because I did after this thing [Referencing step 4] because maybe this was such a big step that like... At first I was like I'll do this and then the next 
step is this and then I spent so much time thinking about this one that I didn't think about that (Step 5).

(13:50) Examiner: On step 1 you said the pictures were clear and then a step 3 you said this looks complicated?

Participant: Like, the more I looked at it, it looked clearer. I think there just is more to look at the directions of where the wires go and the red wire has two parts. So like, this part has to go here and this part is underneath and this part goes down there. I don't know... I think it just the more I looked at it I thought, 'oh, it's not that complicated.' Initially, it looked like there's a lot going on, then it became more clear.

Examiner: On step number 3 also said, you have to take time to see what's going on in the images. So it's like you look and then you see.

Participant: Yeah.

(15:10) Examiner: On step 4, this is our star step, so I guess that you're twisted the wires but the plastic part of the wire was touching the terminals?

Participant: Yeah, I obviously don't understand because I don't know anything about how that stuff works. So I didn't know that the metal had to touch the metal or whatever versus the plastic. Which, it makes sense now, but I was just like here's a wire let me twist it.

(15:40) Examiner: And that's what the manual says, would it have... do you have an idea of an improvement or what would have helped you?

Participant: Like, if it said like, 'note the direction of the wires' or the twisting... or 'twist metal part around itself.'

Examiner: So highlighting the end of that wire?

(16:02) Examiner: so then there's a little bit of question on how the terminals fit in and I think the progression was you were trying to set them inside of this area and then you actually looked us up 5 and you were like, 'oh the terminal should be sitting in their nicely' and then you went back and place at the place to the pieces in. Is that a correct progression?

Participant: Yes.

(16:35) Examiner: So it's flip the page and go to steps number 6. There's a little bit of confusion starting out. You saw that there was a gear tool you had to use but you saw the word gear tool but you didn't see the gear tool. So basically the question is, what the heck is the gear tool.

Participant: Yeah, I didn't know what that was. Like the pictures very clear, but then I was like: this is part of the product not the tool. I didn't connect that this tool was that. 
Examiner: Right, didn't connect those two pieces of information.

(17:11) Examiner: And then another thing is... and maybe it's for that reason, but you put the gears on to the gear tool and then you were looking for another gear tool?

Participant: Yeah that's because it said 'x2.' So, I put these on here and then I'm supposed to do it again. So and I had six of these pieces so I was like where's the other one that's supposed to fit on?

(17:38) Examiner: Then on step 8, I noticed that you organized all the like pieces and then you're able to put together.

Participant: So I did that because I wanted to see if there's a difference between the left leg and the right light pieces. So I was like seeing if there's a distinction between them.

(18:09) Examiner: And then on step 9, you had mentioned this is where future instructions would be helpful?

Participant: I thought when I was working on step 9, I was putting the pegs in and then I was wondering where's this peg? This one has to have a pen and I didn't see it in the photo. So then I was like, 'oh it's on the next instruction.' So I would have put the pegs in the same instruction. Just cuz in my mind, these two things go together. The pegs are one thing and it should be one step, the A and the B pegs.

(18:57) Examiner: Would have been better if you put the leg on in Step 9, and then you put all the pegs in on step 10? Assuming like put this piece [Referencing the toy].

Participant: Because it looks like in this photo [Reference Step 9], you put both of these on and then you put the B pegs in (in step 10). But I would do A and B on this leg and then move to thins leg.

(19:30) Examiner: Ok, you would do the complete one side and then do the complete other side?

Participant: Yes. Rather than, the A pegs then the B pegs.

(19:47) Examiner: Step 11 you said this is probably the same from a high view you were like 'oh okay.'

Participant: 11 and 12 are the same as 9 and 10.

Examiner: Would you say that you referenced 11 and 12?

Participant: No.

Examiner: You just knew that you were going to repeat? 
Participant: I did look at it and I was like oh it's the same thing and then I didn't reference to anymore.

Examiner: Because you knew what to do already?

Participant: Yes.

Examiner: So would you just not show this at all or do you think they're important?

Participant: I don't think I would show them I think I would just say just 'repeat on the other side.'

Examiner: Like 'flip over and repeat.'

Participant: Like I don't think it's necessary to show these.

Participant: See this part I didn't even look at these two little pictures [Referenced boxes in step 10 and 12]. I just kind of figured out that they had to be on opposite once and also these pictures if I had reference them I think I might have been confused because on the one side it's on the far one and on the other side of should be in the close one but these turned so they might not be aligned as they show the pictures.

(21:23) Examiner: So let's turn the page, and what happened was after you complete one full leg assembly and then you move to Step 13 to make sure that you have to make a whole nother leg unit and then you went back and then... Do you remember that at all?

Participant: No.

(21:41) Examiner: One step 10 you had mentioned that you would put step 9 and 10 together.

Participant: Yes.

(21:51) Examiner: Step 13, there was confusion on that 'identical note.'

Participant: It says, 'left and right leg assembly should be identical.' So I didn't know if it had to do with like when these are sitting here. like if the one closest this leg should be down and I didn't realize on this one the leg should be down. So this one's further out than this one. I didn't know what that meant by identical, so I'm just going to ignore that and hope that it works.

Examiner: And yes, I think you're right that that paragraph is saying the inner ones should be in when the outer ones should be out or something like that.

Participant: Yeah, I didn't know what that meant really.

(22:42) Examiner: And then we got to the end and you turned it on and it didn't move. And then you went back and went through this the assembly process, you figured it out, and then the last 
note was then you ended up putting on the switch backwards the second time and you're like, 'wait a minute it's on...'

Participant: I probably wouldn't have realized that unless you had told me because it was on the on position when I started it.

Examiner: And maybe that was premature of me to like 'oh hey by the way.' But do you have an idea of what you would have done if I hadn't said anything?

Participant: I probably would have ignored it and said that was weird but still turns on and off.

Examiner: And then you would have flipped the switch and said oh it's working?

Participant: Yeah.

Examiner: And I think what ended up happening was you switched it and nothing happened and it's because the battery wasn't touching both terminals which it's been a consistent product of this is more of a design issue the battery isn't quite like it doesn't slide very well so this thing can't push the pieces together.

(23:52) Examiner: Just for the sake of looking at everything if you could just look at the back page and tell me if you have any comments or anything on the back page?

Participant: So when you're doing the legs I noticed these and then I was like this must be extras and so when I saw it here then was like oh there are extras there. So I think maybe if that had been in the front parts so I just know that there's extras. But it wasn't hard to figure it out that I don't need this so... I thought it was pretty smart advertising so right after you finish this you'd be like, 'oh that's fun, I just completed this and now I can do another one.' 
(00:06) Examiner: We'll start off with what did you think about the experience?

Participant: I felt that it was tedious, not the easiest to put together, and not exactly fun for me at least. Parts of it I felt like I was going to break because I couldn't get like the part to go where I wanted to and it seems like it should be going because the picture told me to do. But, yeah...

Examiner: So there was things that you weren't super sure about?

Participant: Yes.

Examiner: Was there anything else about the experience?

Participant: It took a lot of time. Maybe if I had more experience it would have been quicker but I don't know if anyone would just have experience with this anyway. I felt like it took a long time.

(01:09) Examiner: So how satisfied or dissatisfied where you with the instruction manual?

Participant: So some of it was good and clear if I had one step, I felt like it was more clear. So some of it was good. Overall, I think if they would have added color or something it would have been more explicit as to where things should go or the way things should go or which leg is right and which one is left. So I think it could have been much better. I think they did get parts of it right but overall kind of confusing yeah and difficult to discern which piece was what.

(01:15) Examiner: Could you point out what things they got right?

Participant: So I liked this one, step 2 because it's just one simple... I liked when they did, they showed exactly on the gear, highlighted which one should be [Reference step 10]. And I liked this, was good when it said, 'two leg units done' because I wouldn't have done both only did one, yeah. And just anytime there was words, that was nice, yeah. And then again this one was nice [Referencing Step 14]and it had arrows pointing exactly where it should go.

(02:44) Examiner: So if you could say satisfied or dissatisfied you would say?

Participant: I would be more dissatisfied.

(02:55) Examiner: So we're going to get a little more specific. Let's talk about aspects of the manual that were particularly useful?

Participant: When they gave the letter for each peg that was useful because even though you can see which ones short and which ones long I still like having a letter. Yeah and then again when they said '2 leg units' to make sure that you did both that was helpful.

(03:51) Examiner: So let's talk about some unuseful aspects. 
Participant: So I can't figure out why parts like this is darker, that's just something I'm noting. I don't know why that is dark and this is dark, maybe it's supposed to help me but I don't know.

Examiner: So that didn't help you?

Participant: No.

Examiner: Did it do anything else? Was it harder to see?

Participant: Yeah, so I liked it when it was the white versus this because it's harder to see where they're pointing to. I think the arrows were meant to be useful but you can't really like see them. They weren't very useful to me. This said, it did say, 'right leg and left leg should be identical' but I didn't really know what they meant by that. So that in that case two words didn't really help.

(05:33) Examiner: So let's talk about aspects of the manual that were particularly enjoyable.

Participant: So, the gear that was kind of fun to put them together. I just think gears are cool. Putting the last piece and that was exciting. And then the added thing, that's kind of cool so your toy can do something different and it wouldn't slide around, so that's kind of fun.

\section{(06:23) Examiner: How about things that were unenjoyable?}

Participant: The legs, it just, it was tedious, I didn't like it/ I feel like the pieces didn't really easily go in. That's where I felt like I was kind of going to break things especially when I had to put them on to this body part.

Examiner: So on steps 8 and 9 you felt like you were going to break stuff?

Participant: Yes, and again they have the arrows but that wasn't very helpful. I messed up, it should be more clear about which side you need to put each piece on because that matters. So, like for the left leg you need to put... well that makes sense I guess you should have put left side of the leg in the lake should be facing down. And then for the right you had to put it in from the right but I messed that up somehow. I didn't like this part.

Participant: This step 3 was unenjoyable. It just wasn't explicit so I think they just try to combine way too many parts into one, I had to pay attention to. Yeah, I think that's the main thing because you had to worry about the wire and this piece and this piece on top and it's not... the picture... the color maybe, I think that the color didn't really help.

(08:20) Examiner: So when you say color your what do you mean?

Participant: So this piece [Referencing step 3], it really blends in where it was important to get the right side up. So even if they drew attention to where this was darker and if they could have made this another color even darker so you could draw more attention to the pieces that you need to pay attention to. Or make those a different steps. 
(09:00) Examiner: So let's rank the top three best steps and why you chose them. It doesn't have to be first, second, third...

Participant: So step 2 because it was one step, pretty simple or one procedure I should say. And then 5 again because the arrows did help on that one and it's just one thing that needed to be done. And then step 6 was good too because there's a tool that helped and then also three pictures of how it should be done in that order. And then they give you a better depiction even to the side.

(10:08) Examiner: So now let's rank are bottom three steps top worst.

Participant: Step 3, again I think too much in it. Yeah, way too much. So step 8, it's just not very explicit. And then step 9. Step 9 was the one that wouldn't cooperate like the leg I felt like I knew it needed to go there but it wouldn't really get on so that's to where I felt like I was going to break the piece. And also if you didn't really pay attention to the leg you would have probably put on backwards to the picture. Like I started to put it on backwards.

(11:11) Examiner: So is there anything you would like to say about the instruction manual or your experience?

Participant: So, I think that they have the right idea but they didn't put much effort into it even the front. You would think that the front picture gave you a good idea of what to expect as far as the final product but it doesn't do a very good job of that. So, it's not very exciting and I can't really tell the pieces. If I didn't know that I had just seen it, I wouldn't be able to tell that this body pieces separate from these legs. It's just kind of like, 'blah' and sometimes I use a picture like that to look back to if I need even more reference of what I should look like at the end. And I think just like they try to combine, it's just like chemistry class, they try to put way too much into one step where chemistry puts way too much one semester. If they would have broke it up more it, could have been more enjoyable and less stressful.

Examiner: There's one more question it's kind of a multi-part. I just have some observations I'd like to ask you about. So, if we could turn to step 3, you looked at step three and you look up to the manual and then you said, 'there's no words.' So what were you thinking there?

Participant: I was hoping that there would be like directions like on step 3 where we are going to do this. Or even just like over here how it gave little things [Referencing step 6 and 7]. That's what I was kind of looking for. Just something to like in addition to the picture. I love it picture with words maybe, but I was just expecting like, 'okay, now on this step this is what we're going to do.'

(13:23) Examiner: Let's go to number 8, so you did a pretty good job assembling the legs so maybe you got about six done and then it seemed like maybe on the 7th and 8th you kind of like had some trouble. So you had this many done over here in this many done over here and then there was some confusion. Do you remember what was going on?

Participant: So probably, that might be where I realized I had to be paying attention to the way the leg was going as far as the way the leg was pointing down or the ark was pointing down. So I 
was worried that was doing them all from the wrong side and then I started having trouble with the middle one I believe. Like I could do the top one and then I could add this one and this little thing in the middle hindered me from getting the top one into that.

(14:27) Examiner: So it's actually hard to put the pieces together.

Participant: Yeah.

(14:33) Examiner: So now on number 9, it seems like looking at this picture you put together the left leg first and then the right leg, but it seem like you put the left leg together very easily and then you had trouble putting on the right leg do you remember that?

Participant: Yes, the right leg was fine. I think it was fine... I don't know why it was fine, but I think on this one it was cuz I would get stuck on this little thing and I wouldn't be able to push it down in order to get the leg up. So I think on this one I'm more... it was more instinct to put out to the side and then or twist but then on this one it just wouldn't go down.

$(15: 23)$ Examiner: So you think that you assemble these two different? Why do you think that is?

Participant: I think the left one had less like obstructions because the leg would come out but then the right one, even though it's the same, I instinctively would put it on the same way each time and then it would just get stuck so maybe it's because I'm right-handed but... But it's definitely different and the right one was definitely harder. I think it's the way that I instinctively try to put it on each time and I were to get stuck on that.

(16:21) Examiner: So to speak to that little bit, I noticed that there are two ways of this piece fits on. You can either fit it over top. Maybe it's how you did it on this side and then you can also fit it on, on the bottom and that's where this gets stuck. So this one, I would imagine it shows it fitting on the upper direction but you ended up putting it on and it getting stuck there. Any thoughts on that or did you feel that the image was telling you to put it on under?

Participant: Yeah, oh I see. So they try to help me to put it on like that on the upper side.

(17:08) Examiner: And then swing it down but instead it was kind of like put on bottom and swing it up.

Participant: Yeah, I think because where this one showed it I just instinctively put it like that, but where this one was pointed down and look lower so I try to put it... That's really funny... yeah. I didn't even think about that. I think I just saw it pointing down like that so I just try to put on underneath.

(17:43) Examiner: And then I did notice there was a little bit of confusion on maybe you took a left leg and then put on the right side and put a take a right leg and put on the left side. Why do you think that is? 
Participant: I tried when I was making them I thought okay I'm probably going to know need to know which one's right and which one’s left. So I put them in different piles but I didn't pay attention, I forgot which pile was which. And yeah and then I took two from this pile thinking a leg is a leg so and then I try to put it on and it didn't fit and so I realize that I may have messed up here [Referencing step 8].

(18:19) Examiner: So there was an organizational issue? Of okay I made right and left and then we get to this like, 'now which one's right which ones left?'

Participant: Right, I have to assume in this step that it would be my right and left and so I had to refer back to this spot [Referencing Step 8] to see which way the leg would go for each one.

(18:54) Examiner: So I noticed also that you finished a full assembly and then you read the note, 'two units done, turn page' and then you turn the page and then you came back like I need to make another one.

Participant: Oh so I didn't really realize what that meant until I saw two. So then I was like 'oh.' So that's why I did that.

(19:27) Examiner: Eventually, [Referencing Step 9] you learned instead of putting it the bottom way this piece, you realized that I can go over the top and then it worked out a lot more.

Participant: I think the last two, I was like 'oh yeah’ and it put it up this way and was a lot easier.

(19:50) Examiner: And then you noted the extra pegs?

Participant: Oh yeah, I was worried I forgot something until I saw back here.

(20:05) Examiner: Let's look at that last page just to see if you have any thoughts or comments about it.

Participant: I mean, I think it's a good idea to put those on there for just the marketing but then again it's just kind of like 'blah.' No color, just like the layout of it. It's just very techy but maybe that's what they're going for. Yeah, it doesn't really make me want to go buy this. And, this is good, cuz I guarantee it a lot of people had to call for help on this but yeah. Was robot by spider fun? No. Not fun. 


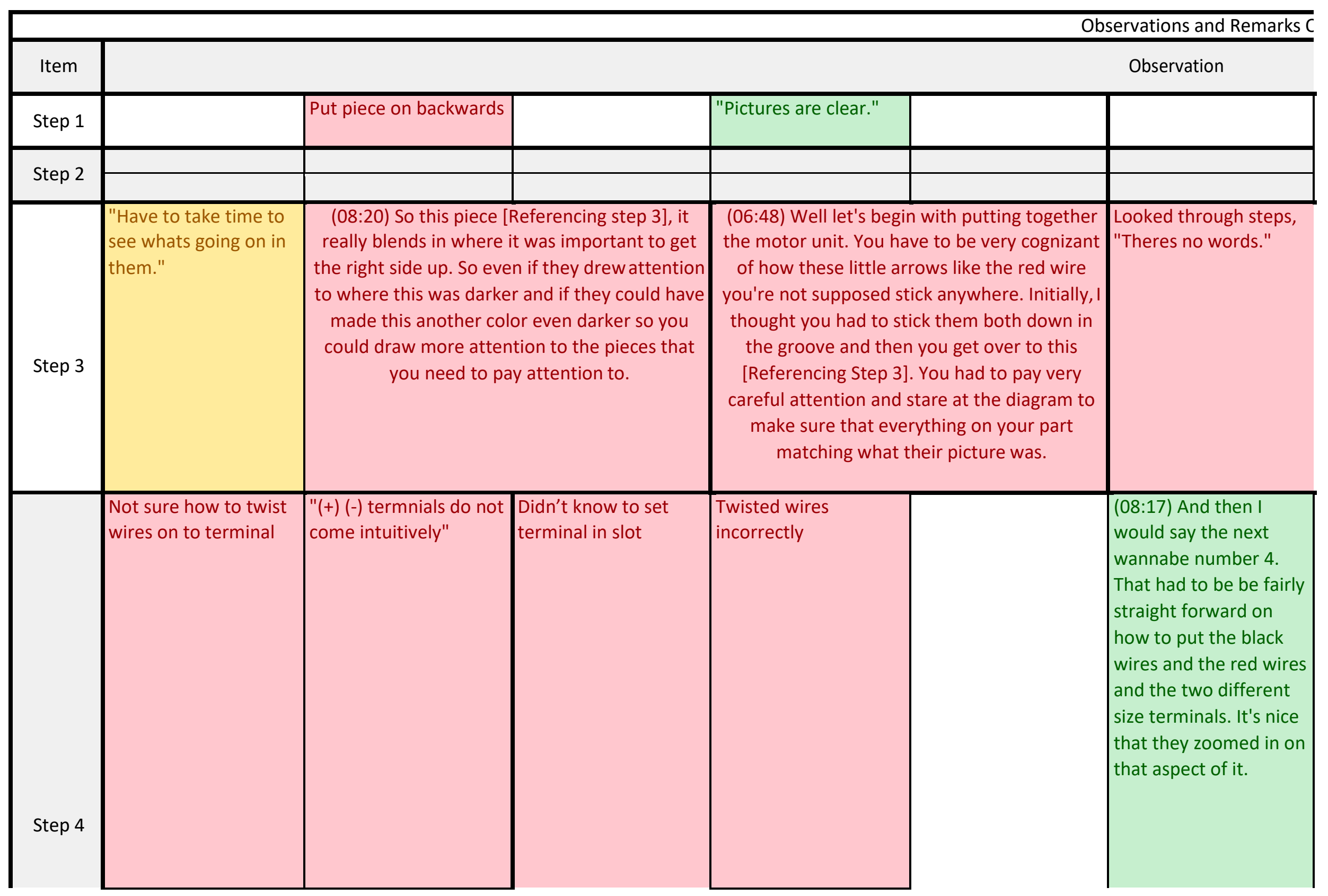




\begin{tabular}{|c|c|c|c|c|c|}
\hline \multicolumn{6}{|l|}{ n Manual Steps } \\
\hline & & & Overall & Usability & Desirability \\
\hline & & & 0.433 & 0.600 & 0.100 \\
\hline & & & 1.433 & 1.950 & 0.400 \\
\hline $\begin{array}{l}\text { (06:23) This step } 3 \text { was unenjoyable. It just wasn't } \\
\text { explicit so I think they just try to combine way too } \\
\text { many parts into one, I had to pay attention to. Yeah, I } \\
\text { think that's the main thing because you had to worry } \\
\text { about the wire and this piece and this piece on top } \\
\text { and it's not... the picture... }\end{array}$ & \multicolumn{2}{|c|}{$\begin{array}{c}\text { (01:18) I think, yeah, the words were helpful and the } \\
\text { labeling of red wire, black wire[Reference Step 3]. So } \\
\text { where there were word instructions and labels that was } \\
\text { helpful. Cause, I like to read things and obviously this } \\
\text { isn't color so you have to know which one's red and } \\
\text { which one's black. }\end{array}$} & . & 0.050 & -0.200 \\
\hline $\begin{array}{l}\text { (10:06) So there is moments when I was confused } \\
\text { which is the positive and which is the negative one } \\
\text { among these terminals. But, then I figured out there is } \\
\text { a clear picture negative is bigger. So these details were } \\
\text { enjoyable. And for these wires, how they will go. I } \\
\text { meant to say like the red wire goes in there, black wire } \\
\text { goes other way. }\end{array}$ & $\begin{array}{l}06: 11 \text { ) Step 4, maybe } \\
\text { because I'm just not } \\
\text { inclined to understand } \\
\text { wiring and stuff. Like I was } \\
\text { confused initially because } \\
\text { the little terminals, I guess. } \\
\text { I didn't realize that they } \\
\text { sat in the little slots like it } \\
\text { was in the photo. Well it } \\
\text { does say place in slots so } \\
\text { maybe I didn't read it well } \\
\text { enough. }\end{array}$ & $\begin{array}{l}\text { (04:17) yeah well, } \\
\text { [Referenced Step 4] these } \\
\text { things I didn't understand } \\
\text { what I was supposed to do. } \\
\text { If maybe it said 'for the } \\
\text { batteries,' then I would have } \\
\text { said oh okay that's the } \\
\text { positive and negative for the } \\
\text { batteries but I didn't know } \\
\text { what that was when I was } \\
\text { putting it in. }\end{array}$ & 0.733 & (1) & 0.700 \\
\hline
\end{tabular}




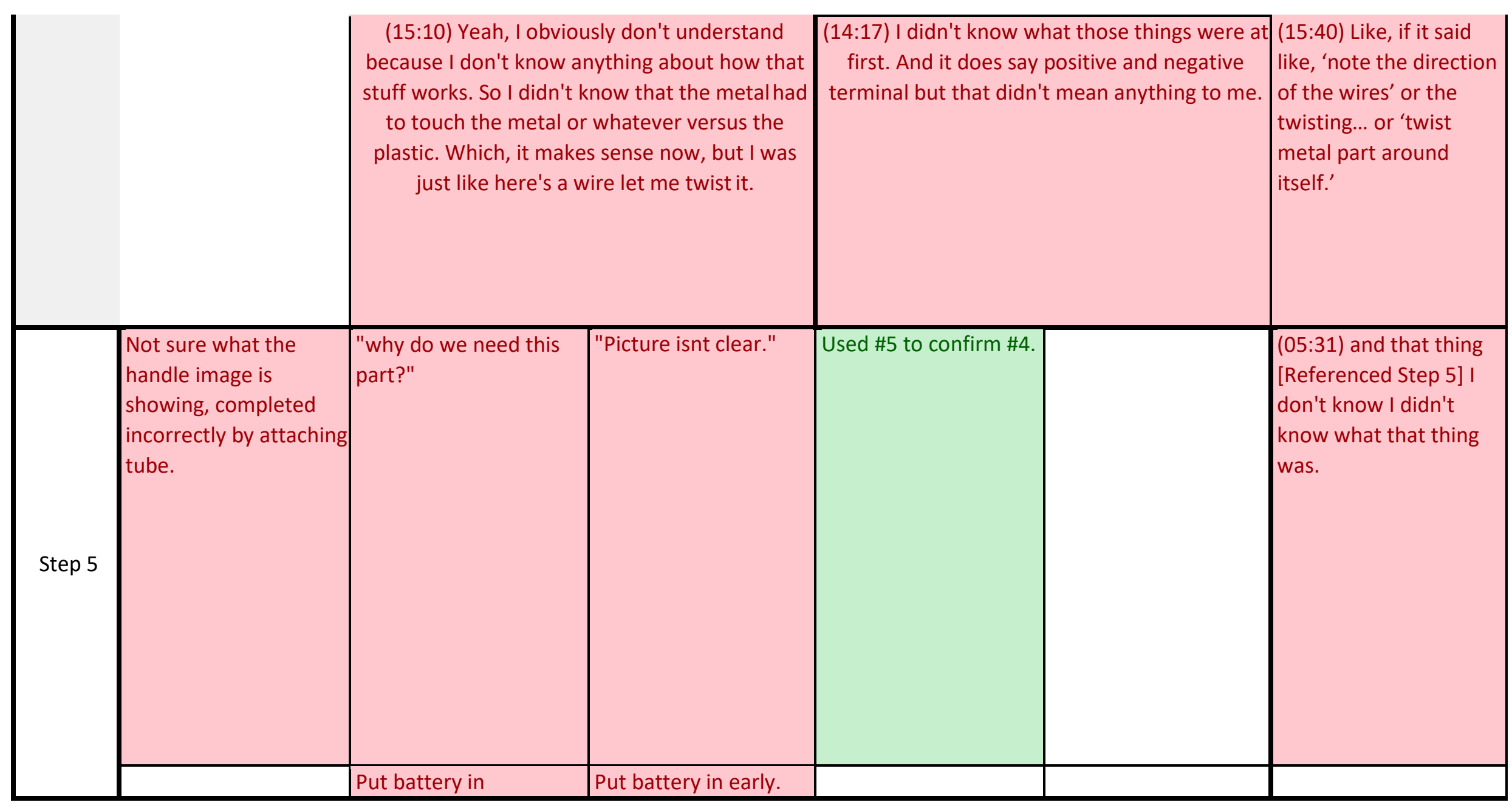




\begin{tabular}{|c|c|c|c|c|c|}
\hline $\begin{array}{c}\text { (20:35) It depends on where you're connect them. Sol } \\
\text { thought they're going to be the same. I thought there } \\
\text { was no difference. And even this picture it's } \\
\text { somewhat clear but this has a side view... like this is a } \\
\text { front view and this is a back view, so if they would } \\
\text { have used a front view here it would have been less } \\
\text { confusing. }\end{array}$ & $\begin{array}{l}\text { (20:39) Examiner: Also you } \\
\text { footers, but you did notice } \\
\text { know, I don't know if it was } \\
\text { my attention or that I knew } \\
\text { was working on so I kne } \\
\text { happen. But, the flip ov } \\
\text { though I didn't really read } \\
\text { kind of drew my atte }\end{array}$ & $\begin{array}{l}\text { didn't notice the headers or } \\
\text { the 'flip'. Participant: I don't } \\
\text { s just the arrow that grabbed } \\
\text { v that it didn't look like what I } \\
\text { ew that something had to } \\
\text { er was really helpful even } \\
\text { a lot of the rest of it. It just } \\
\text { ntion for some reason. }\end{array}$ & & & \\
\hline $\begin{array}{l}\text { (33:31) I believe that since they, let me call it the } \\
\text { holder, maybe it's comparatively more difficult to put } \\
\text { in the battery now like even if you say if you say get } \\
\text { the other way what happens if you put in the battery p } \\
\text { before? In step } 5 \text { you put in the battery and then you t } \\
\text { put in the holder so then it's not going to make any it } \\
\text { difference. Now [Referencing Step 13] it's more } \\
\text { difficult to put the battery because you have to get } \\
\text { past the holder. }\end{array}$ & $\begin{array}{l}\text { (15:08)I knew this piece } \\
\text { but I cant see where the } \\
\text { little grooves were in the } \\
\text { picture the details... it was } \\
\text { too scanned out. It's too... } \\
\text { it's not zoomed in enough. } \\
\text { If they would have showed } \\
\text { me the arm and then the } \\
\text { peg I was to put it in that } \\
\text { would have been more } \\
\text { clear. }\end{array}$ & $\begin{array}{l}\text { (09:44) Yeah I felt } \\
\text { completion (on step 4) and } \\
\text { felt like I could move on. } \\
\text { Maybe step } 5 \text { should have } \\
\text { been at the end because like } \\
\text { I feel like it's a finishing } \\
\text { touch... like this is put on it } \\
\text { at the end [Reference Step } \\
\text { 14] and then that would be } \\
\text { put on at the end. }\end{array}$ & 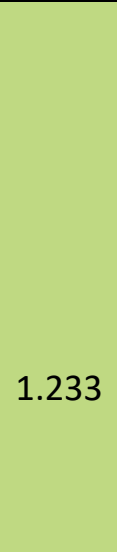 & 1.450 & 0.800 \\
\hline
\end{tabular}




\begin{tabular}{|l|l|l|l|l|l|l|}
\hline Missed x2 direction & $\begin{array}{l}\text { Thought manual } \\
\text { refelected actual part } \\
\text { color }\end{array}$ & $\begin{array}{l}\text { "Gear tool? What is } \\
\text { the gear tool?" }\end{array}$ & $\begin{array}{l}\text { Thinks there is a 2nd } \\
\text { gear tool. }\end{array}$ & $\begin{array}{l}\text { Didn't use gear tool } \\
\text { 2nd time. "Do we } \\
\text { really need this." }\end{array}$ & $\begin{array}{l}\text { (10:26) This is a good } \\
\text { step [Referenced Step } \\
6] \text { this piece shows how } \\
\text { to put the gear together } \\
\text { and slide them right in. } \\
\text { The gear tool is good, } \\
\text { thats the best way to } \\
\text { explain put them in } \\
\text { there make them work } \\
\text { so that's a good step. }\end{array}$ \\
& & & & & & \\
\hline
\end{tabular}




\begin{tabular}{|c|c|c|c|c|c|c|}
\hline $\begin{array}{l}\text { (03:14) So maybe I know } \\
\text { on the parts, it lists } \\
\text { some of the things but } \\
\text { like if there's a list of } \\
\text { what part was what. } \\
\text { Mainly because the gear } \\
\text { tool I was confused } \\
\text { initially I thought since } \\
\text { there's two gearboxes } \\
\text { there would be two of } \\
\text { these [Reference Step 6] } \\
\text { because I didn't know if } \\
\text { they were just a tool. So } \\
\text { maybe labeling evening } \\
\text { if was just had shown } \\
\text { this was the gear tool. } \\
\text { So that wasn't super } \\
\text { helpful... }\end{array}$ & $\begin{array}{l}(01: 39) \text { They also talked } \\
\text { about the gear tool but } \\
\text { nowhere in the document } \\
\text { does it tell you what the } \\
\text { gear tool was. so I thought } \\
\text { that was unhelpful. }\end{array}$ & $\begin{array}{l}\text { (05:12) I like to doing the } \\
\text { little gearbox thing. I don't } \\
\text { know why, well where it } \\
\text { said note peg direction } \\
\text { that was helpful. I don't } \\
\text { know, its just satisfying I } \\
\text { think. It was the first part, } \\
\text { besides the motor unit, } \\
\text { that was the first part } \\
\text { when I was like, 'oh, I put } \\
\text { it together and I can see } \\
\text { where it's going.' }\end{array}$ & $\begin{array}{l}\text { (09:00) And then step } 6 \text { was } \\
\text { good too because there's a } \\
\text { tool that helped and then } \\
\text { also three pictures of how it } \\
\text { should be done in that } \\
\text { order. And then they give } \\
\text { you a better depiction even } \\
\text { to the side. }\end{array}$ & 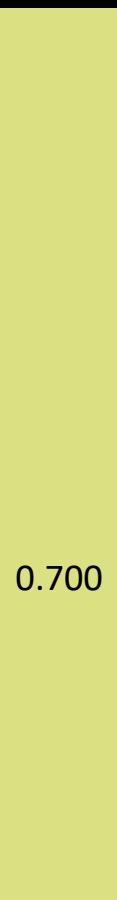 & 0.700 & 0.700 \\
\hline
\end{tabular}




\begin{tabular}{|c|c|c|c|c|c|}
\hline Step 7 & $\begin{array}{l}\text { Said, "im looking for } 3 \\
\text { things." }\end{array}$ & $\begin{array}{l}\text { Thought the gears } \\
\text { should click in }\end{array}$ & & & $\begin{array}{l}\text { (06:15) Participant: I } \\
\text { think this, I don't find } \\
\text { this use of gear tool } \\
\text { very helpful [Reference } \\
\text { Step 6]. Initially, I } \\
\text { thought that when I you } \\
\text { use this gear tool to fix } \\
\text { the gears and the body } \\
\text { it would get fixed and } \\
\text { that very moment but } \\
\text { that didn't happen. }\end{array}$ \\
\hline & $\begin{array}{l}\text { Missed } x 4 \text { right-left } \\
\text { direction. }\end{array}$ & $\begin{array}{l}\text { Built } 2 \text { correct, } 2 \text { wrong. } \\
\text { Then built } 6 \text { left legs. }\end{array}$ & $\begin{array}{l}\text { References own work } \\
\text { for correctness. }\end{array}$ & $\begin{array}{l}\text { Assembled most legs, } \\
\text { then had some } \\
\text { confusion }\end{array}$ & $\begin{array}{l}\text { (02:05) I was fine until I got to the legassembly } \\
\text { [Referenced Step 8]and then I really couldn't } \\
\text { tell until I got it on wrong that these were on } \\
\text { the wrong side. So because they need to be... } \\
\text { and when you look at the arrows you can tell } \\
\text { they need to be the other side and then the last } \\
\text { piece needs to be on the other side. But, I } \\
\text { couldn't tell that until I put it on that I can't } \\
\text { assemble it because these things were in the } \\
\text { way. So then I just had to replicate the same } \\
\text { thing I had done. }\end{array}$ \\
\hline
\end{tabular}




\begin{tabular}{|c|c|c|c|c|c|c|}
\hline $\begin{array}{l}\text { (03:50) Examiner: How } \\
\text { about a time where it } \\
\text { wasn't so good? } \\
\text { Participant: Step 7, } \\
\text { because I was looking } \\
\text { for a base with a light } \\
\text { color and then in Step } \\
10 \text { I thought that the } \\
\text { legs would be in the } \\
\text { light color as well. }\end{array}$ & \multicolumn{2}{|c|}{$\begin{array}{l}\text { (08:17) Let's see the gearbox step number } 6 \text { then } 7 \text {. The } \\
\text { clarity of it, once I figured out what the gear tool was } \\
\text { which it wasn't complicated because I looked at the } \\
\text { pictures once we got that, that was a very simplistic } \\
\text { step. And then } 7 \text { also was pretty simple of how to put } \\
\text { that together. And then it was nice that you had that } \\
\text { they indicated that you have to do that two times in two } \\
\text { different... come up with two things. }\end{array}$} & $\begin{array}{l}\text { (01:39) The words, I like } \\
\text { words. Like Step 7, 'note } \\
\text { peg direction' alerting you } \\
\text { as to which direction pieces } \\
\text { need to come in }\end{array}$ & 0.933 & 1.000 & 0.800 \\
\hline $\begin{array}{l}\text { (08:15) This thing, the } \\
\text { Step } 8 \text {, it was very usefu } \\
\text { but I didn't follow it and } \\
\text { I messed up. I meant to } \\
\text { say that, this part woulc } \\
\text { get under the longer } \\
\text { part and I didn't follow } \\
\text { that at times. So } \\
\text { sometimes the part was } \\
\text { on top of that. So it was } \\
\text { very clear but I missed } \\
\text { on that. }\end{array}$ & $\begin{array}{l}\text { (06:48) So I kept on having } \\
\text { refer back to the pictures } \\
\text { and look and make sure, and } \\
\text { referred a bunch of pictures } \\
\text { and it took me forever to } \\
\text { put the legs together } \\
\text { because I had to keep } \\
\text { staring and confirming that I } \\
\text { had it all put together right } \\
\text { because I know that if I } \\
\text { screwed that up I wouldn't } \\
\text { get it my spider. Once you } \\
\text { got to the leg unit and once } \\
\text { you got it figured out and } \\
\text { then were able to repeat the } \\
\text { process that wasn't as } \\
\text { challenging. }\end{array}$ & $\begin{array}{l}(09: 44) \text { I didn't like } 4 \text { and I } \\
\text { didn't like } 8 \text { just because it } \\
\text { was tedious. }\end{array}$ & $\begin{array}{l}\text { (17:43) I tried when I was } \\
\text { making them I thought okay } \\
\text { I'm probably going to know } \\
\text { need to know which one's } \\
\text { right and which one's left. } \\
\text { So I put them in different } \\
\text { piles but I didn't pay } \\
\text { attention, I forgot which pile } \\
\text { was which. And yeah and } \\
\text { then I took two from this } \\
\text { pile thinking a leg is a leg so } \\
\text { and then I try to put it on } \\
\text { and it didn't fit and so I } \\
\text { realize that I may have } \\
\text { messed up here } \\
\text { [Referencing step 8]. }\end{array}$ & & & \\
\hline
\end{tabular}




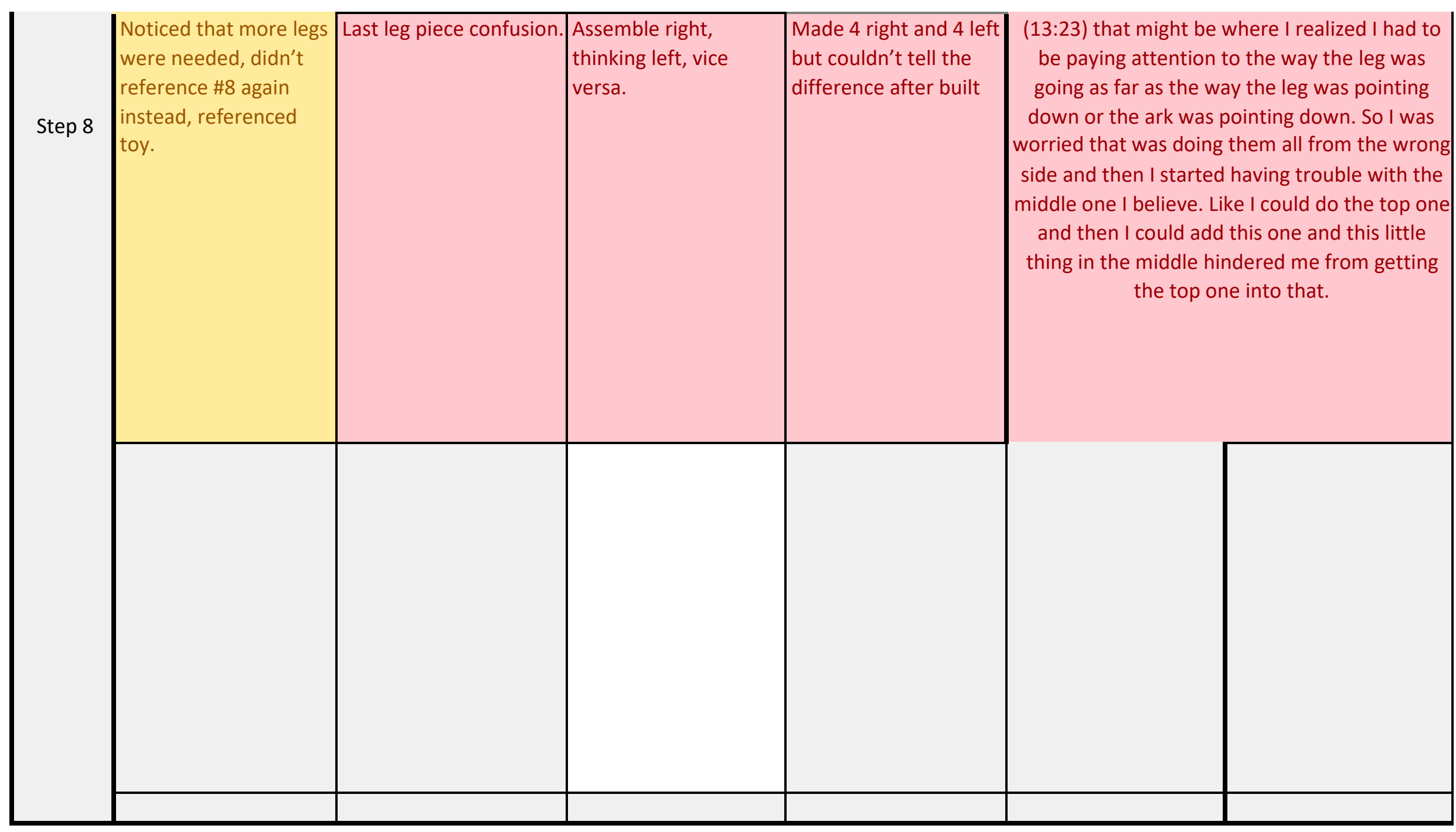




\begin{tabular}{|c|c|c|c|c|c|c|}
\hline $\begin{array}{l}\text { (06:15) I believe for the } \\
\text { left and right leg } \\
\text { [Reference Step 8] } \\
\text { because you cannot } \\
\text { actually differentiate } \\
\text { between them. If you } \\
\text { just have the sub- } \\
\text { assembled parts you } \\
\text { won't be able to } \\
\text { differentiate between } \\
\text { them. }\end{array}$ & $\begin{array}{l}\text { (11:52) So step number } 8 \text { is } \\
\text { the next one. It wasn't a } \\
\text { hundred percent clear the } \\
\text { difference between right } \\
\text { and left. So I kind of had to } \\
\text { ascertain that myself of } \\
\text { here's how the left leg is } \\
\text { different from the right leg. } \\
\text { 'oh' they're pointing and } \\
\text { different directions and 'oh' } \\
\text { the pieces fit on there } \\
\text { differently. }\end{array}$ & \begin{tabular}{|l|} 
(01:18) These little \\
pictures were \\
helpful[Reference Step 8].
\end{tabular} & $\begin{array}{l}\text { (02:05) It does say right } \\
\text { there times } 4 \text { but again just } \\
\text { looking at the big picture of } \\
\text { stuff. }\end{array}$ & -0.367 & -0.550 & 0.000 \\
\hline & $\begin{array}{l}\text { (18:05) (Step 8) This might } \\
\text { have been more useful as a } \\
\text { combined step where you } \\
\text { show the thing with the } \\
\text { arrow going into that hole } \\
\text { and then this coming over } \\
\text { top and plugging into there. }\end{array}$ & $\begin{array}{l}\text { (07:27) Yeah, I think just } \\
\text { the repetition. Also on this } \\
\text { step [Reference Step } 8 \text { ], I } \\
\text { was a little confused... so } \\
\text { are the parts on the left } \\
\text { leg going to be different } \\
\text { than the parts and right } \\
\text { leg and then I realize that } \\
\text { it's just the direction it was } \\
\text { in. }\end{array}$ & & & & \\
\hline
\end{tabular}




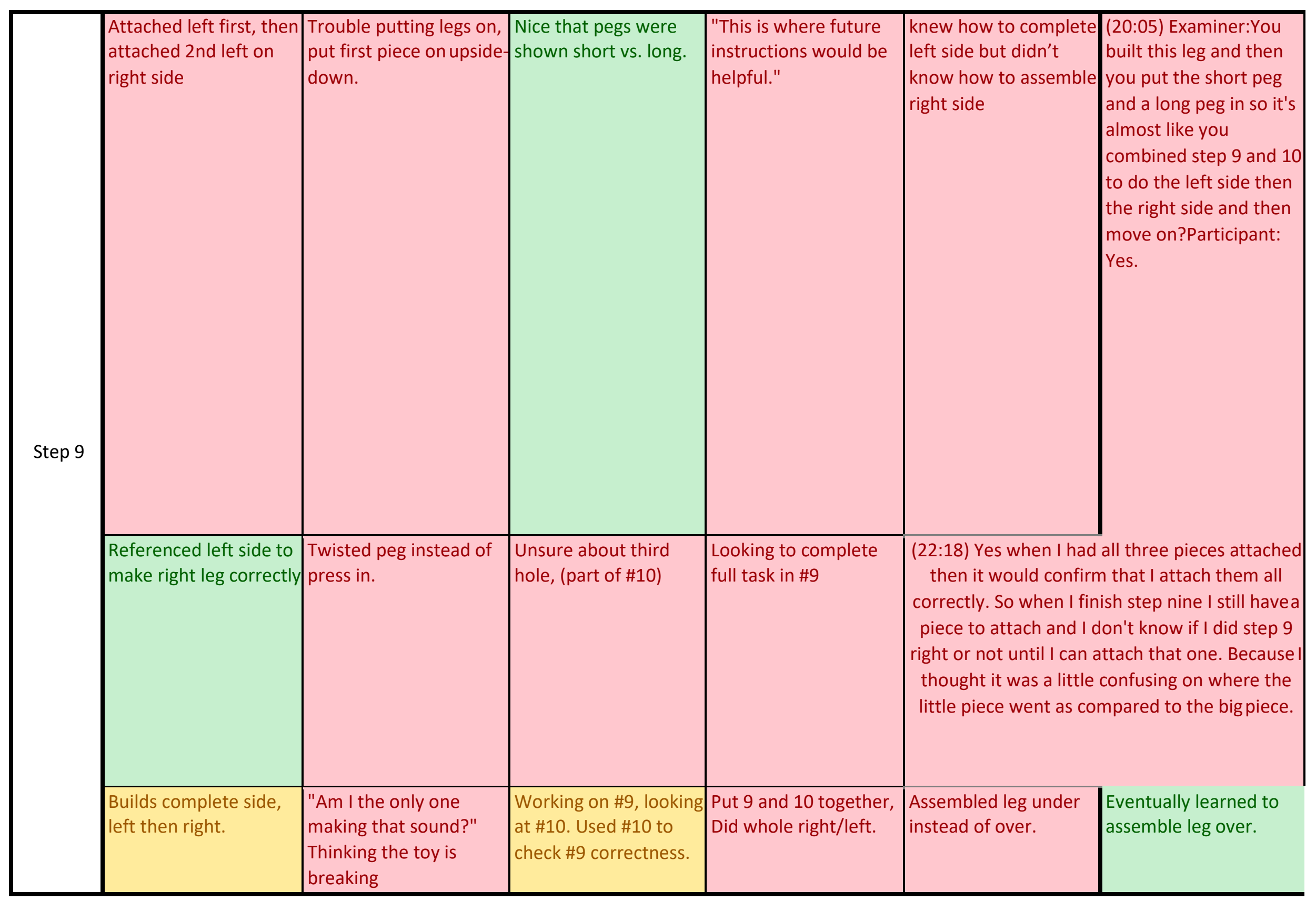




\begin{tabular}{|c|c|c|c|c|c|c|}
\hline $\begin{array}{l}(27: 11) \text { So that would } \\
\text { have been better but } \\
\text { that's what this is trying } \\
\text { to show? Maybe could } \\
\text { break the step up into } \\
9 \mathrm{~A} \text { and } 9 \mathrm{~B}, \text { where you } \\
\text { show first this thing } \\
\text { going in and then the } \\
\text { second one going in. }\end{array}$ & $\begin{array}{l}\text { (10:36) So on step } 9 \text { the } \\
\text { show a whole picture of the } \\
\text { entire leg on the thing that I } \\
\text { was able to reference and I } \\
\text { think that's part of the } \\
\text { problem with Step } 11 . \\
\text { There's no picture of an } \\
\text { entire leg already on the unit } \\
\text { for me to mirror. }\end{array}$ & $\begin{array}{l}\text { (18:09) I thought when I } \\
\text { was working on step 9, I } \\
\text { was putting the pegs in } \\
\text { and then I was wondering } \\
\text { where's this peg? This one } \\
\text { has to have a pen and I } \\
\text { didn't see it in the photo. } \\
\text { So then I was like, 'oh it's } \\
\text { on the next instruction.' So } \\
\text { I would have put the pegs } \\
\text { in the same instruction. } \\
\text { Just cuz in my mind, these } \\
\text { two things go together. } \\
\text { The pegs are one thing } \\
\text { and it should be one step, } \\
\text { the A and the B pegs. }\end{array}$ & $\begin{array}{l}\text { (02:55) When they gave the } \\
\text { letter for each peg that was } \\
\text { useful because even though } \\
\text { you can see which ones } \\
\text { short and which ones long I } \\
\text { still like having a letter. Yeah }\end{array}$ & \multirow[t]{2}{*}{0.267} & \multirow[t]{2}{*}{0.100} & \multirow[t]{2}{*}{0.600} \\
\hline $\begin{array}{l}\text { placed wrong leg on } \\
\text { right side. }\end{array}$ & \multicolumn{3}{|c|}{$\begin{array}{l}\text { (15:23) I think the left one had less like obstructions because the leg would come out } \\
\text { but then the right one, even though it's the same, I instinctively would put it on the } \\
\text { same way each time and then it would just get stuck so maybe it's because I'm right- } \\
\text { handed but... But it's definitely different and the right one was definitely harder. } \\
\text { Yeah, I think because where this one showed it I just instinctively put it like that, but } \\
\text { where this one was pointed down and look lower so I try to put it... That's really } \\
\text { funny... yeah. I didn't even think about that. I think I just saw it pointing down like that } \\
\text { so I just try to put on underneath. }\end{array}$} & & & \\
\hline
\end{tabular}




\begin{tabular}{|c|c|c|c|c|c|}
\hline Step 10 & & $\begin{array}{l}\text { Cofused on hole } \\
\text { orientation, because } \\
\text { they didn't use tool. }\end{array}$ & $\begin{array}{l}\text { (02:55) When they } \\
\text { gave the letter for } \\
\text { each peg that was } \\
\text { useful because even } \\
\text { though you can see } \\
\text { which ones short and } \\
\text { which ones long I still } \\
\text { like having a letter. } \\
\text { Yeah }\end{array}$ & $\begin{array}{l}\text { (19:47) See this part I didn't even look at these } \\
\text { two little pictures [Referenced boxes in step } 10 \\
\text { and } 12 \text { ]. I just kind of figured out that they had } \\
\text { to be on opposite once and also these pictures } \\
\text { if I had reference them I think I might have } \\
\text { been confused because on the one side it's on } \\
\text { the far one and on the other side of should be } \\
\text { in the close one but these turned so they might } \\
\text { not be aligned as they show the pictures. }\end{array}$ & $\begin{array}{l}\text { (03:27) After I noticed } \\
\text { the short peg-long peg } \\
\text { differentiation that was } \\
\text { useful too. }\end{array}$ \\
\hline Step 11 & $\begin{array}{l}\text { "Did it once, Twice } \\
\text { shouldn't be too bad." }\end{array}$ & $\begin{array}{l}\text { "So this is probably the } \\
\text { same..." }\end{array}$ & $\begin{array}{l}\text { "\#11-12 little less } \\
\text { clear." }\end{array}$ & $\begin{array}{l}\text { (02:59) Basically when I came to steps } 11 \text { or } 12, \\
\text { I had already done steps } 9 \text { and } 10 \text { so I already } \\
\text { knew to do so Step } 11 \text { or } 12 \text { weren't really } \\
\text { steps that I looked at. So they were two leg } \\
\text { units, so leg units were times two and then } \\
\text { when I got to the flip it over part I just thought, } \\
\text { 'Nope. I'm just going to mirror what I did up } \\
\text { here and not look at this confusing picture.' }\end{array}$ & $\begin{array}{l}(19: 47) 11 \text { and } 12 \text { are } \\
\text { the same as } 9 \text { and } 10 . \text { I } \\
\text { did look at it and I was } \\
\text { like oh it's the same } \\
\text { thing and then I didn't } \\
\text { reference to anymore. I } \\
\text { don't think I would } \\
\text { show them I think I } \\
\text { would just say just } \\
\text { 'repeat on the other } \\
\text { side.' }\end{array}$ \\
\hline
\end{tabular}




\begin{tabular}{|c|c|c|c|c|c|c|}
\hline $\begin{array}{l}\text { ( } 29: 54) \text { I thought on one } \\
\text { of these, there should } \\
\text { only been one hole. I } \\
\text { meant to say, looking at } \\
\text { the picture I understood } \\
\text { as three should be filled } \\
\text { in and only I was trying } \\
\text { to figure out. }\end{array}$ & $\begin{array}{l}\text { (00:43)And I think some of } \\
\text { pegs in the long pegs, where } \\
\text { didn't pay attention to that a } \\
\text { it it would have made it muc } \\
\text { eyes were drawn to the big }\end{array}$ & $\begin{array}{l}\text { the things, like the shorts } \\
\text { e you put these gears and I } \\
\text { and if I would have lookedat } \\
\text { h more helpful for me...my } \\
\text { what it's supposed to look } \\
\text { e. }\end{array}$ & $\begin{array}{l}\text { (01:15) I liked when they } \\
\text { did, they showed exactly on } \\
\text { the gear, highlighted which } \\
\text { one should be [Reference } \\
\text { step 10]. }\end{array}$ & 1.233 & 1.350 & 1.000 \\
\hline $\begin{array}{l}\text { (03:14) I wouldn't put } \\
\text { some of the steps in the } \\
\text { order that they were. I } \\
\text { would I just would } \\
\text { combine these two } \\
\text { [Referencing step } 9 \text { and } \\
\text { 10] because in my mind } \\
\text { was like, 'okay, put one } \\
\text { peg and put the other } \\
\text { peg in but its not } \\
\text { showing it in this picture } \\
\text { so I was confused and I } \\
\text { had to go to the next } \\
\text { one. }\end{array}$ & $\begin{array}{l}\text { (10:36) So on step } 9 \text { the } \\
\text { show a whole picture of the } \\
\text { entire leg on the thing that I } \\
\text { was able to reference and I } \\
\text { think that's part of the } \\
\text { problem with Step } 11 . \\
\text { There's no picture of an } \\
\text { entire leg already on the unit } \\
\text { for me to mirror. }\end{array}$ & $\begin{array}{l}\text { (02:59) ... Step } 11 \text { and } 12, \\
\text { I'm assuming that because } \\
\text { the gray is the reverse, } \\
\text { looking at the left and } \\
\text { right leg one that also } \\
\text { appears to be one it } \\
\text { appears to be how they } \\
\text { demarcated that. I found } \\
\text { that to be kind of } \\
\text { confusing it also made the } \\
\text { pictures very difficult to } \\
\text { see because they grayed } \\
\text { them out. }\end{array}$ & $\begin{array}{l}\text { (03:51) So I can't figure out } \\
\text { why parts like this is darker, } \\
\text { that's just something I'm } \\
\text { noting. I don't know why } \\
\text { that is dark and this is dark, } \\
\text { maybe it's supposed to help } \\
\text { me but I don't know. Yeah, } \\
\text { so I liked it when it was the } \\
\text { white versus this because } \\
\text { it's harder to see where } \\
\text { they're pointing to. }\end{array}$ & 0.033 & 0.000 & 0.100 \\
\hline
\end{tabular}




\begin{tabular}{|c|c|c|c|c|c|c|}
\hline Step 12 & & $\begin{array}{l}\text { Turned gears to check if } \\
\text { it works }\end{array}$ & $\begin{array}{l}\text { "If they all look the } \\
\text { same, they are all right } \\
\text { or wrong." }\end{array}$ & & $\begin{array}{l}\text { Turned page before } \\
\text { finishing } 2 \text { units, did } \\
\text { read note. }\end{array}$ & $\begin{array}{l}\text { (01:15) And I liked this, } \\
\text { was good when it said, } \\
\text { 'two leg units done' } \\
\text { because I wouldn't have } \\
\text { done both only did one, } \\
\text { yeah. And just anytime } \\
\text { there was words, that } \\
\text { was nice, yeah. }\end{array}$ \\
\hline \multirow{2}{*}{ Step 13} & Completed \#5. & $\begin{array}{l}\text { "Why battery last? } \\
\text { Easier to put battery } \\
\text { then handle" }\end{array}$ & $\begin{array}{l}\text { Looked at \#14 then } \\
\text { extra page. }\end{array}$ & $\begin{array}{l}\text { Confusion on identical } \\
\text { note }\end{array}$ & $\begin{array}{l}\text { Looked at "flip over" } \\
\text { then went back to step } \\
13 \text { and incorrectly } \\
\text { applied to step. }\end{array}$ & $\begin{array}{l}\text { (04:58) That was on this } \\
\text { page towards the end } \\
\text { [Referenced Step 13] } \\
\text { cuz I couldn't if the } \\
\text { battery is on the top or } \\
\text { the bottom of the } \\
\text { spider. }\end{array}$ \\
\hline & $\begin{array}{l}\# 2 \text { part came out } \\
\text { adding confusion. }\end{array}$ & $\begin{array}{l}\text { Did not read words until } \\
\text { very confused }\end{array}$ & $\begin{array}{l}\text { Note clips make } \\
\text { battery placement } \\
\text { hard }\end{array}$ & & & \\
\hline
\end{tabular}




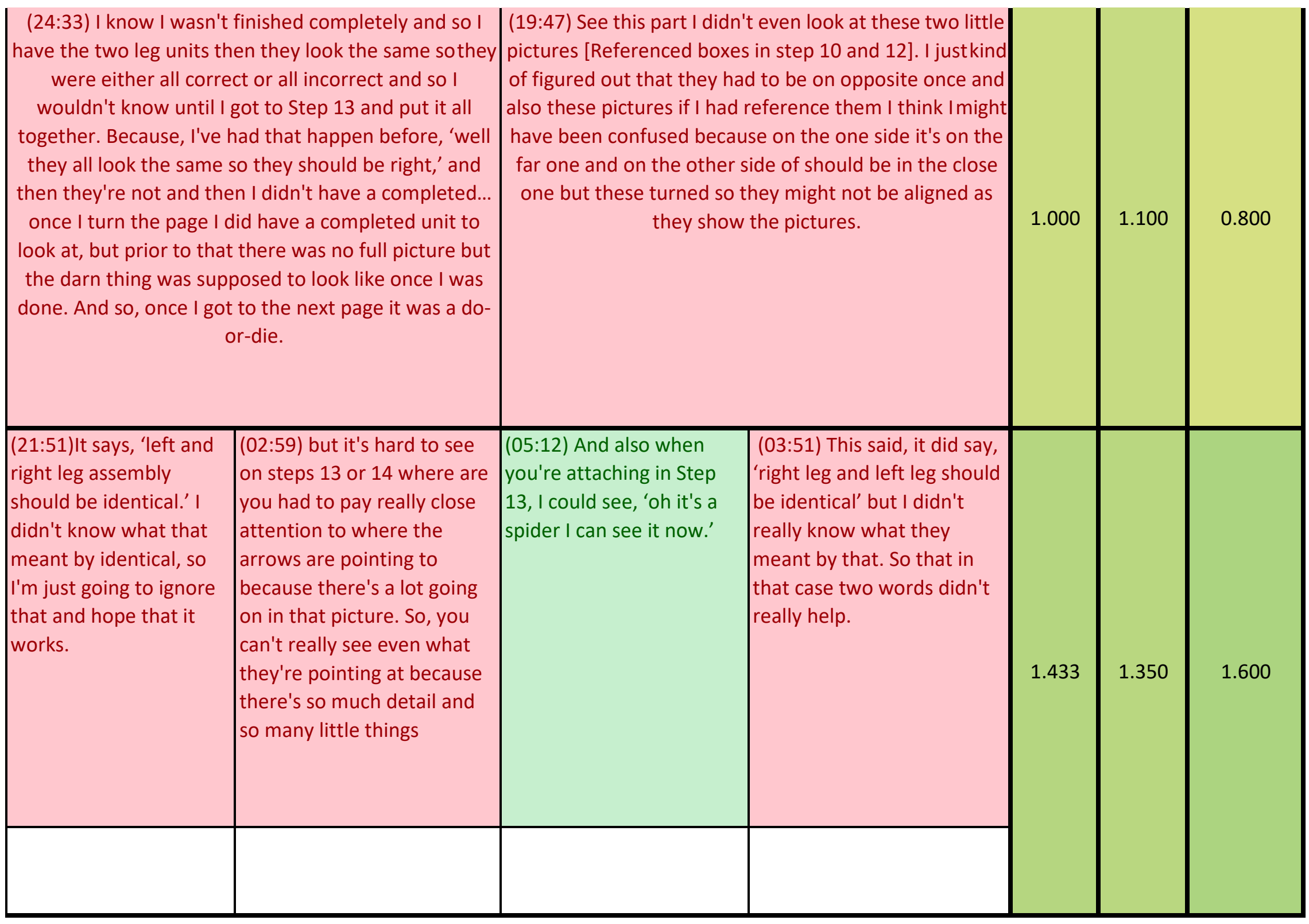




\begin{tabular}{|c|c|c|c|c|c|c|}
\hline Step 14 & $\begin{array}{l}\text { Put switch in } \\
\text { backwards } 2 \text { nd time. }\end{array}$ & $\begin{array}{l}\text { Completed extra step } \\
\text { before turning on. }\end{array}$ & Placed piece on wrong & $\begin{array}{l}\text { Turned on, didn't } \\
\text { work, moved on. }\end{array}$ & Noted extras & $\begin{array}{l}\text { (08:11) [Referenced } \\
\text { Step 14] This is fun } \\
\text { seeing that your } \\
\text { complete, to know that } \\
\text { you are done, turn on. } \\
\text { If it didn't work I would } \\
\text { have been really mad } \\
\text { but yeah. I like that ta- } \\
\text { da part of it. }\end{array}$ \\
\hline Title & & & & & & \\
\hline \multicolumn{7}{|l|}{ Ivıaterıaıs } \\
\hline $\begin{array}{l}\text { Modificati } \\
\text { ons }\end{array}$ & $\begin{array}{l}\text { Used ruler to half, half, } \\
\text { half. }\end{array}$ & $\begin{array}{l}\text { Fold, cut, fold, cut } \\
\text { method }\end{array}$ & & & & $\begin{array}{l}\text { (08:11) This actually } \\
\text { was helpful to the ruler } \\
\text { and scissors thing } \\
\text { [Referenced Extras } \\
\text { Page]. }\end{array}$ \\
\hline
\end{tabular}




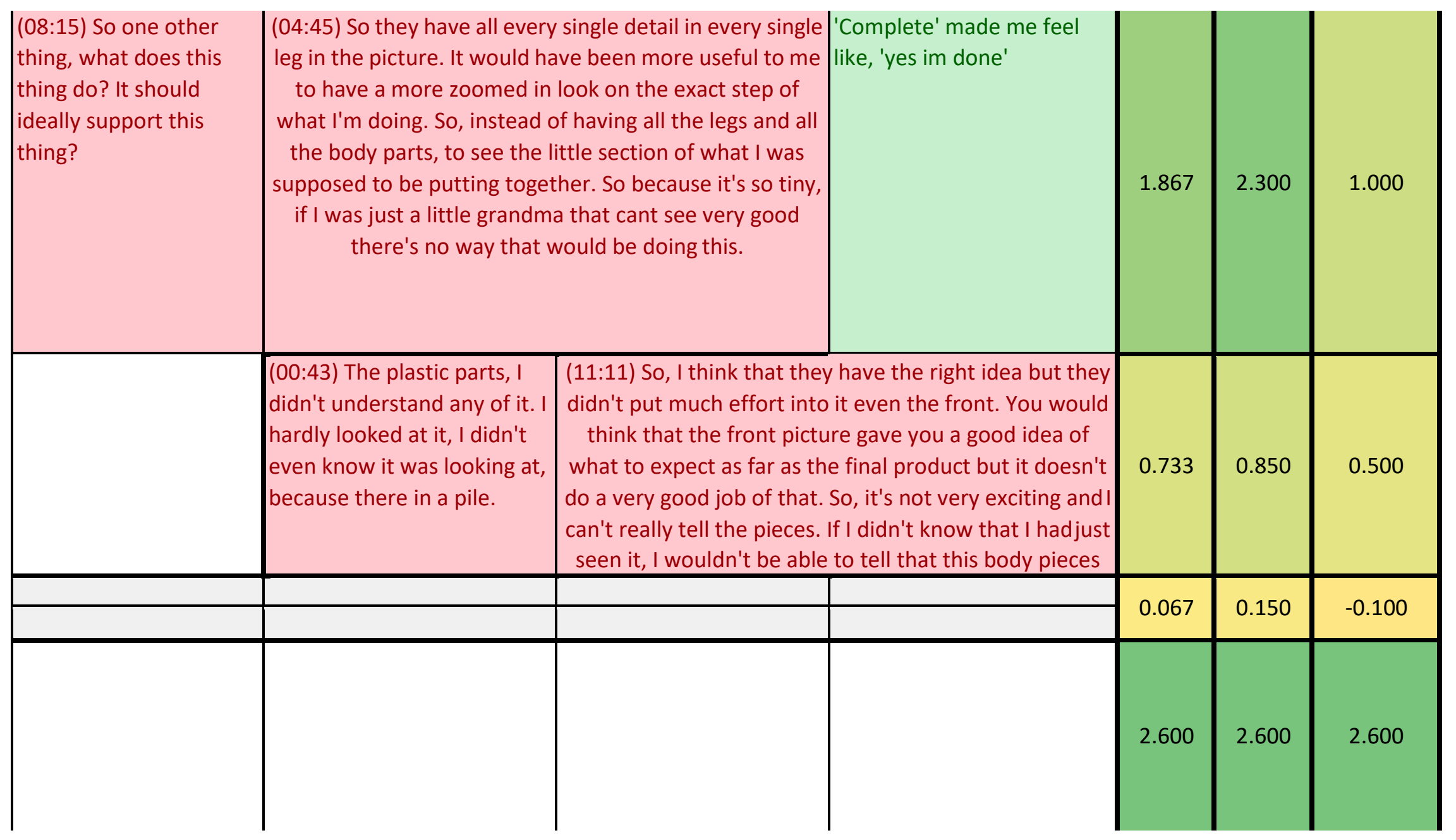




\begin{tabular}{|c|c|c|c|c|c|}
\hline Back & & & & & $\begin{array}{l}\text { (09:21) ] This was good to know because I did } \\
\text { have extra parts and I don't know if it says that } \\
\text { in the beginning that you'll have parts. But, } \\
\text { that's kind of nice to know because I got kinda } \\
\text { concerned when I saw these two extra parts, I } \\
\text { was like, 'I did I forget to put something on?' } \\
\text { But, when I turn to the back and saw }\end{array}$ \\
\hline \multirow{2}{*}{ Other } & $\begin{array}{l}\text { Didn't notice headers } \\
\text { or footers to repeat. }\end{array}$ & $\begin{array}{l}\text { Repeated steps } 9 \text { and } \\
10 \text { before moving on to } \\
11 \text { and } 12 .\end{array}$ & $\begin{array}{l}\text { Used ruler, snipped } \\
\text { large line first. }\end{array}$ & \begin{tabular}{|l|} 
"I like written \\
instruction better than \\
photos."
\end{tabular} & $\begin{array}{l}(09: 21) \text { that I might } \\
\text { actually be helpful to } \\
\text { put closer to the front } \\
\text { so you know that you } \\
\text { have these extras. }\end{array}$ \\
\hline & $\begin{array}{l}\text { Order of operation was } \\
\text { task oriented. } \\
\text { Complete a full } \\
\text { assembly, then repeat }\end{array}$ & $\begin{array}{l}\text { Referenced toy for error } \\
\text { feedback. }\end{array}$ & $\begin{array}{l}\text { "I have spare parts but } \\
\text { its finished, uh oh." }\end{array}$ & "Are these extra?" & \\
\hline
\end{tabular}




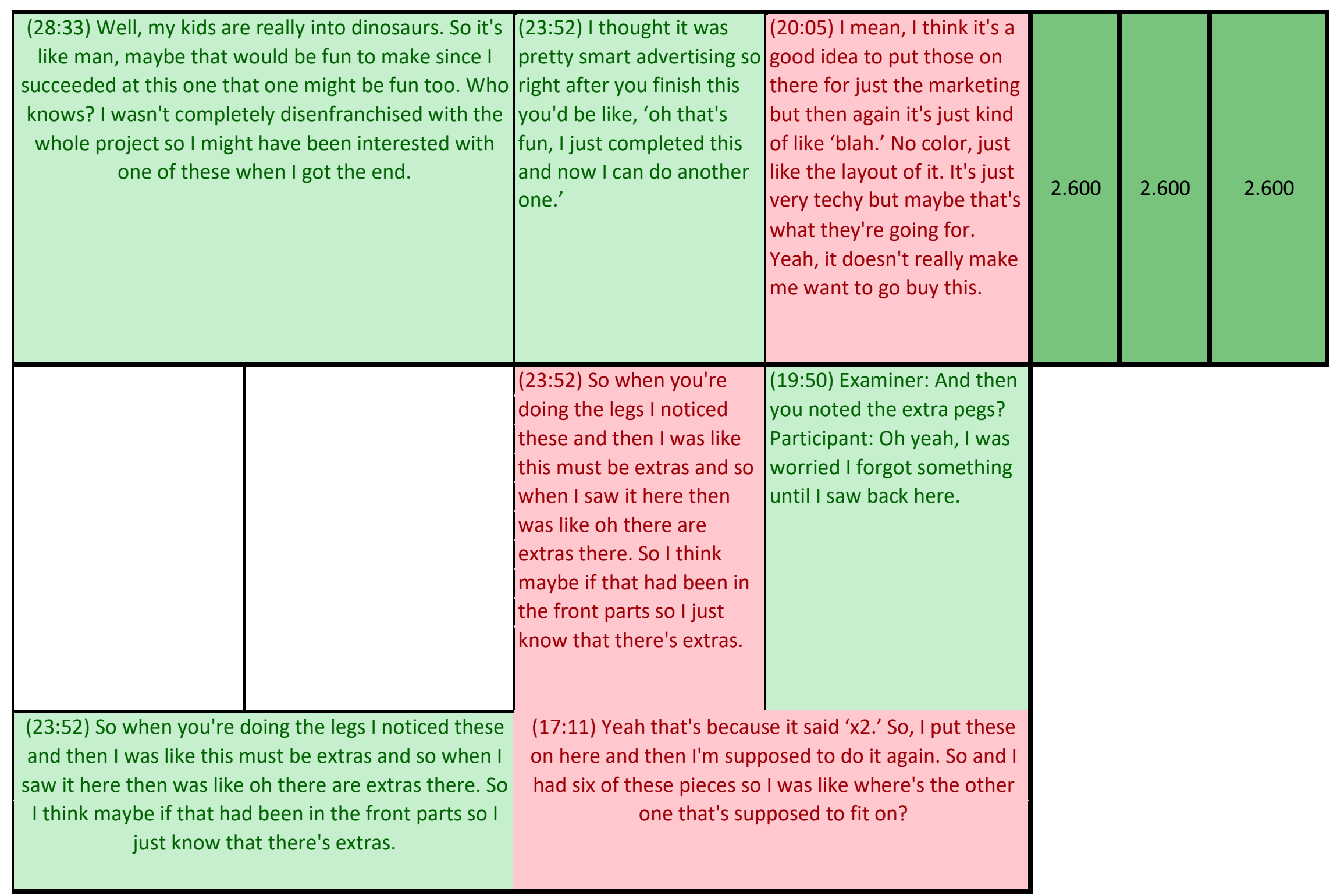


APPENDIX L: Themes Analysis Original Manual

Overall Steps Comparison

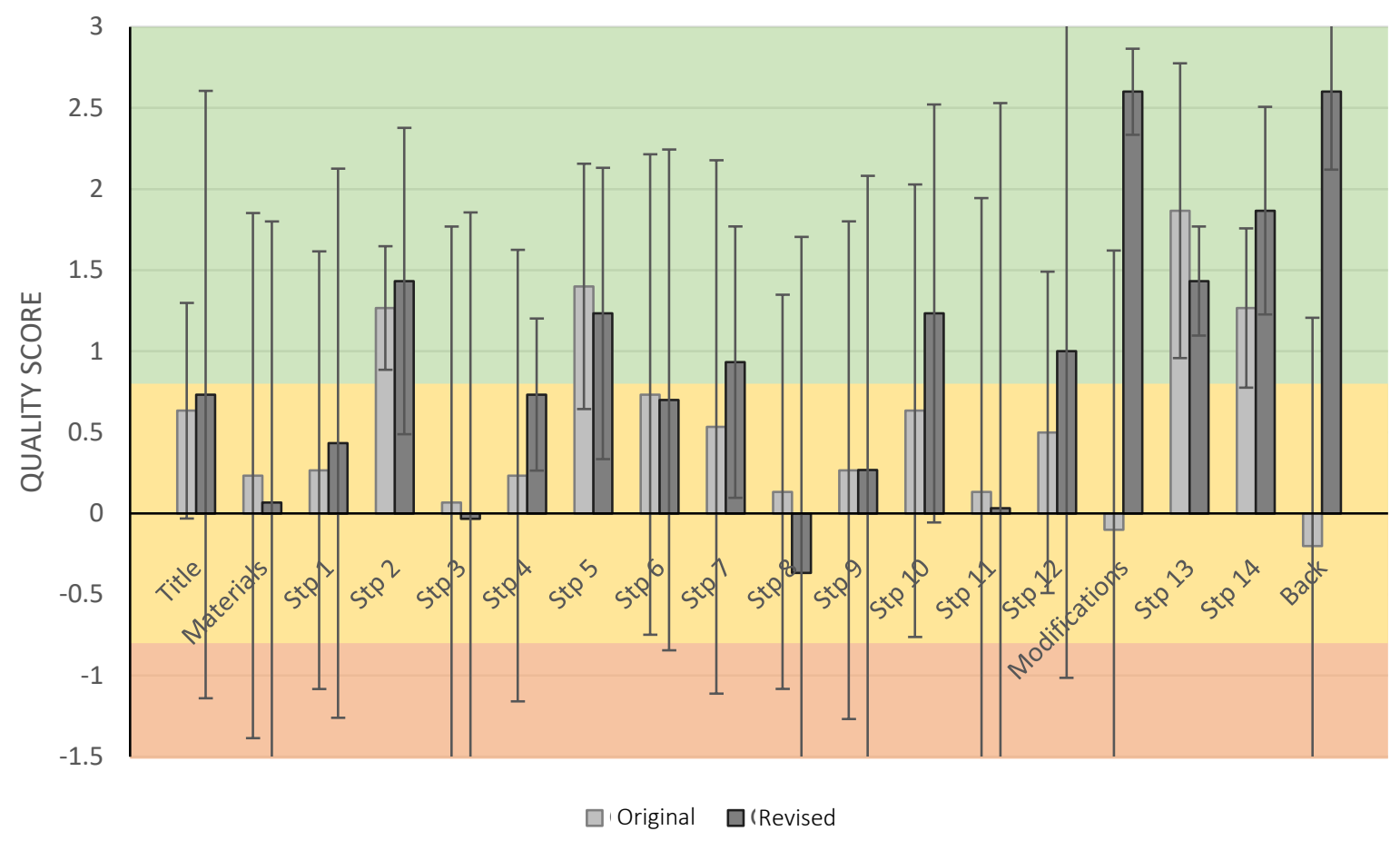

Usability Steps Comparison

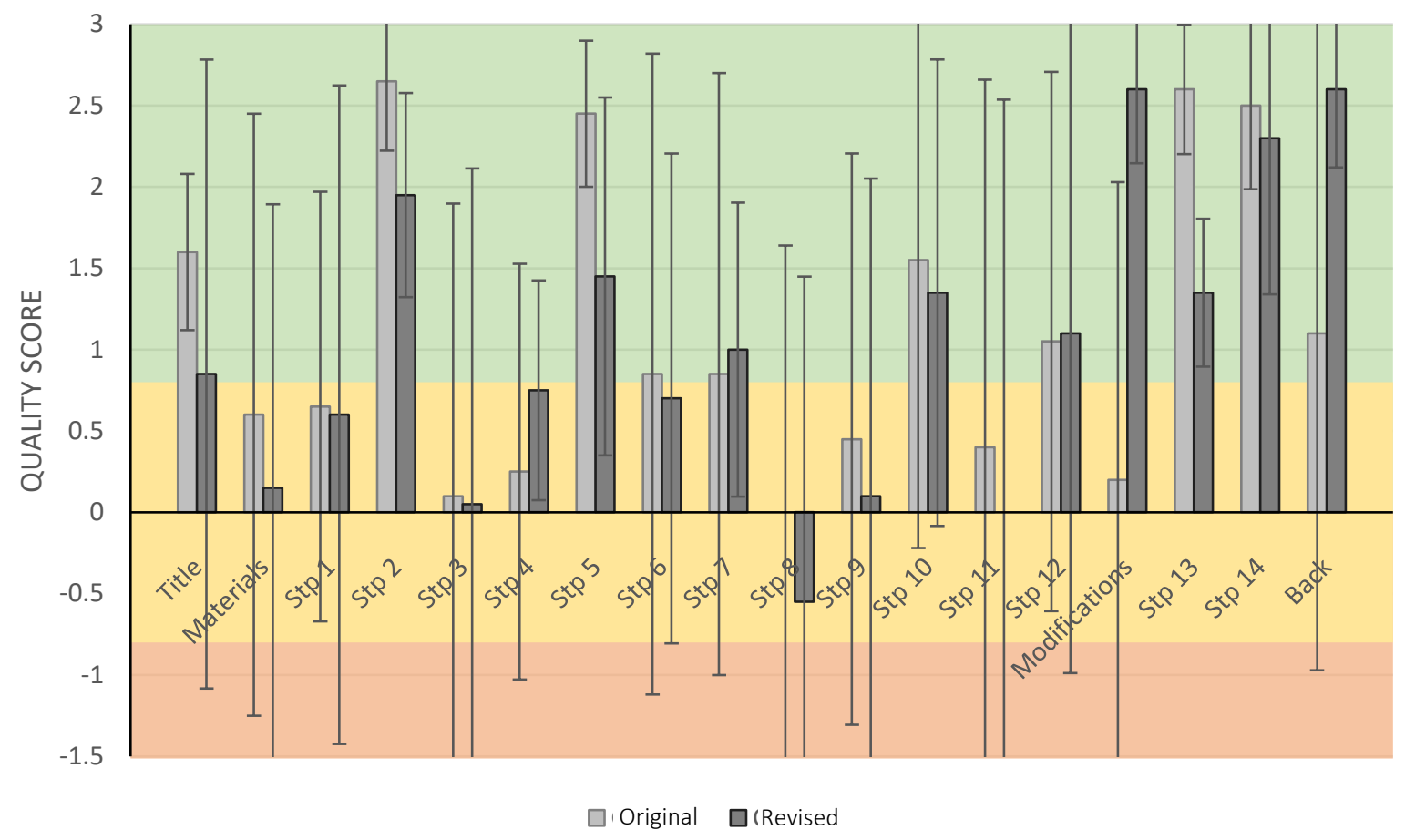




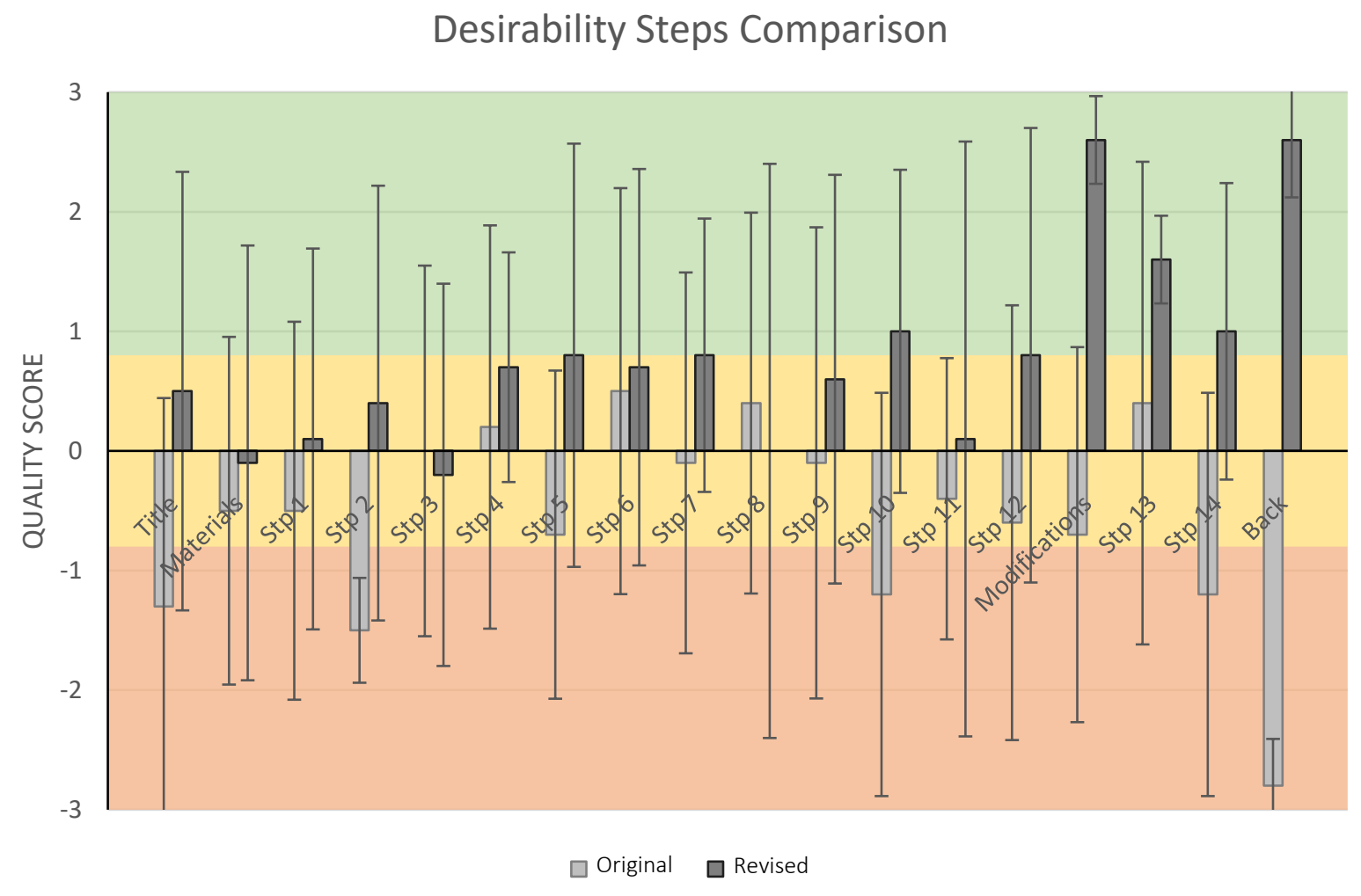

